\title{
"NEW TECHNIQUES AND METHODS FOR COLD CHAIN MONITORING AND TRACKING IN PERISHABLE PRODUCTS"
}

\author{
PhD Thesis
}

Ricardo Badía Melis

Ingeniero Agrónomo

Madrid 2016 

Departamento de Ingeniería Agroforestal Escuela Técnica Superior de Ingeniería Agronómica, Alimentarias y de Biosistemas

\section{"NEW TECHNIQUES AND METHODS FOR COLD CHAIN MONITORING AND TRACKING IN PERISHABLE PRODUCTS"}



Impossible is just a big word thrown around by small men who find it easier to live in the world they've been given than to explore the power they have to change it. Impossible is not a fact. It's an opinion. Impossible is not a declaration. It's a dare. Impossible is potential. Impossible is temporary. Impossible is nothing.

Muhammad Ali 

$\longrightarrow$ 



\section{Acknowledgements}

At the beginning of this document I would like to gratefully acknowledge the help and collaboration received for those persons and organizations that have made possible the development of my PhD Thesis, and specially:

A mi tutor, el profesor Luis Ruiz García, por creer en mi trabajo, no dejar que me tuerza, y recordarme que todo tiene solución.

A la Universidad Politécnica de Madrid, pues estoy muy agradecido por todos los conocimientos que he adquirido estudiando y trabajando en ella. $Y$ al Departamento de Ingeniería Agroforestal, porque he aprendido lecciones de valor incalculable de las personas que lo componen.

A todos y cada uno de los miembros del grupo de investigación LPF Tagralia, donde comencé mi carrera en la cadena del frío. Fueron unos pasos muy importantes que hicieron que me decidiese por este camino profesional. A las profesoras Pilar Barreiro, Margarita Ruiz Altisent y Belén Diezma, las tres directoras del grupo desde que obtuve mi primera beca, siempre confiaron en mi trabajo. 
Al Centro Nacional de Investigaciones Metalúrgicas (CENIM-CSIC), por el apoyo recibido, especialmente a José Ignacio Robla Villalba y a Javier García Hierro.

To Jean Pierre Emond, from the Department of Agricultural and Biological Engineering in the University of Florida, for being a tutor in life, the professional that I would like to become, he inspired many of the work here.

To Cecilia Nunes, from the Department of Cell Biology, Microbiology and Molecular Biology in the University of South Florida, for being my AmericanPortuguese mom, for helping me so much when I was away from home.

To Ismail Uysal from the Electrical Engineering Department at University of South Florida, because we always understood each other very well, he also relied a lot in my work, and that made me trust in what I was doing.

To Ultan Mc Carthy, thanks for the immense and essential work of revision of English, it has really saved me more than once. Thanks for the hundreds of liters of coffee from Starbucks and sandwiches from Subway.

A Pedro Hoyos, por valorarme, y por su enorme esfuerzo para conseguir material imprescindible para la tesis. Él contactó con los agricultores de Villa del Prado (Madrid) los cuales nos dieron los frutos (pepinos) para los experimentos; también con la cooperativa GLUS-I de Cuéllar (Segovia) los cuales nos dieron las raíces (zanahorias), y finalmente al Centro de Investigación Agraria de Marchamalo (Guadalajara), que nos proporcionó las hojas (acelgas). A todos ellos, les agradezco su inestimable ayuda.

A Virginia Díaz, José Luis Pellón González, y al Laboratorio de Termotecnia en la ETSIAAB. Su ayuda fue indispensable para realizar los experimentos en sus cámaras frigoríficas.

To Ryan and Jen, part of my family in the US, now I understand better the American culture... I think so. 
To my people in Florida because they made me feel at home at all times, both the Spaniards and the Americans. I learned to work in a foreign country; I grew a lot as a professional and as a person a lot more.

To my colleagues in the National Engineering Research Center for Information Technology in Agriculture (NERCITA), China, for all the dinners and baiju, for all de good moments, for the laugh because the multiple misunderstanding situations because of the language. Above all, thank you because of the challenge of working in China, I am glad I took the chance. Especially JianPing, LiMing, Han Jiawei, Beiling Fan, Xin Bin and Xinting Yang.

A mis queridos amigos del colegio y de universidad, llevo un pedazo de ellos dentro de mí, y esta tesis en parte es suya también.

Para el final dejo lo más importante, a mis padres, por haberme dado una parte de ellos, haberme educado como soy, apoyarme en lo que hago, y quererme todo lo que me quieren.

Al resto de mi familia, por dejarme aprender de todos ellos y por apoyarme siempre en lo que hago.

Gracias a mi compañera de vida, Julia, mi bastón blanco, una auténtica experta en cadena de frío por analogía, que me ha acompañado en los buenos y no tan buenos momentos durante el camino de este trabajo. 



\section{Contents}

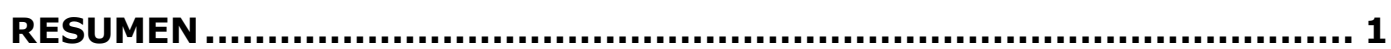

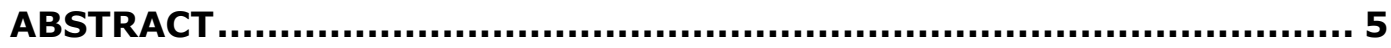

1. LIST OF PUBLICATIONS ..................................................... 7

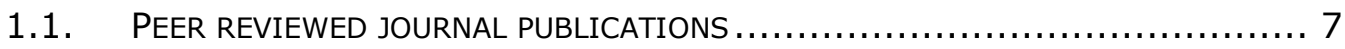

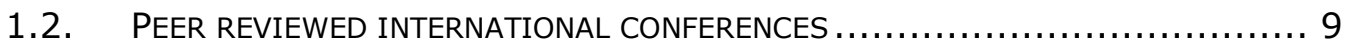

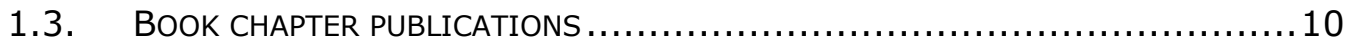

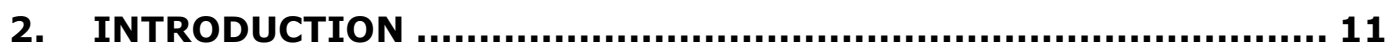

3. PROBLEM STATEMENT ............................................................ 19

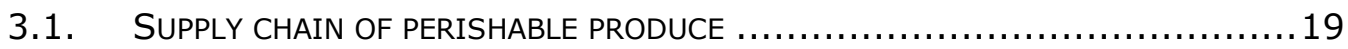

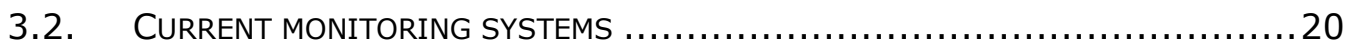

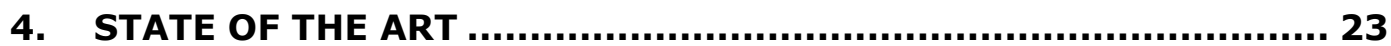


4.1. REAL TIME TRACKING AND REMOTE MONITORING IN FOOD TRACEABILITY 23

4.1.1. How can we can track and monitor in real time?.................25

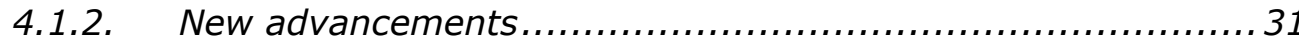

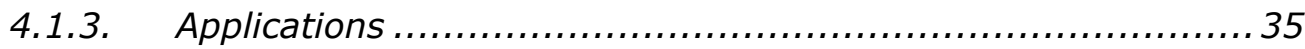

4.1.4. Limitations and Challenges ..................................... 37

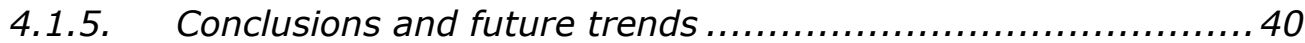

5. PRIOR KNOWLEDGE: BACKGROUND ON FOOD LOGISTICS AND

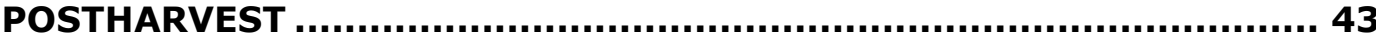

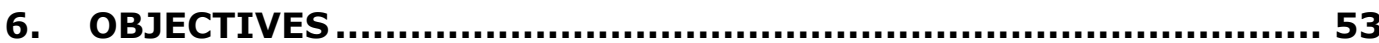

7. EXPERIMENTAL WORKS AND STUDIES................................ 55

7.1. Refrigerated Fruit Storage Monitoring COMBining Two Different WIRELESS SENSING TECHNOLOGIES: RFID AND WSN $\ldots \ldots \ldots \ldots \ldots \ldots \ldots \ldots \ldots \ldots \ldots \ldots \ldots$

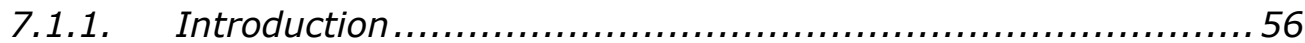

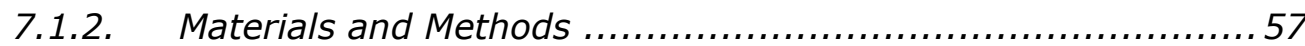

7.1.3. Results and discussion ........................................64

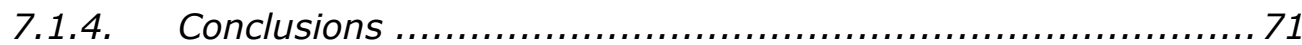

7.2. TEMPERATURE PREDICTION AND MAPPING FOR FRUIT TRANSPORTATION IN

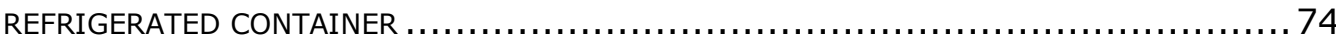

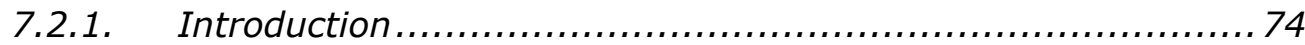


7.2.2. Material and methods. .75

7.2.3. Results 84

7.2.4. Discussion .94

7.2.5. Conclusions. .95

7.3. Artificial NeUral Networks and thermal image for temperature PREDICTION IN APPLES

7.3.1. Introduction

7.3.2. Experiments. 99

7.3.3. Results and discussion 106

7.3.4. Conclusions and future work 115

7.4. EXPLORATIVE STUDY OF USING INFRARED IMAGING FOR TEMPERATURE MEASUREMENT OF PALLET OF FRESH PRODUCE

7.4.1. Introduction

7.4.2. Materials and methods 118

7.4.3. Results

7.4.4. Discussion 131

7.4.5. Conclusions. 132

7.5. EVALUATION OF PALLET COVERS PERFORMANCE FOR PRODUCE PROTECTION IN COLD CHAIN LOGISTICS 
7.5.1. Introduction.

7.5.2. Materials and methods ..................................... 135

7.5.3. $\quad$ Results....................................................... 139

7.5.4. Discussion ................................................... 144

7.5.5. Conclusions ................................................. 146

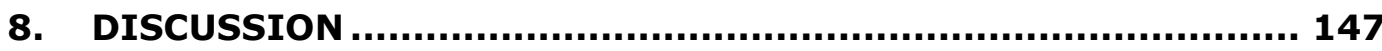

8.1. IMPLEMENTATION OF NEW TECHNOLOGIES IN COLD CHAIN .................. 147

8.2. IMPLEMENTATION OF NEW TECHNIQUES IN COLD CHAIN $\ldots \ldots \ldots \ldots \ldots \ldots \ldots \ldots$

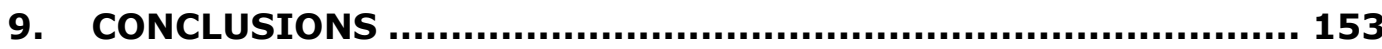

9.1. ON THE IMPROVEMENT OF THE IMPLEMENTATION FOR WIRELESS SENSING

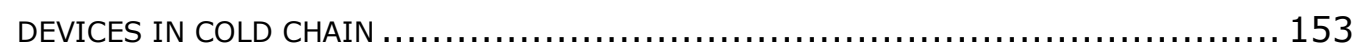

9.2. ON THE TEMPERATURE ESTIMATION FOR PERISHABLE PRODUCTS $\ldots \ldots \ldots \ldots \ldots 154$

9.3. ON THE THERMAL IMAGE AND ANN COMPLEMENTARITY FOR IMPROVEMENT IN

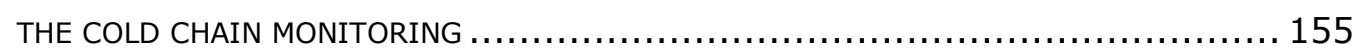

9.4. ON THE SURFACE TEMPERATURE EVALUATION THROUGH THE THERMAL IMAGE. 155

9.5. ON THE EVALUATION OF PALLET COVERS FOR PRODUCE PROTECTION IN COLD

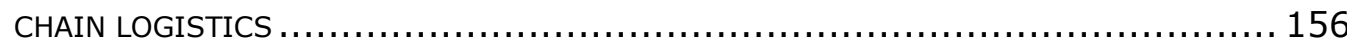

10. SUGGESTIONS FOR FUTURE RESEARCH ......................... 157

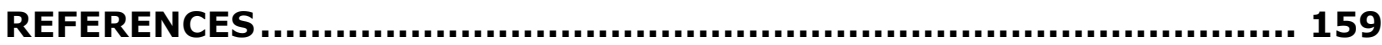




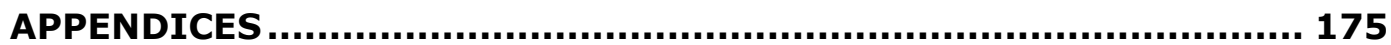

A.1. Food tRACEABILITY: NEW TRENDS AND RECENT ADVANCES. A REVIEW ........... 175 



\section{Tables}

Table 4.1. Commercial container sizes ....................................28

Table 7.1. Experimental conditions............................................ 57

Table 7.2. Coefficients used to compute the psychrometric data, according to

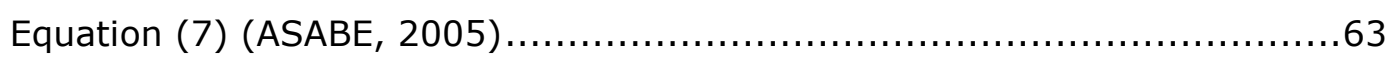

Table 7.3. Percentage of data lost packets and standard error during the experiments....

Table 7.4. RMSE for Kriging Method with different combinations .85

Table 7.5. RMSE for the capacitor method .86

Table 7.6. ANN RMSE in different configurations .88

Table 7.7. Neural network RMSE

Table 7.8. Storage conditions for vegetables. (Maynard and Hochmuth, 2007) 120

Table 7.9. Max, min and point temperatures $\left({ }^{\circ} \mathrm{C}\right)$ measured with thermal camera and temperature sensors.

126 
Table 7.10. RMSE between the thermal image temperature and sensor temperature. Chard 127

Table 7.11. Max, min and point Temperatures $\left({ }^{\circ} \mathrm{C}\right)$ registered with thermal camera and sensor temperatures.

Table 7.12. RMSE between the thermal image temperature and sensor temperature. Cucumber. ...................................................... 129

Table 7.13. Storage conditions for vegetables (Maynard and Hochmuth, 2007)

Table 7.14. Time to increase from $4{ }^{\circ} \mathrm{C}$ to $10^{\circ} \mathrm{C}(\mathrm{min})$. Chard 140

Table 7.15. Time to increase from $4{ }^{\circ} \mathrm{C}$ to $10{ }^{\circ} \mathrm{C}(\mathrm{min})$. Cucumber 142

Table 7.16. Time to rise from $4^{\circ} \mathrm{C}$ to $10^{\circ} \mathrm{C}(\mathrm{min})$. Carrots 143

Table A.1. Technological advancements 179

Table A.2. FTTO and trace food framework 190 


\section{Figures}

Figure 4.1. Monitoring system in refrigerated transport with Wireless

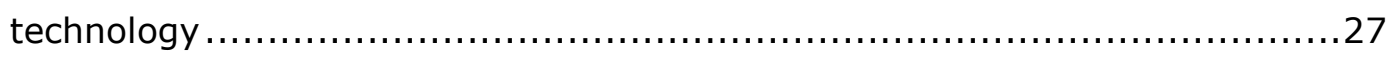

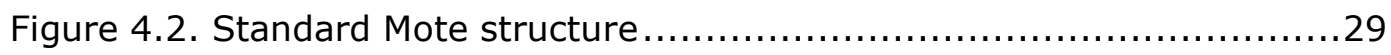

Figure 4.3. Structure of a Neural Network, one hidden layer with ten neurons

Figure 7.1. Scheme of the cold rooms and sensor distribution .58

Figure 7.2. (a) Absolute temperature inside chamber 29; (b) Absolute temperature pre-chamber 29 .66

Figure 7.3. 3D plot of Normalized Temperature Difference and Indoor Variance in Chamber 11 .67

Figure 7.4. 3D plot of Normalized Temperature Difference and Indoor Variance

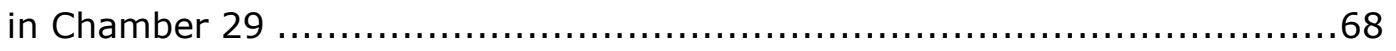

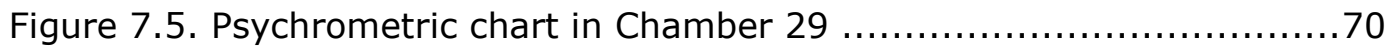

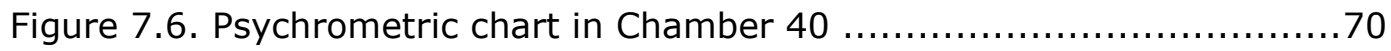


Figure 7.7. A) Plastic capsules simulating the strawberries. B) Top of the pallets inside the ref. container .77

Figure 7.8. Sensors distribution on the pallets 78

Figure 7.9. The structure of an artificial neural network to estimate temperature dynamics .80

Figure 7.10. Semivariogram 12 source sensors Sea Container 82

Figure 7.11. Temperature estimation average for the refrigeration failure

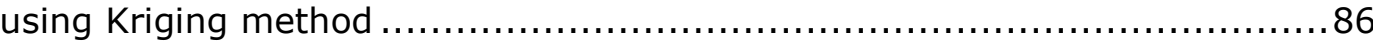

Figure 7.12. Temperature estimation average for the refrigeration failure using Capacitor method

Figure 7.13. Neural network source, estimation and destination average temperatures 89

Figure 7.14. Average temperatures for the capacitor method in the second phase 90

Figure 7.15. Average temperatures for the ANN method in the second phase 91

Figure 7.16. Temperature estimation with only the container sensor in the ANN. 92

Figure 7.17. Smooth temperature curve above. Below the differences between the estimated temp. and the smooth line 93

Figure 7.18. RFID temperature tags distribution in the cold room 99

Figure 7.19. Position of the RFID tags and RH and temperature loggers .... 101

Figure 7.20. Sensor distribution inside the pallet 102

Figure 7.21. Temperature profile 103 
Figure 7.22. Plastic boxes RFID tag distribution 104

Figure 7.23. Representation of a Levenberg-Marquardt Neural Net. In the nftool on Matlab 105

Figure 7.24. Thermal image in cardboard boxes. Cooling process 107

Figure 7.25. Error histogram with 20 Bins 108

Figure 7.26. Best validation performance 108

Figure 7.27. Cardboard boxes regression curves 109

Figure 7.28. Temperature comparison profile between targets, estimation and source data 110

Figure 7.29. Error Histogram with 20 Bins 111

Figure 7.30. Plastic boxes regression curves 112

Figure 7.31. Best validation performance 113

Figure 7.32. Temperature comparison profile between targets, estimation and source data

Figure 7.33. Covers placed on pallets: a) Metallized PET cover base, b) Metalized PET cover, c) Tyvek $®$, d) Metalized PET Bubbles

Figure 7.34. Setting three different emissivity in Metalized PET cover (from left to right emissivity is E 95, E 80, E 60)

Figure 7.35. Tyvek ${ }^{\circledR}$ thermal picture with emissivity 0.8 122

Figure 7.36. Black tape attached to the Metalized PET cover 123

Figure 7.37. Sensor distribution in the pallet 124 
Figure 7.38. Thermal image and picture from middle point of the Metalized PET cover 125

Figure 7.39. Comparison of thermal camera temperatures in measured points. $\mathrm{RD}=$ Right Down, $\mathrm{LU}=$ Left UP, $M=$ Middle

Figure 7.40. Covers placed on pallets: a) Metalized PET cover base, b) Metalized PET cover, c) Tyvek $($, d) Metalized PET Bubbles ..................... 136

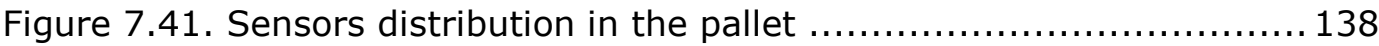

Figure 7.42. Comparison of different cover temperatures and RH for chard 139

Figure 7.43. Comparison of different cover temperatures and $\mathrm{RH}$ for

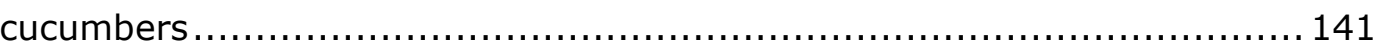

Figure 7.44. Comparison of different cover temperatures and $\mathrm{RH}$ for carrots 143

Figure 7.45 . Time to rise from $4{ }^{\circ} \mathrm{C}$ to $10^{\circ} \mathrm{C}$ (Average) 144 


\section{Abbreviations list}

ANN Artificial Neural Network

ASABE American Society of Agricultural and Biological Engineers

ASAE American Society of Agricultural Engineers

CCTA Conference on Computer and Computing Technologies in Agriculture

CENIM Centro Nacional de Investigaciones Metalúrgicas

CSIC Consejo Superior de Investigaciones Científicas

CTE Critical Tracking Events

EPC Electronic Product Code

ETIAAB Escuela Técnica Superior de Ingeniería Agronómica, Alimentaria y de Biosistemas

FAO Food and Agriculture Organization

FDA Food and Drug Administration 
FEFO First Expire First Out

FSR First Strike Rations

FTTO Food Track and Trace Ontology

HACCP Hazard Analysis Critical Control Points

HBDT Honours Bachelor Degree Thesis

ICIA International Conference on Intelligent Agriculture

IIM Instituto de Investigaciones Marinas

IoT Internet of Things

IRSE International Research Staff Exchange Scheme

ISIITA International Symposium on Intelligent Information Technology in Agriculture

M2M Machine 2 Machine

MEMS Micro Electro Mechanical Systems

NERCITA National Engineering Research Center for Information Technology in Agriculture

NFC Near Field Comunication

NIRS Near-InfraRed Spectroscopy

NIV Normalized Indoor Variance

NRDC Natural Resources Defense Council

NTD Normalized Temperature Difference 


\begin{tabular}{|c|c|}
\hline OTP & One Time Programmable \\
\hline PtP & Point to Point \\
\hline QTT & Quality oriented Tracking and Tracing \\
\hline $\mathrm{RC}$ & Resistor-Capacitor \\
\hline RFID & Radio Frequency IDentification \\
\hline $\mathrm{RH}$ & Relative humidity \\
\hline RISE & Research and Innovation Staff Exchange \\
\hline RMSE & Root Mean Squared Error \\
\hline SE & Standard Error \\
\hline $\mathrm{SECH}$ & Horticultural Science Spanish Society \\
\hline SR & Sample Rate \\
\hline $\mathrm{T}$ & Temperature \\
\hline $\mathrm{T} \& \mathrm{~T}$ & Tracking and Tracing \\
\hline UPM & Universidad Politécnica Madrid \\
\hline WFMTS & Wheat Flour Milling Traceability System \\
\hline WSN & Wireless Sensor Network \\
\hline
\end{tabular}





\section{Resumen}

En el sector agroalimentario resulta de gran importancia controlar la calidad y supervisar los productos hortofrutícolas durante su transporte, almacenamiento y distribución. El mayor reto es asegurar una cadena de frío continua desde el productor hasta el consumidor, para lo cual es preciso contar con sistemas y tecnología de monitorización y control adecuados, así como técnicas de registro y análisis de datos fiables. Actualmente la FAO (Food and Agriculture Organization) estima que un tercio de la producción agroalimentaria mundial se desperdicia, en gran parte debido a que los sistemas de medición que se emplean no proporcionan una información veraz sobre el estado de los productos y las condiciones en que se encuentran. $Y$ también debido a que los sistemas de control no funcionan perfectamente o no se aplican con el rigor necesario. Esta tesis doctoral aborda la aplicación de nuevas técnicas y métodos de control en la cadena de frío, y se centra en los sistemas de supervisión, así como en la utilización de estas nuevas tecnologías y análisis de datos, para reducir la pérdida de calidad de los productos perecederos. 
El trabajo experimental se ha llevado a cabo en cinco fases. En primer lugar se ha realizado un estudio de la utilidad y manejo de sensores inalámbricos RFID (Radio Frequency IDentification) y WSN (Wireless Sensor Network) en cámaras frigoríficas comerciales de un centro de distribución; en este estudio se han encontrado importantes puntos débiles en el manejo del producto y puntos para mejorar en la construcción de los módulos inalámbricos. En segundo lugar se han probado diferentes métodos de predicción de temperaturas en un contenedor (de 20 pies) completamente cargado de producto. Se ha demostrado su validez con errores inferiores a 0,5 ${ }^{\circ} \mathrm{C}$, y por lo tanto su utilidad, ya que se puede prescindir de ciertos puntos de medición directa y reducir el número de sensores. En tercer lugar se ha aplicado, en producto paletizado, la técnica más eficiente de predicción de temperaturas obtenida en el anterior estudio. Para ello se ha usado como referencia una imagen termográfica/espectro infrarrojo. Este método permite prescindir de puntos de medición fijos, pero presenta una gran variabilidad de resultados según los tipos de productos. En cuarto lugar se ha estudiado la viabilidad de supervisar palés de productos hortícolas (acelga y pepino) mediante imagen termográfica, una vez están cubiertos con mantas térmicas protectoras como se usa hoy en día en la industria. Se ha encontrado que la utilización de esta técnica es compleja, ya que existen muchos parámetros en juego tales como la emisividad de los materiales de las mantas, la temperatura real superficial, tipo de producto y densidad de carga, condensación y evaporación de agua del producto. En consecuencia una medición directa sin ajustes podría conducir a error en los resultados.

Por último, en quinto lugar se ha realizado una caracterización de tres tipos de mantas térmicas para palés y se ha dispuesto de diferentes tipos de productos hortícolas: de hoja (acelga), fruto (pepino) y raíz (zanahoria). Todas las mantas reducen el tiempo de absorción de calor en comparación con no tener manta; en dos de las tres se producen condensaciones no deseadas.

Todos los experimentos de esta tesis están enfocados a solucionar problemas reales que ocurren a diario en la industria. Por tanto, todo el conocimiento generado es transferible directamente a la industria alimentaria que trabaja 
con productos perecederos, lo que puede ayudar a reducir costes y el desperdicio de alimentos. 



\section{Abstract}

The quality control and monitoring of horticultural products during transport and distribution is a main issue in the agrofood sector. The biggest challenge is to ensure a continuous cold chain from producer to consumer, and for that it is necessary to count with appropriate monitoring and control systems and technologies, as well as techniques of collection and analysis of reliable data. Currently, FAO (Food and Agriculture Organization) estimates that one-third of the world's food production is wasted, principally since the measurement systems used do not provide truthful information about the status of the products and in which conditions they are; control systems do not work perfectly or are not applied as it is rigorously required. Therefore, this thesis addresses the application of new control techniques and methods for the cold chain, focusing in monitoring systems, especially in the phase of analysis of data and the use of new technologies to reduce the incidence of changes in the quality of perishable products when environmental variations occur.

The experimental work was carried out in five phases. First it has made a study of the use and management of wireless sensors, RFID (Radio Frequency Identification) and WSN (Wireless Sensor Network) in a commercial cold storage distribution center; in this study it was found significant weaknesses in the management of the product and spots with a gap for improvement in 
the construction of wireless modules. Secondly it have been tested different methods of predicting temperatures in a fully loaded of product refrigerated container $\left(20 \mathrm{ft}\right.$ ). It has proved valid with errors lower than $0.5^{\circ} \mathrm{C}$, and therefore its usefulness, since it can dispense with certain points of direct measurement and reduce the number of sensors. Third, it has been applied in pallet of product, the most efficient technique for predicting temperatures selected in the previous study. For this method it has been used a thermal image/ infrared spectrum as temperature reference. This method eliminates the need for fixed measuring points, but has a great variability of results depending on the types of products. Fourthly it has studied the feasibility of monitoring pallets of horticultural products (chard and cucumber) using thermographic image, while the product is already covered with thermal covers, same covers in use for some companies. There is a lot to study and it is not easy task to assess, there are many variables involved, such as cover materials emissivity, actual surface temperature, type and density of product, and water condensation and evaporation of the product. Consequently a direct measurement without parameter adjustments, could lead to errors in the results. Finally there has been a characterization of three types of thermal covers for pallets and different types of horticultural products: leaf (chard), fruit (cucumber) and root (carrot). All covers augmented the warming time compared with having no cover; in addition, with two of the three covers, undesired condensations occur.

All experiments of this thesis are focused on solving real problems that occur daily in industry; therefore all the knowledge acquired is transferable directly to the food industry that is currently working with perishable products, which can help reducing costs and food waste. 


\section{Chapter 1}

\section{List of publications}

The results of this study were disseminated via a number of channels as follows.

\subsection{Peer reviewed journal publications}

Badia-Melis, R., Ruiz-Garcia, L., Garcia-Hierro, J., \& Villalba, J. I. R. 2015. Refrigerated fruit storage monitoring combining two different wireless sensing technologies: RFID and WSN. Sensors, 2015(15), 4781-4795

Badia-Melis, R., Mishra, P., Ruiz-García, L. 2015. Food traceability: New trends and recent advances. A review. Food Control. 57 (2015) 393-401

Badia-Melis R., Mc Carthy, U., Uysal, I. 2016. Temperature prediction and mapping for fruit transportation in refrigerated container. Biosystems Engineering. Under review. 
Badia-Melis, R., Qian, J.P., Fan, B.L., Hoyos-Echevarria, P., Ruiz-García, L., Yang, X.T. 2016. Artificial Neural Networks and Thermal Image for Temperature Prediction in Apples. Food and Bioprocess Technology: An International Journal ISSN 1935-5130

Badia-Melis, R., Emond, J.P., Ruiz-García, L., Garcia-Hierro, J. and Robla Villalba, J.I. 2016. Explorative study of using Infrared imaging for temperature measurement of pallet of fresh produce. Journal of Food Engineering. Under review.

Badia-Melis, R., Hoyos-Echevarria, P., Ruiz-García, L., Garcia-Hierro, J., Robla Villalba J.I. 2016. Evaluation of pallet covers performance for produce protection in cold chain logistics. LWT Food science and technology. Under review. 


\subsection{Peer reviewed international conferences}

Badia-Melis, R., Qian, J.P., Fan, B.L., Hoyos-Echevarria, P., Ruiz-García, L., Yang, X.T. 2015. Oral presentation. Temperature prediction in cold chain operations by means of thermal image and artificial neural networks. Joint International Conference on Intelligent Agriculture (ICIA). The 8th International Symposium on Intelligent Information Technology in Agriculture (8th ISIITA) The 9th International Conference on Computer and Computing Technologies in Agriculture (9th CCTA) AgriFuture Days 2015 International Conference. September $29^{\text {th }}$, 2015. Beijing, China. 


\subsection{Book chapter publications}

Badia-Melis, R., Ruiz-Garcia, L. 2016. Real time tracking and Remote Monitoring in Food Traceability. Book chapter in Advances in Food Traceability Techniques and Technologies, 1st Edition Improving Quality Throughout the Food Chain. Woodhead Publishing. Print Book ISBN : 9780081003107. 


\section{Chapter 2}

\section{Introduction}

The production, storage, distribution and transport of cold sensitive products, occurs daily around the world. For all these products the control of temperature is essential (Ruiz-Garcia \& Lunadei, 2011). The term "cold chain" describes the series of interdependent equipment and processes employed to ensure the temperature preservation of perishables and other temperaturecontrolled products from the production to the consumption end in a safe, wholesome, and good quality state (Gwanpua et al., 2015).

A recent study by the Natural Resources Defense Council (NRDC) has found that the US is losing up to $40 \%$ of its food from farm-to-fork (Gunders, 2012). Fresh fruits and vegetables are the worst offenders by having a waste ratio of more than $50 \%$ meaning at least one out of every two fruits harvested goes uneaten. The root cause of these loss figures has been linked mostly to insufficient temperature control (Pang et al., 2012). Approximately each year $30 \%$ of the food produced for human consumption is being lost or wasted due to the improper management (FAO, 2013). Gustavsson et al. (2011) also notes that the lack of temperature control over the fresh fruit and vegetables leads to premature product spoilage, resulting in $30 \%$ of the products does 
not fit for use. The economic impact of product losses in developed countries including Europe is approximately $10 \%(6-7 \%$ at retail), and is higher in the US at 15\% (Pang et al., 2012). In developing countries this figure increases to $30 \%$, the major cause of this is the lack of temperature control systems "cold chain" across the supply network.

Such product losses most commonly occur but are not limited to product carrying transport distances above several thousand kilometers (Jedermann et al., 2011a) and therefore the implementation of a continuous, unbroken, cold chain, and systems to monitor this cold chain are required to guarantee both the safety and security of food products for both consumer and stakeholders (W. R. Kim et al., 2015).

Fresh Fruit and Vegetables (FFVs) do not last as long as canned or frozen goods. They require specific temperature and related storage conditions as well as very efficient distribution, because of their short shelf life. Inadequate temperature is second on the list of factors causing foodborne illnesses, surpassed only by the presence of initial microflora in foods (Sánchez-López \& Kim, 2008). Any temperature disturbance can undermine the efforts of the whole chain (Mahajan et al., 2014).

It is common knowledge that to maximize shelf life there is a best storage temperature for different FFVs. Too low temperature causes chilling or freezing damage, whereas higher than optimal storage temperatures reduce shelf life.

Mishandling or negligence in the logistics of perishable food products is very common, including goods poorly or excessive cooled. Jedermann et al. (2014a) presented some scenarios that present losses in the food chain (postharvest, distribution and at home), all caused by inadequate management during temperature control.

In relation to produce spoilage, temperature is an environmental attribute of probably the highest significance (do Nascimento Nunes et al., 2014). Previous studies have demonstrated temperature oscillations inside an individual cold room caused due to the on-off cycles of the refrigeration unit, 
resulted in open air temperature variations of between $1-3^{\circ} \mathrm{C}$ to as much as 3-6 ${ }^{\circ} \mathrm{C}$ within each individual item within the cold room (Jedermann et al., 2009). Other common sources of unwanted temperature variations during common logistical processes include loading/unloading of the produce to and from the refrigerated truck, which can result in significant temperature abuse. As reported by Ruiz-Garcia et al. (2010a), in a refrigerated truck with temperature set point to $0{ }^{\circ} \mathrm{C}$, it was registered a maximum of $8.52{ }^{\circ} \mathrm{C}$ and a minimum of $-3.0{ }^{\circ} \mathrm{C}$; on average, $98 \%$ of the time the temperature was outside of the industry recommended range (set-point $\pm 0.5^{\circ} \mathrm{C}$ ). Significant relative humidity $(\mathrm{RH})$ variations within an individual cold room (from $55 \%$ to 95\% RH) have been found (Ruiz-Garcia et al., 2010a). High rates of RH cause condensation which is also a problem as it encourages microbial infection and growth, and it can also reduce the strength of packaging materials (Burg, 2014; Lian et al., 2015).

According to Ruiz-Garcia et al. (2010a), ideal lettuce storage conditions exist at the middle of the trailer given the fact that in that part of the trailer, there was the closest temperature to the optimum lettuce temperature, which is 0 ${ }^{\circ} \mathrm{C}$. A shelf life of 21-28 days can be expected at this temperature, and at 5 ${ }^{\circ} \mathrm{C}$ the shelf-life is reduced to 14 days (Cantwell \& Suslow, 2002). However it cannot be ignored that the ideal storage conditions of lettuce are far from ideal for tropical fruits, for instance, and would in fact cause chilling injuries to these products (Jedermann et al., 2009).

A fully automated intelligent supply chain would fulfill the necessity of reducing the food loses. The primary aim of such a system is to create complete temperature traceability across all the agents involved in the management of the produce. Through increased transparency, such systems have the potential to directly target such high levels of food waste while also increasing the safety, security and integrity of global supply chains.

Current cold chain monitoring systems are not able provide assurances of the existence of a cold chain and accurately predict the remaining shelf life of a particular product. Wireless technologies are at the forefront of product offering and to date have been considered key technological enablers in the field of cold chain monitoring. In an ideal commercial environment at 
operational/functional level tags (wireless enabled) would be attached to food item(s), and they have the ability to transmit product specific predetermined physical parameters (data streams) such as temperature and/or humidity as well as other product specific information including position or movement (Zou et al., 2014) to a data repository. These data streams would then be analysed and used to form the bases of "freshness indicators" of the food product being transported. A major advantage of these systems is their ability to capture data that is specific to the product to which they are attached thus providing more accurate freshness estimates.

In order to address this problem various monitoring technologies (such as traditional data loggers as well as RFID and WSN's) have been implemented across food supply chains. These systems can keep temperature record history relating to the product and provide accurate localized individual measurement results through an unbroken chain of calibrations to accepted reference standards (Opara, 2003).

The validation of these systems are being performed by many researchers, such as testing in refrigerated trucks during international transportation (Jedermann et al., 2009; Ruiz-García, 2008; Ruiz-Garcia et al., 2008; RuizGarcia et al., 2010a), using smart RFID tags which integrate light, humidity and temperature sensors to monitor intercontinental fresh fish logistic chain (Abad et al., 2009), and temperature mapping of the pineapple supply chain (Amador et al., 2009). Badia-Melis et al. (2014) evaluated the influence of the sensor housing in wireless devices for temperature monitoring, the management of big amount of data (Y.-Y. Chen et al., 2014; Qian et al., 2012) and polyvalence and versatility (Badia-Melis et al., 2015; Zou et al., 2014). Regattieri et al. (2007) states that in general an RFID system will reduce labor costs and profit losses, while providing more efficient control of the supply chain and thus improving the management of perishable items.

However these technologies are not without their disadvantages and in many cases their commercial potential cannot be realized as their widespread adoption are prohibited due to their cost (Badia-Melis et al., 2013). 
Both RFID and WSN technologies provide an enhanced level of transparency across the full supply network. The core information is delivered via real time data streams providing information to stakeholders on product quality, safety and integrity. This in turn will lead to more flexible, adaptable and responsive supply chains facilitating end-to-end production and supply chain integrity monitoring. From a commercial perspective this will lead to the formation of smart, sustainable and cost competitive global supply chains. These systems present the opportunity to generate large streams of "actionable data" on which important management decisions can be made and will also help to reduce product waste across the logistic chain.

Once the correct technology/technologies have been selected for the appropriate application there are still a number of issues to consider. A key question is the number of loggers (sensors) required to accurately predict the product area, be it a container, cold room or even a pallet. Extensive literature has been published to address the issue (Jedermann \& Lang, 2009; Jedermann et al., 2011b; Jedermann et al., 2009). These talk about the real possibility of temperature estimation, it means to estimate the temperature in critical places where there is no possibility of placing a sensor or there is no convenience for such a thing.

Regular methods are based on the inverse of the distance weighting or kriging. However it does not detect local variations unless a high density of local sensors are integrated, which means that a small isolated variation may go unnoticed in many cases. With this in mind it is often necessary to implement multiple sensors in a reduced space which may be an excessive cost exercise. Jedermann et al. (2009) proposed the grouping of items with similar temperature requirements in separate batches for reducing the necessity of adding extra sensors. Similar studies propose the idea of an intelligent container where the sensors are positioned between the goods (Lütjen et al., 2013).

Current state of the art sensor technologies are mainly capacitor/resistor based systems; therefore by taking the potential difference between the terminals signal, product temperature estimation can be obtained (capacitor method). Uysal et al. (2011) used this method to estimate the temperature 
profiles in First Strike Rations (FSR military USA rations). Further studies proved the possibility of temperature estimation using capacitor and kriging methods, however the best results were obtained with Artificial Neural Network (ANN) (Badia-Melis et al., 2013; do Nascimento Nunes et al., 2014), with errors of estimation always below $1{ }^{\circ} \mathrm{C}$, being this error the $2.85 \%$ of the total error from the regular measurements. In this case it is assumed that the inherently non-linear relationship between the product temperature inside the pallets of the container and the air temperature can be modeled. This method was proposed for a time series forecasting in other articles with successful results, in all the cases the real measurements are compared with estimated with an error between $0.07 \%$ and 3.57\% (N. Liu et al., 2014; M. Qi \& Zhang, 2008; Romeu et al., 2013; Yousefi et al., 2013).

Food chains have become highly distributed, heterogeneous, cooperative, and globalized with extremely diverse requirements, and thus declares the need for convergence of all the necessary technical requirements (with dedicated analysis for wireless technologies), corresponding operation models, networking protocols, hardware (WSN vs RFID), and software (Badia-Melis et al., 2014).

It happens too often that viable technical solutions are not adopted by industry, whether owing to a communication disconnect between research, technology and real-time operations, or because of a lack of confidence that new technology will "really" provide a significant return on investment for business.

Also tracking and tracing have become essential in the food supply chain. The European Commission Health and Consumers (2010) (2010, p. 15, Article 3 Point 15 ) said that the stablished traceability legislation of 2005 , under the definition "the ability to trace and follow a food, feed, food-producing animal or substance through all stages of production and distribution", is not strict enough and restricted to a documentation of supplier and customer relationships, failing to require the monitoring of batches inside enterprises or any further specifics on a system's quality as, e.g. speed of analysis etc. (Regattieri et al., 2007). Food traceability is studied in deep in the Appendices section of this document. 
Emergent techniques and methods for monitoring and tracking of perishable products have enormous potential to make cold chains smart and more efficient. The aim of this thesis is to explore this potential focusing in the application over the perishable produce. In this framework, the creation of economic value is based on efficient processes that ensure quality both for suppliers and customers 



\section{Chapter 3}

\section{Problem statement}

This chapter explains the motivation of the current PhD Thesis, presenting the statement of the problem and why it should be solved. The central problems addressed in this thesis are the recent techniques and technologies that are emerging for monitoring and tracking or tracing the perishable produce along their supply chain.

\subsection{Supply chain of perishable produce}

The long distance transport and the globalized markets make essential the development of monitoring systems that guarantee the optimum conditions of the products. Exporting countries, such as Costa Rica are sending their products to greater distances every time, as far as Russia for example and it implicates an increase on the time in transportation and as a consequence bigger risk for the products (Amador et al., 2009). These exported products spend even some weeks traveling in refrigerated containers with no information until they reach their destiny. 
The transport includes various transitions and transferences of the product between companies, as well as administrative control in the customs, borders and seaports. Perishable food products have to maintain the temperature and relative humidity during the trip, such that they keep the optimum conditions and freshness. Nonetheless, it is very common that those controlled conditions are not happening along the whole trip, especially in places such as seaports or transitions in airports, where the containers can be exposed to adverse conditions during long periods of time.

High losses are completely unacceptable and it is for this reason it is needed a fully automated, "intelligent" chain wide monitoring sensor system, for cold chain. The primary aim of such a system is to monitor and record temperature across the complete supply chain to ultimately facilitate a complete "chain of custody" across all stakeholders. By increasing the level of transparency, such systems have the potential to directly target such high levels of produce losses.

\subsection{Current monitoring systems}

Current cold chain monitoring systems in use lack the ability to provide real time, all and too often accurate information relating to the products and the conditions in which they are at any given moment in time. This results in the inability to (1) provide assurances of the existence of a cold chain and (2) accurately predict the remaining shelf life of a particular product. However of late there are no shortage of sensing techniques and technologies to maintain and monitor implementation and recording of cold chain conditions on the market nowadays (Badia-Melis et al., 2014).

Wireless technologies have been considered key technological enablers, whereby intelligent tags are attached to an item, within a network with wireless links, which can transmit some physical parameters such as temperature or humidity in addition with other information like position or movement (Zou et al., 2014). 
Monitoring devices are used to ensure the temperature integrity in the cold chain, however resource limitation and cost factors limit their use to one per pallet or even one per container scenarios (Badia-Melis et al., 2013). The validation of these systems are being performed by many researchers, such as testing in refrigerated trucks during international transportation (RuizGarcia et al., 2008); (Ruiz-Garcia et al., 2010a), using smart RFID tags which integrate light, humidity and temperature sensors to monitor intercontinental fresh fish logistic chain (Abad et al., 2009), temperature mapping of the pineapple supply chain (Amador et al., 2009) and validation of RFID semipassive tags for monitoring cold chain in refrigerated trucks (Jedermann et al., 2009).

In many occasions sensor nodes require a specific housing to protect the electronics from harsh environmental conditions, since this kind of equipment was not originally designed for those conditions, i.e. meteorological data acquisition system (Lee et al., 2010), however this effort always shows as contra wise effect, the lack of sensitivity of sensors.

Pizzuti et al. (2014) write about the inability to link food chains records that characterizes the current traceability systems, also describes the inaccuracy and errors in records and delays in obtaining essential data. The access to this information is key in case of a food outbreak disease and it's necessary for the job of food safety agents.

Jedermann et al. (2009) proposed the grouping of items with similar temperature requirements in separated batches in order to reduce the necessity of adding extra sensors; it could be carried out in his intelligent container. Similar studies propose the idea of an intelligent container where the sensors are positioned between the goods (Lutjen et al., 2012).

Temperature estimation has been studied by some authors (Jedermann et al., 2011a; Jedermann \& Lang, 2009; Jedermann et al., 2009), these studies showed to be more relevant in critical places, physical locations of the analyzed scenarios, where there is no possibility of placing a sensor or there is no convenience for such a thing. The regular methods are based on the inverse of the distance weighting or kriging, however it does not detect local 
variations unless it is used a high density of local sensors, which represents a counter effect in reducing the number of sensors.

Approaches to a better monitoring systems and real time tracking are being assessed, as it is shown in this document. Those approaches would lead to a better understanding of the food traceability and therefore a more effective traceability. 


\section{Chapter 4}

\section{State of the art}

The aim of the present section is to review the technical and scientific state of the art of latest monitoring systems and methods used for tracking and tracing perishable products, including the types of sensing technologies available, traceability issues, remote communications (RFID, WSN, Near Field Comunication), cold chain and food processing applications, as well as conceptual advancements.

The section 4.1 has been published as a book chapter in Advances in Food Traceability Techniques and Technologies, 1st Edition, Woodhead Publishing Print Book ISBN : 9780081003107 June 2016. More specific revisions, related to the experimental work, can be found in chapter 7.

\subsection{Real time tracking and remote monitoring in food traceability}

Monitoring systems are essential in the nowadays globalized markets and the long distance transportations to guarantee the optimum conditions of the 
produce. These transports can last thousands of kilometers, from Costa Rica to Russia, which increases the risk of slippage in the stability of the products (Amador et al., 2009).

Temperature and relative humidity have to be maintained during perishable food products transportation, such that they keep the optimum conditions and freshness. Nonetheless, it is very common that those controlled conditions are not happening along the whole trip, especially in places such as seaports or transitions in airports, where the containers can be exposed to adverse conditions during long periods of time.

The U.N. FAO estimates that each year, approximately one-third of all food produced for human consumption in the world is lost or wasted (FAO, 2013). The United Nations Environment Program says that 222 millions of tons are annually wasted in developed countries, almost as much as the entire production of the sub-Saharan Africa (230 million tons) (UNEP, 2013). A study performed in USA, Canada, Australia and New Zealand reveals that during production, the $20 \%$ of the fruit and vegetables are loosed; consumers waste the $28 \%$ and during distribution it is wasted the $12 \%$ mainly because of the lack of refrigeration control (Gunders, 2012).

Adequate temperature monitoring in order to ensure the longest shelf life for perishable food products represents a difficult jigsaw to solve due to the many factors involved. Thus, studying and analyzing temperature gradient data inside refrigeration rooms, containers and trucks is a primary concern for the industry. Any temperature disturbance can undermine the efforts of the whole chain (Mahajan et al., 2014) it is very common in perishable food products, including goods poorly or excessive cooled. Jedermann et al. (2014a) reported many examples where the inadequate management during temperature control usually leads to losses in the food chain (post-harvest, distribution and at home). To understand this variation is possible by a remote monitoring (Jedermann et al., 2015); this remote monitoring would require a high number of data loggers to identify weak points in specific spots through a container, cold room or even a pallet. 
The specialization of the agents in the current transportation and distribution chains must entail an improvement the coordination, in the contrary breaks in the cold chain would appear and the consequent loss of quality of the products.

Jedermann et al. (2009) studied temperature gradients during transport of perishable products, and they proposed that the products have to be separated into different groups depending on the temperature requirements of each product, this would reduce the need to use more sensors. There are similar studies, which describe an intelligent container that has its own sensors, these sensors are placed between the load (Lutjen et al., 2012).

\subsubsection{How can we can track and monitor in real time?}

The integration of diverse technologies is required in the supervision of refrigerated transportation, being especially important the communications and the sensors (see Figure 4.1). This data collecting has to be done in critical points and in determinate moments; otherwise this data would not help. Other techniques recently emerged will contribute for the adequate monitoring, such as the Internet of Things, the concept of intelligent traceability and the temperature estimation methods.

\section{Wireless Sensing Technologies}

Wireless technologies are considered an important advance, smart tags, communicating wirelessly independently, connecting to a network, and transmitting parameters to a gateway sensor, such as temperature, humidity, light or movement (Zou et al., 2014). Due to resource limitations and cost factors monitoring devices are limited to one-per-pallet or even one-percontainer in certain scenarios (Badia-Melis et al., 2013).

The potential for monitoring technologies, WSN and RFID, has been suggested by several studies and extensive literature has been published to address the issue (Badia-Melis et al., 2014; Hendrik Haan et al., 2013; Jedermann et al., 2014b; L. Qi et al., 2014; Ruiz-Garcia et al., 2010a). Nevertheless, due to characteristics of food and insulation of the packaging, the temperature is not 
always homogeneously distributed inside the pallet, and using a single sensor for the entire pallet does not provide a realistic representation of the temperature mapping since it only represents the temperature of one spot, meantime the rest of the container or pallet does not have any temperature reference.

\section{Remote communications}

Remote communications in long and middle range have been extraordinarily developed in the last few years. The usage of Wi-Fi, GSM or GPRS is so common that are barely noticed nowadays, but when it is about machine to machine (M2M) communications, these are no as common, e.g. communications needed between a container travelling across the Atlantic ocean and a server located thousands of kilometers away, even more taking into account that there are hundreds of thousands of containers being moved daily in the world.

Jedermann et al. (2014b) present a detailed description of technical challenges and solutions for a wireless monitoring in transport, talking about pros and cons in device communication, protocols, energy consumption and data accessibility. On the other hand Badia-Melis et al. (2015) show how a warehouse with cold rooms of the size of $26 * 6 * 12=1848 \mathrm{~m} 3$ can be instrumented combining two different technologies, RFID and WSN in a way such as both can benefit from each other and give complementary data. 


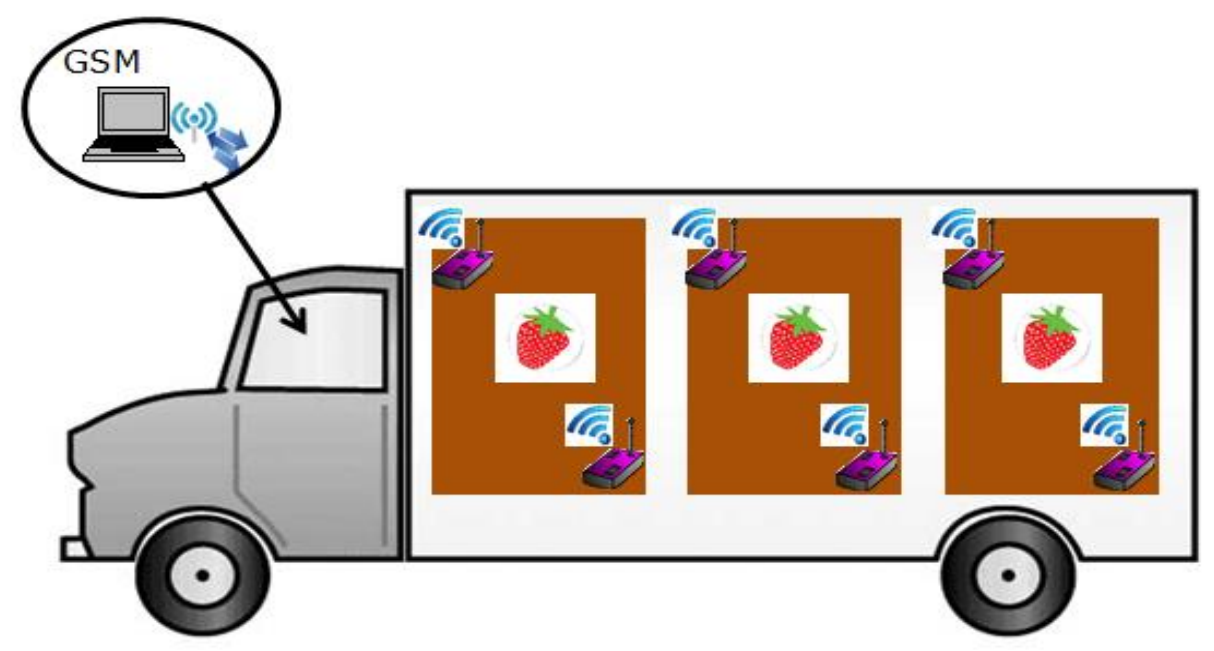

Figure 4.1. Monitoring system in refrigerated transport with Wireless technology

Figure 4.1 represents a standard wireless monitoring system integrated into a refrigerated trailer, in every pallet there are a certain number of devices that can communicate wirelessly with either a standalone gateway or a gateway connected to a computer and at the same time the gateway or the computer can be connected to the internet and GPS emitting to a remote database.

Short range communications are not exempt of risks, since everything happens in the container with the size of $12 \mathrm{~m}$ length, 2.3 width and 2.5 high (Table 4.1). The key is not only about transmitting data inside the container, but making an adequate integration of the sensors. The fusion between both is what is being called wireless sensing. Inside this field the technologies considerate with greater potential are Radio Frequency Identification (RFID) systems and Wireless Sensing Networks (WSN) (Ruiz-Garcia \& Lunadei, 2011). 
Table 4.1. Commercial container sizes

\begin{tabular}{llccc}
\hline & & $\begin{array}{c}\text { Reefer 45'High-Cube } \\
(\mathbf{m})\end{array}$ & $\begin{array}{c}\text { Reefer } \\
\mathbf{4 0}(\mathbf{m})\end{array}$ & $\begin{array}{c}\text { Reefer } \\
\mathbf{2 0}(\mathbf{m})\end{array}$ \\
\hline Interior & Length & 13.10 & 11.57 & 5.44 \\
size & Width & 2.29 & 2.29 & 2.29 \\
& High & 2.50 & 2.21 & 2.14 \\
Capacity & & $75.40 \mathrm{~m}^{3}$ & $58.70 \mathrm{~m}^{3}$ & $28.31 \mathrm{~m}^{3}$ \\
\hline
\end{tabular}

Currently RFID is the most mature technology and it is commercially available. On the other hand WSN has not evolved as fast as expected in the agro food sector, since nowadays, important aspects are due to be solved such as the encapsulation, the size of the devices or the battery life among others (Badia-Melis et al., 2014). The very first WSN nodes on the market, held a whole variety of sensors able to control refrigerated logistics, such as temperature, relative humidity and acceleration (vibration and shocks). Its drawback was that it was working in the microwave band $(2.4 \mathrm{GHz})$ and its power was not higher than $1 \mathrm{~mW}$ (Figure 4.2 ). The $2.4 \mathrm{GHz}$ microwave band has the advantage of being available all around the world but the main disadvantage is the coincidence with the water resonance frequency (than is the reason of the food heating), therefore its propagation is difficult through the water and the air with high relative humidity. That is to say the typical conditions in a fruit and vegetable transportation, where the air has around $90 \%$ of $\mathrm{RH}$ and the products water content is usually more than $90 \%$ (RuizGarcia \& Lunadei, 2011). 


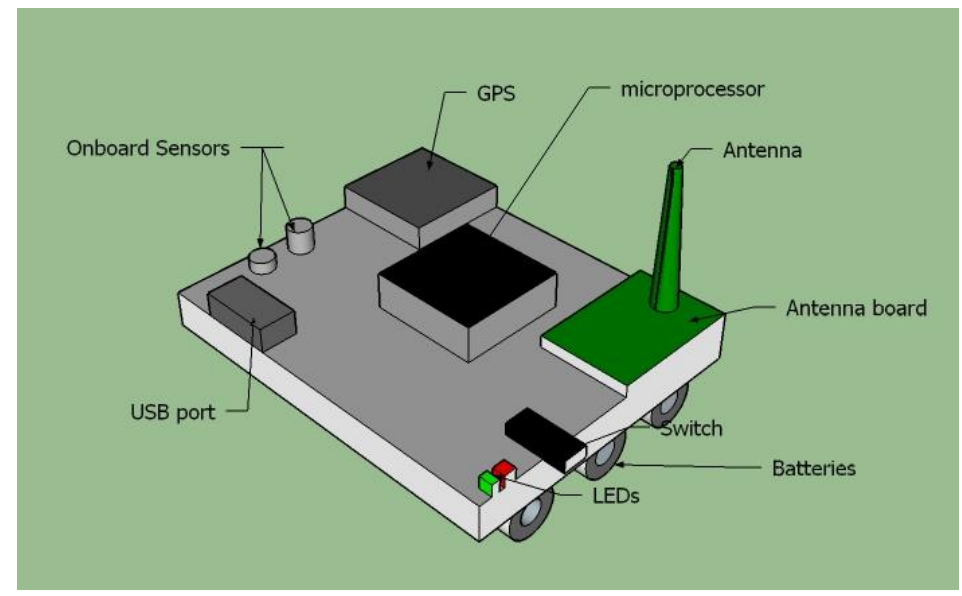

Figure 4.2. Standard Mote structure

\section{Internet of things}

The Internet of Things (IoT) is a network that combines everyday objects with the ability to identify and interact with each other to reach cooperation goals (Giusto et al., 2010). Its purpose is that all the items can be perceived and controlled remotely, and combined with the internet to form a more wisdom production and living systems. IoT describes a world where humans are surrounded by machines that communicate with each other and can allow people to interact with the digital world. The concept of IoT break the traditional ideas and start a new technology field, it will bring a new revolution of world information industry after the computer, internet and mobile communication network.

Internet of things is an infrastructure to facilitate the information exchange of products (Amaral et al., 2011; Atzori et al., 2010). The system itself is composed of three dimensions which contain information items, independent networks and intelligent applications. Information items are those that can identify and perceive their own message; independent networks have the capabilities of self-configuration, self-healing, self-optimizing, self-protection; intelligent applications mean the application with the capabilities of intelligent control and processing.

RFID can enhance the efficiency of Food chain by storing the meaningful information such as producing area, the planting methods, the producing 
process and other special information that consumer will consider about them when they purchase products (M. Zhang \& Li, 2012). The conceptual sensor data integration has been exploited the classification approach by using the EPC in RFID (Theodorou, 2006). Kiritsis (2011) introduced the "intelligent products", which are meant to be used in the IoT.

Atzori et al. (2010) describe in their article how EPC is a mean to support the spread use of RFID in world-wide modern trading networks, and to create the industry-driven global standards for the EPCglobal Network ${ }^{\mathrm{TM}}$. These standards are mainly designed to improve object visibility (i.e. the traceability of an object and the awareness of its status, current location, etc.).

\section{Intelligent traceability}

After an extensive review of many studies, Bosona and Gebresenbet (2013) concluded that food traceability should be considered as an important and integral part of logistics management, so the information is stored on the go and it can be retrieved at any moment.

The term intelligent food logistics is becoming and important topic about food chain, meantime, as described by Jedermann et al. (2014a), intelligent food logistics are called to reduce the perishable waste along the food supply chain by means of reduction of the deviation from the optimal cold chain, to do that it is necessary to quantify these deviations, making shelf life variation know and remote monitoring. Ruiz-Garcia et al. (2010b) proposed a web-based system for data processing, storage and transfer. It integrates all information along the food and feed chain, oriented for the needs of the consumer. These kinds of studies lead to a more intelligent food logistic chain.

In the other hand, traceability as is described in the introduction of this document, is an integral part of food safety, food quality and food defense which make it part of the food supply-chain, pretends to be of high potential for the protection of consumers. Both intelligent logistics like traceability are happening during the supply chain. 
As Scheer (2006) described in his article, the data obtained in the traditional tracking and tracing (T\&T) systems are usually used only to recall management, nonetheless the proposed quality oriented tracking and tracing system (QTT) uses the information retrieved with what we could call intelligent logistic tools, such as wireless sensors (temperature and humidity for instance).

The QTT concept represents a perfect alliance between logistics and traceability, improving the supply chain. Jedermann et al. (2014b) published how the integration of QTT and FEFO (first expire first out) using shelf life models, can enhance the demand and supply chain. Van der Vorst et al. (2007) also emphasizes in the implementation of quality controlled logistics in the food supply chain networks, if the product quality can be predicted in advance it can lead to a better goods flow and better chain design.

\subsubsection{New advancements}

The current advancements in RFID technology and the incorporation of integral parts such as data logger capabilities and integrated sensors, have provided a new dimension to the application of RFID technology in the food traceability systems, as it is gathered in the article of Ruiz-Garcia and Lunadei (2011), the applications of RFID to the food traceability are many and varied. During the last decade RFID has emerged as a lead actor in the development of traceability systems in the food supply chain and their implementations are increasing at a fast rate (Costa et al., 2013). With the implementation of RFID technology, food traceability systems can become more reliable and efficient since RFID enables a higher reading rate than traditional barcodes (Hong et al., 2011). With identification of the products without any physical contact, the RFID technology provides effective information sharing with efficient customization and handling (M. Zhang \& Li, 2012). Kelepouris et al. (2007) proposed an infrastructure using RFID, where it was compared with the traditional lot numbering and internal information systems; it has the advantages of automatic identification, uniform EPC for all partners, small investment in equipment and easily drawn information. 
Agro-food logistics and supply chain management processes for food traceability using RFID are discussed since some years ago by several authors, i.e. Angeles (2005); Attaran (2007); Jones et al. (2004); Ngai et al. (2007); Sugahara (2008); Twist (2005). Amador and Emond (2010) developed a system of RFID temperature tracking for combat feeding logistics. The capability of hosting sensors of the tags allows the called "cold traceability", concept that has been introduced to trace groups of temperature-sensitive products are transported in different atmosphere requirements (Ruiz-Garcia et al., 2010b).

Feng et al. (2013) developed and evaluated a cattle/beef traceability system, which integrated RFID technology with PDA and barcode printer. They obtained real-time and accurate data acquisition and transmission, and the high efficiency of information tracking and tracing across the cattle/beef supply chain.

An Internet of Things (IoT) platform is a concept used in this case by Zou et al. (2014), it consist of two-layer network architecture; it is an innovative way for implementing RFID for traceability in what is called "intelligent food logistics", consisting of an asymmetric tag-reader link (RFID layer) and an adhoc link between readers (WSN layer), which are further connected to the Internet via cellular or $\mathrm{Wi}-\mathrm{Fi}$.

\section{Near Field Communication}

NFC or Near Field Communication is actually an extension or a subcategory of RFID. NFC technology enables simple and safe two-way interactions between electronic devices; it complements many popular wireless technologies at consumer level (in the existing standards for contactless card technologies ISO/IEC 14443 A\&B and JIS-X 6319-4). NFC enables devices to share information in less than $4 \mathrm{~cm}$ (NFC-Forum, 2014). It operates at $13.56 \mathrm{MHz}$ and currently supports data rates of 106, 212, 424 or $848 \mathrm{Kbit} / \mathrm{s}$ (Mainetti et al., 2013a). These tags are made very small so that they can fit inside products for various reasons such as security, anti-theft and individual identification. NFC is the newer version of RFID that is typically for use in a very short distance range for making payments (Mainetti et al., 2012) and 
information retrieval. Like RFID, the main advantage of NFC technology above barcode and QR codes is that it does not require a laser beam to have a solid path so that it can travel between two devices.

MIT chemists have developed a NFC tag based in chemiresistors that is able to detect certain gases. They disrupted the electronic circuit by making a hole in it, and after reconnect the circuit with a linker made of carbon nanotubes. When the targeted gas is present the conductivity of the nanotubes change and they are able to read the tag with a smartphone and detect the presence of the gas (Trafton, 2014). In this case real time tracking of gasses can be done with NFC and it can be recorded in the traceability of the product. At the same time it is important to notice that the low cost of the NFC adds that benefit in front of other technologies more expensive.

\section{Temperature estimation}

Some of the articles introduced years ago the real possibility of temperature estimation (Jedermann et al., 2011a; Jedermann \& Lang, 2009; Jedermann et al., 2009), it means to estimate the temperature in critical places where there is no possibility of placing a sensor or there is no convenience for such a thing.

\section{Capacitor}

A temperature sensor is a capacitor/resistor system; therefore by taking the difference between the terminals, the signal estimation can be done. The temperature rise and fall rates within a food pallet fit quite accurately the rise/fall time constants in a resistor-capacitor (RC) electrical circuit (BadiaMelis et al., 2013). Therefore pallet temperature is modeled by the potential differences between the terminals of a capacitor. Uysal et al. (2011) used this method to estimate the temperature profiles in First Strike Rations (FSR military USA rations) they call it capacitor method, the improvement was of $90.11 \%$ comparing the estimated temperature by capacitor method as a reference versus the environmental temperature which is the traditional reference. Badia-Melis et al. (2013) achieved an $86.69 \%$ of improvement in temperature estimation regard to no temperature estimation. 
Kriging

Kriging method is presented in this document as the second algorithm. There are various linear interpolation methods that multiply the measured values at the source points with a set of weighting factors in order to estimate the value at a destination point. The weighting factors can be set by a heuristic approach proportional to the inverse squared distance or by statistically more solid through the Kriging method. This method is based on an analysis of the spatial correlation of the measurements; it uses the Variogram, which gives the expected difference of the physical quantity between two points as a function of their distance (Jedermann \& Lang, 2009).

This method has previously been used in environmental estimation problems defined within a continuous feature space (such as temperature inside a homogenous container), Badia-Melis et al. (2013); Jedermann et al. (2011a); Jedermann and Lang (2009) obtained in the best of the cases $40 \%, 20 \%$ and $79 \%$ respectively improvement of the errors in comparison with traditional methods.

\section{Artificial Neural Network}

Finally, as the third algorithm, it is assumed that the inherently non-linear relationship between the product temperature inside a pallet and the air temperature can be modeled by an artificial neural network (ANN) (M. Qi \& Zhang, 2008). Input to the network consists of time-temperature data provided by the sensors placed outside the pallet whereas output is the estimated time-temperature data for products placed inside the pallet. Hidden layers consist of artificial neurons which weigh and sum their inputs as they propagate their outputs to the next hidden layer (Figure 4.3). ANNs need to be trained with part of the temperature data to learn how to estimate the non-linear relationship between its input and target output. 


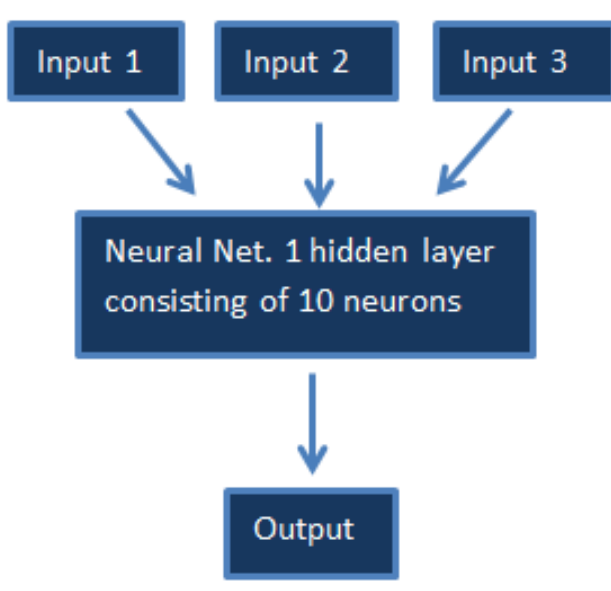

Figure 4.3. Structure of a Neural Network, one hidden layer with ten neurons

\subsubsection{Applications}

As new advancements are showing the latest updates and trends in the food traceability, the applications show how some of these advancements are applied to the real world in most of the cases in experimental approaches. Cold chain is an essential part of the traceability since many of the perishable goods need refrigeration during the supply chain and it is important to record what is happening with the temperatures. In the other hand the food processing needs a process registration for the record and for further recall in case it is needed due to a foodborne illness or information for the customer.

\section{Cold chain}

It is important to take into account that the quality of perishable products cannot be enhanced during transportation, storing and distribution. Each product has its own specific shelf life, limiting their good conditions for consumption. What is achieved with a proper cold chain is to delay the deterioration of the product (Ruiz-Garcia \& Lunadei, 2011). But the loss of quality is accumulative, and it depends on numerous factors and interactions. The lack of control can occur at any moment. Also the temperature distribution is not homogeneous both in a cold room like in a refrigerated container, shelf life is as well not homogeneous, having variations between pallets and even between cartons (Badia-Melis et al., 2013). 
If the cold chain is broken at any moment the freight arrives in bad conditions. The losses can go from few cartons to an entire container. When the loss is significant it is necessary to use insurances and experts, and the responsibility assumption needs to be done and it can fall into conflicts. At this moment is when monitoring technologies become essential (Badia-Melis et al., 2015), since the information retrieved from the sensors allows determining the moments where the products were at risk.

\section{Food processing}

Barge et al. (2014) automatically recorded cheese wheels movements during the production, handling in the maturing room and warehouse, delivery, packing and selling phases in a dairy factory with the help different techniques by fixing RFID tags to the cheese. They considered factors such as tag type and shape, required power, antennas polarization and orientation, fixing method and ripening duration to verify their effect on reading performance and system reliability.

Catarinucci et al. (2011) used a combination between WSN and RFID, in order to enhance the traceability of the white wine from vineyard to consumer glass. WSN is a wireless technology like RFID also tried by many other authors to improve the food quality in terms of traceability (L. Qi et al., 2014) and aquaculture (L. Qi et al., 2011).

A Wheat Flour Milling Traceability System was developed by Qian et al. (2012) (WFMTS), incorporating 2D barcode and RFID technology, to validate the system in wheat flour mill in China. Labels with a QR Code were used to identify small wheat flour packages, and RFID tags were used to identify wheat flour bins and record logistics information automatically. They obtained that the total cost of the system increased by $17.2 \%$ however, with the new system the sales income increased by $32.5 \%$ and proved the high potential of good application of WFMTS in medium and large wheat mill enterprises.

Recently, Mainetti et al. (2013b) describe the potentialities from the combination of RFID and NFC; it allows the end consumer to know the complete history of the purchased product. They implemented the usage of 
NFC in a IV gamma products supply chain. NFC is proved to work together with a mobile app to allow the linking of plants and traceability information (Mainetti et al., 2013a).

Y.-Y. Chen et al. (2014) propose a scenario in the near future, where the consumer can use the smart phone to read passive information and essential parameters, and finally safely purchase the food.

\subsubsection{Limitations and Challenges}

The most important topic for food industries is to measure the temperature in the most possible points without a big investment. This achievement is possible by implementing RFID semi passive tags which incorporate temperature sensors. The major disadvantage is it operates in the $13.56 \mathrm{MHz}$ frequency and with this low emission power the reading range does not go beyond 2 to $3 \mathrm{~cm}$. Despite of this tags register date and time and record it in their internal memory, it is necessary to wait until the end of the journey to download the information one by one. Retrieving this information takes time and the information is not live.

Are there any other systems able to provide live information? The answer is yes, but there are not completely developed due to its complexity. To achieve this information is needed to implement active RFID or WSN, they can be configured to send data every certain periods of time, it is called the sample rate, and they are provided with the enough radio frequency power to send the signal through the pallets even they operate in $2.4 \mathrm{GHz}$ band. Although it would be better to implement systems that use other frequencies, for example $433 \mathrm{MHz}$. Currently this frequency band is considered the most appropriate for the refrigerated monitoring systems, since it is available in all over the world and goes through the obstacles better than other high frequencies such as $915 \mathrm{MHz}$ or $2.4 \mathrm{GHz}$ (Laniel et al., 2011).

Regard to cattle/beef sector, the main challenges for implementing RFID in their traceability system are the inapplicable method of inputting information, the inefficient sequence of data input and communication mechanism 
associated with RFID reader, and the high implementation cost (Feng et al., 2013). With many advantages of RFID technology it is still not a preferable choice of most of the companies as it leads additional cost to the company. However, the balance between the benefit and safety requirement of the company is the major driving force for the adoption of technologies like RFID (M. Zhang \& Li, 2012).

Other challenge is going around almost any obstacle, which these technologies have surpassed. The standard ZigBee protocol being used for some WSN and RFID class 4, are able to adopt net topology with data transference point to point (PtP). It means that the data can be hopping from one node to the following without having to go directly to the gateway; it allows the communication to go around any object, such as metals or liquids. It is necessary to take into account that this situation would need an increment on the number of nodes, increment of complexity and the consequent increase in the costs. Despite of the sensing devices have a relatively low price ( 15 to $100 €$ ), it is necessary to use routers, gateways, concentrators and even sometimes specialized computers, and it makes the entire system increasing the costs.

Some of the Ultra High Frequency tags (bands 860 MHz Europe $915 \mathrm{MHz}$ USA) potentially useful and currently used for cold chain monitoring and traceability control present the disadvantages of more interferences than other frequencies. These different bands are only available in USA and Europe. Japan and China do not allow these transmissions (Ruiz-Garcia \& Lunadei, 2011).

The reduced size of the wireless sensing devices allows them to be installed in any place inside the freight or the container. RFID tags have a similar size of a credit card and WSN nodes are not bigger than a tobacco packet. This is a big advantage since it can be located either inside the cartons, the pallets, the container's walls or in the direct airflow of the refrigerated system. Inside the container the temperatures are not homogeneous and different gradients can occur, warm air tends to stay in the upper part and cold air stays at the bottom. From all the temperatures among the container, the most important to control is the product temperature itself, it means the pulp of the pineapple 
or the leaf from the lettuce, because if the temperature is taken outside of the cartons or in the wall of the container, it cannot be possible to determine whether the product temperature is in the proper range or not, therefore if the purpose is to avoid cold damages or excessive ripening it is necessary the best control over the product.

Is it mandatory to put a device in every box? It is not necessary, since it would dramatically increase the cost of the implementation. Determining the optimum number of sensors and their location is a topic not yet solved, and it is being investigated (Badia-Melis et al., 2013; Jedermann \& Lang, 2009; Jedermann et al., 2011b) by using temperature estimation methods, it is a useful thing to know since it will be know when a sensor is essential or can be substituted by an estimated point. A bigger number of nodes are not only providing more reliable data, but a rise in the expenses, management and maintenance.

Therefore the use of an estimation method can begin to consolidate and so the use of ANN, which has been applied to forecasting for several authors ( $N$. Liu et al., 2014; M. Qi \& Zhang, 2008; Romeu et al., 2013; Yousefi et al., 2013). Badia-Melis et al. (2013) achieved an improvement of $95.3 \%$ in comparison of using only the ambient temperature as a reference, with errors of estimation always below $1{ }^{\circ} \mathrm{C}$.

Nowadays it is known that meanwhile the average temperature throughout transportation might be similar for all cartons in a pallet, since the shelf life losses increase exponentially at higher temperatures, the remaining shelf-life of products can be significantly different at the end of the transportation. do Nascimento Nunes et al. (2014) showed in their experiment the cartons in the middle of the pallet possessed longer shelf lives compared to the cartons located near the outside. Therefore, since the temperature estimation techniques it is possible to assess temperature variations inside a pallet, hence have a quantifiable impact on individual product qualities.

These techniques generate big amount of data, which complicate the system causing significant increments of the daily data to manage. It is estimated that a regular RFID system generates between 10 to 100 times the 
information that a traditional $2 \mathrm{~d}$ barcode system does. It is necessary the implementation of management advanced system for the database that avoids collapses and guarantee an adequate speed for further consultation. Where some people see inconveniences, others see opportunities, for example Wal-Mart and other multinational companies, work in data mining techniques, that provide complementary information about performed operations (RuizGarcia \& Lunadei, 2011).

In the case of fruit and vegetables logistics, the detection of volatile gases related with the ripening state of the freight, involve a great challenge, the two most important gases are ethylene and ethanol. The development of specific sensors for those two gases is a problem which is being investigated from some years ago, and an adequate solution has not been achieved. Certain sensors have been developed to detect both gasses, but the detectors fail when it is necessary to differentiate them in the same air mass. This fact makes no possible the use of these sensors with fruit, since ethylene indicates the ripening in the fruit and the ethanol in the other hand indicates when the fruit is rotting. Hence the usage of a nonspecific sensor could lead to serious mistakes in cargo management, such as discard valid containers or accept shipments that are rotting.

\subsubsection{Conclusions and future trends}

As it is shown in this chapter, there are numerous topics that need to be improved in the wireless sensing for real time tracking and remote monitoring. That does not mean that these technologies are not valid. Many advances in the technologies have been done; there are new concepts that are created in order to complement the technological advancements, the intelligent traceability will provide intelligence to the traceability chains, combined with the internet of things it will be possible to train the systems, those systems will learn and enhance the procedures. Temperature estimation can become key in these cases, saving money and reducing tools management operations. This forecasting makes the freight more predictable, it is possible to build records of the chain and predict what is going to happen next. 
Using real time tracking and monitoring technologies it is possible to reduce the risks of non-desired situations, the freight becomes a more controlled environment, in addition because of the cargo is being under surveillance less people will be touching or opening up goods until the final destination.

Both, food processing like the cold chain are beneficiated from the advancements that are really useful for the food industry. Usually the companies do not monitor the chain in all the stages or even in any of the stages; a simple sensor system would bring answers to the many problems that they face day by day and will reveal the unseen situations that need to be improved.

Although there are yet many limitations and challenges to face, the application of these technologies and advancements in refrigerated transport supervision is doable, under a technical and economical point of view; since their current state allows obtaining valuable information about transports that until now was not possible to achieve. 



\section{Chapter 5}

\section{Prior knowledge: Background on food logistics and postharvest}

The current $\mathrm{PhD}$ thesis represents the continuation of several research works made by the author and the departments and research groups where the work was developed, the most important of them are detailed in this chapter.

Prior background has been gathered by the PhD candidate and also by his tutor. PhD candidate has participated in six international projects, four out of the six were European projects and two projects were developed in the USA.

His Honours Bachelor Degree Thesis (HBDT) was developed during his internship in the research group LPF-TAGRALIA, the directors of this group from 2009 to 2016 have been Prof. Margarita Ruiz Altisent, Prof. Pilar Barreiro and Prof. Belen Diezma, this laboratory is integrated in the Agroforestry Department, in the Escuela Técnica Superior de Ingeniería Agronómica, Alimentaria y de Biosistemas (ETIAAB). PhD candidate Ricardo Badia Melis worked on multiple research projects, involving sustainable production of fruits and vegetables, logistics for cold chain monitoring of food and health 
products, as well as smart sensors for food quality control; those projects were the following:

1- "Sensórica Inteligente para el control de la calidad en línea de procesos alimentarios-SMART-QC" (2009 - 2011). Founded by the Innovation and Science Ministry with the reference number: GL200805267-C03-03/ALI. The participating entities were the UPM (Universidad Politécnica Madrid), CENIM-CSIC (Centro Nacional de Investigaciones Metalúrgicas - Consejo Superior de Investigaciones Científicas) and IIM-CSIC (Instituto de Investigaciones Marinas). The project director was Prof. Pilar Barreiro. The main objective of the project was the development and implementation of novel computer aided process engineering tools and methods for optimal on-line quality control of food processes. The research focused on, first the development of novel sensing techniques which combine previous results and experience in Micro Electro Mechanical Systems (MEMS) and Wireless sensor networks (WSN), with efficient modelling and simulation approaches to build up online food quality sensors. And second the integration of the sensing techniques into an optimal online control framework for quality control in food processing, with particular emphasis in thermal processes.

2- "Increasing fruit consumption through a trans disciplinary approach leading to high quality produce from environmentally safe, sustainable methods-ISAFRUIT" (2006 - 2011). Founded by FP6-FOOD 016279-2. -Project director was Prof. Margarita Ruiz Altisent. ISAFRUIT was an integrated project aiming at improved health of the European community by increasing fruit consumption. The basis of the project say that increased consumption shall be achieved through consumer satisfaction, therefore ISAFRUIT aimed to better fulfil the consumer preferences and expectations with regard to the quality, safety, convenience and availability of fruit and fruit products at the point of sale.

3- "Plataforma de Control Logístico Avanzado para el seguimiento de la cadena de fRÍo de productos Sanitarios y Agroalimentarios- CLARISA" 
(2008 - 2011). Founded by the Ministry of Industry, Tourism and Trade with reference code TSI-020100-2009-851. Project director was Pilar Barreiro. CLARISA aims to integrate the embedded intelligent technologies and wireless communications to transform cold chain monitoring systems in an intelligent food traceability system, within temperature controlled perishable product environments.

Ricardo Badia Melis was awarded in 2012 by The Horticultural Science Spanish Society (SECH acronym in Spanish) Award for his HBDT named "Monitoring the cold chain of fruit and vegetable products by means of radio frequency identification technology (RFID) and wireless sensor networks (WSN) in Mercamadrid's refrigerated warehouses".

The HBDT approaches the application of new wireless sensor technologies in the cold chain since the current systems at work don't provide truthful information about the conditions and state of the products. It focuses in the development of supervision systems through implementing Radio Frequency IDentification technology (RFID) and Wireless Sensor Networks (WSN); and studying the impact of sensor housing on the equipment. From this work was published a scientific article:

Badia-Melis, R., Garcia-Hierro, J., Ruiz-Garcia, L., Jiménez-Ariza, T., Villalba, J. I. R., \& Barreiro, P. (2014). Assessing the dynamic behavior of WSN motes and RFID semi-passive tags for temperature monitoring. Computers and Electronics in Agriculture, 103, 11-16.

From 2012 to the middle of 2014 Ricardo Badia Melis worked in the RFID Laboratory for applied research in the University of South Florida, under the direction of Prof. Ismail Uysal. His role as a cold chain engineer was to develop comparative analysis of different kind of RFID systems for food monitoring; monitoring cold chain of food and logistic chain with RFID technologies; monitoring storage process for food shelf life optimization, designing testing protocols for the cold chain. He also learned how to develop Graphical User Interfaces for helping the industry to improve the cold chain logistics with advanced data analysis techniques and food pallet 3D temperature mapping. 
During his stay in the USA PhD candidate took part in the following projects:

1- Remote Environmental Modeling and Diagnostics in the Perishables Supply Chain Phase II (01/03/2011 - 30/09/2013). Performed in University of South Florida and University of Florida, USA. Founded by U.S. Army Natick Soldier Research, Development and Engineering Center, with reference code W911QY-11-C-0011. Responsible team for the project was Prof. Brecht, Jeffrey K; Prof. Uysal, Ismail; Prof. Nunes, Maria C; Sims, Charles A; Obadasi, Asli; Pliakoni, Eleni; Prof. Emond, Jean-Pierre; Bennett, Gisele and Wells, Jeffrey L. This project involved the evaluation of state-of-the-art technologies including wireless temperature sensors, remote monitoring using RFID, algorithms, and diagnostics, to demonstrate that combat ration shelf life can be automatically calculated in real time using predictive models. A prototype system including sensor equipped pallet level RFID tags, handheld readers, and computer shelf life models was developed to determine the remaining shelf life of the First Strike Ration and Meal, Ready-to-Eat based on product time and temperature storage history.

2- Reducing Strawberry Waste and Losses in the Postharvest Supply Chain via Intelligent Distribution Management (01/07/2013 $31 / 07 / 2014)$. Performed in University of South Florida and University of Florida, USA. Founded by Walmart Fundation. Responsible team for the project was Prof. Brecht, Jeffrey K; Prof. Uysal, Ismail; Prof. Nunes, Maria C; Prof. Emond, Jean-Pierre; Wells, Jeffrey L. and Saenz, Jorge. The main goal consisted on to model fresh fruit vegetables shelf life considering all the possible shelf life limiting quality factors over a wide temperature range, to develop a dynamic shelf life prediction model that accommodates real world fluctuating temperature conditions measuring the initial product quality at the harvest, the distribution center and the store. And consequently enhance the fruit and vegetables supply chain by substituting the traditional First In First Out by the new First Expired First Out. 
Due to that participation, a scientific article in the international journal Philosophical Transactions of the Royal Society A-Mathematical Physical and Engineering Sciences was published

Nascimento Nunes, M. C., Nicometo, M., Emond, J. P., Badia-Melis, R., \& Uysal, I. (2014). Improvement in fresh fruit and vegetable logistics quality: Berry logistics field studies. Philosophical Transactions of the Royal Society A-Mathematical Physical and Engineering Sciences, 2014(372), 20140212.

The cited work addresses the convenience of using "first expiring first out" logistics over traditional methods, since it is known that shelf life of fresh fruits and vegetables is greatly influenced by environmental conditions. Increasing temperature usually results in accelerated loss of quality and shelflife reduction, which is not physically visible until too late in the supply chain to adjust logistics to match shelf life. Some food pallets would be sent on longer supply routes than necessary, creating avoidable waste. In this document it is shown that using simple temperature measurements much waste can be avoided using 'first expiring first out'. Results from the studies presented in the article, showed that shelf-life prediction should not be based on a single quality factor as, depending on the temperature history, the quality attribute that limits shelf life may vary. Various methods were developed to use air temperature to predict product temperature for highest shelf-life prediction accuracy in the absence of individual sensors for each monitored product.

From 2013 until 2017, the tutor of the present PhD thesis, Prof. Luis RuizGarcia is the coordinator for UPM of a Marie Skłodowska-Curie IRSES (International Research Staff Exchange Scheme) action. These actions, named after the double Nobel Prize winning Polish-French scientist famed for her work on radioactivity, support researchers at all stages of their careers, irrespective of nationality. Researchers working across all disciplines, from life-saving healthcare to 'blue-sky' science, are eligible for funding. Now IRSES actions are named RISE (Research and Innovation Staff Exchange), and it funds short-term exchanges for staff to develop careers combining scientific excellence with exposure to other countries and sectors. RISE 
actions enable more interaction between academia and non-academic organizations within Europe and worldwide.

The name of the IRSES action is: "A Traceability and Early warning system for supply chain of Agricultural Product: complementarities between EU and China (TEAP)" (01/11/2013 - 31/10/2017).

It is being performed between Europe and China .Founded by FP7-PEOPLE2013-IRSES with the reference code PIRSES-GA-2013-612659 .Total funding amount is $546.000 €$. 
The participants are as follows:

\begin{tabular}{|c|c|c|c|}
\hline $\begin{array}{l}\text { Participant } \\
\text { Number }\end{array}$ & Participant name & Acronym & Country \\
\hline $\begin{array}{l}1 \text { Beneficiary } 1 \\
\text { (coordinator) }\end{array}$ & $\begin{array}{l}\text { Universidad de Almeria } \\
\text { (University of Almeria) (Co- } \\
\text { leader) }\end{array}$ & UAL & Spain \\
\hline 2 Beneficiary 2 & Agricultural University of Athens & AUA & Greece \\
\hline 3 Beneficiary 3 & $\begin{array}{l}\text { Rheinische Friedrich-Wilhelms- } \\
\text { Universitaet Bonn (University of } \\
\text { Bonn) }\end{array}$ & UB & Germany \\
\hline 4 Beneficiary 4 & $\begin{array}{l}\text { Universitá di Pisa } \\
\text { (University of Pisa) }\end{array}$ & UNIPI & Italy \\
\hline 5 Beneficiary 5 & $\begin{array}{l}\text { Universidad Politécnica de Madrid } \\
\text { (Polytechnic University of Madrid) }\end{array}$ & UPM & Spain \\
\hline 6 Partner 6 & $\begin{array}{l}\text { Beijing Research Center for } \\
\text { Information Technology In } \\
\text { Agriculture } \\
\text { (Co-leader) }\end{array}$ & NERCITA & China \\
\hline 7 Partner 7 & Shandong Agricultural University & SDAU & China \\
\hline 8 Partner 8 & $\begin{array}{l}\text { Tianjin Climate Center (Tianjin } \\
\text { Ecological \& Agricultural } \\
\text { Meteorology Center, Tianjin } \\
\text { Meteorological Satellite Remote } \\
\text { Sensing Center) }\end{array}$ & TJCC & China \\
\hline 9 Partner 9 & $\begin{array}{l}\text { Tianjin Pollution-Free Agri- } \\
\text { Products (Crop Planting) } \\
\text { Management Center }\end{array}$ & TMMCNAP & China \\
\hline 10 Partner 10 & $\begin{array}{l}\text { Guangzhou Agricultural Products } \\
\text { Quality and Safety Supervisory } \\
\text { Institute }\end{array}$ & GZNCP & China \\
\hline 11 Partner 11 & China Agricultural University & CAU & $\begin{array}{l}\text { China } \\
\text { (Beijing) }\end{array}$ \\
\hline
\end{tabular}

The main objective of the TEAP project is to obtain a better mutual understanding of the state and the possible roadways of agricultural product quality and safety in both the European Union and China, and deepen into the knowledge and the technologies that assure the following ultimate objectives.

The program focuses in four areas:

1. Good Agricultural Practices and Quality Standards in application.

2. Alert programs in the production and disease warning models.

3. Hazard Analysis Critical Control Points (HACCP) software in the logistics. 
4. Traceability systems for the supply chain of agricultural products "seed-toplate".

The objectives will be achieved via staff exchange between the different partners and thematic workshops (linked with the four working areas), distributed equally between the EU and China. Finally, the project members wish to improve the actual relations between the partners of both sides, fixing areas for long time collaboration.

The tutor, Prof. Luis Ruiz-Garcia has researched and published about the techniques and methods applied in the Cold Chain in the recent years, he also has participated in international projects. Some of his most representative articles are exposed as follows.

Related to the role of the RFID in agriculture as a key technology for food monitoring, prof. Ruiz-Garcia has published the following article:

Ruiz-Garcia, L., \& Lunadei, L. (2011). The role of RFID in agriculture: Applications, limitations and challenges. Computers and Electronics in Agriculture, 79(1), 42-50.

It discusses the recent advances in RFID since it offers vast opportunities for research, development and innovation in agriculture. The aim of this paper is to give readers a comprehensive view of current applications and new possibilities, but also explaining the limitations and challenges of this technology.

RFID has been used for years in animal identification and tracking, being a common practice in many farms. Also it has been used in the food chain for traceability control. The implementation of sensors in tags, make possible to monitor the cold chain of perishable food products and the development of new applications in fields like environmental monitoring, irrigation, specialty crops and farm machinery.

However, it is not all advantages. There are also challenges and limitations that should be faced in the next years. The operation in harsh environments, 
with dirt, extreme temperatures; the huge volume of data that are difficult to manage; the need of longer reading ranges, due to the reduction of signal strength due to propagation in crop canopy; the behavior of the different frequencies, understanding what is the right one for each application; the diversity of the standards and the level of granularity are some of them.

Applied to the real time monitoring of fruit logistics, Prof. Ruiz-Garcia published the following article:

Ruiz-Garcia, L., Barreiro, P., Robla, J. I., \& Lunadei, L. (2010). Testing ZigBee motes for monitoring refrigerated vegetable transportation under real conditions. Sensors, 10(5), 4968-4982.

This work discusses the suitability of ZigBee protocol for monitoring refrigerated transportation. The main objective of the experiment was to test wireless sensor motes based in the ZigBee/IEEE 802.15.4 protocol during a real shipment. The experiment was conducted in a refrigerated truck traveling through two countries (Spain and France) which means a journey of 1,051 kilometers. The paper illustrates the great potential of this type of motes, providing information about several parameters such as temperature, relative humidity, door openings and truck stops. Psychrometric charts have also been developed for improving the knowledge about water loss and condensation on the product during shipments.

Related to the actual performance of wireless technologies utilized for perishable products, Prof. Ruiz-Garcia published the following paper:

Ruiz-Garcia, L., Barreiro, P., \& Robla, J. I. (2008). Performance of ZigBeebased wireless sensor nodes for real-time monitoring of fruit logistics. Journal of Food Engineering, 87(3), 405-415.

In the paper it is said that the progress in fruit logistics requires an increasing number of measurements to be performed in refrigerated chambers and during transport. Wireless sensor networks (WSN) are a promising solution in this field. The paper explores the potential of wireless sensor technology for monitoring fruit storage and transport conditions. It focuses in particular on 
ZigBee technology. The main contributions of the paper relate to the analysis of battery life under cooling conditions and the evaluation of the reliability of communications and measurements. Psychrometric equations were used for quick assessment of changes in the absolute water content of air, allowing estimation of future water loss, and detection of condensation on the product. 


\section{Chapter 6}

\section{Objectives}

The aim of this thesis is to apply and develop new techniques and methods for the improvement of monitoring and tracking the cold chain of perishable food products. With this purpose in mind, the research work was divided in 5 main objectives:

1. To analyze the performance of semi-passive RFID loggers and WSN motes, in order to enable an economical solution for the spatial profiling of refrigerated chambers, with a high number of loggers. The aim of this work is to demonstrate the compatibility and feedback in a combination of the RFID and WSN in order to improve the refrigerated storage of perishable food products. It is also intended to provide some recommendations to improve current wireless devices and some management protocols or rules for the usage of the cold storage rooms.

2. To demonstrate the possibility of achieving higher resolution monitoring by estimating temperatures in a refrigerated sea container by using a minimum number of sensors. The temperature estimation methods aim to estimate temperature curves closer to the real temperature of the product, than the 
source ambient sensor. The predicted data can be used for more accurate shelf life calculations and enhancing the logistical operations of all stakeholders of the largest industrial sector in the world.

3. To demonstrate the possibility of temperature estimation in a pallet using the temperature registered with the thermal camera. This temperature estimation consists on the usage of ANN, previously proved accurate enough for the temperature estimation task. Also, to evaluate the performance between different packaging, such as cardboard and plastic boxes, by applying the estimation parameters obtained in the first part of the experiment.

4. To evaluate the possibility of using surface temperature of a pallet of fresh produce measured by an infrared thermal camera as a valid method to assess temperature distribution. One of the sub-objective is to compare different types of materials for pallet covers as well as different products in different temperature scenarios

5. To determine the suitability, and compare the performance of the covers in real critical situations, such as could be exposure to temperatures out of range. It is expected to find empirical data that demonstrate lower temperature loss compared with no coverage. 


\section{Chapter 7}

\section{Experimental works and studies}

In this section are presented the research works and studies following a logical evolution carried out by the PhD candidate in the field of improving the cold chain. It have been revised the considered key technologies for improving the cold chain, it have been implemented new techniques to save time and costs in cold chain and also it have been investigated the usefulness of certain new technologies; all of it focused on waste reduction towards a more efficient cold supply chain.

\subsection{Refrigerated Fruit Storage Monitoring Combining Two Different Wireless Sensing Technologies: RFID and WSN}

This section was published in the journal of Sensors. Badia-Melis, R., RuizGarcia, L., Garcia-Hierro, J., \& Villalba, J. I. R. (2015). Refrigerated fruit storage monitoring combining two different wireless sensing technologies: RFID and WSN. Sensors, 15(3), 4781-4795. 


\subsubsection{Introduction}

The properties of perishable items, like fruit, vegetables, flowers, fish, meat and dairy products or medical products like drugs, blood, vaccines, organs, plasma and tissues, are affected by temperature changes. In case of deviations from the optimal cold chain conditions, the shelf life of the sensitive products will be reduced, yet the consequences of this shelf life drop are only physically visible in the advanced stages of the supply chain in many occasions. To understand this variation is possible by a remote monitoring (Jedermann et al., 2015).

Wireless technologies represent an important advance, independent nodes communicating forming networks; they collect data and transmit sensor information such as temperature, motion, humidity or position. (Zou et al., 2014).

Some studies have demonstrated that a proper control over the cold chain using RFID loggers can lead to reduced waste of products by using the "First Expiring First Out", rather than the classical "First In First Out" paradigm, and also have implemented prediction temperature methods in order to improve the estimation of shelf life (do Nascimento Nunes et al., 2014). RFID tags are not limited to identification or temperature and $\mathrm{RH}$ reading tasks, and recent advancements have produced RFID units able to identify volatile chemicals such as ethylene or ammonia (Fiddes \& Yan, 2013).

Specialized Wireless Sensor Network (WSN) monitoring devices can revolutionize the shipping and handling of a wide range of perishable products by providing suppliers and distributors with continuous and accurate readings throughout the distribution process. In this framework, WSN was developed as a very promising technology due to its low energy consumption and advanced networking capabilities. The potential for monitoring with both technologies, WSN and RFID, has been suggested by several studies; however there is still a lack of implementation and experimentation in real environments, and no study combines the advantages of using both at the 
same time (Badia-Melis et al., 2014; Hendrik Haan et al., 2013; Jedermann et al., 2014b; L. Qi et al., 2014; Ruiz-Garcia et al., 2010b).

The present section is focused on the analyses of the performance of semipassive RFID loggers and WSN motes, in order to enable an economical solution for the spatial profiling of refrigerated chambers, with a high number of loggers. The aim of this work is to demonstrate the compatibility and feedback in a combination of the RFID and WSN in order to improve the refrigerated storage of perishable food products. The authors also want to provide some recommendations to improve current wireless devices and some management protocols or rules for the usage of the cold storage rooms.

\subsubsection{Materials and Methods}

\section{Refrigerated Chamber}

Experiments were performed in three commercial wholesale refrigerated stores, numbered 11, 29 and 40 and each of which has a volume at of $26 * 6 * 12=1848 \mathrm{~m}^{3}$, with an on/off glycol cooling system and insulated walls built of foam sandwiched between two layers of corrugated plate (total wall thickness is $0.16 \mathrm{~m}$ ). The set point experimentation times were different in each one (see Table 7.1). Each chamber has a common pre-chamber space where a devoted sensor is placed. Therefore, two different ambient conditions occur: pre-chamber (right outside the chamber) and the inside chamber with a well-known set point (see Table 7.1).

Table 7.1. Experimental conditions

\begin{tabular}{cccc}
\hline $\begin{array}{c}\text { Cold Store } \\
\text { Number }\end{array}$ & Set Point $\left({ }^{\circ} \mathbf{C}\right)$ & $\begin{array}{c}\text { Experimentation } \\
\text { Time (days) }\end{array}$ & Dates \\
\hline 11 & 8 & 13 & $7-19$ July \\
29 & 7 & 8 & $20-27$ July \\
40 & 14 & 4 & $28-31$ July \\
\hline
\end{tabular}


Chamber number 11 was divided into two equal size sections by a central wall with a door that remained open all the time. The dimensions of the door were the same as the main door to the exterior of the whole room, i.e., it was big enough to allow a forklift with a big pallet to pass. The room was provided with two cooling systems, one per each section of the chamber. Inside were two shelves on either side of the room with three heights, where the products were stored. When the temperature of the room reached $8{ }^{\circ} \mathrm{C}$ the refrigerator was triggered to cool down to $6.5{ }^{\circ} \mathrm{C}$. A scheme of the chambers can be seen in Figure 7.1.
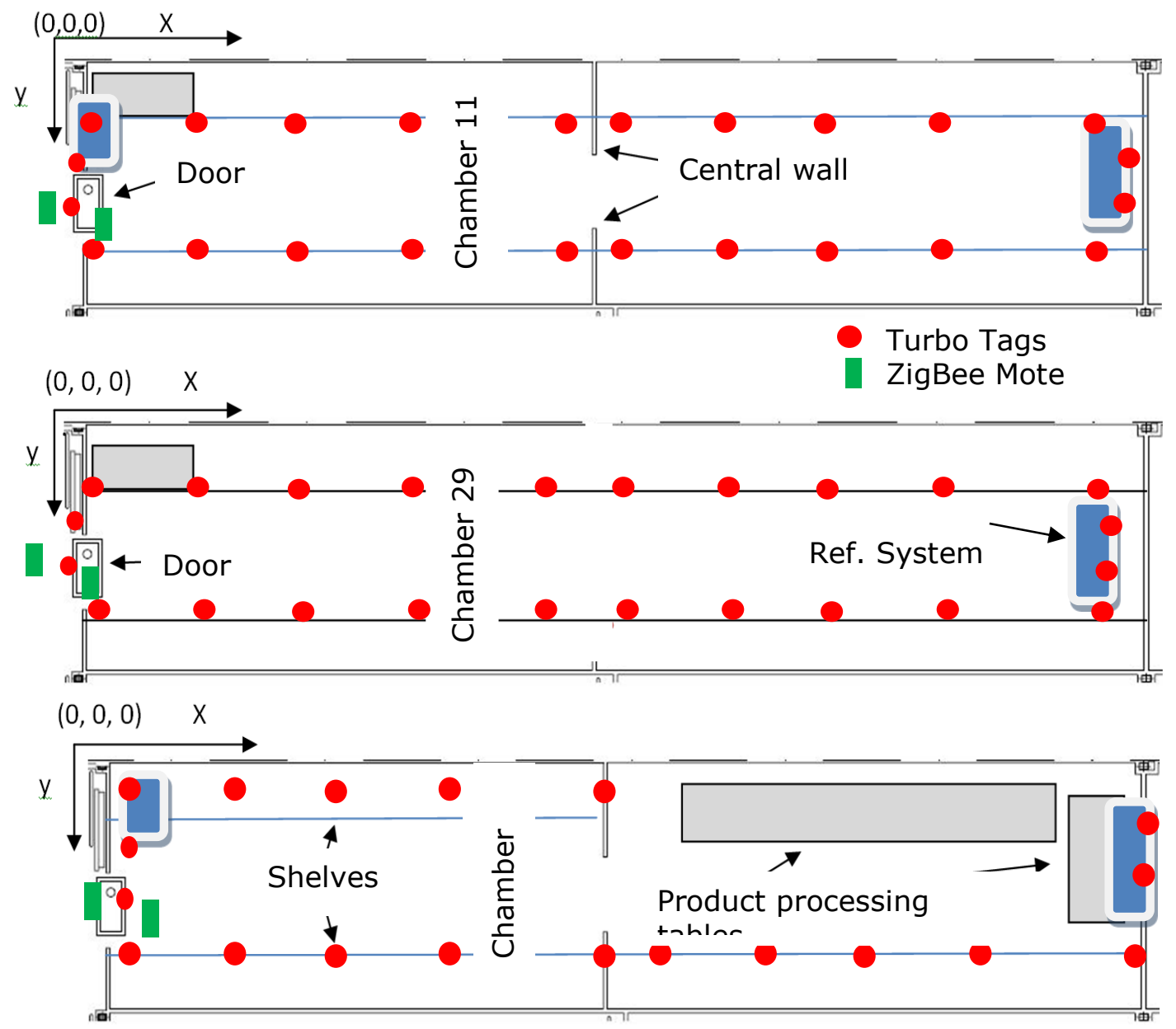

Figure 7.1. Scheme of the cold rooms and sensor distribution

Chamber number 29 had identical dimensions but with no separating central wall in the middle, and the temperature was set at $7{ }^{\circ} \mathrm{C}$ and dropped to 5.5 
${ }^{\circ} \mathrm{C}$. Both these rooms were designated to store mostly citric fruits and different varieties of nuts.

The last chamber (number 40) was divided into two sections separated by a central wall with a semiautomatic blind door; the first section was designated for the storage of vegetables and the other section was designated for fruit and vegetable packaging.

\section{WSN Motes}

Two ZigBee/IEEE 802.15.4 motes (transmitters) and one base station (receiver) were used. One mote was installed outside the chamber, close to the door and the other one inside, at the other side of the wall. Sampling rate was set to $180 \mathrm{~s}$.

These motes were manufactured by Crossbow $®$ (Milpitas, CA, USA ) and they have a microcontroller board (IRIS, Milpitas, CA, USA) together with an independent transducer board (MTS400, Andover, MA, USA) attached by means of a 52 pin connector. Its processor \& radio platform is a XM2110CA, based on the Atmel ATmega1281. The RF power was configured to $3 \mathrm{dBm}$ (60\% higher than previous MICA Motes). Power was supplied by two AA lithium batteries.

The MTS400 board hosts a variety of sensors: temperature and relative humidity (Sensirion SHT, Staefa, Switzerland), barometric pressure and temperature (Intersema MS5534B, Hampton, VA, USA), light intensity (TAOS TSL2550D, Plano, TX, USA) and a two-axis accelerometer (ADXL202JE, Norwood, MA, USA). A laptop computer is used as the receiver, and it communicates with the nodes through a Micaz mounted on the MIB520 ZigBee/USB gateway board; this device also provides a USB programming interface. In this study only the data from the Sensirion and Intersema units was used.

The Sensirion SHT is a single-chip relative humidity and temperature multisensor module that delivers a calibrated digital output. Each SHT is individually calibrated in a precision humidity chamber. The calibration 
coefficients are programmed into the One Time Programmable (OTP) memory. These coefficients are used internally during measurements to calibrate the signals from the sensors.

For temperatures significantly different from $25{ }^{\circ} \mathrm{C}$, and according to the manufacturer recommends performing humidity and temperature compensation, using Equations (1) and (2):

$$
R H_{\text {linear }}=(-4)+0.0405 * S O_{R H}+\left(-2.8 * 10^{-6}\right) * S O_{R H}^{2}
$$

where $S O_{R H}=$ Sensor Output Relative Humidity.

$$
R H_{\text {true }}=\left(T^{\circ} \mathrm{C}-25\right) *\left(0.01+0.00008 * S O_{R H}\right)+R H_{\text {linear }}
$$

The MS5534B is a SMD-hybrid device including a piezoresistive pressure sensor and an ADC-Interface IC. It provides a 16 bit data word from a pressure and temperature $\left(-40\right.$ to $\left.+125{ }^{\circ} \mathrm{C}\right)$ dependent voltage. Additionally the module contains six readable coefficients for a highly accurate software calibration of the sensor. MS5534B is a low power, low voltage device with automatic power down (ON/OFF) switching. A 3-wire interface is used for all communications with a microcontroller. Sensor packaging options are plastic or metal caps.

\section{Semi-Passive RFID Tags}

RFID tags can be active, passive, or semi-passive. Passive and semi-passive RFID send their data by reflection or modulation of the electromagnetic field that was emitted by the reader. The battery of semi-passive RFID is only used to power the sensor and recording logic (Ruiz-Garcia \& Lunadei, 2011). In this study we used semi-passive tags.

Up to 90 RFID semi-passive loggers were installed in each chamber, the tags are distributed in four layers or heights; each layer is as shown in Figure 7.1. The tags were manufactured by Sealed Air (New York, NJ, USA), and two different types were used, a Turbo Tag T700 $\left(-30{ }^{\circ} \mathrm{C}\right.$ to $\left.+55^{\circ} \mathrm{C}\right)$ and the 
T702-B $\left(-70{ }^{\circ} \mathrm{C}\right.$ to $+80^{\circ} \mathrm{C}$ ). Each tag operates in the 13.56 (ISO $15693-3$ compliant) $\mathrm{MHz}$ band, has the size of a credit card, is accurate to within \pm 0.5 ${ }^{\circ} \mathrm{C}$, and both have KSW Microtec (Dresden, Germany) temperature sensors and can store up to 702 temperature measurements.

\section{Data Analysis}

In the particular case of the WSN system, since its task consists of sending data to a gateway in a continuous flow, a specialized Matlab program has been developed for assessing the percentage of lost packets (\%) in transmission, by means of computing the number of multiple sending failures for a given sample rate (SR). A multiple failure of " $\mathrm{m}$ " messages occurs whenever the elapsed time between two messages lies between $1.5^{*} \mathrm{~m} * \mathrm{SR}$ and $2.5 * \mathrm{~m} * \mathrm{SR}$. For example, with a sample rate of $11 \mathrm{~s}$, a single failure $(\mathrm{m}=$ 1) occurs whenever the time period between consecutives packets is longer than $16.5 \mathrm{~s}(1.5 * 1 * 11)$ and shorter than $27.5 \mathrm{~s}(2.5 * 1 * 11)$. The total number of lost packets is computed based on the frequency of each failure type. Accordingly, the total percentage of lost packets is calculated as the ratio between the total number of lost packets and the number of sent packets.

The standard error (SE) associated to the ratio of lost packets is computed based on a binomial distribution as expressed in Equation (3), where $\mathrm{n}$ is the total number of packets sent, and $p$ is the ratio of lost packets in the experiment:

$$
S E=\sqrt{\frac{p(1-p)}{n}}
$$

A second dedicated Matlab code was used for plotting 3D temperature gradients. This program makes use of linear spatial interpolation in order to obtain 3D representations of normalized temperatures and variances inside the chambers. Due to the significant variation of external conditions in the Spanish summer, temperature analysis make use of a normalized temperature difference $(\Delta T n)$, which is computed with respect to the set point and to the outside temperatures (see Equation (4)). This value gives a 
normalized measure with respect to the varying ambient conditions of the experiments:

$$
\Delta T_{n}=\sqrt{\frac{T_{m}-T_{s}}{T_{e}-T_{s}}}
$$

where $\Delta T_{\mathrm{n}}$ (dimensionless) stands for the normalized temperature difference, $T_{\mathrm{m}}$ is the average temperature value $\left({ }^{\circ} \mathrm{C}\right)$ of each RFID logger, $T_{\mathrm{s}}$ is the temperature set point value $\left({ }^{\circ} \mathrm{C}\right)$, and $T_{\mathrm{e}}$ refers to the average outside temperature $\left({ }^{\circ} \mathrm{C}\right)$.

Finally, a 3D plot of indoor temperature variance with regard to outdoor temperature variance is recorded in order to represent the indoor temperature variability corrected with regard to changes in ambient experimental conditions (see Equation (5)):

$$
V_{n}=\frac{V_{i}}{V_{e}}
$$

where $V_{\mathrm{n}}$ is the normalized indoor variance for experiment, $V_{\mathrm{i}}$ is the indoor temperature variance of each logger, and $V_{\mathrm{e}}$ is the outside variance. The indoor variability is expected to be lower than the pre-chamber variability, this value will give us an estimation of the differences in the temperatures in the two ambient; the closer to the unit the normalized indoor variance is, the closer the two variances are. This can provide an idea of the influence of the outdoor temperatures without taking into account the set point, therefore it is possible to evaluate the transit of the staff and the isolation of the cold room itself, while in the normalized temperature difference the cooling unit appears as a factor in the equation. The complete set of data is included for each experiment:

\section{Psychrometric Data}

The ASAE (American Society of Agricultural Engineers) D271.2 standard, defined in April 1979 and reviewed in 2006, is used for computing the psychrometric properties of air (ASABE, 2005). Equations (6)-(8) and Table 
7.2 enable the calculation of all psychrometric data of air whenever two independent psychrometric properties of an air-water vapor mixture are known in addition to the atmospheric pressure:

$$
P S=R * e^{\frac{A+B * T+C * T^{2}+D * T^{3}+E * T^{4}}{F * T-G * T^{2}}}
$$

273.16 K $\leq \mathrm{T} \leq 533.16 \mathrm{~K} . T=$ Temperature $(\mathrm{K}), P S=$ Saturation vapor pressure $(\mathrm{Pa})(\mathrm{ASABE}, 2005)$.

$$
P v=P s \frac{R H}{100}
$$

$P V=$ Vapor pressure $(\mathrm{Pa})(\mathrm{ASABE}, 2005)$

$$
H=\frac{0.6219 * P v}{P a t m-P v}
$$

$H=$ Absolute humidity $\left(\mathrm{g} / \mathrm{kg}\right.$ dry air), $P_{a t m}=$ Atmospheric pressure $(\mathrm{Pa})$ (ASABE, 2005).

Table 7.2. Coefficients used to compute the psychrometric data, according to Equation (7) (ASABE, 2005)

$$
\begin{array}{ll}
\hline R=22,105,649.25 & D=0.12558 \times 10^{-3} \\
A=-27,405.526 & E=-0.48502 \times 10^{-7} \\
B=97.5413 & F=4.34903 \\
C=-0.146244 & G=0.39381 \times 10^{-2} \\
\hline
\end{array}
$$




\subsubsection{Results and discussion}

The presentation of the results in this work is divided into three parts. The first is the percentage of lost packets in the WSN transmission, which is key knowledge since is telling how much information is lost in translation, and it is saying that probably there should be a better transmission, the reasons are either a reading range problem, volumes of data are too big or there is some physical limitation, e.g. a massive amount of loggers, as Ruiz-Garcia and Lunadei (2011) address in their article, there are certain challenges and limitations that hinder a perfect data flow. That is another reason why RFID shows good complementarity with WSN, and the data loss can be addressed with the RFID tags.

The second part is about the temperature distribution, and as it was only possible to carry out this measurement due to the high volume of data generated from the RFID tags; it allows creating a uniform mesh of temperature nodes with many data points which is necessary for the 3D representation, in this case this big volume was not a limitation, but when there is a good understanding of the environment, certain spots of the cold room can be monitored with temperature estimation methods and bypass the actual sensors, as was successfully shown by other authors (Badia-Melis et al., 2013; Jedermann \& Lang, 2009; Uysal et al., 2011).

The third part is the psychrometric representation, where both the humidity sensor like the temperature sensor (in the WSN nodes) are gathered in the Sensirion SHT unit. This graphics are meant to compare the air inside and outside the cold rooms close to the door.

\section{Percentage of Lost Packets}

The $3 \mathrm{dBm}$ of RF power used by the motes was enough to enable sending data outside the chamber. More than $98 \%$ of the packets sent were able to cross the walls (see Table 7.3 ). Only $1.25 \%$ of signals were lost in the worst case (Chamber 11). In previous experiments (Ruiz-García, 2008) under very similar conditions, the average of lost packages was $1.92 \% \pm 0.07 \%$, in that case the gateway was located in the same room as the mote and in our 
experiment one of the motes is across the isolating door of the room for better performance.

Table 7.3. Percentage of data lost packets and standard error during the experiments

\begin{tabular}{ccc}
\hline $\begin{array}{c}\text { Cold Store } \\
\text { Number }\end{array}$ & Mote Inside (Data) & Mote Outside (Data) \\
\hline 11 & $0.26 \pm 0.01(6117)$ & $1.25 \pm 0.01(6007)$ \\
29 & $0.24 \pm 0.02(3244)$ & $0.89 \pm 0.02(3223)$ \\
40 & $0.21 \pm 0.02(1846)$ & $0.70 \pm 0.02(1826)$ \\
\hline
\end{tabular}

\section{D Plots}

Before starting with the 3D views, it is important to take a look on the absolute temperatures, which will give the reader a better understanding of the following Figure 7.3 and Figure 7.4. Figure 7.2a shows the cooling cycles inside the cold room, recorded by the sensors in the WSN mote and the RFID tag located near the mote. Accordingly with the normalized temperature one can appreciate that the temperature from the Turbo tag rarely surpasses the set point, and that gives a negative normalized temperature. In Figure 7.2b the day and night cycles are shown and the differences between the maximum and minimum values are around $5{ }^{\circ} \mathrm{C}$ and are bigger than inside the room (around $3{ }^{\circ} \mathrm{C}$ ), which gives a normalized indoor variance between 0 and 1 . 


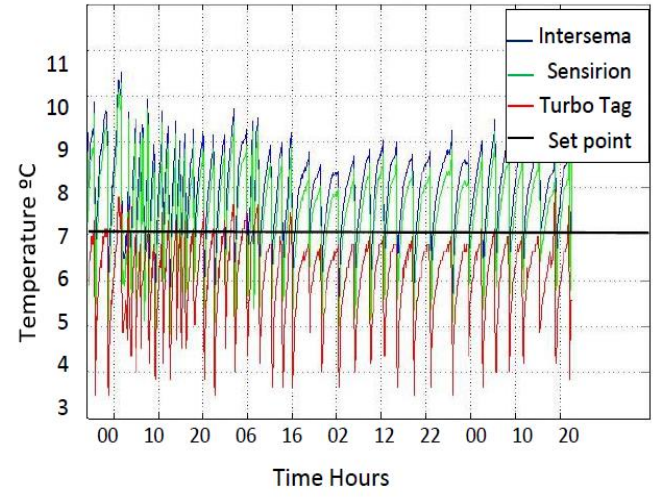

(a)

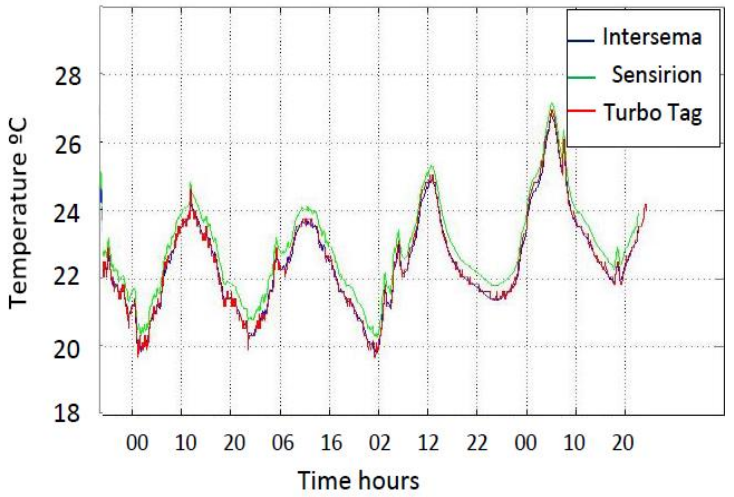

(b)

Figure 7.2. (a) Absolute temperature inside chamber 29; (b) Absolute temperature pre-chamber 29

Figure 7.3 and Figure 7.4 show a summary of the 3D views corresponding to temperature behavior for Chambers 11 and 29. Both the normalized indoor variance $\left(\Delta T_{n}\right)$ and normalized temperature variance are represented. In both cases mean temperatures were close to the set point, which means almost 0 normalized indoor variance $\left(\Delta T_{\mathrm{n}}=0\right)$. The highest differences in room 11 were registered by the sensors located in the ceiling, where in the back part of the room it can reach a normalized temperature difference (NTD) of 0.01 points and in a spot in the front part it goes to -0.05 points.

In Figure 7.3, in Chamber 11 one can appreciate how the temperatures are closer to the set point in the back part of the room with an average of -0.01 than in the front part with a lower average -0.03 , the front part presents the most different temperature from the set point despite the fact the two parts of the room each have a cooling system, so it would be justified by the influence of the transit of people going in and out of the room to cause the opening and closing of the door repeated times it makes the refrigeration system work harder and makes that the NTD goes below the set point, reaching at some points less that -0.05 units. The NTD corresponds with the normalized indoor variance (NIV) where one can appreciate as well the separation by the wall and how the variance values are higher where the door on the outside is located, with an average in NIV of 0.01 . 


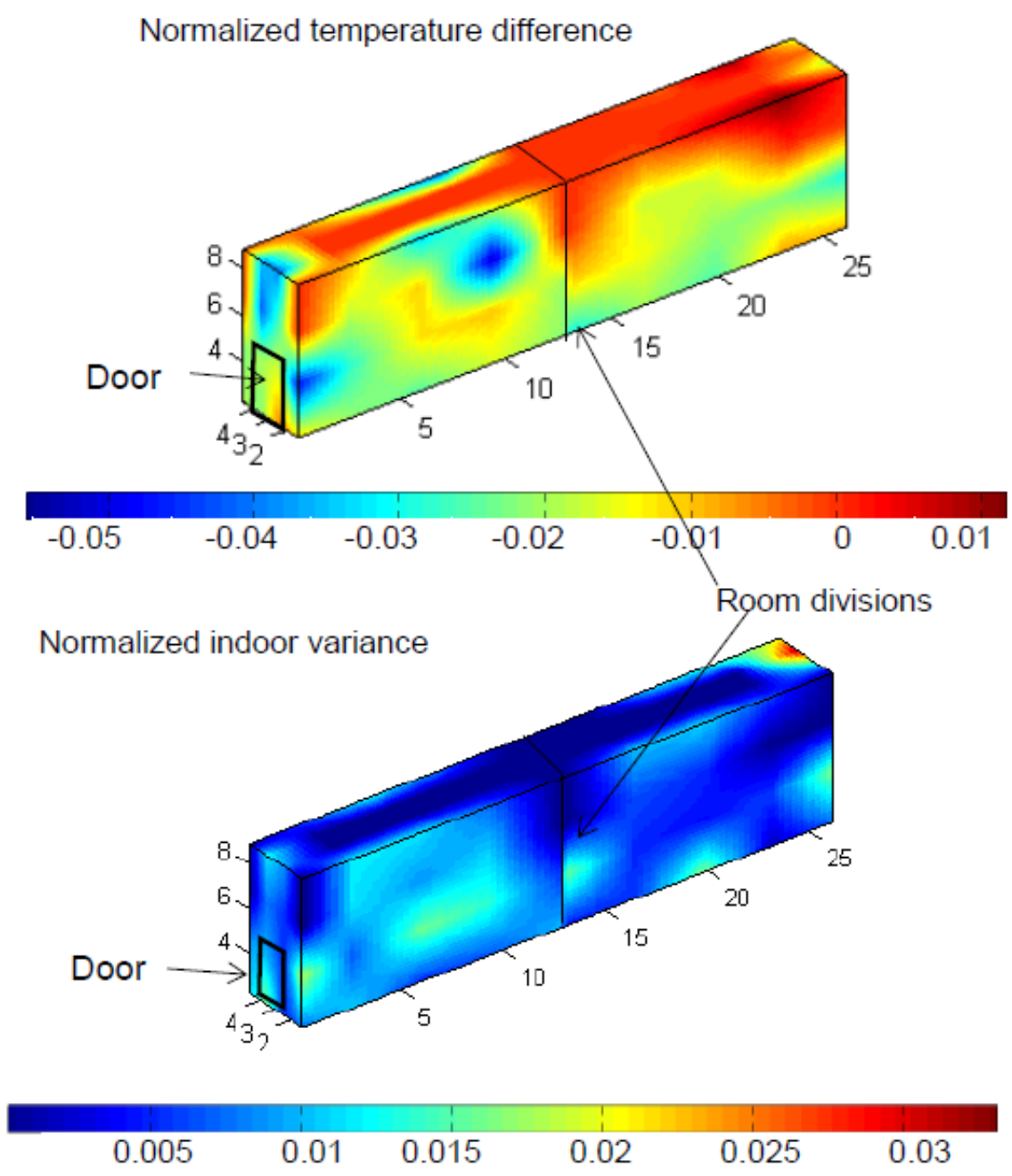

Figure 7.3. 3D plot of Normalized Temperature Difference and Indoor Variance in

Chamber 11

Room 11 shows a NIV always below the unit which means that the indoor variance is always lower than the outside one; this is justified by the big variability of temperatures during the Spanish summer, and the controlled temperature inside the cold rooms. The temperature in Chamber 11 was horizontally less homogeneous (having more or less an average NIV of around 0.01 in the entire room with no differentiated layers) than in Chamber 29, which has different NIV levels each with a homogeneous NIV such as 0.03 , 0.02 and 0.015 , which can be justified by the existence of an intermediate wall that divides the refrigerated chamber into two zones, while Chamber 29 is less homogeneous vertically having the perfectly differentiated layers 
mentioned above, which is justified because the Chamber 29 is only provided with one cooling unit for the same space than room 11 which is provided with two units, one per each part of the room.

Room 29 as is said (Figure 7.4), is not provided by a separation wall, which makes the air flow along the space without interruptions, but with the characteristic that it has to cool down a space double the size of Chamber 11. NTD gets closer to the set point value close to the ceiling of the room than in the rest of it, reaching in some spots almost 0 , but always below the set value, while in the rest of the room it has an average NTD of -0.13 .

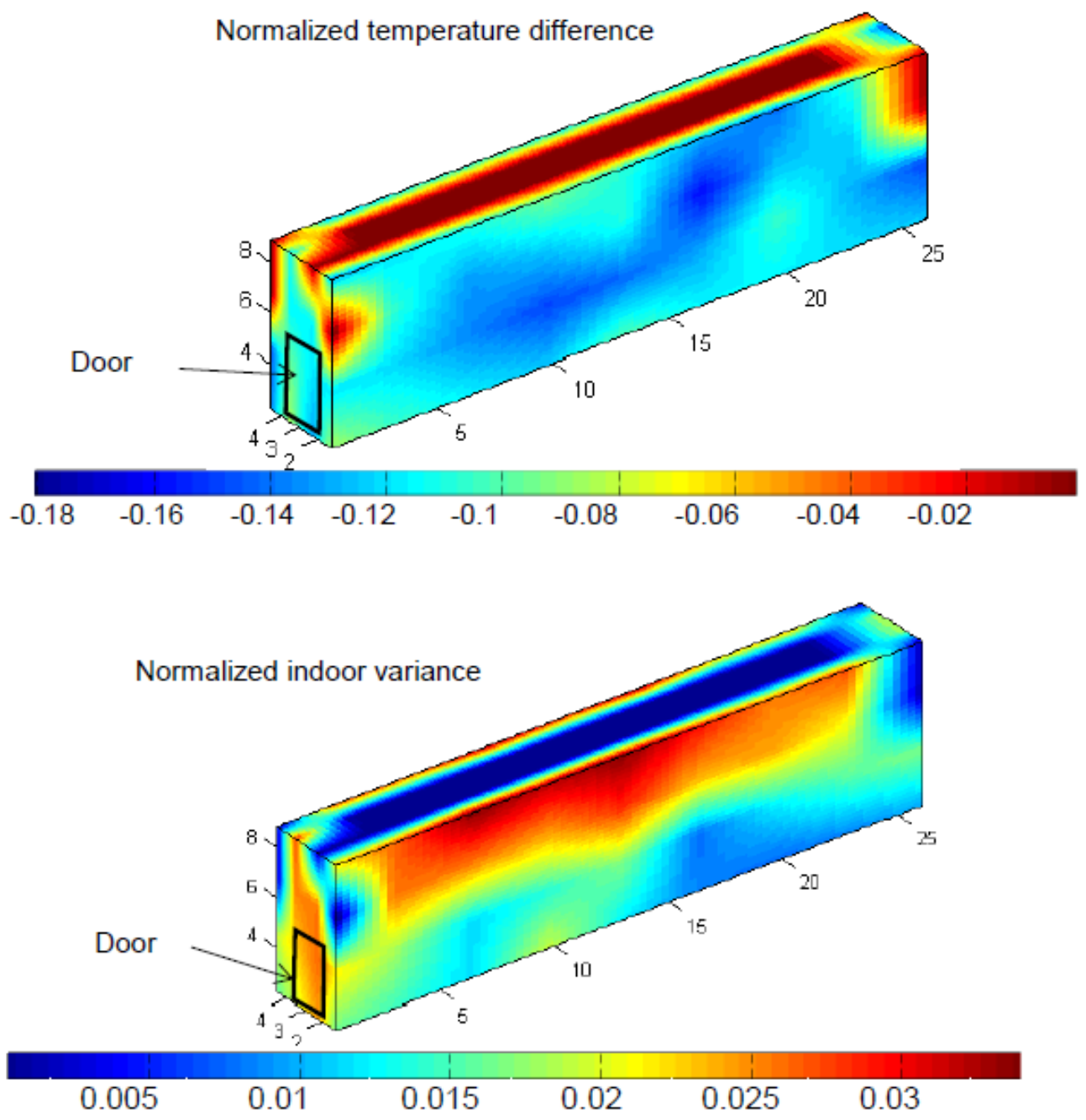

Figure 7.4. 3D plot of Normalized Temperature Difference and Indoor Variance in Chamber 29 
Chamber 40 does not have a 3D representation due to technical problems. It is necessary to deploy a homogeneous and dense mesh of RFID tags to represent the 3D plots and in the room 40 it was not possible since structure of the room itself did not allow such a deployment.

\section{Psychrometry}

The absolute humidity of the air inside the chambers was calculated, based on the ASAE standard D271.2 (1979) (ASABE, 2005), using the data recorded during experiments. Psychrometric charts for two chambers (numbers 29 and 40) are included in Figure 7.5 and Figure 7.6, which illustrate the evolution of air absolute humidity $\left(\mathrm{H}, \mathrm{kg}\right.$ of water $/ \mathrm{kg}$ of dry air) related to the $\mathrm{T}\left({ }^{\circ} \mathrm{C}\right)$. The blue cloud corresponds to the mote inside the chamber while the red one refers to the mote located outside (pre-chamber). Door openings created an increase in $\mathrm{T}\left({ }^{\circ} \mathrm{C}\right)$ and $\mathrm{H}$ ( $\mathrm{kg}$ of water $/ \mathrm{kg}$ of dry air), which then returns to normal again once the door is closed. During the rest of the time, it is also possible to detect the interaction between air properties and the product; with the cycles of cooling, variations in the absolute humidity can be estimated: condensation over the products (as loss of absolute humidity), or water evaporation (as an increase in absolute air humidity). The diagram corresponding to room 11 is similar to that of room 29 , which is why is not presented in this document.

In Figure 7.5, corresponding to Chamber 29, an important difference of temperatures between inside and outside the room is appreciated, as the blue cloud in many occasions reaches a $\mathrm{RH}$ of $100 \%$, water saturation in the air, and this cloud of dots is always higher in $\mathrm{RH}$ lines than the cloud corresponding to the outside. One can appreciate differentiated paths moving up and down the $\mathrm{RH}$ lines, corresponding to a vapor condensation and increase of the temperature due to the door opening, when the air with different enthalpies is mixing. Both the inside node and the outside node present very similar lower $\mathrm{H}$ (equal to $4 \mathrm{~kg}$ water $/ \mathrm{kg}$ dry air), while the upper $\mathrm{H}$ reaches more than $12 \mathrm{~kg}$ water/ $\mathrm{kg}$ dry air in the outside node, and inside does not go beyond $8 \mathrm{~kg}$ water $/ \mathrm{kg}$ dry air. There is no exchange of air flow at any moment; the air masses are clearly separated. The cloud is more compact in the interior of the room than in the exterior and it remains around 
5 to $10{ }^{\circ} \mathrm{C}$, while outside it has a wider temperature interval (from 20 to 30

${ }^{\circ} \mathrm{C}$ ) and with the same absolute humidity, it stays below in $\mathrm{RH}$.

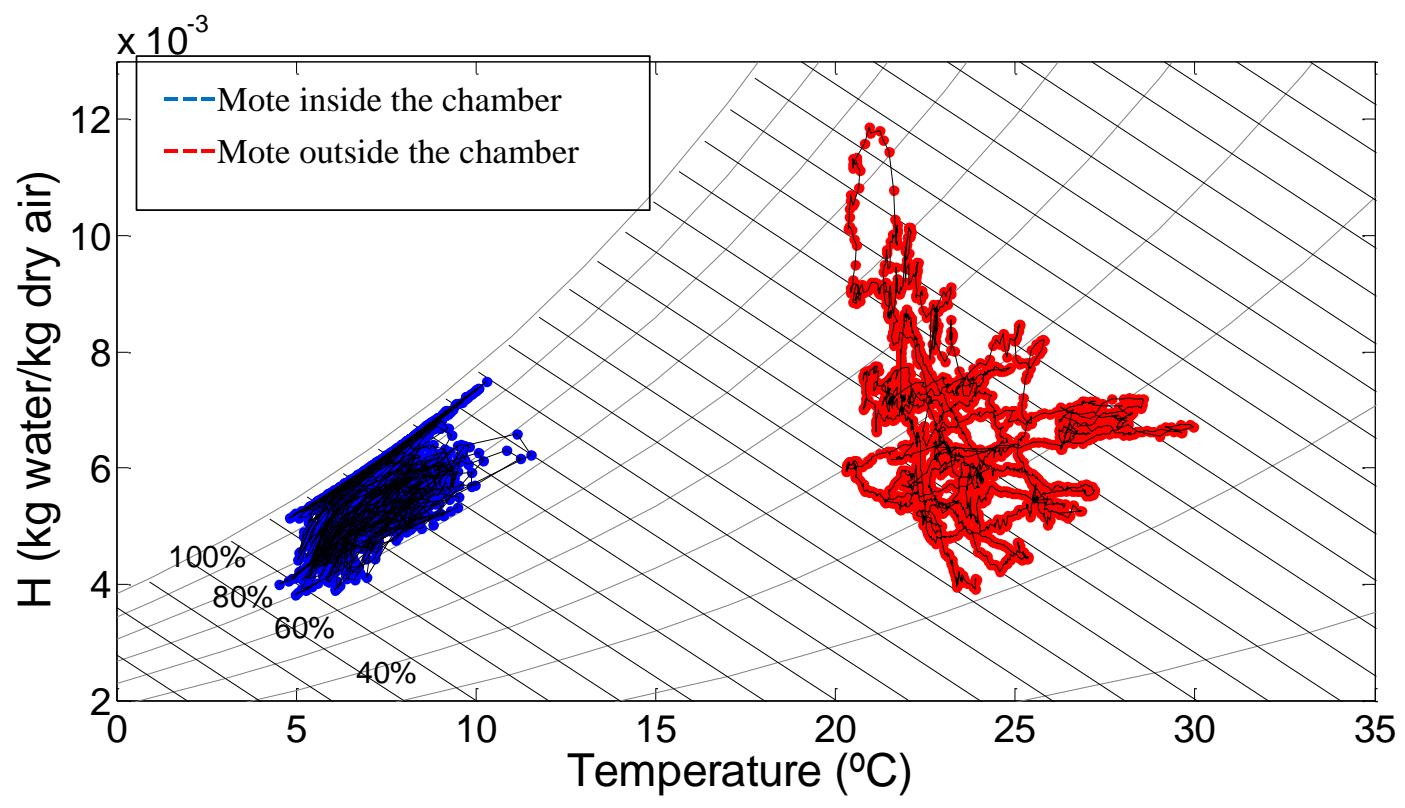

Figure 7.5. Psychrometric chart in Chamber 29

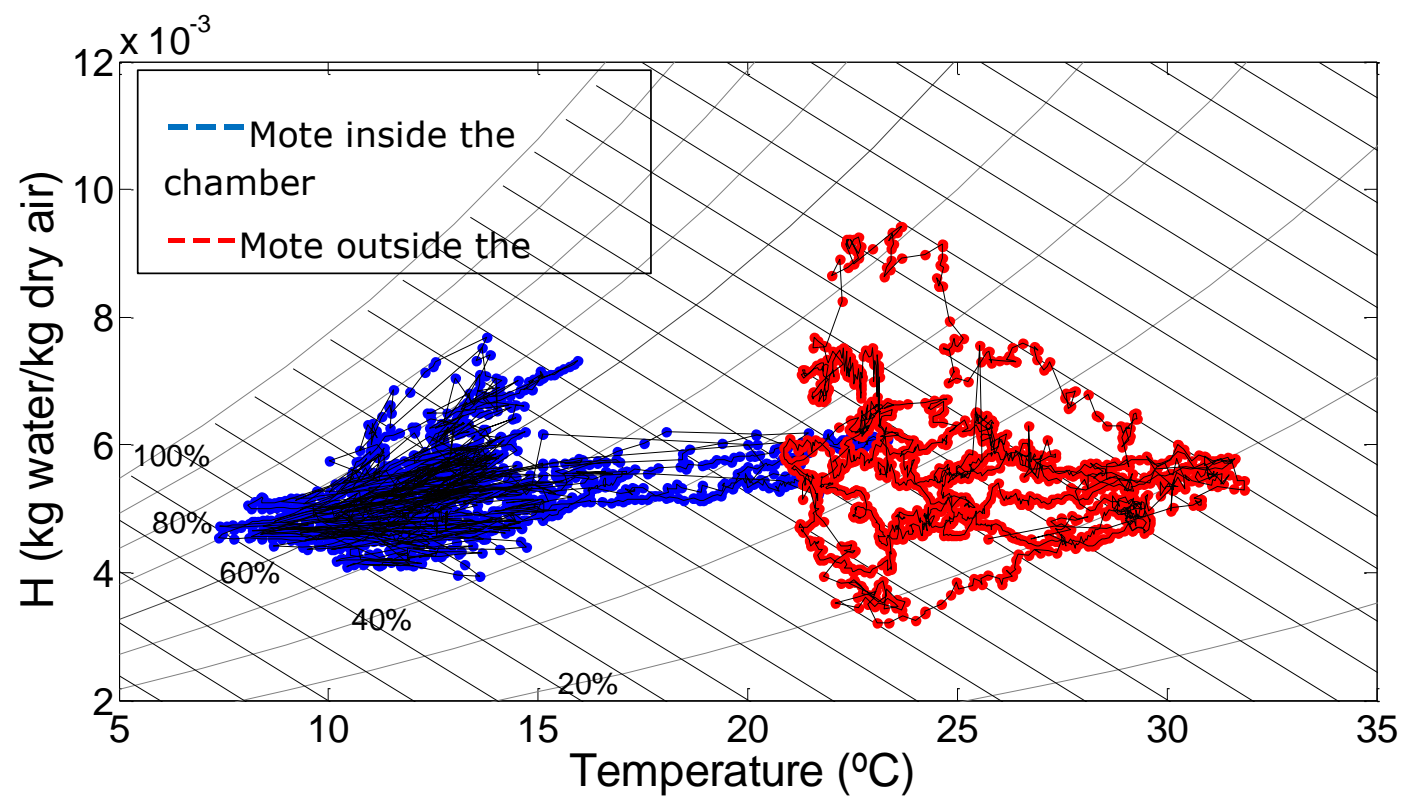

Figure 7.6. Psychrometric chart in Chamber 40 
In chamber 40 (Figure 7.6) the air inside has an $\mathrm{H}$ oscillating in a smaller range (between 4 and $8 \mathrm{~kg}$ water/ $\mathrm{kg}$ dry air) than in the outside (between 3 and $10 \mathrm{~kg}$ water $/ \mathrm{kg}$ dry air), and a much wider range of temperatures than the other two chambers (Figure 7.5) because the room was open during long periods of time; it even reaches $23{ }^{\circ} \mathrm{C}$, which is a regular temperature registered in the node outside. The blue cloud (inside) shows horizontal movements corresponding to an increase in temperature due to the door opening. The outside cloud contains wide cycles that correspond to an opening and closing of the door and/or changes between day and night, since the pre chamber area is directly influenced by the heat of the sun. In contrast to Chamber 29, it is appreciated how the temperatures are equalized in the middle of the image due to the fact the door stays open for a long time, which is causing the mixing of the air and heat exchange, and a temperature and humidity gradient is also appreciated inside the chamber, in some occasions the $\mathrm{RH}$ reaches $80 \%$ whereas outside it never goes above $55 \%$ despite the door usually being open.

The use of a psychrometric equation provides very valuable information regarding air fluxes and water transport phenomena from the product to the air. Using two sensors of just one single mote it is possible to obtain such information in real time, and one can conclude by observing Figure 7.4 and Figure 7.5, both from Chamber 29, that the data obtained are complementary, since it is not possible to deduce that there is no exchange of air flow at the door by observing Figure 7.4 alone. In addition, the temperature registered by the inside node near to the door is not representative of the entire room; therefore the RFID tags are completing the data pool for the subsequent analysis. The continuous data flow coming from the nodes can be accessed at any moment; the nodes are located in critical spots (like the doors). This information is an indicator of the surrounding area, which can be studied in detail thanks to the data obtained from the temperature tags.

\subsubsection{Conclusions}


In this present section a practical demonstration in a real scenario of the complementarity of RFID semi passive tags and the WSN is shown. The performance of the RFID tags and the WSN nodes was positive overall, the data losses was acceptable, small enough to allow one to analyze the parameters in order to create temperature distribution maps and psychrometric diagrams, but this set up is only possible in a testing phase. Since such a massive quantity of RFID tags is not possible in this scenario in the way those were positioned, it means an ad hoc version of this system should be developed for each case. The relative low cost of the RFID loggers allows dense implementations that provide accurate information about temperature gradients inside the chambers. The amount of data obtained from all the tags is manageable with a proper program such as devoted programs developed in Matlab. In the other hand extracting the data from a big number of these units in the cold rooms that are subject of study was a difficult task to accomplish, due to the location and the main limitations of these loggers which are their reading range and sensing capabilities.

Some of the loggers could be substituted by certain temperature estimation methods, but although these techniques are demonstrated to be reliable, other loggers located in critical spots should not be removed since there are changing conditions that cannot be predicted, such as the movement of the pallets inside the room.

Further experiments can provide a closer implementation of the two technologies, by developing a complex system comprising WSN nodes and RFID units. The benefits of this implementation are shown in this work, on the one hand WSN presents a long reading range thanks to the point to point (PtP) data transmission and a constant information flow, while in the other hand RFID lacks a PtP chain and also the tags used in the present experiments do not send information unless requested by the reader. The high price of the sensor nodes makes a dense node mesh difficult to afford, but this weakness could be resolved by using cheaper tags, and also the RFID tags are more manageable and robust due to their encapsulation.

After a detailed analysis of the data gathered in these experiments, and the experience achieved using the devices that are provided with the sensors 
used, the authors would like to recommend some improvements and changes to be made in the construction of the sensors. The reading range should be addressed; long range reading fixed readers or handhelds should be implemented and enhanced so communication of large amounts of data can be done with commercial RFID temperature tags. Also the range of sensing can be improved, some prototypes like the named in the introduction of this document could be turned in commercial units, as shown in this document, the use of pressure and humidity is a useful tool to see the air exchange in critical points such as the door of the cold room. As demonstrated in the experiment, WSN nodes can provide information that can be essential to detect breaks in the cold chain, nonetheless WSN nodes lack robustness, these devices are always weak and the electronics are very exposed to any possible damage, so manufacturers should work on motes able to support friction, impacts and adverse climatological conditions. Maybe some kind of hybrid unit creating a RFID sensor network, where the lightness, robustness and price from RFID is combined with the extended reading range PtP and diversity of sensors characteristic from the WSN units.

In the other hand, the authors want to provide some chamber design rules and management protocols that can save energy consumption costs in the cold room and help to extend the freshness of the cargo. As seen in the Chamber 11 the back part of it is closer to the set point than the front which is connected with the pre-chamber through a door, therefore, the most sensitive goods should be placed in the back part. In Chamber 40, a big waste of energy was noted because the outdoor and indoor air is being mixed constantly, hence the stored vegetables should be placed in the back part, and the processing tables moved to the front part. Finally an influencing factor that affects all the rooms is the opening and closing of the door, so a cooled pre-chamber should be studied; the actual pre-chamber is a corridor connected with the exterior with no isolation, and this has a certain negative effect on the temperatures when there is transit of the staff. 


\subsection{Temperature prediction and mapping for fruit transportation in refrigerated container}

This section includes the theory, materials, methods and results followed and attained during a study for Refrigerated container-wide temperature estimation and mapping for strawberries. Contents of this section have been submitted to the journal of Biosystems Engineering, and are currently under review.

\subsubsection{Introduction}

When considering "intelligent" systems as an end-to-end solution one has to ensure the correct technology is properly implemented. This is due to the fact that a number of available technologies are not able to capture temperature variations within the sea container that do not exceed five minutes in duration, due to the negative influence of the sensor housing which prevents the "real" temperature being recorded (Badia-Melis et al., 2014). This can significantly underestimate the product spoilage at all levels of the supply chain and at retail level may result in reductions of the shelf life or chilling injuries to the products (Likar \& Jevšnik, 2006; Montanari, 2008).

The influence of many factors would require a high number of sensors to detect the local variations throughout a single container, a practice that has proven cost prohibitive across the food industry, and thus creating a difficult jigsaw puzzle. If one could increase the monitoring capability and resolution inside a shipping container without necessarily using more sensor units, all stakeholders could benefit from it. There already is extensive research and published literature in this area in an attempt to address and overcome the issue such as Jedermann and Lang (2009); Jedermann et al. (2011b); Jedermann et al. (2009). The proposed methods in the literature try to estimate the temperature in a fixed number of key spots where it is not feasible to place a sensor. Such methods are typically built on inverse distance weighing like Kriging algorithm, but cannot detect local peaks (high variations) unless a high density of source sensors is used, which ultimately goes against the very idea to make the monitoring system economically 
feasible. Other proposals include grouping products with similar temperature characteristics to reduce the number of necessary sensors in an intelligent container (Jedermann et al., 2009) or placing sensors strategically between the transported goods instead of affixing them to the container (Lutjen et al., 2012). Badia-Melis et al. (2013) looked at estimating pallet product temperatures by measuring the ambient temperature surrounding the pallet, and then using a parametric exponential time-decay function, which models a capacitor/resistor system for a capacitive heat transfer approach (Badia-Melis et al., 2013).

The main objective of the present section is to determine the utility of three parameter estimation tools in a one-of-a-kind test environment, which emulates a real-life scenario where a refrigerated sea container loaded with multiple pallets undergoes a cooler failure. The three methods, which will be used for temperature estimation and mapping, are i) Kriging method, ii) a capacitive heat transfer model and finally iii) time-series prediction with artificial neural networks (ANN). Although more commonly used for classification purposes, ANNs can also be used for non-linear time series forecasting (M. Qi \& Zhang, 2008; G. Zhang \& Qi, 2005), Assuming the relationship between the product and the surrounding ambient temperatures is inherently non-linear, our hypothesis is that a properly trained ANN can model this relationship. Currently, there are no studies in the literature that the authors are aware of about temperature estimation and mapping for food under realistic transportation and storage scenarios, especially using the ANN non-linear time series framework.

For this study, mixed pallets of synthetic oranges and strawberries were used. Two distinct temperature scenarios were used: (1) a refrigeration failure after the product is stabilized at $2{ }^{\circ} \mathrm{C}$, and (2) long term temperature behavior during a regular day-profile at both pallet level and container level. The three different temperature estimation methods were trained and tested for each different scenario.

\subsubsection{Material and methods}


In this experiment two characteristically different profiles were used for predictive mapping of temperature, (1) refrigeration failure, and (2) day profile, with a full load 20-foot container with 8 pallets (based on the size of the refrigerated sea container).

The refrigeration failure (1) and the day temperature profiles (2) are representative of commonly occurring situations during transport and therefore serve as an efficient test method to obtain necessary data to analyze different predictive algorithms. The refrigeration failure in the form of a lack of power supply to the refrigerators or even an accidental unplug at the distribution center will produce a temperature excursion, resulting in a significant loss of product's remaining shelf life. Proper characterization of the temperature trend is essential because it determines the available reaction time to save the product or prolong its shelf life. The day profile on the other hand, provides temperature distribution throughout the container when the refrigeration system is disconnected or turned-off and there is no airflow in the container. This profile will be necessary to estimate the shelf life of the product for optimal decision-making across the supply chain

The hardware utilized in this study were (1) Intelleflex TMT- 8500 and (2) CAEN RFID A927Z tags and their respective readers.

Intelleflex TMT- 8500 RFID tag, from Intelleflex brand based in USA, with a temperature range from $-30{ }^{\circ} \mathrm{C}$ to $70{ }^{\circ} \mathrm{C}$, accuracy $\pm 0.5{ }^{\circ} \mathrm{C}$, temperature resolution of $\pm 0.1{ }^{\circ} \mathrm{C}$, supports EPCglobal C1G2 standards-based, ISO/IEC $18000-6 \mathrm{C}$ class 3 , and its reading range is up to 100 meters. Data was downloaded with the same brand reader HMR-9090 Handheld Reader, multiprotocol, ISO/IEC 18000-6:2010, EPCglobal C1G2.

Caen RFID A927Z tags are ruggedized, semi-passive UHF loggers which also operate from $-30^{\circ} \mathrm{C}$ to $+70^{\circ} \mathrm{C}$ with the same temperature resolution and accuracy. For this particular experiment the RFID reader needed to be in short range of the tag in order to download the data. 
A)

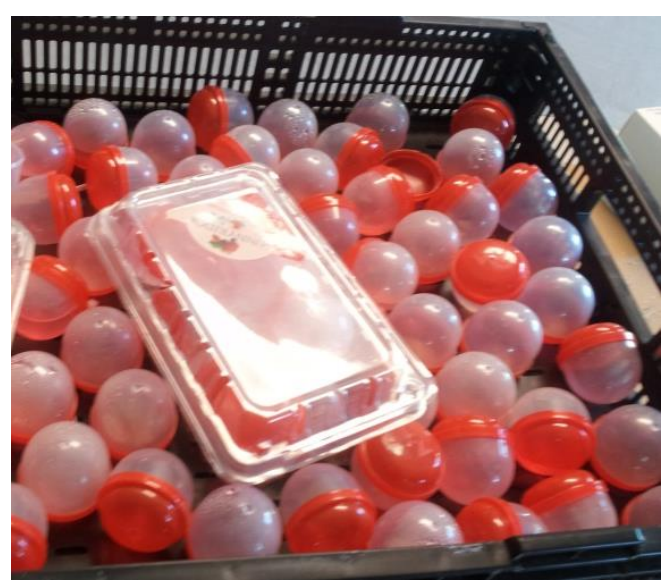

B)

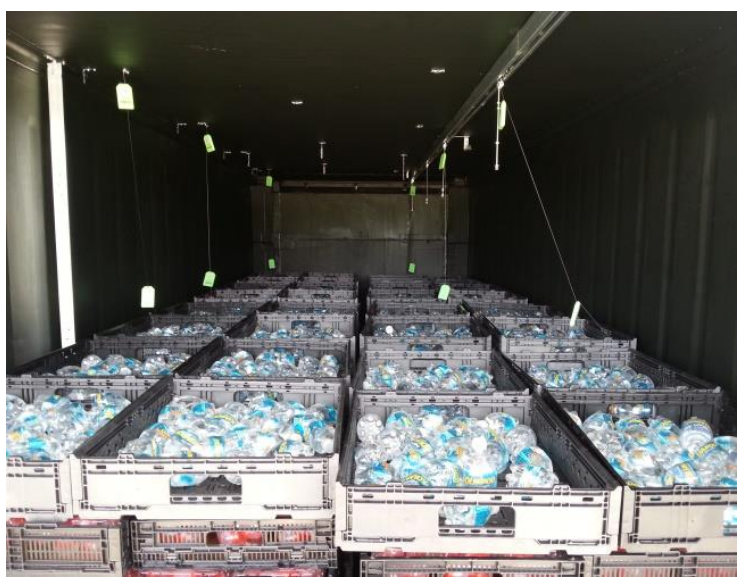

Figure 7.7. A) Plastic capsules simulating the strawberries. B) Top of the pallets inside the ref. container

A single sea container, 20-foot long (5.9 m length, $2.3 \mathrm{~m}$ width and $2.4 \mathrm{~m}$ high), was used throughout these trials, which included a fitted refrigeration system, and 8 pallets built with synthetic strawberries and oranges. The strawberries consist of a plastic capsule filled with water with similar shape and size of a strawberry, and the oranges are similarly round bottles of plastic filled with water. Figure 7.7 A) shows the simulated fruit, 500 grams of synthetic strawberries fill each clamshell and each box contains 8 clamshells, both clamshell and plastic foldable box are showed in Figure 7.7 A). Figure 7.7 B) shows the pallets inside the refrigerated container. Using synthetic produce helped us model real produce for heat-transfer purposes without perishing or changing characteristics mid-trial.

The synthetic strawberries were placed into commercial clamshells which weigh about 50 grams each and can hold approximately 10 units. Each clamshell contains $0.5 \mathrm{~kg}$ of produce, where eight clamshells were placed per box. Each layer in a pallet had five boxes with ten layers per pallet hence; it is approximately $200 \mathrm{~kg}$ of synthetic strawberries distributed in 50 boxes per load. Finally a layer of boxes filled with round water bottles (synthetic oranges) was added on top of the pallet with a total $220 \mathrm{~kg}$ per pallet. While building the pallets a total of 5 RFID tags were placed inside each pallet, two in the penultimate lower layer, in opposite corners, one in the exact mid-point 
of the pallet, and 2 in the penultimate layer of the top of the pallet in the same vertical orientation as the sensors in the lower layer as shown in Figure 7.8 .

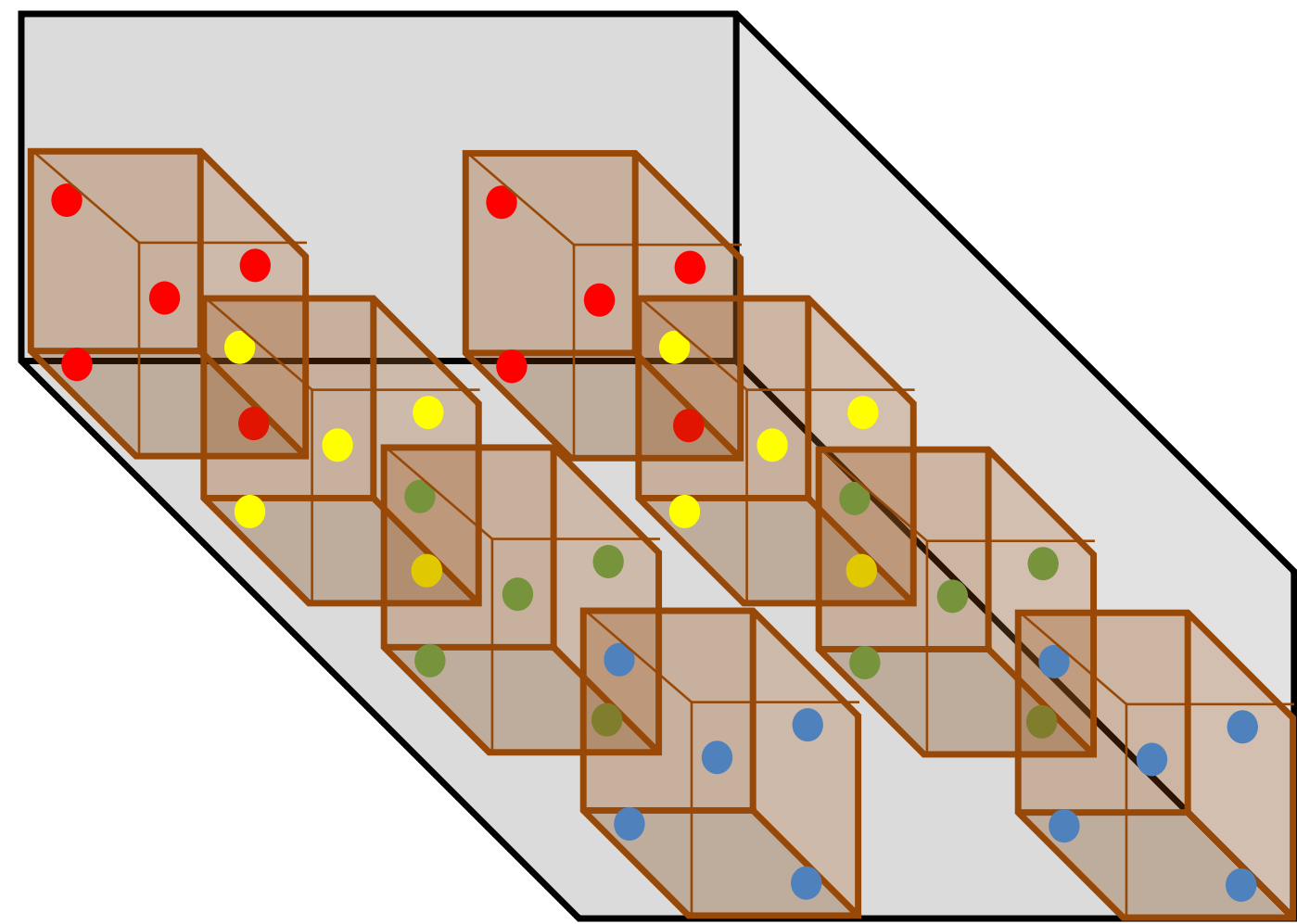

Figure 7.8. Sensors distribution on the pallets

Each sphere color of the Figure 7.8 represents the sensor distribution inside individual pallet, diagonally along the container.

In addition to these placements, 18 Intelleflex TMT- 8500 RFID tags were put in the container between the pallets (hanging from the ceiling mid-air), to record the air temperature in the container. This particular container also has a separate wired temperature sensor placed in an isolated panel inside the container to show the instantaneous temperature and set the target point. This sensor is located in the rear upper corner for which we put an additional wireless tag right next to it to use as a source sensor for some of the estimation methods to model container temperature with a single sensor.

Once the pallets are prepared within the container, and pallet and container are instrumented it is time to star performing the temperature profiles. The 
first profile was achieved by keeping the refrigeration system running until the entire container was stabilized at the desired temperature $\left(2^{\circ} \mathrm{C}\right)$, and then rising the temperature to $30{ }^{\circ} \mathrm{C}$ to obtain a steep rising curve. After reaching the constant high temperature it was turned down again until it arrived back at $2{ }^{\circ} \mathrm{C}$. This temperature profile was used specifically to estimate the time constant, T, for the capacitor method.

The second profile, similar to the first one, initially stabilized the temperature of the container at $2{ }^{\circ} \mathrm{C}$ and then disabled the refrigeration unit, resulting in a temperature rise that will simulate a more realistic transportation system failure.

The third and last profile included temperature changes over a period of 48 hours where the container was closed with no refrigeration at all, modeling just the daily temperature changes, similar to outside storage of containment units in a warehouse type setting.

After the different profiles were applied, the data was downloaded from the RFID tags and analyzed with ad hoc programs developed in Matlab software environment. The three estimating algorithms briefly discussed in the introduction section are described here in detail.

\section{Temperature estimation methods}

The main objective and measure of performance for all temperature estimation methods is to predict pallet temperatures closer to actual values than simply using only the ambient sensor as reference.

\section{1) Artificial Neural Network}

The main assumption in using artificial neural networks (ANN) to model any input-output dynamic is that the inherently non-linear relationship between the two, in this case the product temperature inside a pallet and the ambient temperature, can be learned by the ANN given enough training samples.

The structure of a feed-forward neural network, which consists of two hidden layers of neurons to model a 3-to-1 input-output relationship, is shown in 
Figure 7.9. In this study, the input to the network actually consists of timetemperature data provided by the sensor(s) placed outside the pallets measuring the ambient temperature, whereas the output is the timetemperature data around the actual products placed inside the pallets. Hidden layers consist of artificial neurons, which weigh and sum their inputs as they propagate their outputs to the next hidden layer. The ANN needs to be trained with part of the temperature data to "learn" how to estimate the non-linear relationship between its input and desired output.

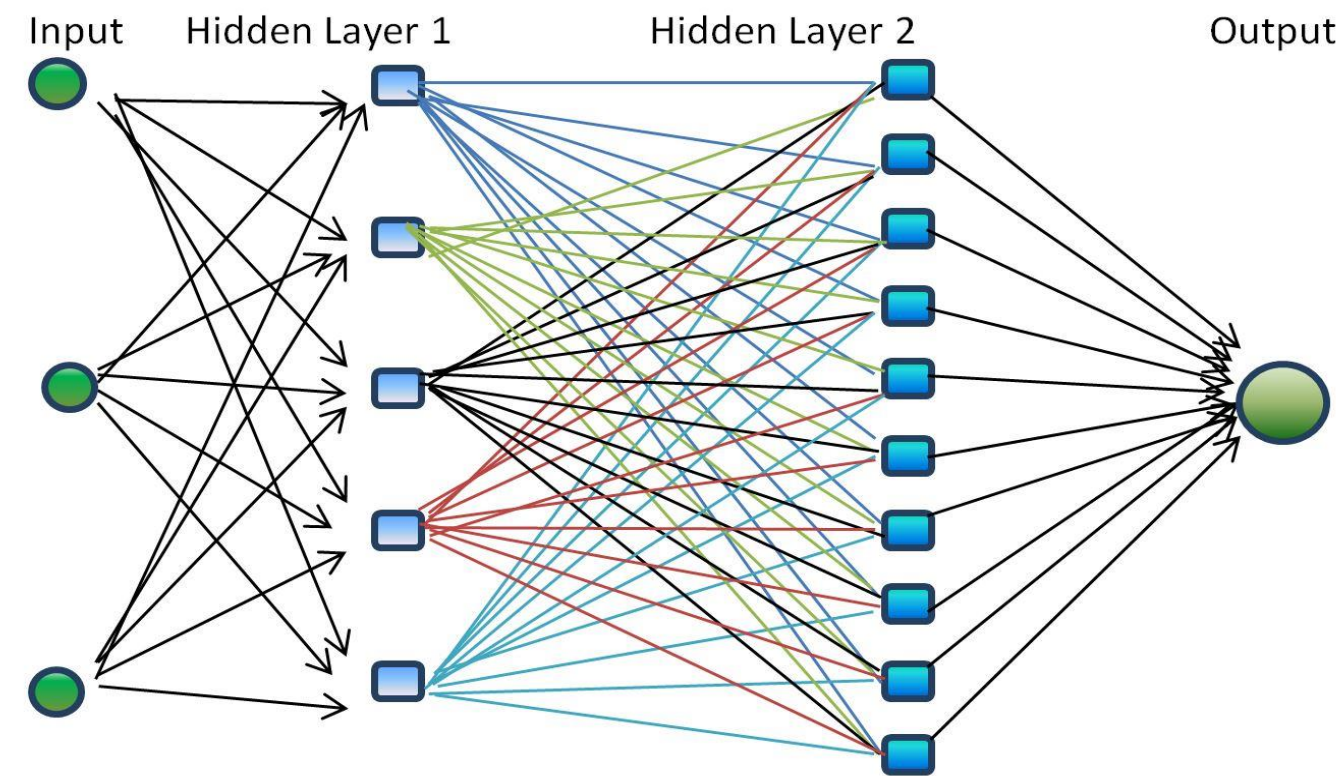

Figure 7.9. The structure of an artificial neural network to estimate temperature dynamics

ANNs are used for system classification and/or estimation purposes where the goal is to estimate a specific output value given a corresponding input value. For instance, in this case the input values are obtained as time-temperature recordings of the source sensors measuring ambient temperature and the destination sensors generate the desired output values. The main challenge in training a neural network is the fact that there are many parameters, which have a significant impact on estimation performance, such as the number of hidden layers, the number of neurons in each hidden layer and the learning constant for the gradient descent which is used in backpropagation learning of 
ANNs. Hence, one needs to sweep a reasonable amount of parametric combinations when using ANNs for proper estimation. Different combinations which were tested in this study are presented in detail in the results.

\section{2) Kriging}

The Kriging method has previously been used in environmental estimation problems specifically defined within a continuous feature space, such as temperature inside a homogenous container (Jedermann \& Lang, 2009).

Ultimately Kriging method is a form of interpolation, such as linear interpolation, which multiplies the measured input values at the source points with a set of weighing factors in order to estimate the desired output value at a destination point. The weighing factors can be set by a heuristic approach proportional to the inverse squared distance or by-statistically more solidKriging method. The Kriging method is based on the analysis of spatial correlation of the measurements. This method uses the technique called variogram, which calculates the expected difference of the physical quantity between two points as a function of their distance in space (Jedermann \& Lang, 2009).

The first step is to calculate the experimental variogram from the training data set and estimate the parameters of the theoretical model (in this case a Gaussian model) to approximate the underlying system function. Using this approximation one can calculate the weights of the destination points, and then estimate the temperature inside the pallet from the environmental temperature similar to ANN method.

In this study the Kriging method is applied via the Matlab script obtained from Mathworks website developed by Wolfgang Schwanghart (Schwanghart, 2010). This script along with the subscripts Variogram and Variogramfit calculates the estimated parameters of the modeling function. First the variances between source points at different distances are calculated using the previously mentioned subscript Variogram which employs the following statistical variance: 


$$
\operatorname{Var}(X)=\frac{1}{n} \sum_{i=1}^{n}\left(x_{i}-\mu\right)^{2}
$$

Then Variogramfit subscript uses the calculated variances at different points to fit a Gaussian model curve from which one can obtain the weight coefficients at any given distance.

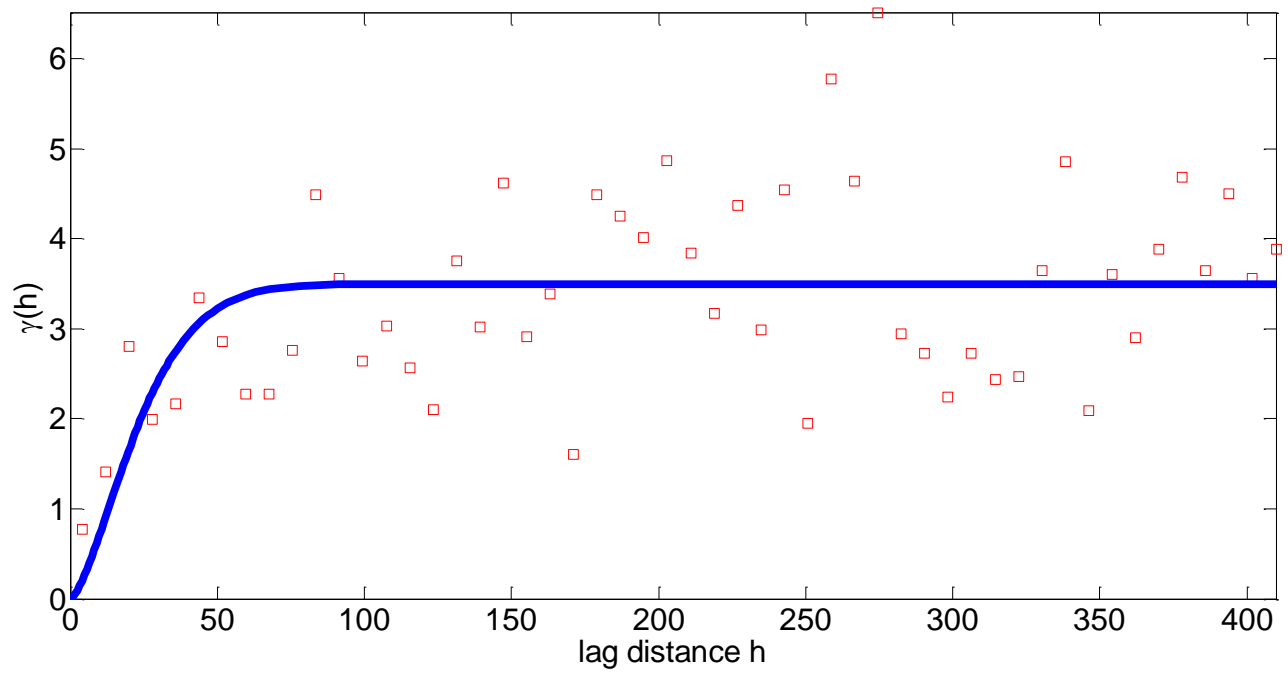

Figure 7.10. Semivariogram 12 source sensors Sea Container

Therefore, using Variogramfit, one can now obtain the weights for each source sensor relative to each destination sensor to create the matrix with Wij elements as its entries where $j$ is the source sensor and " $i$ " is the destination sensor. Using this matrix, calculating the estimated product temperature values is a linear operation as shown in equation (2) where $\mathrm{Zi}$ denotes the estimated temperature and $\mathrm{Sj}$ denotes the measured source temperatures:

$$
\mathrm{z}_{\mathrm{i}}(\mathrm{k})=\sum_{\mathrm{j}=1}^{\mathrm{N}_{\mathrm{s}}} \mathrm{s}_{\mathrm{j}}(\mathrm{k}) \cdot \mathrm{w}_{\mathrm{ij}}
$$

Figure 7.10 is a sample curve-fitted semivariogram which shows the distribution of temperature variances as a function of the distance between two sensors. As can be observed from the figure, the variance between two sensors become less as the distance between two increases such that at distances larger than $100 \mathrm{~cm}$ there remains almost no statistical correlation between the recordings as the fitted curve saturates. This observation implies that the source sensors at distances greater than $100 \mathrm{~cm}$ relative to a 
destination sensor will have little impact on estimation and instead have a common, smaller weight, which will be multiplied with their recordings before being summed up to yield the final temperature estimation.

Kriging method requires use of more than one source sensor to create an informative semivariogram and obtain good performance. Furthermore, the source sensors should be strategically located to surround destination points such that the Kriging function can properly evaluate the influence (or weights) of the source points as a function of distance to the destination points

\section{3) Capacitive heat-transfer method (Capacitor method)}

The relationship between ambient and pallet temperatures and rise-fall rates closely model an exponential fit between the input-output variables, which rise/fall time constants in a typical resistor-capacitor (RC) electrical circuit (Uysal et al., 2011). Hence, the estimation method to fit the parameters of this exponential system is called the capacitive heat-transfer method.

This is based on the idea of calculating the $\mathrm{T}$ constant for both rising and falling sections of ambient temperature vs. pallet temperature. Using Matlab, the authors have developed a script to first calculate an approximate $T$ and then sweep this parameter around this value to find the optimal $\mathrm{T}$ which gives the least square error. The mathematical relationship between ambient and pallet temperatures has a close analogy with that of the potential differences between the terminals of a voltage source, and a capacitor. For example, in equation (3) which calculates the capacitor voltage based on its initial value and the time constant of the circuit, $\vee$ represents the environmental temperature, $V_{c}$ represents the container temperature

$$
V c=V c^{\text {initial }}+\left(V-V c^{\text {initial }}\right) \cdot\left(1-e^{-t / R C}\right)
$$

The container temperature, according to this model, will have an upward trajectory or a downward trajectory with a speed determined by the time constant RC, or $\mathrm{T}$, and the differential between the ambient and pallet temperatures. 
The following equations can then be derived from the previous; taking into account that there are two different systems to model rising (4) and falling (5) as shown below:

$$
\begin{gathered}
\text { If } T_{e n v}>(T-1)_{p a l} \text { then, } \\
T_{p a l}=(T-1)_{p a l}+\left(T_{e n v}-(T-1)_{p a l}\right) \cdot\left(1-e^{-t / \tau \text { rising }}\right) \\
\text { If } T_{e n v}<(T-1)_{p a l} \text { then, } \\
T_{p a l}=(T-1)_{p a l}+\left(T_{e n v}-(T-1)_{p a l}\right) \cdot\left(1-e^{-t / \tau \text { falling }}\right)
\end{gathered}
$$

\section{B. Temperature profiles used for testing}

In order to compare different estimation algorithms, we looked at the least square error in the form of average Root-Mean-Squared-Error (RMSE) between actual and estimated temperatures for each sensor inside the pallets and the air temperature for a number of temperature profiles.

\subsubsection{Results}

For the first phase, it was used the first temperature profile to extract the necessary parameters to tune the estimation models such as the time constant $\mathrm{T}$ for the capacitive heat-transfer method, the weight vector for the Kriging method and the weight and bias matrix for the ANN. In this study, it will be presented the results for the refrigeration failure scenario, as it represents a greater challenge for the transportation industry.

\section{A. Training phase}

In this section, the same set of experimental data is used to both train and test individual estimation algorithms. Predictably, the estimators do quite well 
- however the actual measure of performance can only be obtained when they are tested with novel data as described later in section B of the results.

\section{1) Kriging}

To measure the performance of Kriging we used two different combinations for source sensors. First, we used the source sensors placed at the middle and bottom layers of the container for estimation. Second, we used only the source sensors placed at the bottom layer. The results are shown in Table 7.4 in terms of RMSE.

Table 7.4. RMSE for Kriging Method with different combinations

\begin{tabular}{lcccc}
\hline & \multicolumn{2}{c}{ Entire SeaCo RMSE } & \multicolumn{2}{c}{ Pallet by pallet RMSE } \\
\hline & $\begin{array}{c}\text { Est. } \\
\text { avg. }\end{array}$ & $\begin{array}{l}\text { Source } \\
\text { sensor }\end{array}$ & Est. avg. & $\begin{array}{c}\text { Source } \\
\text { sensor }\end{array}$ \\
\cline { 2 - 5 } $\begin{array}{l}\text { Bottom and } \\
\text { middle }\end{array}$ & $1.41^{\circ} \mathrm{C}$ & $3.97^{\circ} \mathrm{C}$ & $1.88^{\circ} \mathrm{C}$ & $2.93^{\circ} \mathrm{C}$ \\
$\begin{array}{l}\text { layers } \\
\text { Bottom } \\
\text { layer }\end{array}$ & $1.48^{\circ} \mathrm{C}$ & $3.97^{\circ} \mathrm{C}$ & $1.32^{\circ} \mathrm{C}$ & $2.93^{\circ} \mathrm{C}$ \\
\hline
\end{tabular}

As shown in the Table 7.4, using only the source sensors placed at the bottom of the container provided better results for pallet temperature estimation. However, in every combination, using the estimation method lessened the difference between the ambient temperature and pallet/container temperatures. For example, the average RMSE between the source sensors (ambient temperature) and pallet sensors was $2.93{ }^{\circ} \mathrm{C}$ and it was reduced to $1.32{ }^{\circ} \mathrm{C}$, a greater than two-fold decrease, when the Kriging estimation method was used. It is also true for estimating not just the pallet temperatures but other points in the sea container as shown in the first two columns of the table. 


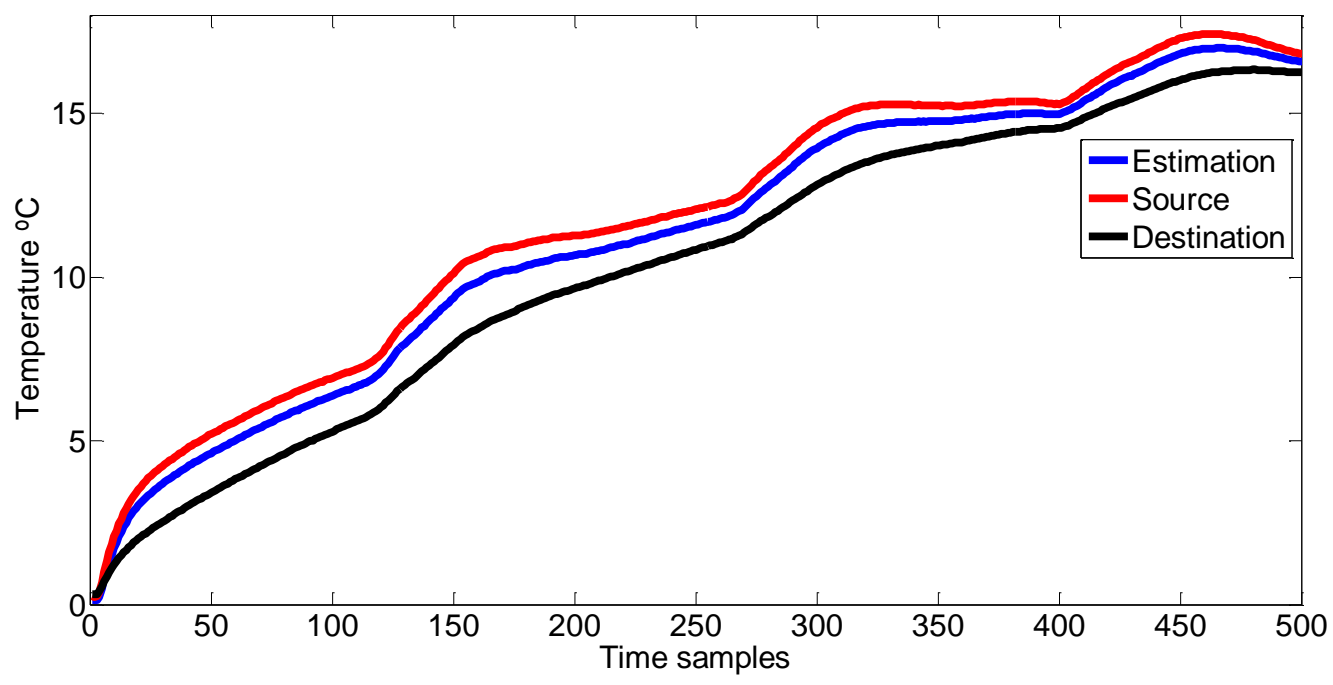

Figure 7.11. Temperature estimation average for the refrigeration failure using Kriging method

Figure 7.11 shows the average of the estimated temperatures for different destination sensors compared to source sensor and actual destination sensor averages. One can clearly see that the estimated temperatures moved closer to the actual pallet temperatures when compared to the ambient source sensors.

\section{2) Capacitive heat-transfer method (Capacitor method)}

Unlike the Kriging method, which requires multiple source sensors to create the variogram, the capacitor method only requires a single source sensor to create the exponential target fit for the pallet sensors. To create a more practical albeit more difficult estimation scenario, we used the container sensor as the ambient source sensor and calculated $T$ values for each pallet sensor point. Table 7.5 shows the average estimated temperature RMSE for the capacitor method.

Table 7.5. RMSE for the capacitor method

\section{Capacitor method RMSE}

\begin{tabular}{ll}
\hline Estimated temp. avg. & $1.28^{\circ} \mathrm{C}$ \\
Container sensor & $3.97^{\circ} \mathrm{C}$ \\
\hline
\end{tabular}


As shown in the Table 7.5 the errors are slightly lower than the Kriging method. Figure 7.12 shows the average of the estimated temperatures for different destination sensors compared to the source sensor and actual destination sensor averages.

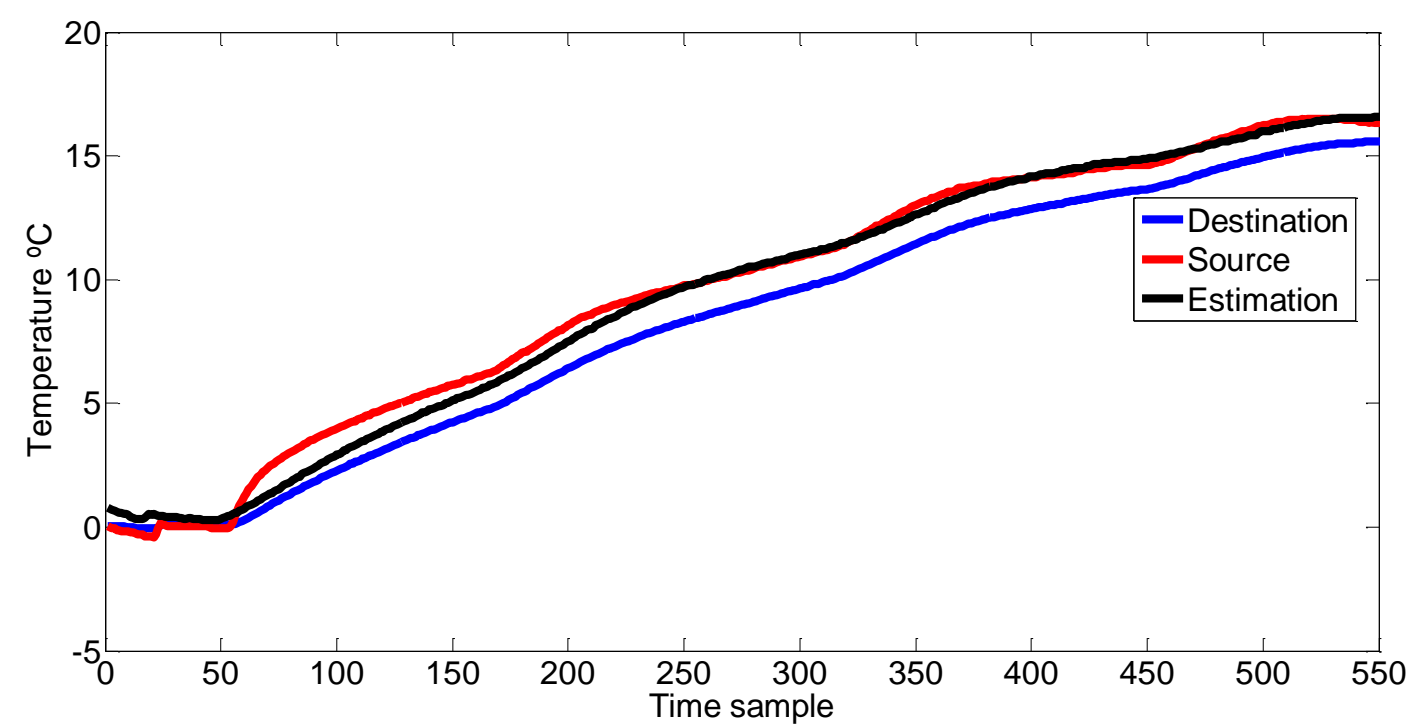

Figure 7.12. Temperature estimation average for the refrigeration failure using

\section{Capacitor method}

3) Artificial Neural Network (ANN)

Unlike both Kriging and capacitor methods, one can create and train an artificial neural network in a variety of different ways, such as using different numbers and sizes of hidden layers, adopting different learning rates, etc. Table 7.6 summarizes the results for two different network structures using a single hidden layer with 10 neurons vs. three hidden layers with 5 neurons each. Both structures were trained with three different learning rate constants as also shown in the Table 7.6. 
Table 7.6. ANN RMSE in different configurations

\begin{tabular}{lcccccc}
\hline \multicolumn{7}{c}{ Neural Network RMSE } \\
\hline Layer & 555 & 555 & 555 & 10 & 10 & 10 \\
Learning Constant & $1 \mathrm{e}-2$ & $1 \mathrm{e}-3$ & $1 \mathrm{e}-4$ & $1 \mathrm{e}-2$ & $1 \mathrm{e}-3$ & $1 \mathrm{e}-4$ \\
& & & & & & \\
Estimated temp. avg. ${ }^{\circ} \mathrm{C}$ & 1.42 & 1.42 & 1.47 & 1.02 & 1.00 & 0.94 \\
Container source sensor & & & \multicolumn{2}{c}{$3.97{ }^{\circ} \mathrm{C}$} & & \\
\hline
\end{tabular}

The minimum RMSE was obtained using a single hidden layer with 10 neurons and a performance gradient of 0.0001 . An RMSE of $0.94{ }^{\circ} \mathrm{C}$ in this case, shows almost a 50\% improvement over the errors of both Kriging and capacitor methods. This is not completely unexpected considering the fact that ANN is a more complex estimator which can model different system dynamics which also comes at a cost with higher system resource needs.

Since in this case the estimated temperature profile is very close to the desired output, plotting the two curves in full time scale is not very helpful. Hence, Figure 7.13 shows a detailed version of the plot to highlight the relative differences between source/estimated/desired temperature curves. As expected from the numerical results in Table 7.6, the estimated temperature curve in blue is a much better approximation of the product temperature (shown in black) than just using the ambient temperature (shown in red). 


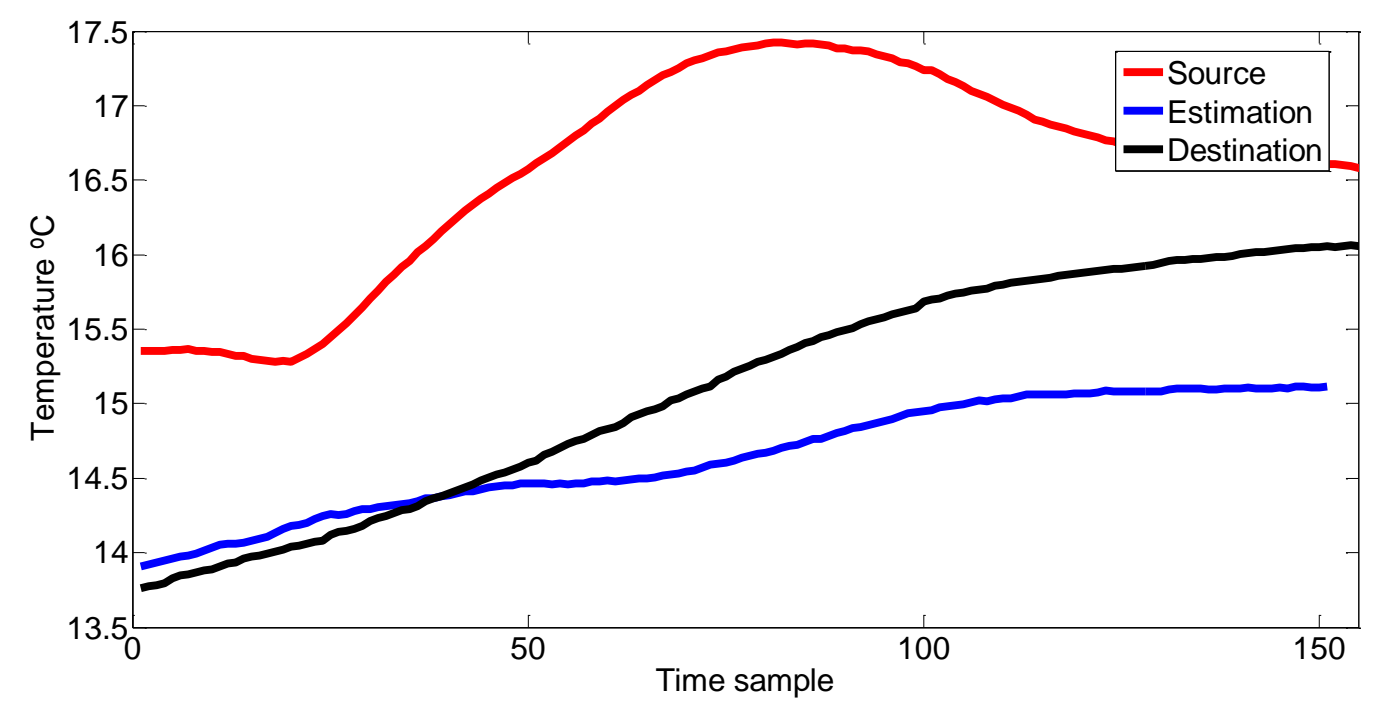

Figure 7.13. Neural network source, estimation and destination average temperatures

As indicated before, the results shown for the first phase of testing are used to train all three prediction systems and the actual comparison will be applying the testing data obtained in the next phase of the study.

\section{B. Testing phase}

With the temperature data obtained in the 1st phase of testing, it was deemed necessary to test the estimation methods with new and unknown data. Since all three methods require training to optimize model fit and accuracy, 1st phase data was used for training and 2nd phase data for testing.

\section{1) Kriging}

Kriging method had an average RMSE of $3{ }^{\circ} \mathrm{C}$ compared to the ambient temperature RMSE of $3.2{ }^{\circ} \mathrm{C}$, hence the approximation of the product temperature in this case can be assumed to be statistically insignificant. One of the reasons for this is the fact that Kriging method is primarily developed for sensors placed in a continuous variable environment or a homogenous medium such as the walls of a container, or the ambient air inside the container. In our current test case, the differential transition from the ambient air surrounding the perishable pallet to the products inside is anything but 
homogenous. It is for this reason Kriging displays an overall poorer performance compared to the other two methods as shown below.

\section{2) Capacitive heat-transfer method (Capacitor method)}

The results of the capacitor method in the 2 nd test phase were obtained with the trained T constants from the 1st phase. In this case, the average RMSE for all the estimated product temperatures was $2.26{ }^{\circ} \mathrm{C}$. Even though this is still higher than the errors obtained for the first phase of the study, considering the RMSE of the ambient source point is $3.2{ }^{\circ} \mathrm{C}$, it is still a significant improvement over simply using the ambient temperature for shelf life prediction where $+/-1{ }^{\circ} \mathrm{C}$ may result in days of shelf life difference. Figure 7.14 shows the average estimated temperature data in comparison to source and desired temperature data. The estimated temperature average curve is closer to the real pallet temperature curve than the ambient source temperature.

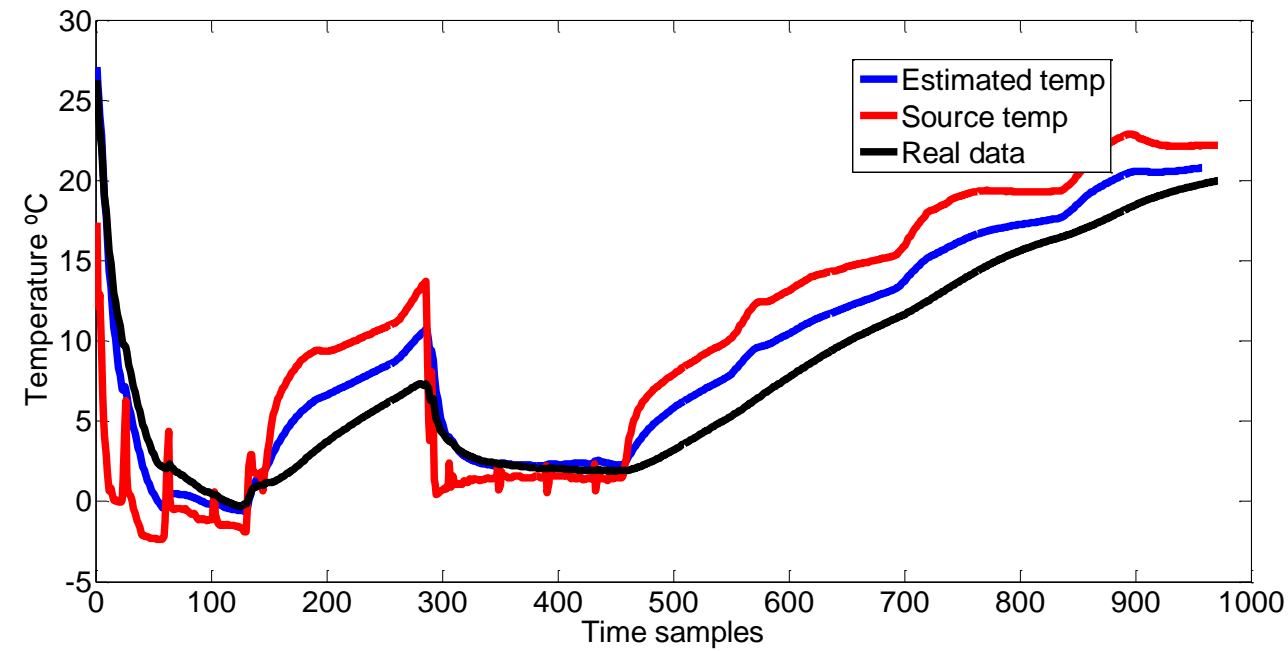

Figure 7.14. Average temperatures for the capacitor method in the second phase 
3) Artificial Neural Network (ANN)

Table 7.6 presents the results for testing of the ANN, similar to Table 7.7 for different source sensor configurations, but the same network topology with [5 10] layer structure and a performance gradient of 0.001 .

Table 7.7. Neural network RMSE

\begin{tabular}{lcc}
\hline Source sensors combinations & RMSE $\left({ }^{\circ} \mathbf{C}\right)$ & Source RMSE $\left({ }^{\circ} \mathbf{C}\right)$ \\
\hline 8 sources & 0.11 & 3.85 \\
4 sources (bottom) & 0.32 & \\
3 sources (2 bottom + cont.) & 0.44 & \\
3 sources (2 top + cont.) & 0.37 & 3.93 \\
4 sources (top) & 0.71 & \\
3 sources (bottom + top + & 0.42 & \\
cont.) & 1.79 & \\
Cont. sensor & & \\
\hline
\end{tabular}

As expected, the lowest RMSE of $0.11^{\circ} \mathrm{C}$ is achieved when the full set of 8 source sensors are used as inputs to the network which presents a significant improvement over both the Kriging and the capacitive heat-transfer methods. More importantly, even when less source sensors were used in combination with the existing container sensor, the RMSE is still significantly lower.

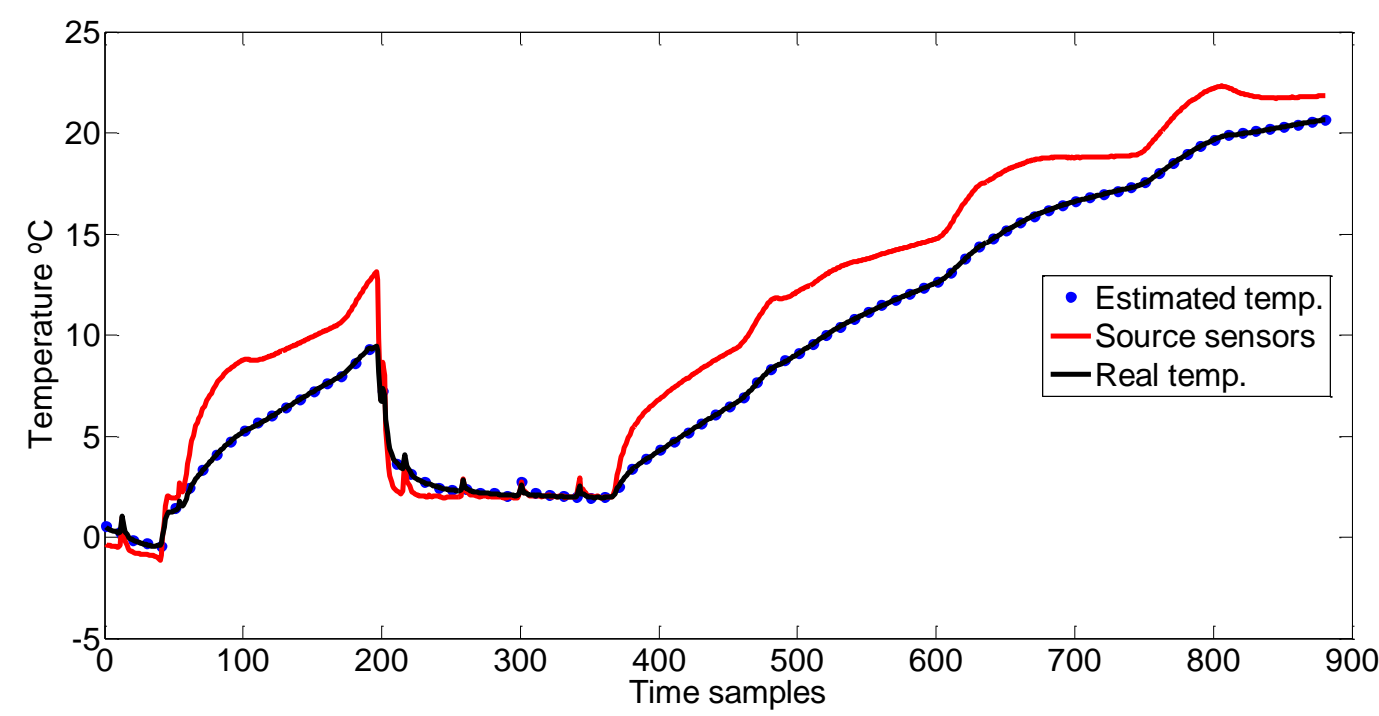

Figure 7.15. Average temperatures for the ANN method in the second phase 
The three temperature curves are shown in Figure 7.15 which shows the estimated temperature profile is a much superior approximation of the product temperature when compared to ambient temperature.

Although, using all 8 source sensors provide a reliable mapping of the container temperature, the primary goal of this study to achieve high resolution temperature monitoring using a minimum number of sensors, possibly only one - the container sensor, which would eliminate any additional cost associated with wireless sensor implementation.

To accomplish this objective, the estimation performance of the neural network is analyzed when only the container sensor, which exists in every temperature-controlled container, is used as the input metric. Surprisingly, estimation RMSE in this case is $1.79{ }^{\circ} \mathrm{C}$, which although not as good as the estimation performance with 8 source sensors, is still better than both Kriging and capacitive heat-transfer methods. Furthermore, when compared to the source sensor RMSE of $3.93^{\circ} \mathrm{C}$, there is a more than two-fold reduction in error where temperature curves are as shown in Figure 7.16.

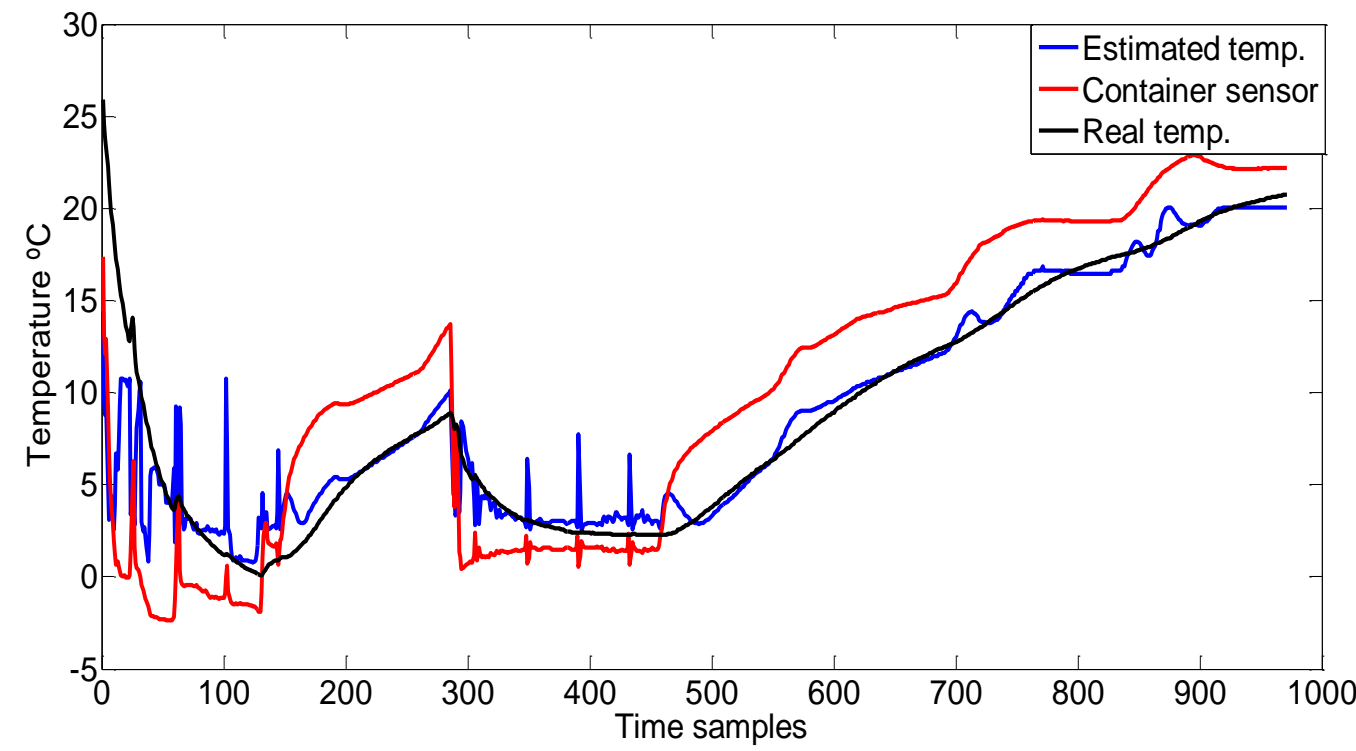

Figure 7.16. Temperature estimation with only the container sensor in the ANN

One can see that although the estimation curve follows the actual pallet product temperatures relatively well, the estimation error is amplified around 
regions of defrost cycles (little peaks as shown in the red curve compared to larger peaks in the estimation curve). In order to minimize such discrepancies, a simple yet efficient smoothing filter is applied to the output of ANN to obtain the final prediction. Whenever the filter detects a temperature differential of more than $0.5{ }^{\circ} \mathrm{C}$ between two consecutive sampling instants, say $t_{a}$ and $t_{b}$, it searches for the next time-temperature instant where the temperature differential is less, say $t_{c}$, and filters out the data points between $t_{a}$ and $t_{c}$, to replace them with a linear interpolation of the two temperatures, thereby eliminating peaks.

Figure 7.17 shows the curves for real and estimated temperatures as well as the final output after the smoothing filter is applied. One can see that the discontinuous error discrepancies are reduced significantly for the red curve after smoothing. In fact, the bottom graph with the differential curves obtained from the top one $(x[n]-x[n-1])$ shows that the smoothing filter largely eliminates such errors and creates a much closer difference curve to the actual product temperatures. With the smoothing filter the updated RMSE becomes $1.49{ }^{\circ} \mathrm{C}$ which corresponds to a further reduction of more than $17 \%$ regard to the error with no smooth filter.
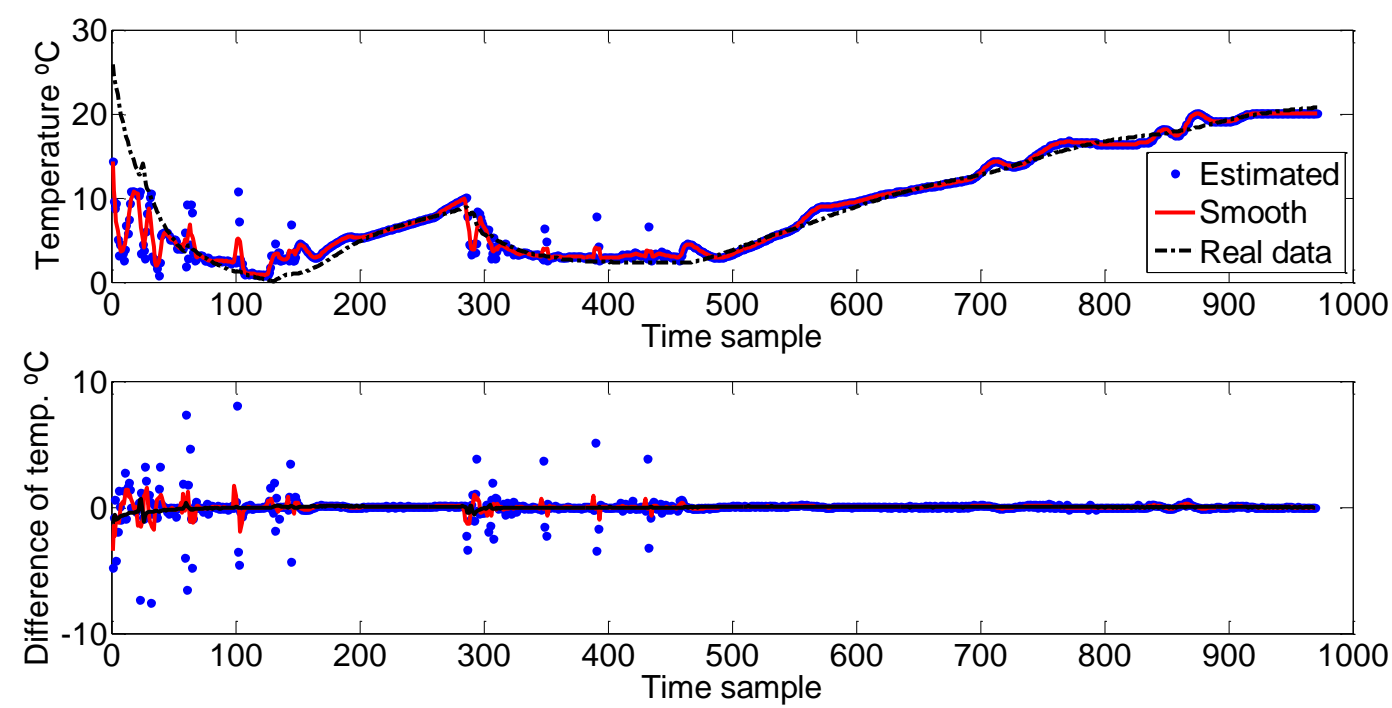

Figure 7.17. Smooth temperature curve above. Below the differences between the estimated temp. and the smooth line 


\subsubsection{Discussion}

Previous studies from the authors showed an error in temperature estimation using capacitor method between $0.45-1.91{ }^{\circ} \mathrm{C}$ of RMSE (Badia-Melis et al., 2013), Uysal et al. (2011) achieved an error of $1.9{ }^{\circ} \mathrm{C}$, in their cases the estimations was over a single pallet of First Strike Rations (military rations). However, for the trials in the present section, the estimation was examined across eight fully loaded (synthetic strawberries) pallets in a refrigerated container, and the error was $1.28{ }^{\circ} \mathrm{C}$.

It has been reported that the Kriging method works more efficiently when there is a homogeneous and continuous test scenario (Jedermann \& Lang, 2009; Jedermann et al., 2011b; Jedermann et al., 2009). This, however does not apply in this case since there were two different materials in the pallets plus the air gaps between the pallets. In their trials Jedermann and Lang (2009), obtained an error when estimating temperatures in refrigerated transportation, with Kriging method between $1.38-2.17{ }^{\circ} \mathrm{C}$ where their transport container examined was $3 \mathrm{~m}$ in length, $2.5 \mathrm{~m}$ wide and $2.5 \mathrm{~m}$ high. In contrast to this for the tests presented in this trial, the lowest kriging error is $1.32{ }^{\circ} \mathrm{C}$, where the container size was $5.9 \mathrm{~m}$ long, $2.3 \mathrm{~m}$ wide and $2.4 \mathrm{~m}$ high. It is thus possible to assume the Kriging method works better in a more homogeneous space with no well-defined discontinuous boundaries. Therefore in this case a sea container is not the perfect candidate for this method.

Finally when applying ANN, the temperature prediction yielded $0.11{ }^{\circ} \mathrm{C}$ as an RMSE. Similarly, Ibarra et al. (2000) obtained (at product level) an error of $1.07{ }^{\circ} \mathrm{C}$, when estimating the temperature of cooked chicken using temperature from thermal image as input for the ANN. Similarly, to predict moisture in papaya, Yousefi et al. (2013) had $0.007{ }^{\circ} \mathrm{C}$ as RMSE. It is worth noting that the use of ANN seemed to yield the best prediction results whilst also requiring the most elaborate training process of all methods used.

It is important to highlight that, using the algorithmic estimation methods described in this section, the most accurate estimation result had an average error of $0.11{ }^{\circ} \mathrm{C}$ when using 8 source sensors. This represents a reduction of 
the $97.14 \%$ of the absolute error, which is over the error using only the container ambient sensor as a reference. It is further shown in this document that it is possible to estimate the pallet level temperature by processing the time-temperature data collected by the single container sensor. This results in an average RMSE of $1.49{ }^{\circ} \mathrm{C}$ which is another significant error reduction (up to $62 \%$ ) of the absolute error.

Although all three temperature estimation methods discussed in this section estimated closer temperature curves than the source ambient sensor, we observed varying levels of performance. For example, Kriging method works better in a more homogeneous space with no well-defined discontinuous boundaries, and evidently a sea container is not the perfect candidate for this method. Capacitive heat-transfer method can model the relationship between pallet and ambient temperatures using a relatively simple single parameter model, whereas ANN performed best compared to the other predictor methods which is a more complex learning algorithm and requires an elaborate training process with more data. It is also worth noting that smoothing filters can help improve the ANN estimation during defrost cycles as occurred in this case.

\subsubsection{Conclusions}

In this study, it is demonstrated that it is possible to achieve higher resolution temperature monitoring by estimating pallet level temperatures in a refrigerated sea container by using a reduced (or even zero) number of wireless sensors.

It is also shown that under critical real-life situations such as refrigeration failure, it is possible to better predict product stability at pallet level by utilizing such algorithms. One can use this information to predict acceptable and appropriate reaction times to fix such problems or to make more informed decisions regarding product stability, re-routing, distribution and waste volumes. 
In conclusion, algorithmic temperature mapping and prediction in transportation containers can be a very potent tool in developing cold chain strategies with better monitoring to significantly reduce product losses and reducing waste. The predicted data can be used for more accurate shelf life calculations and enhancing the logistical operations of all stakeholders of the largest industrial sector in the world, food, without the need for significant capital investments. 


\subsection{Artificial Neural Networks and thermal image for temperature prediction in apples}

This section has been published as an article in the Food and Bioprocess Technology An International Journal. Badia-Melis, R., Qian, J. P., Fan, B. L., Hoyos-Echevarria, P., Ruiz-García, L., \& Yang, X. T. (2016). Artificial Neural Networks and Thermal Image for Temperature Prediction in Apples. Food and Bioprocess Technology, 1-11.

\subsubsection{Introduction}

The ability to implement automated quality control and supervision systems across the full supply chain present significant challenges for food professionals. This challenge is further exadurated by the fact that foods "as an asset" come in multiple shapes, sizes and properties which require a variety of treatments and storage conditions to delay spoilage thus making this challenge more difficult to provide a single solution. However irrespective of food type, quality control and supervision during transport, distribution and storage are very important in the food industry and fruit and vegetables are no exception to this (Ruiz-Garcia \& Lunadei, 2011). Across all the food groups the biggest challenge is to assure a continuous cold chain from the producer to the consumer, a goal which cannot be achieved without adequate control systems monitoring (Gwanpua et al., 2015).

Apples are one of the most popular economic fruit in the world, and China's apple cultivation area, total yield and export volume rank first in the world a trend which is currently increasing year on year (FAO, 2012; Y. Liu et al., 2013; Lopuch et al., 2011). The four main regions are the Bohai Bay region, the Northwest Loess Plateau, the Yellow River region and the highlands of southwest China (Yang, 2006). Given their well documented health benefits apples are consumed during the whole year, which place significant demand on the product distribution network. This in turn increases the need for optimum handling and shipping conditions during storage, transporting and packaging to avoid product loss. Packaging techniques are essential to 
maintain the apple quality during storage and transporting. In order to extend the apple shelf life many studies have been carried out on advanced packaging materials and techniques. Apples are usually stored under controlled atmosphere packaging which can delay ethylene-induced ripening (by a factor of months) but in China the percentage of controlled atmosphere cold storage is low. This results in a loss of $15 \%$ 20\% in apples per year (Varela et al., 2008). Therefore, to ensure product safety and security it is important to protect apples from high temperature to avoid accelerated degradation but traditional packaging materials such as wooden box, cardboard box and plastic box cannot satisfy it. This creates a significant commercial need for advanced cold chain monitoring technologies across the supply network (Iglesias et al., 2012).

It is proven that there are potential possibilities and benefits of having a system able to predict temperature at any point with a reduced number of sensors, and it can aid significantly in reducing food waste across the supply chain. Jha et al. (2011) within their article presented nondestructive quality evaluation methods for food, and shown how the cooked level inside the chicken can be assessed by using thermal image and ANN. Q. Chen et al. (2013) also revealed the thermal image as a technique for food safety. Castro-Giráldez et al. (2014) implemented the thermal imaging as a temperature control for meat freezing process.

Thermal imaging can possibly help to achieve what other technologies are trying, i.e. a complete wireless temperature monitoring. This is thanks to the wide open range the thermal camera offers, whilst reducing the number monitoring devices used and also the technologies ability to estimate temperatures where it cannot be seen. The authors of this document wished to further explore the cost factor associated with this technology. The objective of this work was to demonstrate the possibility of temperature estimation in a pallet using the temperature registered with the thermal camera. Secondly a comparison of the estimation parameters between different packaging, such as cardboard and plastic was also investigated. The experiments were conducted in the National Engineering Research Center for Information Technology in Agriculture (NERCITA) experimentation base in 
Beijing, China, in partnership with the Technical University of Madrid (UPM) Madrid Spain.

\subsubsection{Experiments}

NERCITA experimental environmental controlled room: This provided an ability (via specialized software) to control temperature, humidity and the percentage of oxygen and $\mathrm{CO} 2$ in the air.

Collihigh(c) semi passive RFID tags, $\pm 0.5^{\circ} \mathrm{C}$ of sensitivity and temperature range between $-20^{\circ} \mathrm{C}$ and $+60^{\circ} \mathrm{C}$, it can store up to 10000 data points. 42 tags were recording temperature in the room, hanging from the ceiling as showed in the Figure 7.18; the distribution was in 3 columns, 7 lines in 2 different layers or highs. Also 27 tags were located inside the pallet.

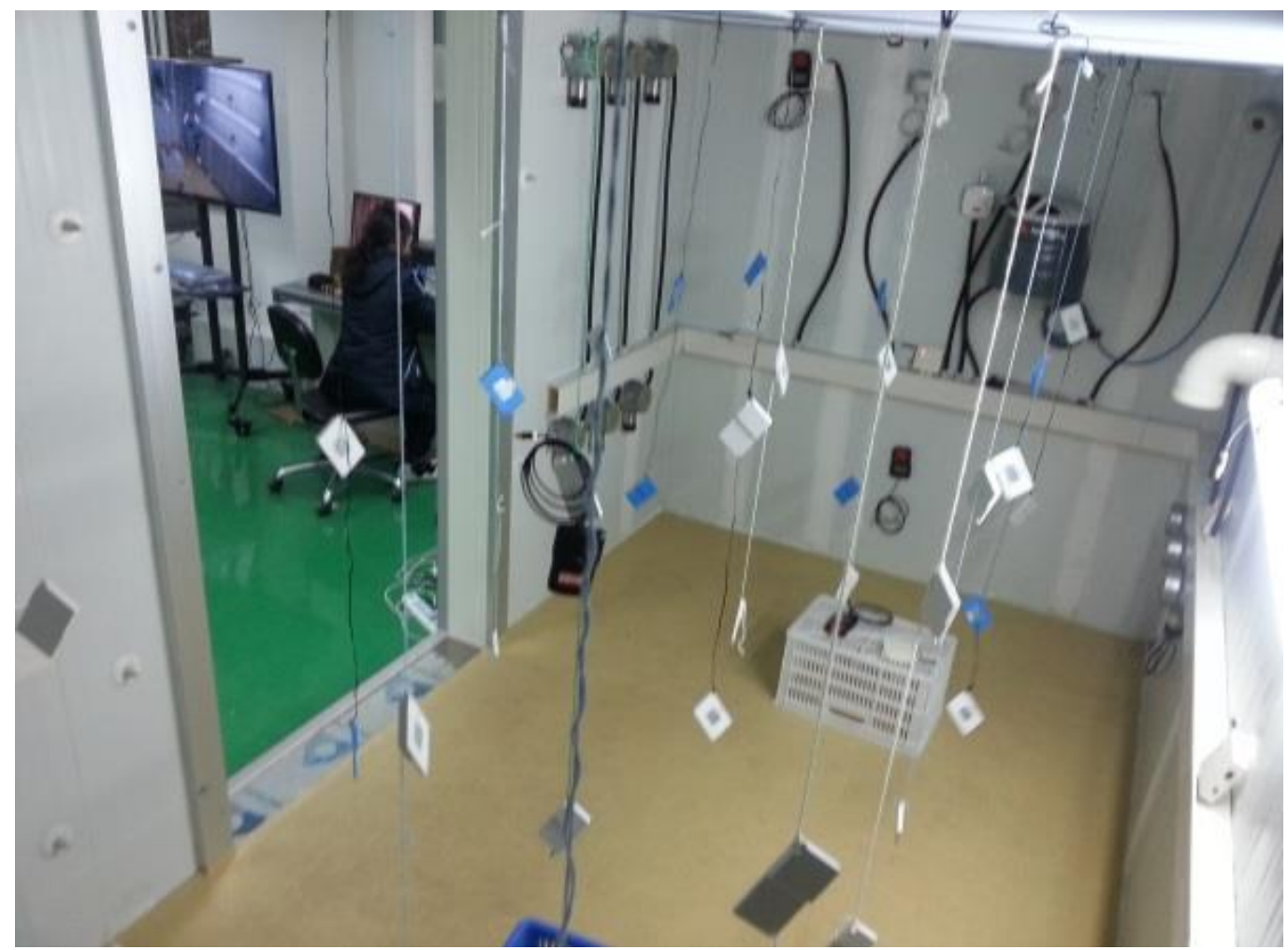

Figure 7.18. RFID temperature tags distribution in the cold room 
All data was downloaded with a reader attached to a computer, being the reading range around $10 \mathrm{~cm}$. After each experiment was finished, the tags were extracted and read.

Extra data was recorded with 9 Apresys $($ data loggers, registering temperature and relative humidity, inside the pallet. Temperature data was readily available via the logger display as the sensor was introduced into the boxes with a probe attached to the Apresys (C).

All the data was analyzed in Matlab (version R2014a) with specialized programs, developed ad hoc for this section. The temperature estimation programs require a specific toolbox native of Matlab (nftool 2014 version).

Commercially available Flir thermal camera (model A615) was used. Thermal image resolution $640 \times 480$ pixels, thermal sensitivity $<0.05{ }^{\circ} \mathrm{C}$ at $30^{\circ} \mathrm{C}$, object temperature range $-40{ }^{\circ} \mathrm{C}$ to $+150{ }^{\circ} \mathrm{C},+100{ }^{\circ} \mathrm{C}$ to $+650{ }^{\circ} \mathrm{C},+300{ }^{\circ} \mathrm{C}$ to $+2000{ }^{\circ} \mathrm{C}$; and accuracy of $\pm 2{ }^{\circ} \mathrm{C}$ or $\pm 2 \%$ of reading.

720 kilos of Fuji apples. 48 cardboard boxes, stacked in 6 layers of 8 boxes each. 36 plastic boxes distributed in 6 layers with 6 boxes per layer. The base formed with both type of boxes was the same and the plastic boxes were about $20 \mathrm{~cm}$ higher than cardboard boxes.

\section{Conducting the tests with real product}

The purpose of this second part was to obtain the temperature data from the pallet with the RFID tags, the data loggers and the thermal image all together. These tests were divided in two parts since two different boxes of apples were used with the same apples. The purpose of using these two types of packaging is to demonstrate the possibility of temperature estimation with two of the most used commercial boxes for the apple transport and storage in China. The first part was made with the apples inside the cardboard boxes and the second with plastic boxes. 
Two Apresys loggers recording temperature and relative humidity $(\mathrm{RH})$ were located (1) near the fixed sensors of the room, and (2) on top of the pallet. The loggers were programed to record every 5 minutes.

In order to control the temperature distribution in the room, 42 RFID tags were programed to record every 5 minutes. Each RFID tag was labelled to take note of the tag number and the exact position inside the room. Regular coordinates $X, Y, Z$ were associated with the tag number to control the positions. Therefore, the tags were distributed in the room in the same positon than the previous test with no product inside.

27 RFID tags and 9 Apresys loggers were programed recording data every 5 minutes and pre-pared to instrument the pallet. First the plastic pallet-base in the cold room, and put 8 apple boxes, inside are distributed 9 RFID tags and 4 data loggers with a probe inside the boxes in the corners Figure 7.19. Then the pallet was built until the half height, and the sensors were introduced as shown in Figure 7.20, the white ellipses are representing the RFID tags and the black circles represent the Apresys loggers. Finally in the upper level the instrumentation was finished in the same disposition as the bottom layer.
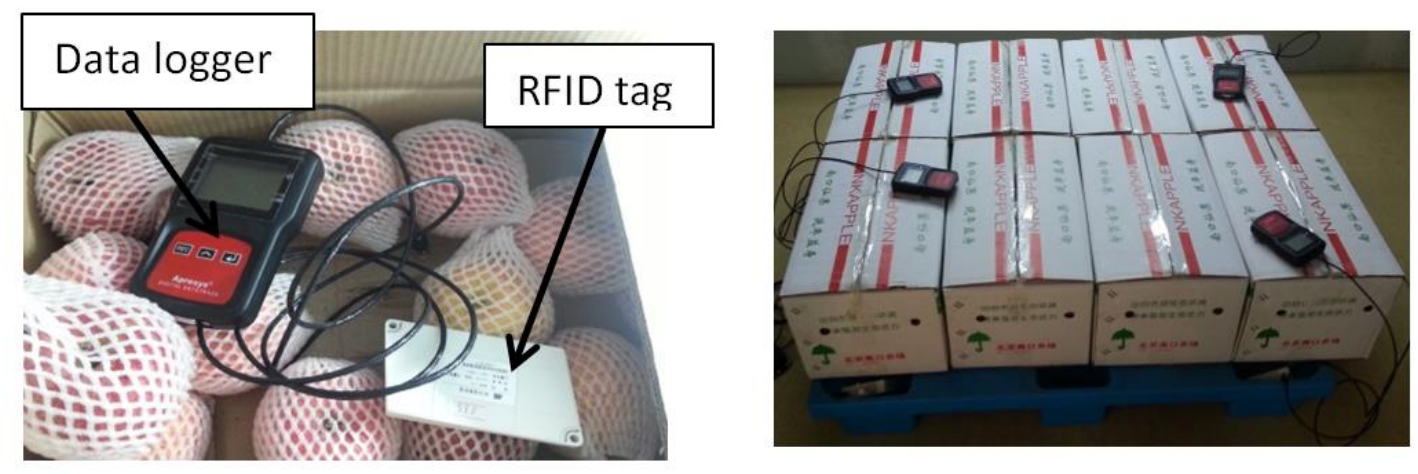

Figure 7.19. Position of the RFID tags and RH and temperature loggers

After the pallet is completely instrumented and placed in position, the thermal camera was placed inside the cold room with a top view of the pallet programed to take images every 15 to 20 minutes. 4 points from the image of the surface of the pallet were then used as the source sensors needed for reference in order to execute the Artificial Neural Networks. 

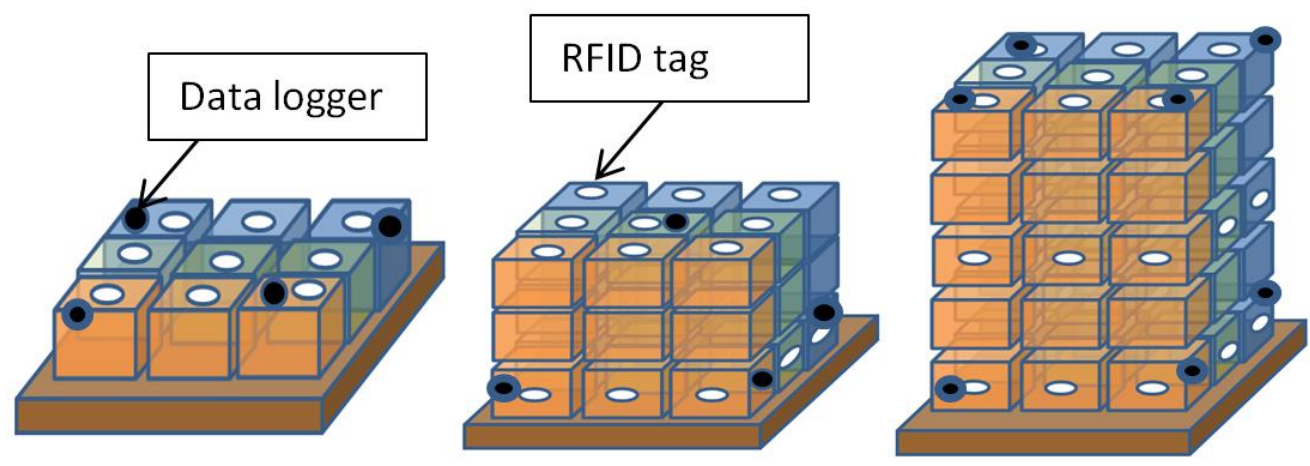

Figure 7.20. Sensor distribution inside the pallet

\section{Programming the temperature profiles}

As presented in the introduction, temperature control is key in the food supply chain; many incidents can occur during transportation or storage, some typical situations are the called temperature excursions, which consist of certain time under the refrigerated conditions out of the optimum temperature range. Taking into account this fact as a premise, it was developed a temperature profile that simulates a temperature excursion during one day and then return to the initial temperature conditions.

On the other hand, the data analysis performed includes the temperature estimation with ANN, this kind of method requires a training phase (it will be called first phase), so the network can be trained and it will learn the behavior of the destination points for estimating further temperatures, and a testing phase, where the already trained network is tested with new data, and its performance can be evaluated.

The first step involved the temperature setup of the room to $4{ }^{\circ} \mathrm{C}$, and when the pallet was stabilized at $4{ }^{\circ} \mathrm{C}$, the refrigeration system is disconnected for one day, this is the temperature excursion previously mentioned, i.e. a break point in the cold chain. 


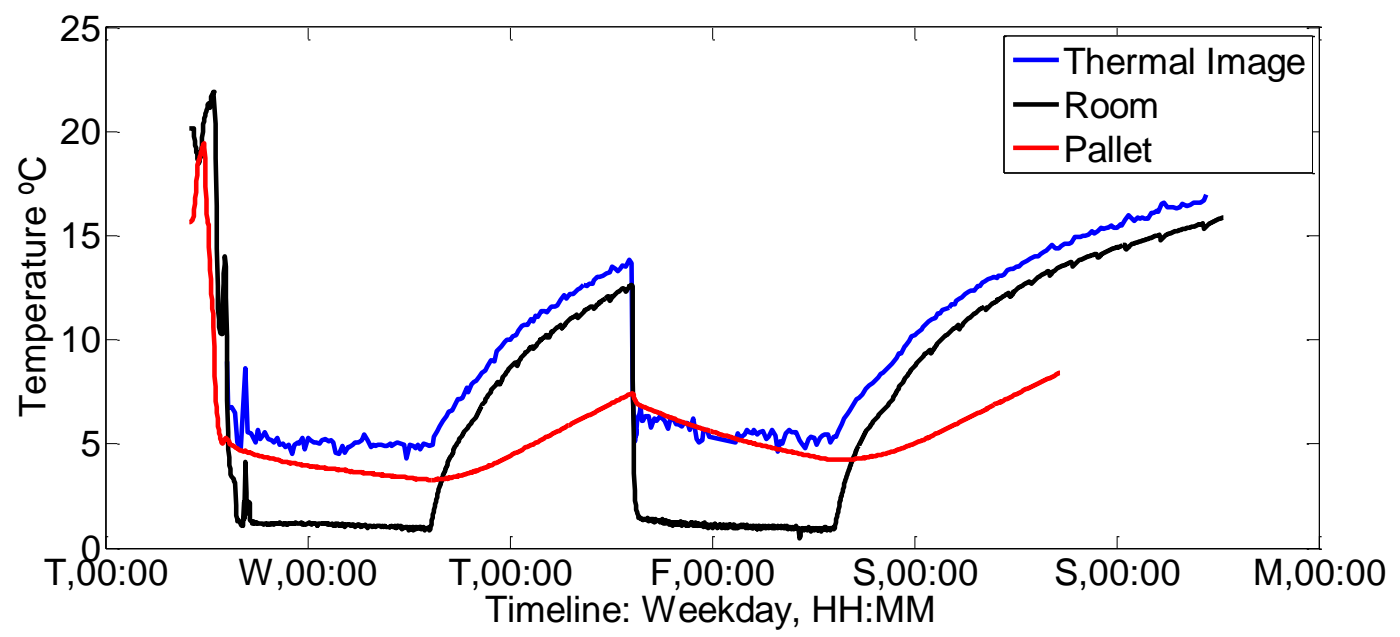

Figure 7.21. Temperature profile

After one day disconnected, the refrigeration system was started again at $4^{\circ} \mathrm{C}$, and stabilized for another day at that temperature. Then it was disconnect again, this time during 2 days. The first disconnection will be the training for the Neural Network and the second will be used for the testing phase. Figure 7.21 shows the 3 curves corresponding to the temperature average of the utilized points in the thermal image, the temperature tags distributed in the room and the tags inside the pallet. As it is indicated the left part of the image was dedicated for the NN training, and the right part is dedicated for testing the NN. This implies that the NN was using this new data (on the right of the image) never seen before for the network. 


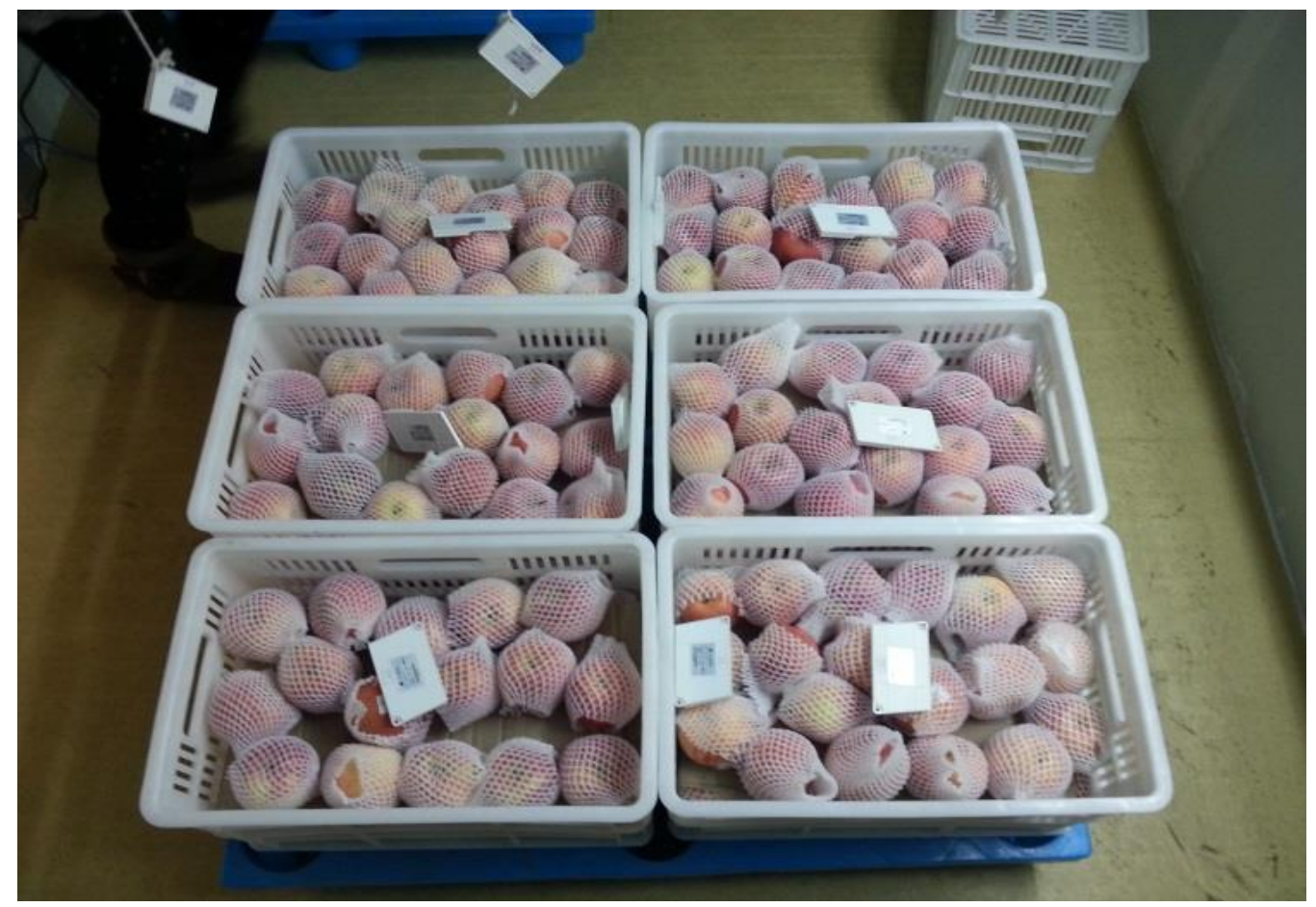

Figure 7.22. Plastic boxes RFID tag distribution

The second part of the test was performed with plastic boxes (Figure 7.22). Identical sensor distribution was used, including the same temperature profile. In this case the boxes were bigger, and it was necessary to put only 6 boxes per layer instead of 8 like in the case of the cardboard boxes. The pallet was built with 6 levels of boxes.

\section{Data analysis}

All temperature estimation methods are intended for predict the temperature better than using only the reference sensor. This reference sensor is not inside or near to the product that is desired to track.

\section{Temperature estimation method: Artificial Neural Network}

ANN is used for system classification or estimation purposes when the goal is to estimate a specific output value for given input values. It was assumed that the inherently non-linear relationship between the product temperature inside a pallet and the air temperature can be modeled by an artificial neural 
network (ANN). Figure 7.23 shows the Matlab structure of a neural network, where the input to the network consists of time-temperature data provided by the sensors. The inputs in this case, are the selected points from the thermal image from outside the pallet, whereas output is the estimated timetemperature data for products placed inside the pallets. Hidden layers consist of artificial neurons which weigh and sum their inputs as they propagate their outputs to the next hidden layer. ANNs need to be trained with part of the temperature data to learn how to estimate the non-linear relationship between its input and target output.

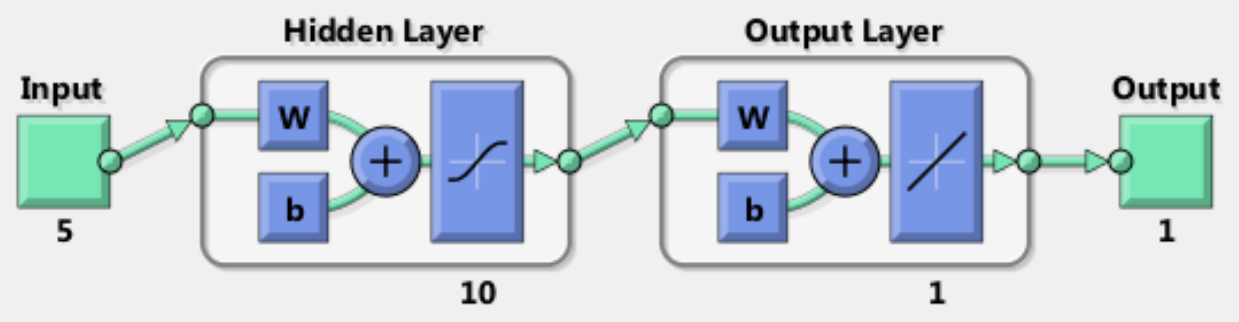

Figure 7.23. Representation of a Levenberg-Marquardt Neural Net. In the nftool on Matlab

The default training algorithm in the Neural Network Toolbox of MATALB is the Levenberg-Marquardt backpropagation algorithm, which was also the algorithm used in this study. It is a network training function that updates weight and bias values according to Levenberg-Marquardt optimization.

The great challenge in training a neural network is the fact that there are many parameters involved, such as the number of layers, the number of neurons in each layer and minimum performance gradient. The combination of these parameters has been studied by the authors previously (Badia-Melis et al., 2013).

The left part of Figure 7.21 is dedicated exclusively to do the training (composed by training, testing and validation). In this part, training is taking randomly the $70 \%$ of the data (percentages are selected during the data analysis); these data points are interspersed from the total amount of data from first phase. In the validation as well as in the testing parts it is given the 
$15 \%$ of the data. The best performance from validation part is extracted and the corresponding Neural Network is saved. Then the network is used with the right side of the data set to perform the temperature estimation. It was also tried a combination of sensors configurations to identify the minimum number of sensors that can be used for reliable product temperature estimation.

The novel singularity in this work is that the input is not coming from a physical sensor; it is coming from an image captured from a thermal camera. In this case the input points do not depend on the position of the sensors and are not limited by the time or the space, since at any moment it is possible to return to the images and extract more source points, and it is not necessary to determine all the source points since the beginning.

The input for the Neural Network was extracted from the upper four corners of the pallet and the center of the top; these points were selected in the thermal image (Figure 7.24). The output was an average of the temperature from the RFID tags showed in Figure 7.20.

Once the temperature data was achieved from the surface, the ANN was trained with the RFID as destination points. And finally it is possible to extract the output which is compared with real data to calculate the performance, for this assessment it is used the Root mean squared error (RMSE) as well as the correlation coefficient.

\subsubsection{Results and discussion}

Results are presented as follows; firstly, the performance of the NN training using the first part of the data set as indicated in the previous section; and secondly the testing information is provided using the last part of the data set. To carry out the temperature estimation it was necessary to prepare the temperature profile explained in the previous section.

\section{Pallet of cardboard boxes}

The performance of the training is analyzed within this section. As showed in Figure 7.24, the interior of the pallet remains hot (around $10^{\circ} \mathrm{C}$ ); the 
influence of the cool air flowing in the room is cooling down the surface of the pallet getting $2.6{ }^{\circ} \mathrm{C}$ (Figure 7.24). This is normal distribution as the cooling unit cools down the air until the native sensor from the room reaches $4{ }^{\circ} \mathrm{C}$ (the set point), in order to do so, the air flowing can be colder in some occasions.

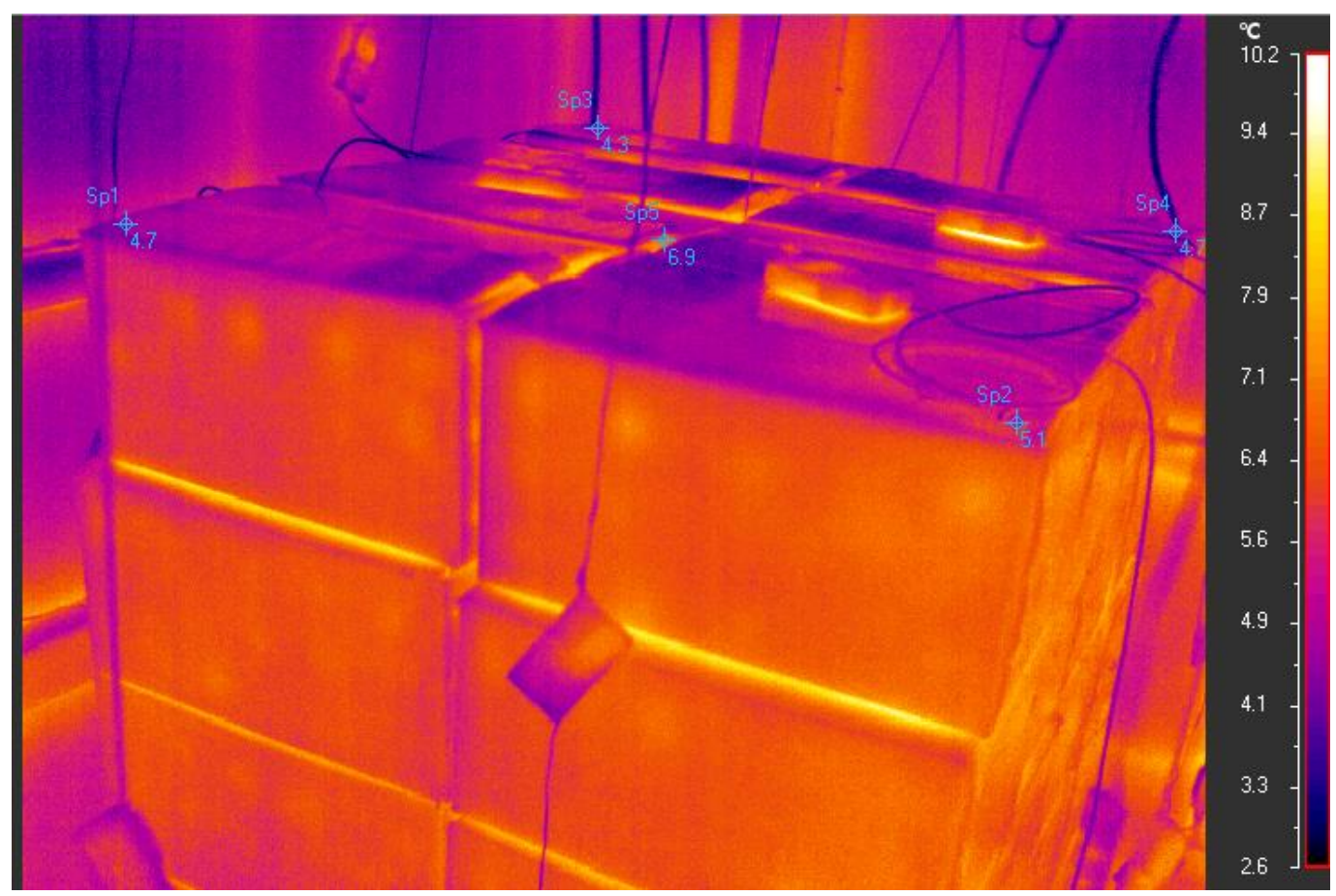

Figure 7.24. Thermal image in cardboard boxes. Cooling process

Analysis of the data is as described in the previous sections. The data is divided in two phases, the first one is used for creating the neural network, this network will characterize the behavior of the pallet during the temperature changes, and will no longer be necessary to create it again unless some general aspects are changing in the scenario, such as type of boxes, product or isolation materials in the cold room. 


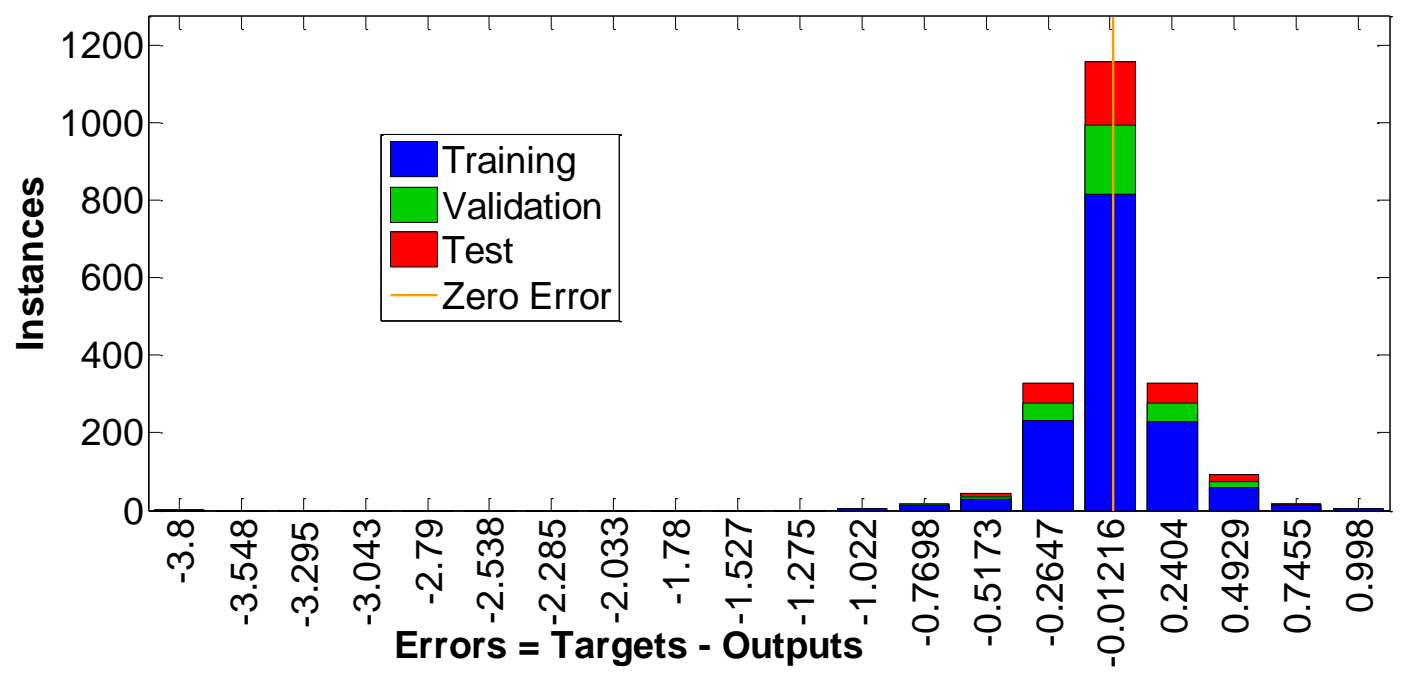

Figure 7.25. Error histogram with 20 Bins

In the second phase, the created (trained, validated and tested) network (during the first phase) is used to estimate the data never seen before (Figure 7.28). Figure 7.26 presents the error histogram of the difference between the targets and the outputs. Errors are located in an area very near to the zero, with the exception of some minor isolated elements that reach -3.8 . Overall there are more training errors than in the validation and in the test. This is an expected occurance since the percentage of data designated to be used in the training was $70 \%$ and the validation and testing only $15 \%$ each.

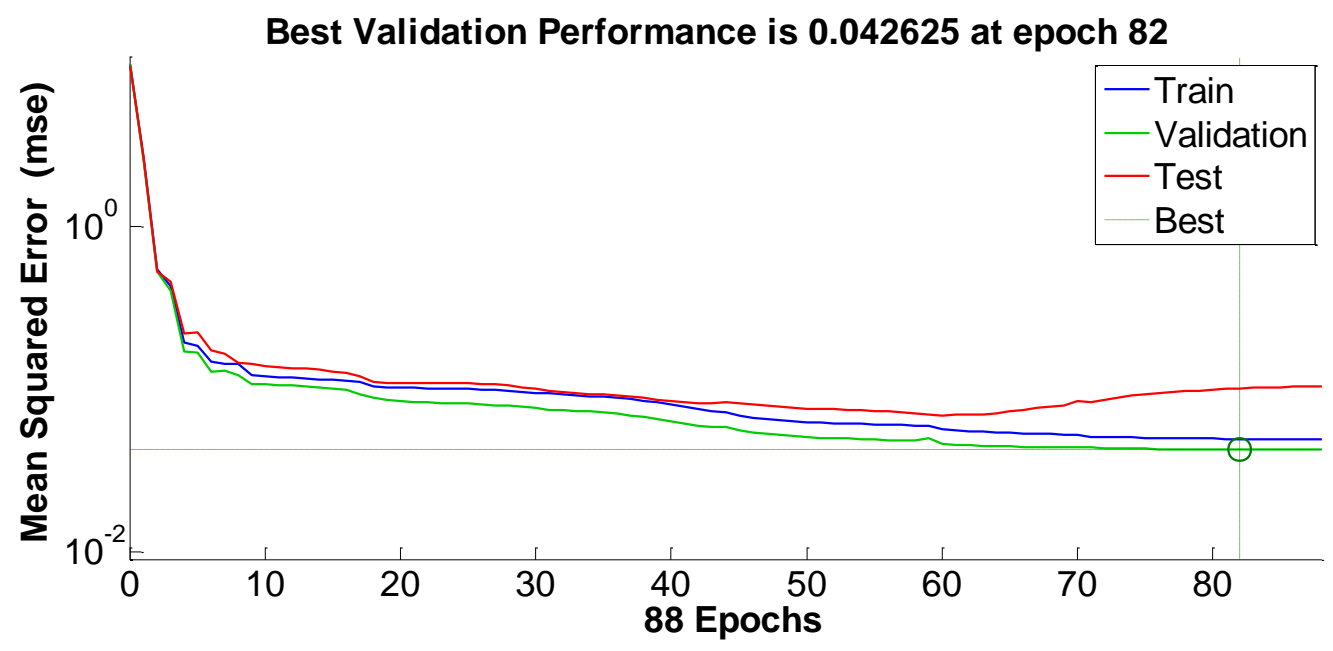

Figure 7.26. Best validation performance 
The NN program defined in Matlab, works by doing iterations of the estimation until it finds the minimum Root Mean Squared Error (RMSE). Figure 7.26 depicts how all the parts, train, validation and test are lowering their RMSE as it progresses the number of epochs. In the moment the program determines the validation part has achieved the minimum, it records that network as well as the minimum in order to use the network for further phases. The minimum validation achieved in this case corresponds to a RMSE $=0.2{ }^{\circ} \mathrm{C}$ in the $82 \mathrm{nd}$ iteration.

Training: $\mathbf{R}=0.98497$

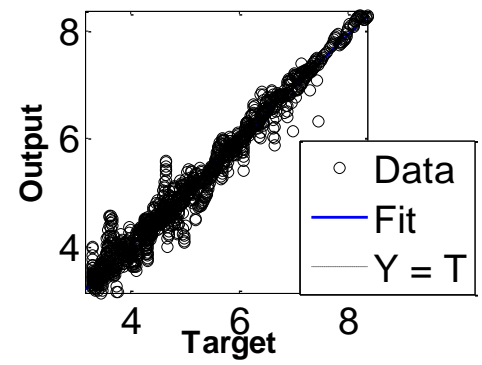

Test: $\mathbf{R}=\mathbf{0 . 9 7 1 1 1}$

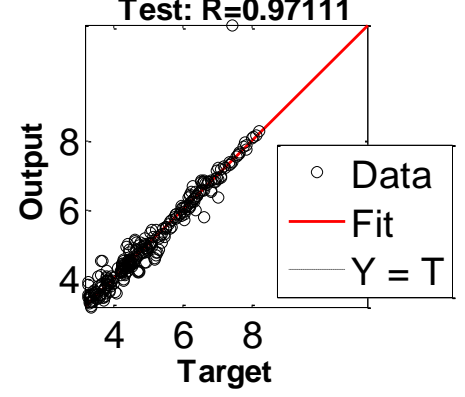

Validation: $\mathbf{R = 0 . 9 8 5 9}$

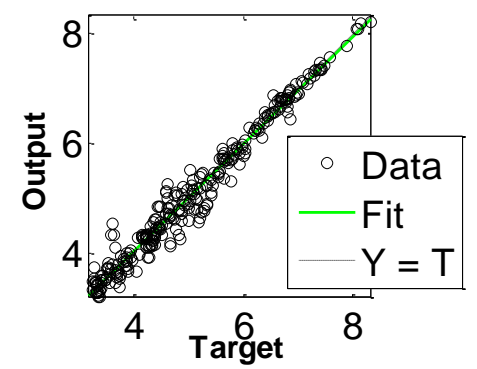

All: $\mathbf{R}=0.9828$

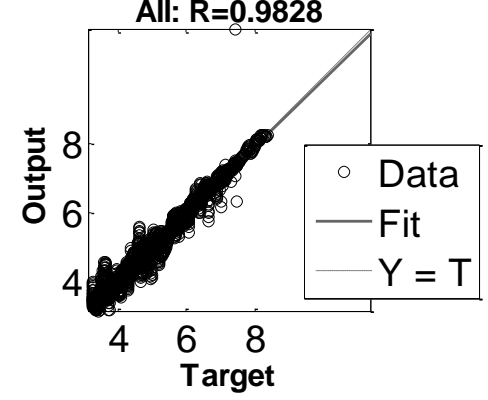

Figure 7.27. Cardboard boxes regression curves

The performance is also evaluated in Figure 7.27 with the regression curves of the training, testing, validation and all the parts together; the $\mathrm{R}$ values are very close to 1 . Best $R$ value is happening during validation with $R=0.9859$, the worst value is in the test part with an $R=0.9711$ since some data points are out of the fitted curve, but it appears to be an isolated case. 


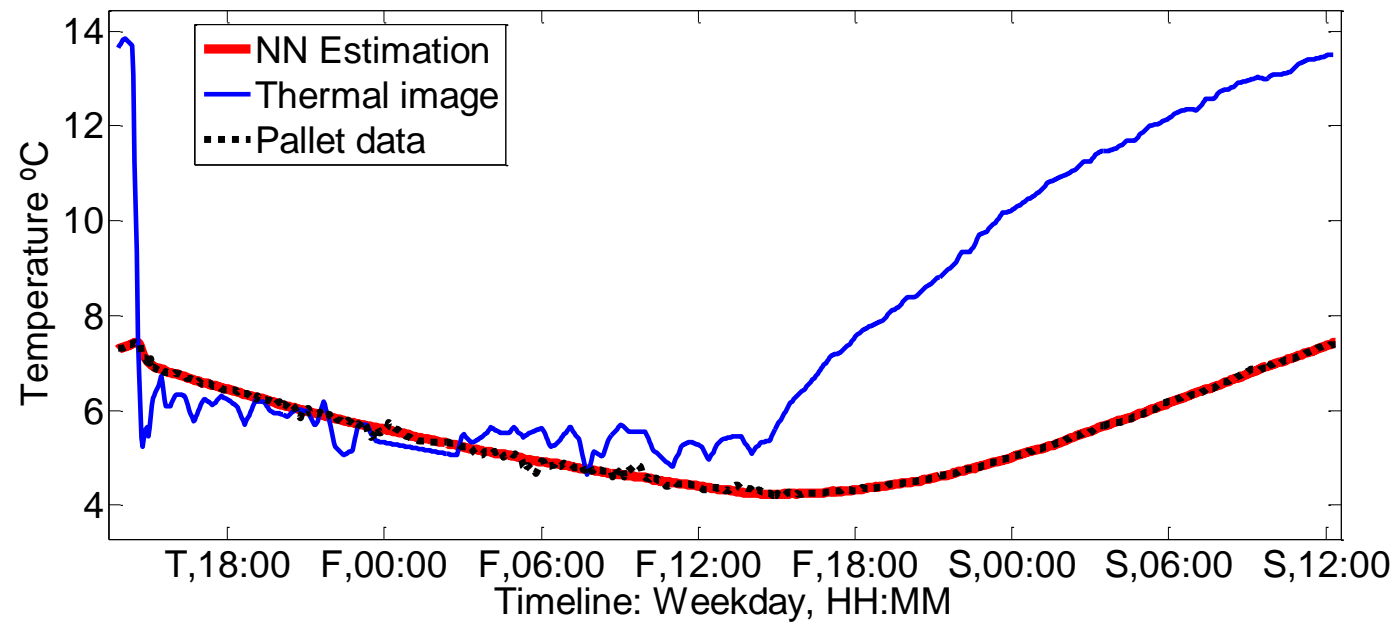

Figure 7.28. Temperature comparison profile between targets, estimation and source data

As shown in Figure 7.28 the estimation curve is very close to the pallet data. This figure is extracted by using the NN with the second part of the temperature profile given (Figure 7.21); only new data was used, it was never seen for the network before. The error achieved is $0.086{ }^{\circ} \mathrm{C}$ whilst the error achieved only taking into account the thermal image (blue line in Figure 7.28) data would be RMSE $3.56{ }^{\circ} \mathrm{C}$.

\section{Plastic boxes}

Same experiment with same profile was carried out with a pallet of plastic boxes as shown in Figure 7.22. Results are also distributed in the same way as the previous section with cardboard boxes. The Figure 7.29, Figure 7.30 and Figure 7.31 correspond to the first phase of the profile where it is trained, validated and tested, and in the last image (Figure 7.32) the NN is tested with new data. 


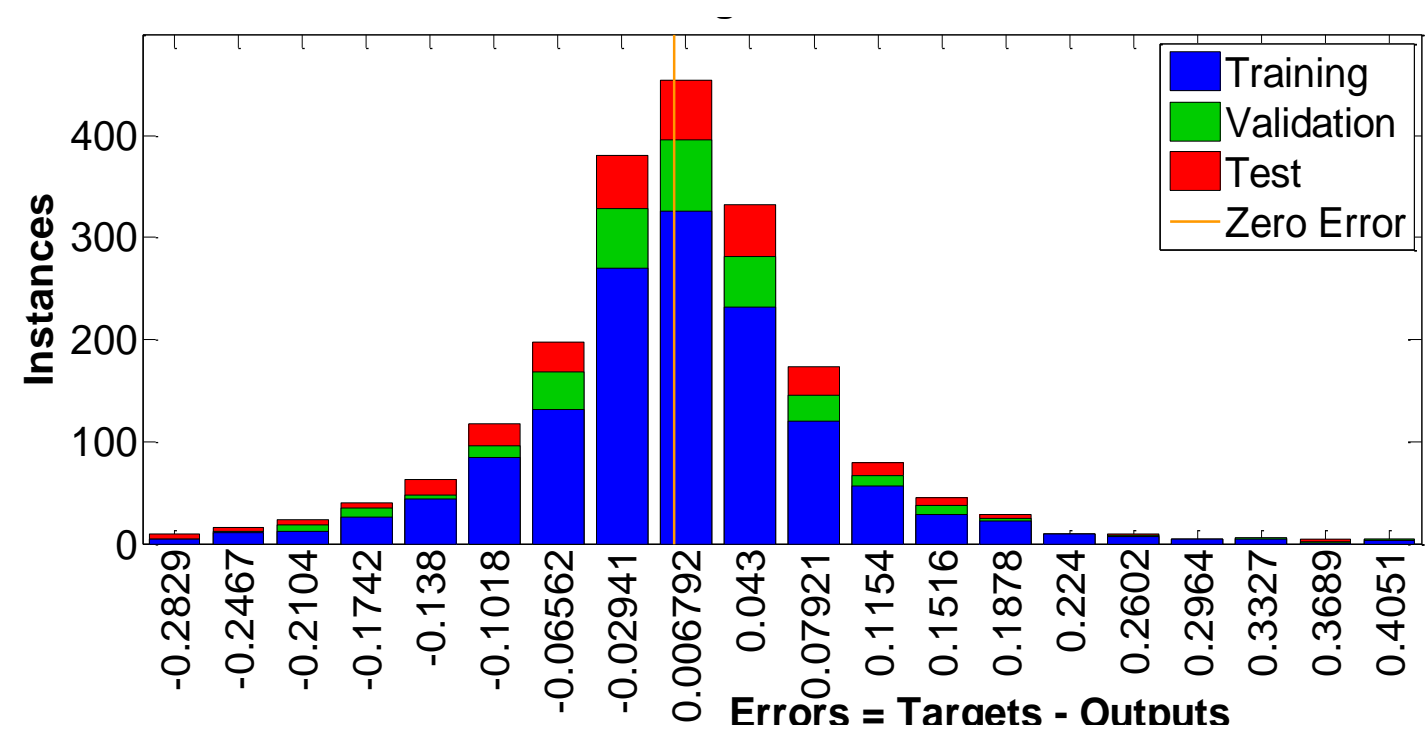

Figure 7.29. Error Histogram with 20 Bins

Most of the errors in Figure 7.29 are centered on zero error and homogeneously distributed to both sides. Similarly the most frequent errors correspond to the training part since it was using the $70 \%$ of the data. The biggest difference in Figure 7.29 with Figure 7.25 is that the errors are homogeneously distributed in a gauss bell shape around the zero error, while in the Figure 7.25 the errors are mostly concentrated in the zero zone with a marginal dispersion, that the zero bin in Figure 7.25 gathers almost 1200 instances and only the bins to the sides of the central one contain significant errors. On the other hand in Figure 7.29 there are more errors in more bins, gradually decreasing to both sides from the center (center with around 450 instances). 

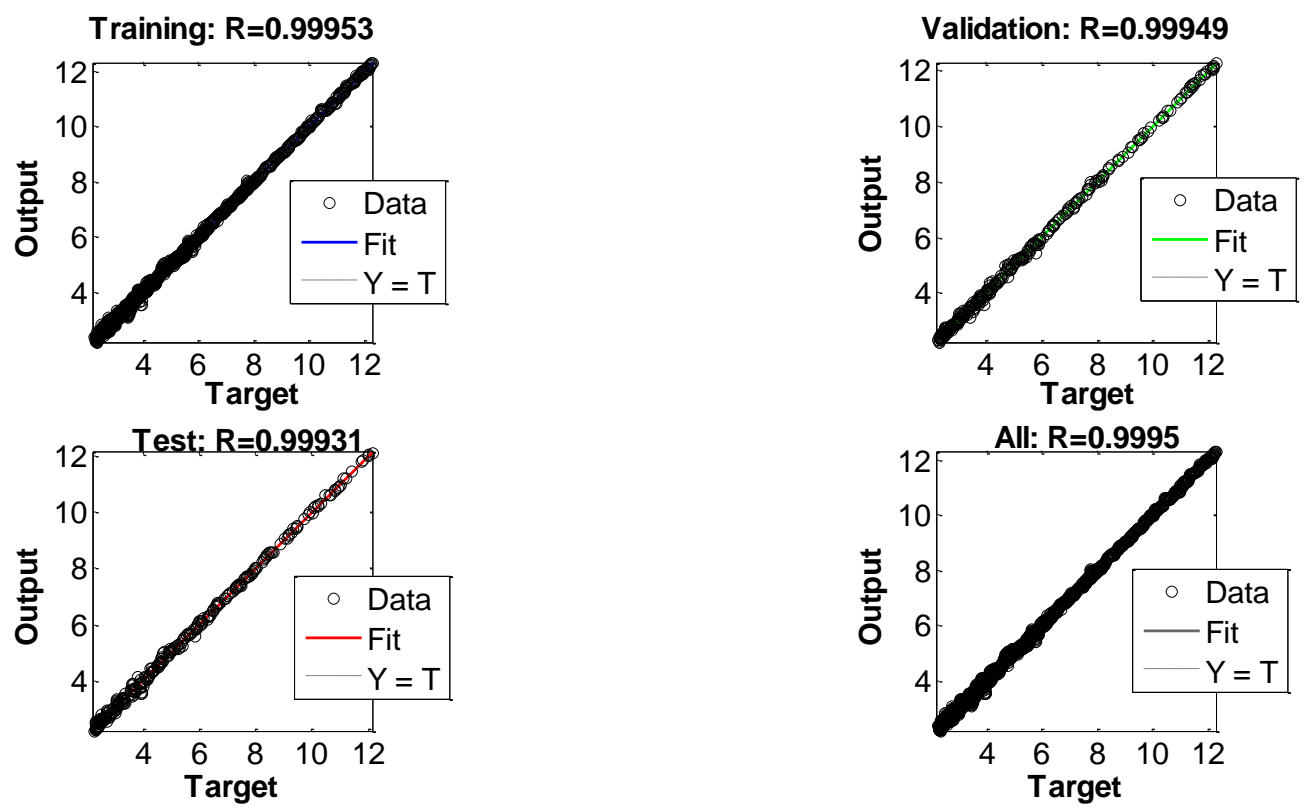

Figure 7.30. Plastic boxes regression curves

The regression plot shows the actual network outputs plotted in terms of the associated target values. Figure 7.30 represents the regression achieved in the first phase of the profile, training curve has an $R=0.99953$, closest $R$ to 1 despite the training has the biggest number of errors, as shown in Figure 7.29; due to it also has the biggest amount of data in comparison with test and validation, $70 \%$ in training versus $15 \%$ the other two. All the pieces together are able to obtain an $\mathrm{R}=0.9995$, very close to the unit. 


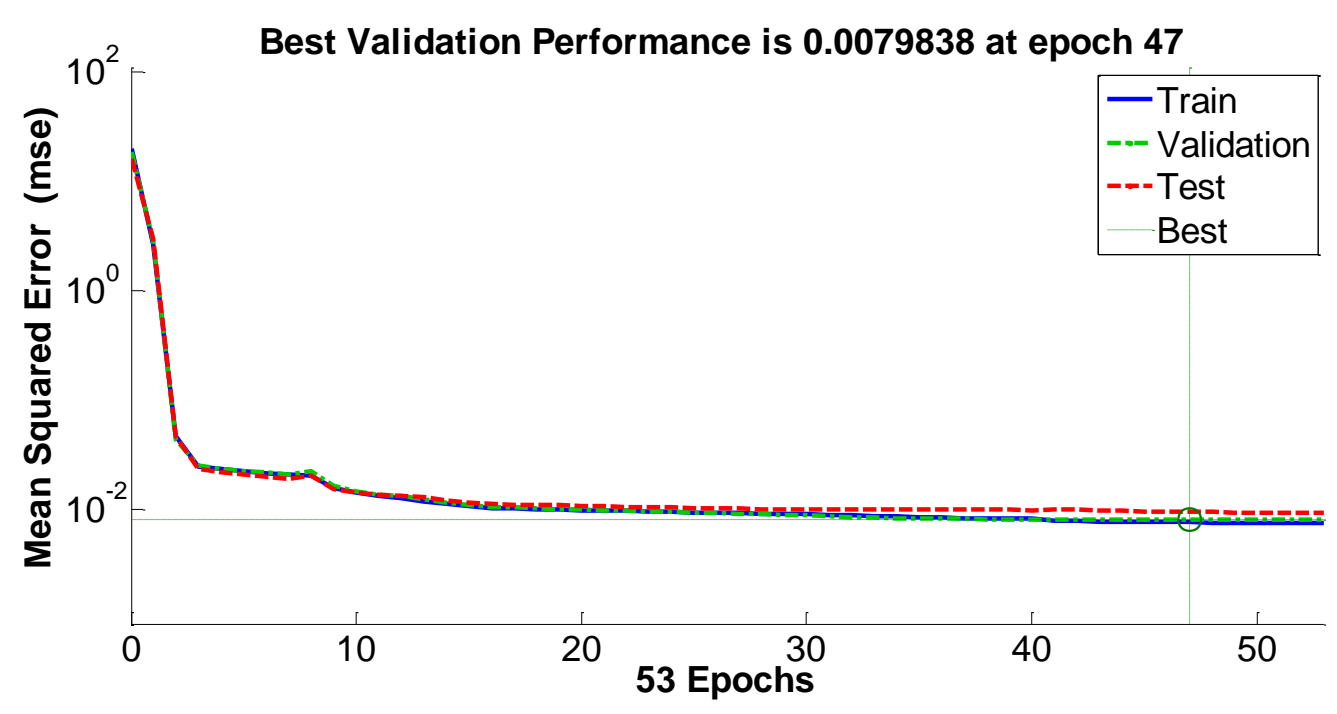

Figure 7.31. Best validation performance

The performance results are shown again in terms of RMSE in a logarithmic scale, and it decreased as the network was trained (Figure 7.31). In the case of plastic boxes 53 iterations were necessary to get the best approximation (RMSE of $0.088{ }^{\circ} \mathrm{C}$ ). At this point the validation does not reduce the error, then it is concluded that the network is optimized. All the parts seem to arrive at the cross point at the same iteration, but the training part appears to continue improving.

The temperature data (form the second part of the profile) were validated and tested using the NN previously trained (Figure 7.32). The RMSE between the estimation and the average of the real pallet data temperatures was $0.41{ }^{\circ} \mathrm{C}$; and comparing the thermal camera data showing the surface temperature, with the pallet curve, the RMSE was $2.14{ }^{\circ} \mathrm{C}$. The estimation fits very well the real data along the curve; the two lines get separated only at the end of the curve. 


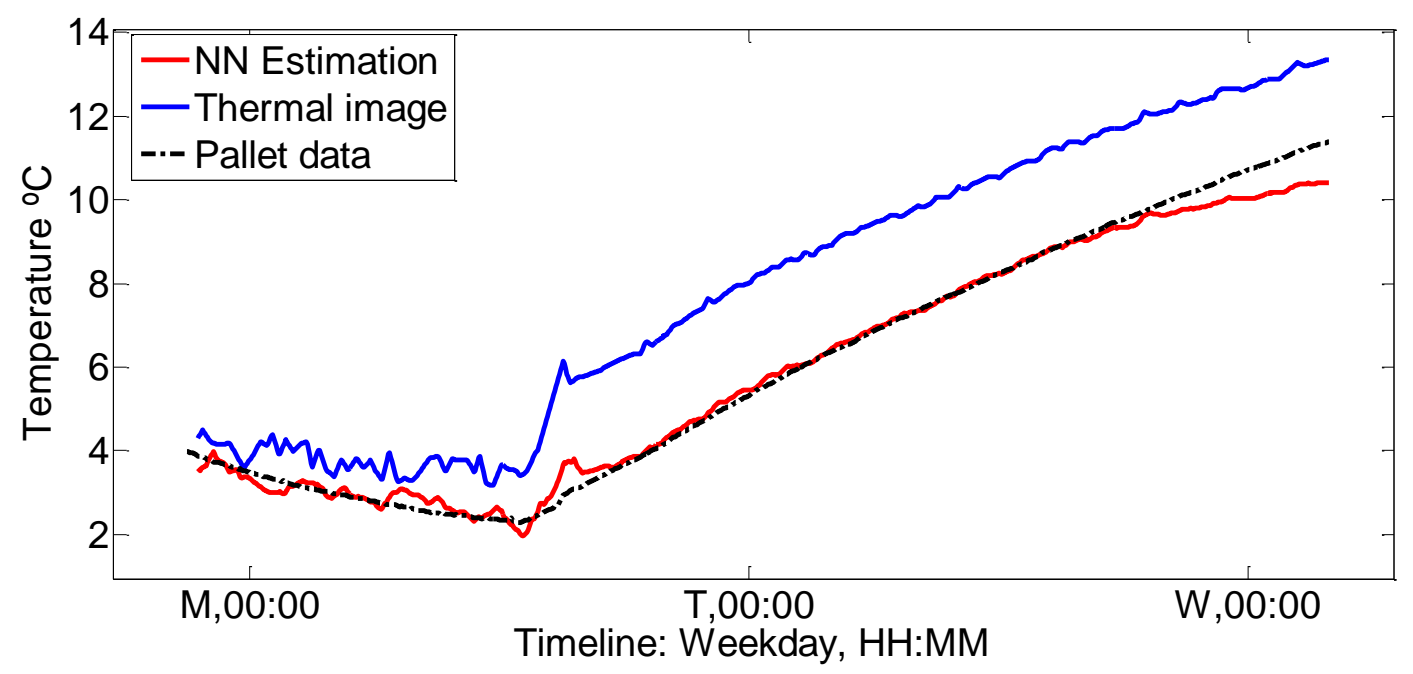

Figure 7.32. Temperature comparison profile between targets, estimation and source data

It is important to remark that in the present section, a realistic application of the time series ANN as a tool for the food industry is investigated, with the main purpose of enhancing the cold chain, cost saving and reducing waste. The results are based on the profit obtained by using these tools in a real industrial scenario, whereas on the other hand, there are other authors that focus on the neural network modeling and its structure, mainly for research purposes, e.g. N. Liu et al. (2014); M. Qi and Zhang (2008); Romeu et al. (2013), and comparing performance of different ANN or doing studies of deep learning techniques.

According to the results from other authors (do Nascimento Nunes et al., 2014), better estimations were obtained, those results only used the cold room temperature as a reference. In this case, the thermal image gave 3.56 ${ }^{\circ} \mathrm{C}$ of RMSE compared with the real temperature, and in the other cited article, the results obtained at room temperature gave an error of $3.38{ }^{\circ} \mathrm{C}$ RMSE with regards to real temperature (do Nascimento Nunes et al., 2014). In this case, the temperature prediction gave an error of $0.08{ }^{\circ} \mathrm{C}$ RMSE across all the errors, meantime do Nascimento Nunes et al. (2014) obtained $0.16{ }^{\circ} \mathrm{C}$ as an average error, with a temperature sensor as the input for the ANN. 
In the cooking industry, at product level, Ibarra et al. (2000) obtained an error of $1.07{ }^{\circ} \mathrm{C}$, similar results however it is important to highlight that it was a food application using temperature from thermal image as input for the ANN. Finally in papaya moisture prediction, Yousefi et al. (2013) had $0.007{ }^{\circ} \mathrm{C}$ as RMSE, and a correlation coefficient $\mathrm{R}^{2}=0.9994$, whilst in the present study an $R^{2}=0.9995$ was achieved for plastic boxes and $R^{2}=0.9828$ for cardboard boxes.

\subsubsection{Conclusions and future work}

A new temperature estimation procedure was evaluated in this section, it was performed with thermal image as the source and it was possible to successfully estimate the temperature across a pallet of real product (apples).

If only thermal imaging was used, only the temperature of the surface would be obtained. However by applying this estimation method, the temperature across the freight can be known with high levels of accuracy. Any error between the estimated temperature and the real temperature, that is below the error between the source temperature and the real temperature, is positive, taking into account that in this experiment the errors between sources and real temperature were between 4 and $12{ }^{\circ} \mathrm{C}$.

Future work will be undertaken to address multiple camera angles, or multiple cameras recording. In the case here presented, one camera was enough since the target was only one pallet, but with more difficult viewing angles, such as in a warehouse with corners and shelves, a multiple camera solution could prove useful to enhance accuracy. A next step should include an image recognition dimension with the supervision of a bigger surface, such a loading and unloading dock, either in a warehouse or in an outdoor area like in an airport. In addition it would be interesting to characterize specific products, it means to carry out similar experiments as the presented in this section, and achieve their characteristic Neural Networks and create a database for commercial purposes. In this way, in the future, it would only be necessary to consult the database to get the NN and have the direct estimation of the temperatures of an entire container. 
Also detached from these experiments, in the near future it is planned to perform tests that involve the influence of a pallet cover measured by thermal image. Since the achieved success on estimating the temperature using ANN, it is a natural way to continue the research line by using the thermal image with ANN for the temperature estimation in different scenarios, so it is possible to evaluate the viability of the proposed method for commercial purposes.

There were some issues using the thermal camera, such as the output represents a big amount of data, therefore it was necessary to change from a video sampling to an image capturing mode with a sample rate of 15 to 20 minutes, and despite that, the authors of the present work recommend the implementation of thermal imaging in certain places during the cold chain transportation or storage. This can also be an advantage since the information provided by the thermal camera can always give a real idea of what is happening in any moment with the surface temperature which is usually the most sensitive one. 


\subsection{Explorative study of using Infrared imaging for temperature measurement of pallet of fresh produce}

This section includes the theory, materials, methods and results followed and attained during a study for the validation of the surface temperature as a source for the evaluation of pallet temperature changes. Contents of this section have been submitted to Journal of Food Engineering, and it is currently under review.

\subsubsection{Introduction}

It is important to understand heat transfer when studying packaging for temperature protection. There are three types of heat transfer involved with passive thermal protection systems; conduction, convection and radiation (Peck et al., 2015). Each of them play an important role on how the heat is absorbed in the pallet load (pallet covered or not).

Defraeye et al. (2015a) presented a review about thermal performance of fresh produce packaging in the cold chain. The study of the influence of pallet covers is not well reported in literature, though Macnish et al. (2012) conducted some experiments studying the benefits of different cover systems over strawberry pallets. The predominant heat transfer mechanisms that affect the loads are radiation and convection. The cover acts as a barrier to these two types of mechanisms and also as barriers to humidity transfer between the external environment and the air trapped between the covers and the product.

This present study is investigating the possibility of using surface temperature readings from a thermal camera as a reference for the pallet temperature. Thermal imaging has already been proven to be a powerful tool when working with real product scenarios. Jha et al. (2011) discussed nondestructive quality evaluation methods for food, and demonstrate how the cooked level inside a chicken can be assessed using thermal imaging and Artificial Neural Network (ANN). Q. Chen et al. (2013) also demonstrated thermal imaging to be a 
technique for food safety and Castro-Giráldez et al. (2014) implemented thermal imaging as a temperature control for the meat freezing process.

However, when working with Infrared thermal imaging it is important to take into account the surface emissivity, which depends of the nature of the materials and its emitted radiation. Emitted radiation by the surface is what is measured by thermal imaging apparatus (Bulanon et al., 2008).

The fresh produce industry is currently using thermal imaging to measure temperature of fresh produce (Dupont, 2016), but there is no comparative study between temperatures measured traditionally by temperature probes and the temperatures measured by thermal imaging reported in the literature.

The main objective of this study is to evaluate the possibility of using surface temperature of a pallet of fresh produce measured by an infrared thermal camera as a valid method to assess temperature distribution. One of the subobjective is to compare different types of materials for pallet covers as well as different products in different temperature scenarios.

\subsubsection{Materials and methods}

An experimental programmable refrigerated cold room was used to simulate conditions encountered during produce distribution. The room is $2 \times 1.50 \times$ 1.50 meters made of polyurethane sandwich panel of $0.1 \mathrm{~m}$ thick. The refrigerated system is an internal evaporation with an external condensation unit of hermetic alternative compressor of $5 \mathrm{~kW}$ with R-134a as a refrigerant. Air speed inside the room is set at $2.5 \mathrm{~m} / \mathrm{s}$. The room temperature sensor is located on the wall of the door at $1.50 \mathrm{~m}$ above the floor.

Data loggers were utilized to measure the ambient parameters. U12-013 HOBO measured temperature (range of $-20{ }^{\circ} \mathrm{C}$ to $70{ }^{\circ} \mathrm{C}$ ) and $\mathrm{RH}(5 \%$ to 95\%). Each logger had two external ports where two temperature probes using thermistors (model TMC6-HD). With an accuracy of $\pm 0.25^{\circ} \mathrm{C}$. 
The thermal camera used was Flir brand, E6 model. Thermal image resolution was $160 \times 120$, with a thermal sensitivity of $<0.006{ }^{\circ} \mathrm{C}$, temperature range of $-20^{\circ}$ to $250^{\circ} \mathrm{C}$, and accuracy of $\pm 2 \%$ or $2^{\circ} \mathrm{C}$.

a)

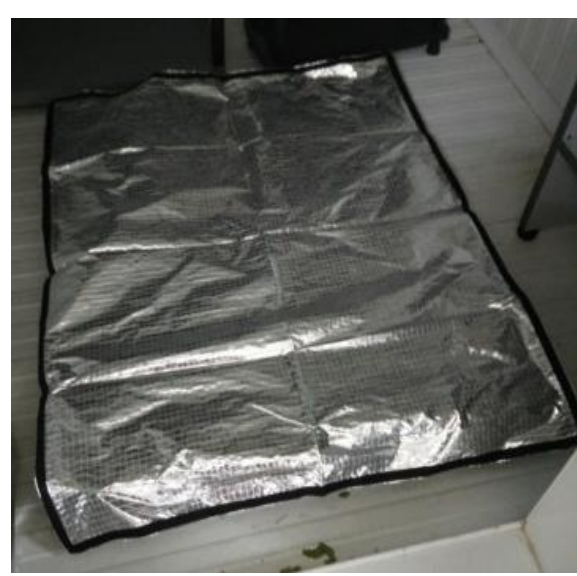

c)

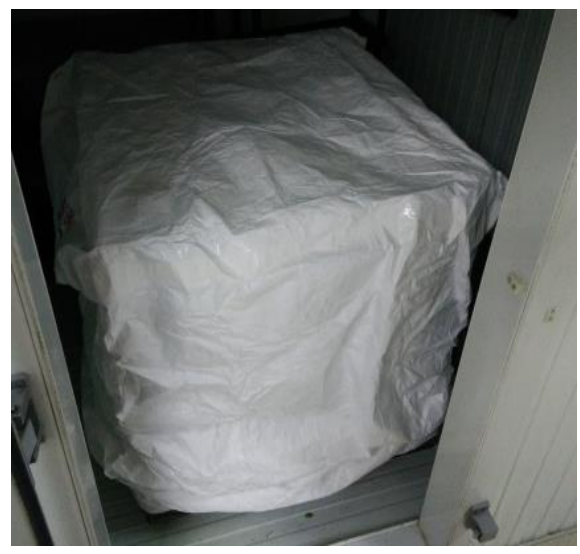

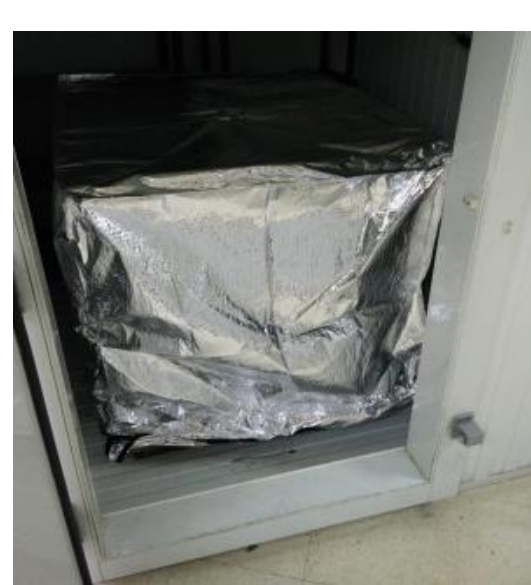

b)

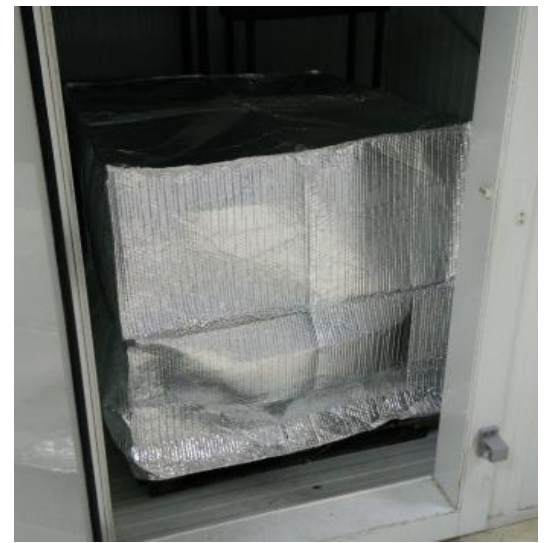

d)

Figure 7.33. Covers placed on pallets: a) Metallized PET cover base, b) Metalized PET cover, c) Tyvek $($, d) Metalized PET Bubbles

Three different types of pallet covers were used as coverage for the pallets (see Figure 7.33). The first was a DuPont ${ }^{\mathrm{TM}}$ Tyvek ${ }^{\circledR}$ Air Cargo Cover, breathable allowing $\mathrm{O} 2$ to permeate to support normal respiration of perishable products, while allowing harmful gases such as $\mathrm{CO} 2$ and ethylene to vent through the covers (which can help to prevent anaerobic respiration),

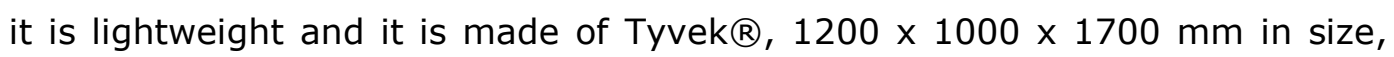
made by combining continuous fibres of high density polyethylene into a sheet through a process using heat and pressure. The product is $0.15 \mathrm{~mm}$ 
thick and white in colour(Dupont, 2010). The second cover manufactured by (C) C\&S Packaging Supplier, was made of Metalized PET and raffia $(0.14 \mathrm{~mm}$ thick), and was not breathable. The third also by (C) C\&S, was a cover composed of three layers, the inside and outside made of Metalized PET with the middle layer made of plastic bubbles ( $5 \mathrm{~mm}$ thick). The size of the last two covers was $1200 \times 1000 \times 1700 \mathrm{~mm}$. The pallet used was $1200 \times 1000$ $\mathrm{mm}$ in size and the plastic grid boxes were $500 \times 380 \times 280 \mathrm{~mm}$, nine boxes per layer in three layers.

The products used were fresh vegetables, and in all cases the experiment did not start more than 24 hours after harvest. Products included $400 \mathrm{~kg}$ of chard for the first experiment and $400 \mathrm{~kg}$ of cucumbers for the second.

The optimum storage conditions for these products are presented in Table 7.8. As can be seen, both products can be stored for same period of time since they have similar water content, however cucumber must be stored and transported at higher temperature than chard.

Table 7.8. Storage conditions for vegetables. (Maynard and Hochmuth, 2007)

\begin{tabular}{cccc}
\hline \multicolumn{4}{c}{ Storage conditions } \\
\hline Vegetable & Temperature $\left({ }^{\circ} \mathbf{C}\right)$ & RH $(\%)$ & Storage life \\
\hline Chard & 0 & $95-100$ & $10-14$ days \\
Cucumber & $10-12.78$ & 95 & $10-14$ days \\
\hline
\end{tabular}

\section{Methods}

A thermal imaging camera records the intensity of radiation in the infrared part of the electromagnetic spectrum and converts it to a visible image, which allows temperature values to be read from the image (FLIR, 2015).

In order to interpret thermal images correctly, it is required to know how different materials and conditions influence the temperature readings from the thermal imaging camera. Emissivity, defined as the ratio of energy emitted from an object to that of a black body at the same temperature, can vary from 0 (perfect white body) to 1 (perfect black body) (Gowen et al., 2010). 
If the body that emits radiation has emissivity 1 (the radiation of the target is $100 \%$ emitted from the target surface), and the camera is set to capture emissivity 1 , the apparent temperature will be equal to the actual temperature, however if the body has emissivity lower than 1 , and the camera is configured for higher emissivity, the camera is capturing emissivity, transmission and reflection, and taking this last one as the actual temperature. Hence it is needed to reduce the reflectance of the body and thus improve the measurement accuracy, as well as reduce the emissivity set in the camera to make it equal to the body emissivity. The measured temperatures at the surface of the covers used in this study are resulting from a combination of emitted, transmitted and reflected radiation. So it is important to set the right emissivity value in the FLIR E6 camera during the tests

In our case, aluminum foil has an emissivity of 0.04 to 0.09 ; this material is the most similar to the used in the surface of two of the covers, Metalized PET and Metalized PET and bubbles. White paper emissivity of 0.7 to 0.9 , can be used for the Tyvek ${ }^{\circledR}$ cover (FLIR, 2013).
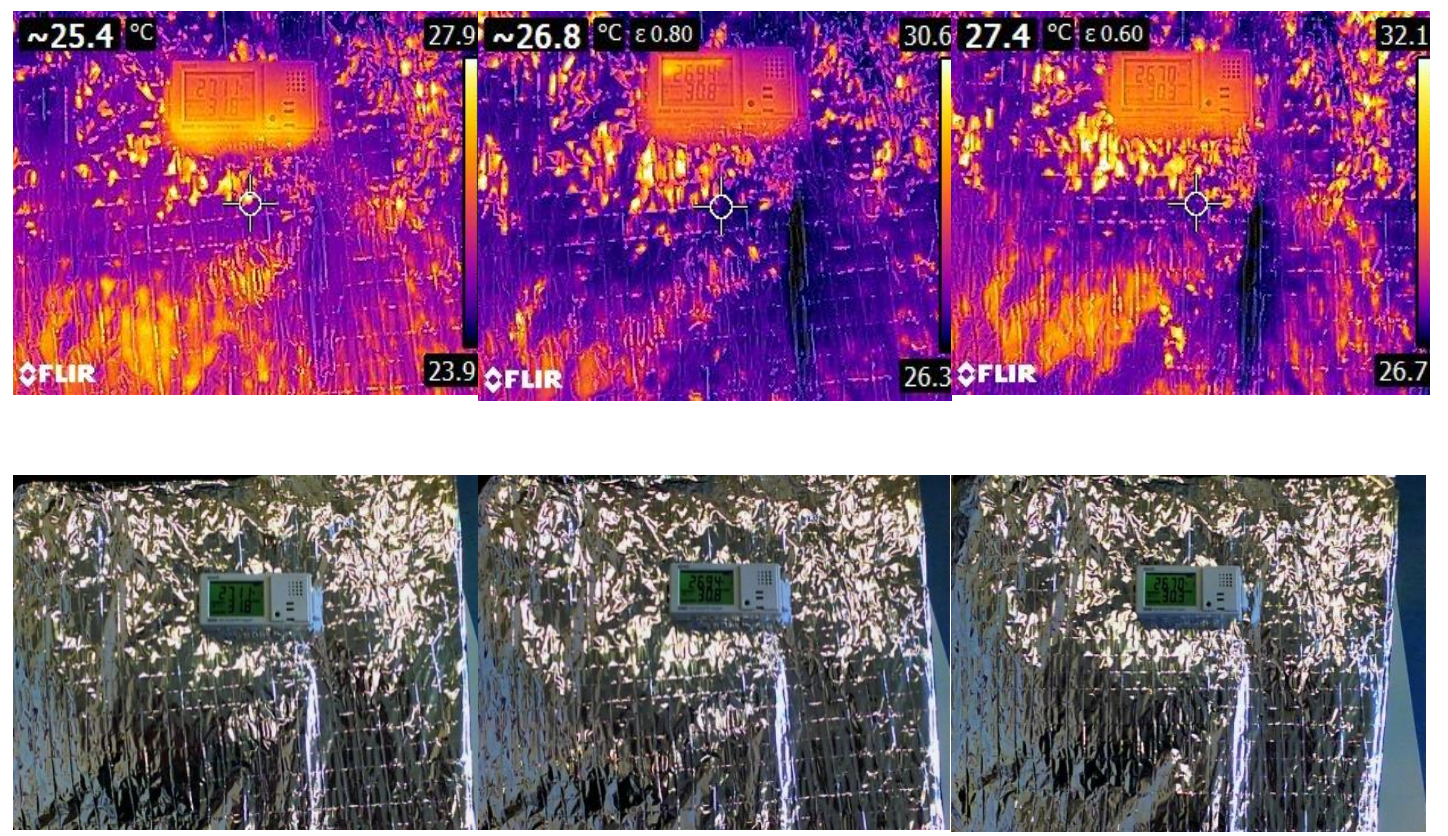

Figure 7.34. Setting three different emissivity in Metalized PET cover (from left to right emissivity is E 95, E 80, E 60) 
Materials with emissivity below 0.7 are difficult to measure, materials with emissivity below 0.2 are almost impossible to measure, without increasing the emissivity value in some way such as adding a material with high emissivity to the surface point where temperature is measured. In this case metallized surface from two of the three covers presents a problem when reading the temperature since it has emissivity lower than 0.2 .

A preliminary test was done in order to study the effects of the emissivity on temperature reading. First the camera was set to emissivity of 0.04 to 0.09 , as recommended by the camera manufacturer but because of this low emissivity no temperature read was possible.

Emissivity was set with values of $0.95,0.8$ and 0.6 . The camera gave a value similar to the real temperature which is shown in Figure 7.34. It can be seen values of $27.11^{\circ} \mathrm{C}, 26.44{ }^{\circ} \mathrm{C}$ and $26.7^{\circ} \mathrm{C}$. The temperature points $\left(25.4{ }^{\circ} \mathrm{C}\right.$, $26.8^{\circ} \mathrm{C}$ and $\left.27.4{ }^{\circ} \mathrm{C}\right)$ are near the real temperature $\left(27.11^{\circ} \mathrm{C}, 26.44{ }^{\circ} \mathrm{C}\right.$ and $26.7^{\circ} \mathrm{C}$ ), but the lower the emissivity, the wider the temperature range, and the higher the maximum temperature.

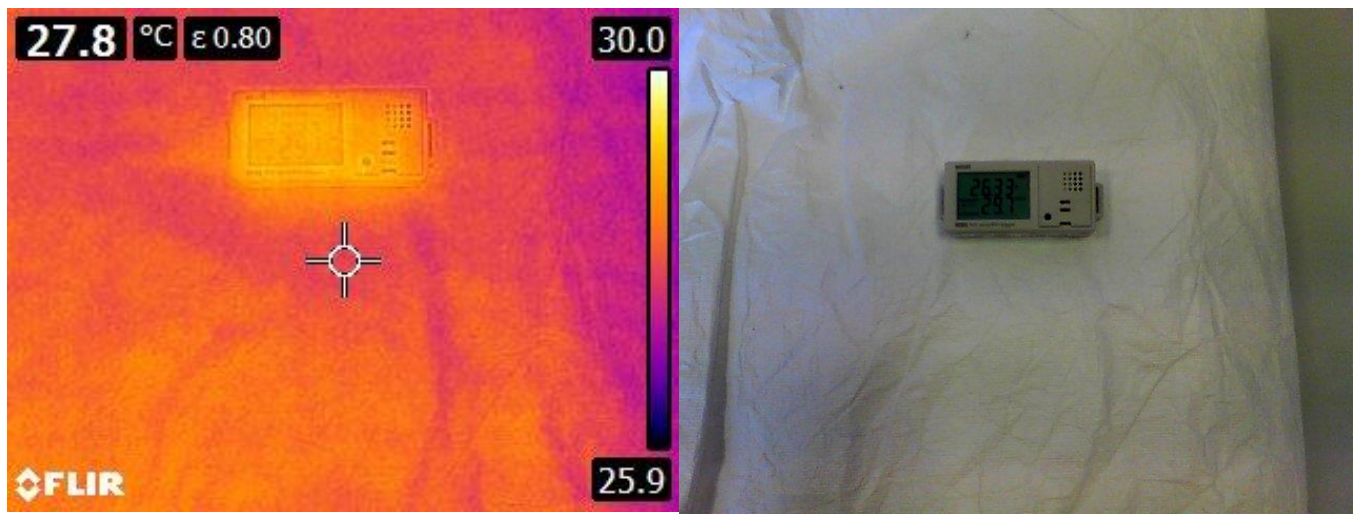

Figure 7.35. Tyvek ${ }^{\circledR}$ thermal picture with emissivity 0.8

Tyvek $\AA$ cover did not show this extreme variability when reading the temperatures due to its higher emissivity. Figure 7.35 does not show high variability in temperature range on the surface of the cover, the sensor is at $26.33{ }^{\circ} \mathrm{C}$ and the camera is showing temperatures in the cover surface from 25.9 to $28{ }^{\circ} \mathrm{C}$. 
When a black tape (with high emissivity) is attached to the Metalized PET cover (Figure 7.36), the temperature measured does not present the characteristic variability from the Metalized PET surface; the temperature is more homogeneous and more approached to the real temperature. However if the black tape is exposed to direct sun light, it will get hotter than the temperature from the surface and inside the pallet, therefore it won't be valid for certain scenarios where the pallet remains under the direct sun light.

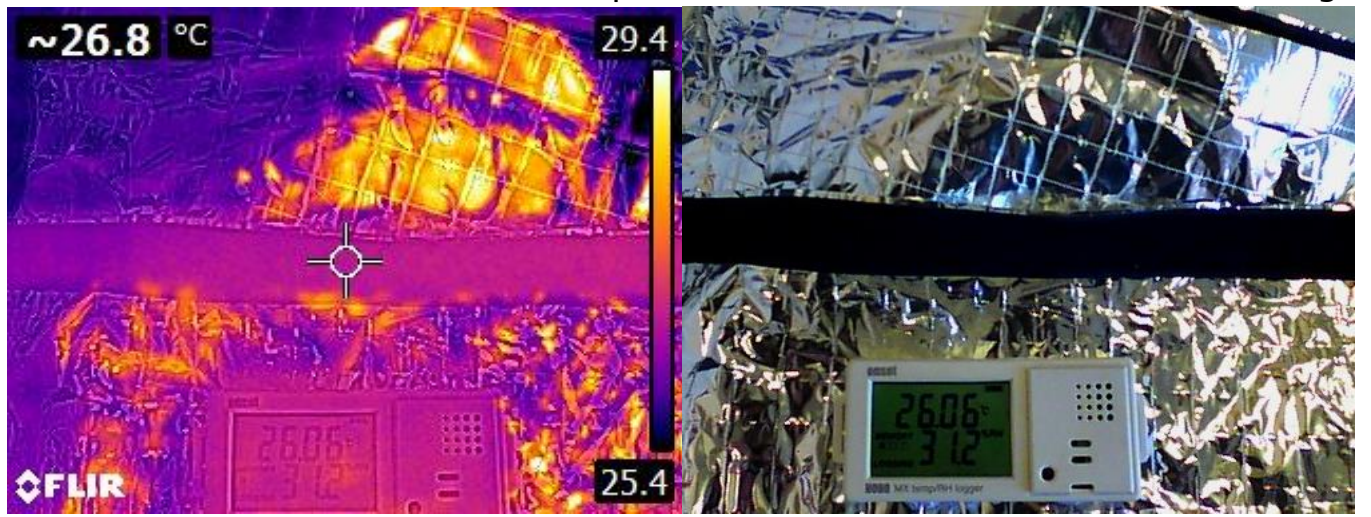

Figure 7.36. Black tape attached to the Metalized PET cover

\section{Experiment settings}

The following experiments settings were performed three times with each product, six times in total at different times. Each product was distributed into 18 boxes; about 15 kilos per box for chard and 20 kilos for cucumbers. The pallet was built in three layers, with a data logger installed inside the boxes, in the center of each layer, and two probes installed as well inside the boxes, at the end of a cable in opposite boxes in diagonal, as shown in Figure 7.37. In total 9 temperature sensors were conforming a diagonal mesh of sensors in the pallet. The sensors were set to record temperature every 5 minutes. The position of the sensors is covering the three layers of the pallet and one diagonal, which represents the maximum, minimum and average temperatures among the pallet, as observed in previous studies (Badia-Melis et al., 2013; Badia-Melis et al., 2016; do Nascimento Nunes et al., 2014). 


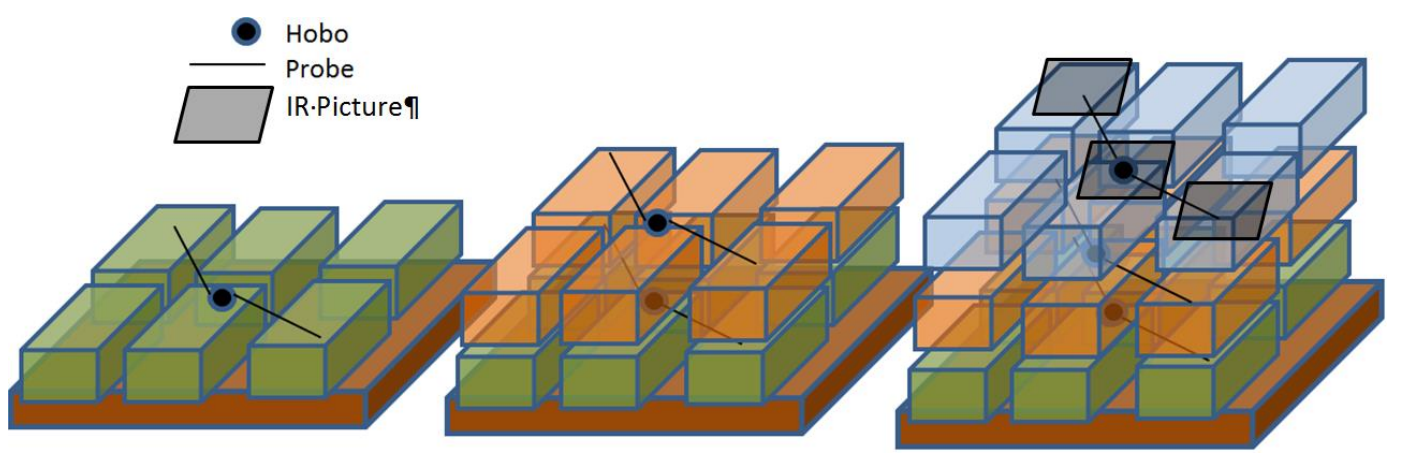

Figure 7.37. Sensor distribution in the pallet

The sensors in the upper layer are used for comparison with the data from the thermal camera. The pallet was covered with one of the types of covers. Three pictures from the surface on top of the pallet were taken using the thermal camera, one picture from the top right corner, one in the middle and one in the left down corner as indicated in Figure 7.37, on top of the pallet representation there are represented the three pictures taken, one in the upper left part of the image, other in the middle and other at the right down.

The product was at room temperature $\left(23^{\circ} \mathrm{C}\right)$ and the cold room was set to cool down to a temperature of $4{ }^{\circ} \mathrm{C}$. After 24 hours, the refrigerating unit was switched off and the temperature increased until reach the ambient temperature $\left(23^{\circ} \mathrm{C}\right)$, and the surface of the pallet was recorded with pictures from the thermal camera and the corresponding temperature data that was registered in the image, those pictures were taken in the same points as in the beginning.

The temperature ramp was replicated in eight six times, with two different real fresh vegetables.

Data were analysed with ad hoc software developed in Matlab. Thermal pictures record the maximum and minimum temperatures that appear in the image, as well as the temperature from the selected point in the camera screen. All of these temperatures were compared with the surface temperatures from the temperature sensors as it is showed in the results section. 


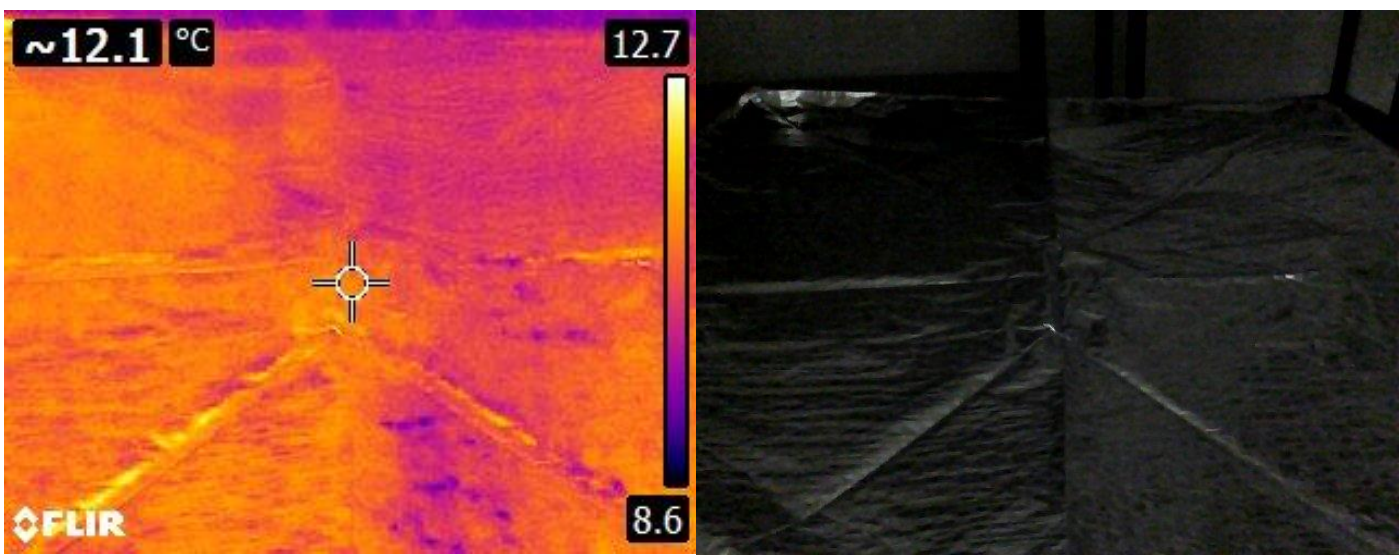

Figure 7.38. Thermal image and picture from middle point of the Metalized PET cover

The temperature shown in the thermal picture is the value taken in the middle of the picture. It was this value that was compared with the sensor temperature (Figure 7.38). The maximum and minimum temperatures can be found from the temperatures legend bar at the right of the image (Figure 7.38)

\subsubsection{Results}

The presented results are separated by product. The same figures and tables are shown for all the products.

\section{Chard}

Table 7.9 shows the temperatures recorded with the thermal camera from the surface of the pallet, divided by product and the location on top of the pallet (the meaning from the different abbreviations in the Table 7.9 are as follows, $\mathrm{RD}=$ Right Down, $\mathrm{LU}=$ Left UP, $M=$ Middle). The three covers were used at different times. The first 3 lines of data correspond to the beginning of the temperature curve, which was at low temperature, with temperature set point in the cold room at $4{ }^{\circ} \mathrm{C}$; the last 3 lines correspond to the end of the curve, when the pallet was exposed to ambient temperature $23^{\circ} \mathrm{C}$. 
Table 7.9. Max, $\min$ and point temperatures $\left({ }^{\circ} \mathrm{C}\right)$ measured with thermal camera and temperature sensors.

\begin{tabular}{|c|c|c|c|c|c|c|c|c|c|c|c|c|}
\hline & \multicolumn{4}{|c|}{ Tyvek $®$ in chard } & \multicolumn{4}{|c|}{ Metalized PET in chard } & \multicolumn{4}{|c|}{ Metalized PET Bubbles in chard } \\
\hline & \multicolumn{3}{|c|}{ Camera } & \multirow[b]{2}{*}{ Sensors } & \multicolumn{3}{|c|}{ Camera } & \multirow[b]{2}{*}{ Sensors } & \multicolumn{3}{|c|}{ Camera } & \multirow[b]{2}{*}{ Sensors } \\
\hline & Point & Max & Min & & Point & Max & Min & & Point & Max & Min & \\
\hline \multicolumn{13}{|c|}{ Start } \\
\hline LU & 5.4 & 6 & 1.9 & 4.5 & 4.4 & 5.8 & 1.7 & 4.4 & 4.6 & 5.5 & 1.4 & 4.4 \\
\hline RD & 8.1 & 7.8 & 2.9 & 5.2 & 5.8 & 9.4 & 2.5 & 6.5 & 8 & 12.9 & 3.8 & 4.9 \\
\hline $\mathbf{M}$ & 7.6 & 8 & 3.2 & 7 & 6.7 & 9.8 & 2.6 & 6.4 & 6.4 & 7.7 & 3.6 & 5.3 \\
\hline \multicolumn{13}{|l|}{ End } \\
\hline LU & 21.4 & 22.6 & 18.5 & 19.2 & 21.2 & 22.7 & 18.6 & 18.7 & 22.1 & 23.7 & 19.6 & 18.9 \\
\hline RD & 20.6 & 21.8 & 17.7 & 18.2 & 21.4 & 23.2 & 19.2 & 17.2 & 22.7 & 24.9 & 20.9 & 16.2 \\
\hline $\mathbf{M}$ & 20.6 & 22.1 & 18 & 18.1 & 21.6 & 23.2 & 19.2 & 17.3 & 21.7 & 23.3 & 19.3 & 16.9 \\
\hline
\end{tabular}

The most important camera values are the ones measured at the same point as the sensor temperatures. The maximum and minimum points are used to provide a reference to show the variability in the measurements.

As found in Table 7.9, the distribution of sensors temperatures in Tyvek $\mathbb{R}$ cover (from 4.5 to $7{ }^{\circ} \mathrm{C}$ ) are all within the temperature range provided by camera temperatures (from 1.9 to $8.1^{\circ} \mathrm{C}$ ). Same thing happen with the other two covers, but in Tyvek $\AA$, all the temperature data are grouped closer than with Metalized PET (1.7 to $9.8{ }^{\circ} \mathrm{C}$ ) and Metalized PET with bubbles (1.4 to $12.9^{\circ} \mathrm{C}$ ) covers.

At the end of the test the camera measurements are mostly above the temperature measured by the sensors ( $81 \%$ of the cases). It is especially the case for the Metalized PET bubbles and Metalized PET covers. Only the minimum temperatures measured on the Tyvek ${ }^{\circledR}$ cover are below the temperature obtained by the sensors. 
Table 7.10. RMSE between the thermal image temperature and sensor temperature.

Chard

\begin{tabular}{cccc}
\hline Chard & Tyvek® & Metalized PET & Metalized PET Bubbles \\
\hline $\begin{array}{c}\text { Mean Error }\left({ }^{\circ} \mathbf{C}\right) \\
\text { Maximum Error }\end{array}$ & 1.9 & 2 & 3.1 \\
$\left({ }^{\circ} \mathbf{C}\right)$ & 14.1 & 12.2 & 16 \\
Minimum Error $\left({ }^{\circ} \mathbf{C}\right)$ & 1.6 & 0.2 & 0.1 \\
\hline
\end{tabular}

In all tests the left up corner sensor temperature was the highest from the high end temperatures (last three lines in Table 7.9), and also the lowest temperature in start temperatures (first three lines in Table 7.9).

In Table 7.10 there are showed the maximum, minimum and average errors between the thermal image temperatures and the sensor temperatures. The maximum error corresponds to the Metalized PET bubbles cover with $16{ }^{\circ} \mathrm{C}$, and the minimum is found also in the Metalized PET bubbles cover with $0.1{ }^{\circ} \mathrm{C}$ of difference. However the lowest mean error is found for Tyvek $\circledR$ cover (1.9 $\left.{ }^{\circ} \mathrm{C}\right)$.

\section{Cucumbers}

In Table 7.11 are showed the different temperature measurements from the thermal camera and the sensors for the tests with cucumbers (the meaning of the different abbreviations in Table 7.11 are as follows, $\mathrm{RD}=$ Right Down, $\mathrm{LU}=$ Left UP, $M=$ Middle). The three experiments with different covers were performed at different times. Results are presented like in Table 7.9.

In Tyvek ${ }^{\circ}$ and Metalized PET the low temperatures measured by the sensors are always higher than the temperatures measured with the camera in selected points, not taking into account the maximum and minimum. 
Table 7.11. Max, $\min$ and point Temperatures $\left({ }^{\circ} \mathrm{C}\right)$ registered with thermal camera and sensor temperatures.

\begin{tabular}{|c|c|c|c|c|c|c|c|c|c|c|c|c|}
\hline & \multicolumn{4}{|c|}{ Tyvek $®$ in cucumber } & \multicolumn{4}{|c|}{ Metalized PET in cucumber } & \multicolumn{4}{|c|}{$\begin{array}{c}\text { Metalized PET Bubbles in } \\
\text { cucumber }\end{array}$} \\
\hline & \multicolumn{3}{|c|}{ Camera } & \multirow[b]{2}{*}{ Sensors } & \multicolumn{3}{|c|}{ Camera } & \multirow[b]{2}{*}{ Sensors } & \multicolumn{3}{|c|}{ Camera } & \multirow[b]{2}{*}{ Sensors } \\
\hline & Point & Max & Min & & Point & Max & Min & & Point & Max & Min & \\
\hline \multicolumn{13}{|l|}{ Start } \\
\hline LU & 5.4 & 5.1 & 1 & 8 & 2.8 & 4.1 & 0 & 4.2 & 4.2 & 5.7 & 1.6 & 4.2 \\
\hline RD & 6.6 & 7.3 & 2.3 & 9.2 & 3.7 & 8.4 & 0.7 & 6.2 & 6.7 & 14.8 & 3.2 & 5.6 \\
\hline $\mathbf{M}$ & 6.4 & 6.3 & 1.6 & 9.8 & 3.5 & 4.4 & 0.3 & 6 & 7.8 & 9 & 3.1 & 6.1 \\
\hline \multicolumn{13}{|l|}{ End } \\
\hline LU & 20.6 & 21.9 & 17.8 & 16.8 & 19.9 & 21.6 & 17.1 & 14.1 & 22.4 & 23.2 & 19.2 & 13.9 \\
\hline RD & 20.9 & 21.6 & 17.5 & 13.6 & 21.6 & 21.7 & 17.2 & 12 & 22.6 & 23 & 19 & 10 \\
\hline M & 21.1 & 22.4 & 18.3 & 14.8 & 19.8 & 21.4 & 17.3 & 14.6 & 23 & 23.9 & 19.8 & 10.9 \\
\hline
\end{tabular}

In the case of Metalized PET bubbles cover, the sensor temperatures are more aligned with the point temperatures from thermal camera. However, when looking at high temperatures, in all cases the sensor temperatures are lower than thermal image.

Similar results were observed during the chard tests as the majority of the measurements from the camera in high temperatures in both products (chard and cucumbers) are above the measurements from the sensors. However there is an apparent trend in low temperatures where the camera temperatures are lower than the sensor temperatures. The Metalized PET bubbles cover for both vegetables did not show such consistency with only $61 \%$ of the camera measurements are above the sensors measurements.

And again as well as observed in chard, the left up (LU) sensor temperatures are in the three covers experiments, always the lowest temperatures among the low temperatures(first three lines in Table 7.11). 
Table 7.12. RMSE between the thermal image temperature and sensor temperature.

\section{Cucumber.}

\begin{tabular}{cccc}
\hline Cucumber & Tyvek® & Metalized PET & $\begin{array}{c}\text { Metalized PET } \\
\text { Bubbles }\end{array}$ \\
\hline $\begin{array}{c}\text { Mean Error }\left({ }^{\circ} \mathbf{C}\right) \\
\text { Maximum Error } \\
\left({ }^{\circ} \mathbf{C}\right)\end{array}$ & 3.9 & 4.5 & 6 \\
Minimum Error $\left({ }^{\circ} \mathbf{C}\right)$ & 1.23 & 17.5 & 21.8 \\
\hline
\end{tabular}

The differences between the two types of temperature measurements are shown in Table 7.12. The maximum difference occurred when using the Metalized PET bubbles cover with an RMSE of $21.8^{\circ} \mathrm{C}$; this cover also had the second lowest error, with $0.3^{\circ} \mathrm{C}$, with the lowest error being the Metalized PET cover $\left(0.1^{\circ} \mathrm{C}\right)$. The biggest difference between errors is in the maximum line, $4.3^{\circ} \mathrm{C}$ of difference, when comparing the Metalized PET maximum and the Metalized PET bubbles maximum. However the lowest mean error is again, as in Table 7.10, the one from Tyvek ${ }^{\circledR}$ with $3.9^{\circ} \mathrm{C}$.

Figure 7.39 shows the comparison of the thermal camera temperatures taken in the three selected points, the two diagonal corners and the center of the surface of the pallet (Figure 7.37), which match the exact locations of the physical sensors. The points are divided in 2 regions that correspond to the beginning of the temperature curve with low temperatures around $4-6{ }^{\circ} \mathrm{C}$, and high temperatures around $20-23{ }^{\circ} \mathrm{C}$, which was ambient temperature.

The points in the low temperature region are more spread than in the high region in general. When analyzing the dispersion of points it shows that Tyvek ${ }^{\circ}$ cover has a lower dispersion than the other two covers, this is no more than $2.5^{\circ} \mathrm{C}$ of separation in low temperatures, and barely $1{ }^{\circ} \mathrm{C}$ in high 
temperatures.

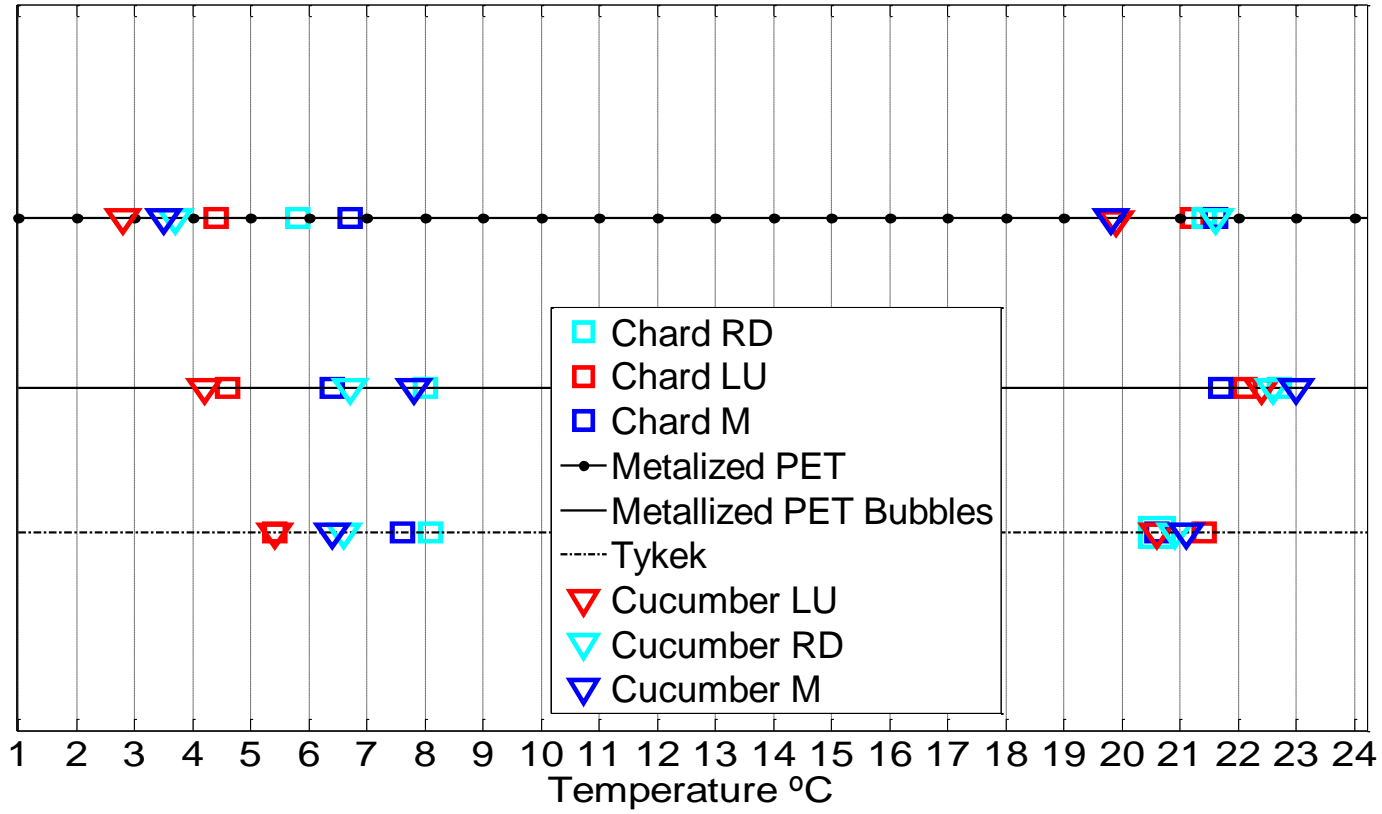

Figure 7.39. Comparison of thermal camera temperatures in measured points. $R D=$ Right Down, LU= Left UP, $M=$ Middle

The data from the Metalized PET bubbles cover has a symmetric dispersion in low temperatures between cucumbers and chard, but with a separation of 4 ${ }^{\circ} \mathrm{C}$ between maximum and minimum, however in the other section the points are grouped within $1.5{ }^{\circ} \mathrm{C}$ interval, with no apparent order between the two products.

The Metalized PET cover has also $4{ }^{\circ} \mathrm{C}$ of separation between all the points in low temperatures; cucumber data points are separated from chard points unlike the data with Metalized PET bubbles cover. In the region of high temperatures, the dispersion of the points is almost $2{ }^{\circ} \mathrm{C}$.

If the data are analyzed by product instead by cover, the biggest gap between points occurs in cucumbers with the Metalized PET bubbles cover, in the region of $4-8{ }^{\circ} \mathrm{C}$, with almost $4{ }^{\circ} \mathrm{C}$ of separation; it is followed by the chards in the same area but this time $3.5{ }^{\circ} \mathrm{C}$ of separation. 
There is a trend of temperatures taken at the top left (LU) of the surface of the pallet, (red points on the graph); they present temperatures below the rest of those taken in other areas of the surface of the pallet.

Finally, the cover isolation was analyzed measuring the temperature increments in the middle of the pallet from the start temperature at $4{ }^{\circ} \mathrm{C}$ during 300 minutes. When using chard, Tyvek ${ }^{\circledR}$ cover increased $8{ }^{\circ} \mathrm{C}$, Metalized PET $7{ }^{\circ} \mathrm{C}$ and Metalized PET bubbles $5{ }^{\circ} \mathrm{C}$, and when using cucumbers, the temperature increments were $5{ }^{\circ} \mathrm{C}, 5{ }^{\circ} \mathrm{C}$ and $3{ }^{\circ} \mathrm{C}$ respectively in Tyvek ${ }^{\circledR}$, Metalized PET and Metalized PET bubbles.

\subsubsection{Discussion}

As pointed in the literature (Estrada-Flores \& Eddy, 2006, 2007) the emissivity of the surfaces may cause difficulties during the interpretation of the thermograms; a reflected image appears when there is a radiation source that directly impacts the surface of the covered pallet and can create a "false positive". It was the main difficulty encountered during this study.

The average errors, between sensor temperature and thermal image ranged from 1.9 to $6{ }^{\circ} \mathrm{C}$. These discrepancies demonstrate well that cover surface temperatures are not good indicators of what is happening under the cover and even less in the middle of the pallet. As reported by Estrada-Flores and Eddy (2006, 2007); FLIR (2013, 2015); Gowen et al. (2010), the very low emissivity of the Metalized PET produces random values with the thermal camera readings. This explains the average errors observed between the measured temperatures by the thermal camera and the sensors which ranged from $3.1{ }^{\circ} \mathrm{C}$ to $6{ }^{\circ} \mathrm{C}$ in Metalized PET bubbles for chard and cucumbers respectively.

As shown in Figure 7.39 data points are more spread at lower temperatures than at higher. It is caused by the low emissivity from Metalized PET used as external layer for two of the covers. However higher grouping of points occurs with the Tyvek ${ }^{\circledR}$ cover due to its higher emissivity (in high and low temperatures). Even when the emissivity on the thermal camera is set at 
0.95, the temperature readings are difficult to measure with Metalized PET materials even when using consistently the same location on the cover. A temperature difference of $4{ }^{\circ} \mathrm{C}$ was observed even though the measurement was made at the same location $\pm 10 \mathrm{~mm}$. Changing the emissivity did not affect to the measured temperature, however it affected the temperature range captured by the camera (maximum and minimum). Gowen et al. (2010) reported cases with high emissivity coatings where the emissivity needed to be corrected on the thermal camera as well as the positioning of the reading point.

According with the results on the present study, the thermal image measurements are not reliable because of the different emissivity found on each cover surface. Another source of reading errors can be caused by the fact that the cover made with Metalized PET with bubbles also acts as thermal barrier compared to the Tyvek $\AA$ and single layer of metallized PET that do not create the thermal barrier which contribute to lower errors. As showed in the results, the slowest temperature change occurs using the Metalized PET bubble cover, increasing $3{ }^{\circ} \mathrm{C}$ in 5 hours.

Results shown that there was no difference between the two products used during this study. Even though the chard and the cucumber have different packing densities both products experienced the same variability in surface temperature measured by the thermal camera and the sensors.

Due to the problem encountered with the surface emissivity, it is recommend to include an area made of a material that has a high emissivity and low solar radiation absorption (like a patch). This way the measurements from the thermal camera would be closer of the real surface temperature.

\subsubsection{Conclusions}

The main conclusion is that we cannot use thermal camera to read the temperature of a pallet when using pallet covers, this methodology must be revised and improved before taken as valid. It is no easy topic to evaluate, since it is needed to study the many factors involved that play an important 
role, such as the emissivity settings in the camera adjusted to the object emissivity, the material of the cover in case the pallet is covered, the type of product and the density of the load, the condensation inside the cover and the evaporation. Tyvek $\AA$ is the only cover that presents transpiration and so evaporation and it can cause certain cooling effect in the surface.

Pallet covers offered different temperature protection levels. Metalized PET bubbles cover gave the best thermal protection. Tyvek $\AA$ cover offered the lowest temperature protection since it is usually used to protect against direct sun exposure.

More research is needed to study the interaction between emissivity and thermal image readings as well as the effects of sun exposure on different cover materials. 


\subsection{Evaluation of pallet covers performance for produce protection in cold chain logistics}

This section includes the theory, materials, methods and results followed and attained during a study for the evaluation of the usefulness of different covers for protecting the perishable products in cold chain logistics. Contents of this section have been submitted to the journal of LWT Food science and technology, and it is currently under review.

\subsubsection{Introduction}

Most of the new advancements in cold chain are applicable in developed countries, but there are many countries where the resources are extremely limited, and access to technology is not a common fact. In these cases there must be some alternatives to maintain the cold chain. Precooling and storage are very important part of the cold chain (Kumar et al., 2008; Norton et al., 2013), nonetheless, not too much attention is paid in the transport (James et al., 2006), if it is taken into account that the fresh produce suffer transport distances above several thousand kilometers (Jedermann et al., 2011a; Jedermann et al., 2011b). There is room for improvement and optimization in new protocols during the transportation (Defraeye et al., 2015b).

Packaging effects in cold chain preservation have already been studied; with different package designs for citrus fruit (Defraeye et al., 2013) or with different cooling techniques such as ventilation rates for grapes ( $\mathrm{Ngcobo}$ et al., 2013). The study of the influence of pallet covers is not widely referenced in literature, though Macnish et al. (2012) conducted some experiments studying the benefits of different cover systems (CO 2 West, PEAKfresh, PrimePro, Tectrol) over strawberry pallets. Pelletier et al. (2011) carried out different temperature profiles and cooling procedures using commercial covers, and evaluating visual quality and weight loss as performance indicators for the different methods.

Presumably, the predominant heat transfer mechanisms that affect the loads are radiation and convection. The covers thus act as barriers to these two 
types of mechanisms and also as barriers to humidity transfer between the external environment and the air trapped between the covers and the product.

Different types of covers are evaluated in the present study, and the different performance they offer regarding different products. The main objectives in our study are to determine the suitability, and compare the performance of the covers in real critical situations, such as could be exposure to temperatures out of range. It is expected to find empirical data that demonstrate lower heating rates compared with no coverage.

\subsubsection{Materials and methods}

An experimental refrigerated cold room, with programmable temperatures was used for doing the experiments. It simulates a refrigerated truck. It has a polyurethane sandwich panel as isolation material; the measures are $2 \times 1.50$ $x 1.50$ meters, the refrigerated unit works by internal evaporation with external condensation unit, of hermetic alternative compressor of $5 \mathrm{~kW}$ with R- $134 \mathrm{a}$ as refrigerant. Air speed is constant, and it flows around $2.5 \mathrm{~m} / \mathrm{s}$. The room has its own temperature sensor to show the temperature in the control display. This sensor is placed on the wall of the door, $150 \mathrm{~cm}$ above the ground.

To measure the ambient parameters, data loggers were utilized. The model was U12-013 HOBO that measures Temperature, Relative humidity (RH), and has 2 external ports for additional sensors. The temperature measurement range is $-20^{\circ}$ to $70^{\circ} \mathrm{C}$, and the relative humidity $(\mathrm{RH}) 5 \%$ to $95 \%$. With an accuracy of temperature $\pm 0.35^{\circ} \mathrm{C}$ from $0^{\circ}$ to $50^{\circ} \mathrm{C}$, $\mathrm{RH}$ between $\pm 2.5 \%$ from $10 \%$ to $90 \% \mathrm{RH}$. Resolution of Temperature is $0.03^{\circ} \mathrm{C}$ at $25^{\circ} \mathrm{C}$, and in $\mathrm{RH}$ is $0.03 \%$.

Two temperature probes were connected to the two external ports. The model used was TMC6-HD, an air, water, or soil temperature sensor. The measurement range was $-40^{\circ}$ to $50^{\circ} \mathrm{C}$ in the water or soil and $-40^{\circ}$ to $100^{\circ} \mathrm{C}$ in the air. 
The pallet used was $1200 \times 1000 \mathrm{~mm}$ in size and the plastic grid boxes were $500 \times 380 \times 280 \mathrm{~mm}$, nine boxes per layer in three layers. Three different types of pallet covers were used as coverage for the pallets (see Figure 7.40). The first was a DuPont ${ }^{\mathrm{TM}}$ Tyvek ${ }^{\circledR}$ Air Cargo Cover, breathable, lightweight and made of Tyvek $\AA, 1200 \times 1000 \times 1700 \mathrm{~mm}$ in size. The second cover was made of Metalized PET and raffia manufactured by (C) C\&S Packaging Supplier, and was not breathable, therefore accumulating condensation inside. The third was a cover composed of three layers, also manufactured by (C) C\&S Packaging Supplier, the inside and outside made of Metalized PET with the middle layer made of plastic bubbles. The size of the last two covers was $1200 \times 1000 \times 1700 \mathrm{~mm}$. The pallet used was $1200 \times 1000 \mathrm{~mm}$ in size and the plastic grid boxes were $500 \times 380 \times 280 \mathrm{~mm}$.

a)

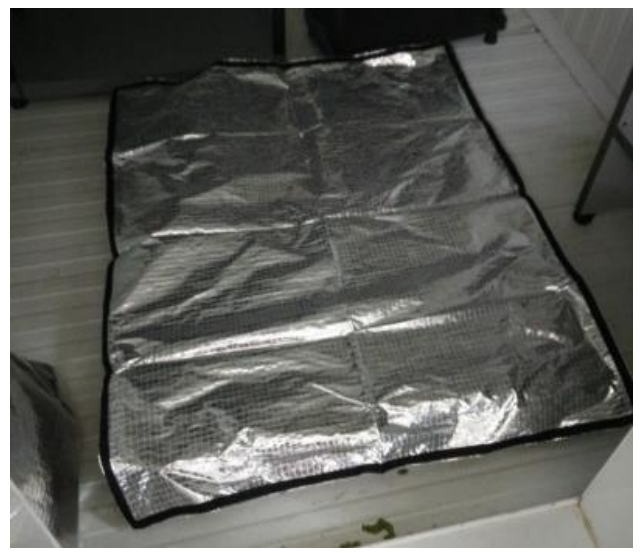

c)

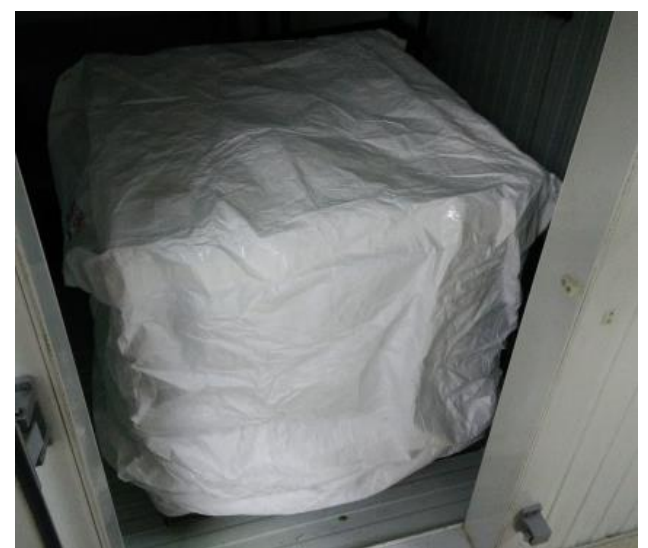

b)

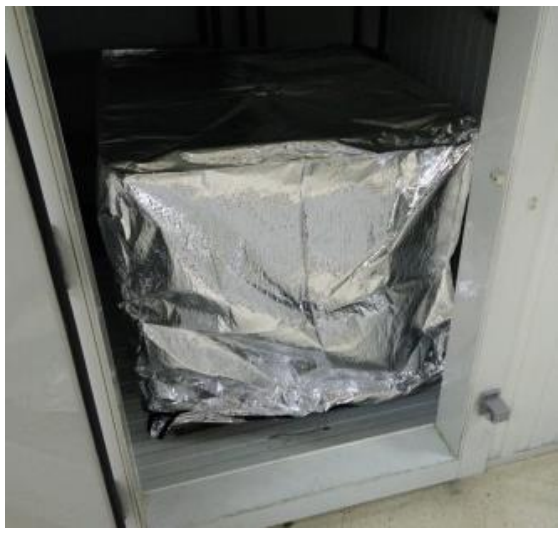

d)

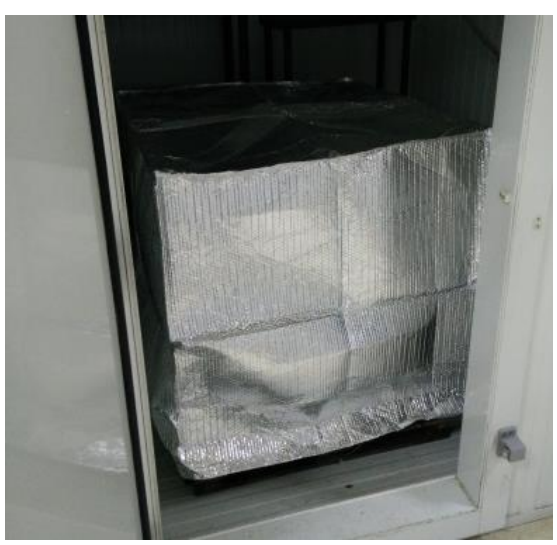

Figure 7.40. Covers placed on pallets: a) Metalized PET cover base, b) Metalized PET cover, c) Tyvek $\circledast$, d) Metalized PET Bubbles 
The products used were fresh vegetables, and in all cases the experiment did not start more than 24 hours after harvest. Products included $400 \mathrm{~kg}$ of chard for the first experiment, $400 \mathrm{~kg}$ of cucumbers for the second, and $500 \mathrm{~kg}$ of carrots for the last experiment.

The optimum storage conditions for these products are presented in Table 7.13. As can be seen, carrots can be stored for a longer period of time than chard or cucumbers due to their lower water content.

Table 7.13. Storage conditions for vegetables (Maynard and Hochmuth, 2007)

\begin{tabular}{lccc}
\hline & \multicolumn{2}{c}{ Storage conditions } \\
Vegetable & Temperature $\left({ }^{\circ} \mathrm{C}\right)$ & RH $(\%)$ & Storage life \\
\hline Chard & 0 & $95-100$ & $10-14$ days \\
Cucumber & $10-12.78$ & 95 & $10-14$ days \\
Mature Carrot & 0 & $98-100$ & $7-9$ months \\
\hline
\end{tabular}

\section{Methods}

The following method descriptions are separated according to the three different products used. The three have different experimentation times, but share the same procedure.

Each product was distributed into 18 boxes; about 15 kilos per box for chard and 20 kilos for cucumbers and carrots. The pallet had 6 boxes per layer and 3 layers.

Once the product is distributed in the boxes, the first layer of boxes is positioned on top of the wood pallet inside the cold room, and a data logger is settled in the centre of the layer, then the two probes are distributed in opposite corners as showed in Figure 7.41, and the probes are covered by the carrots. 


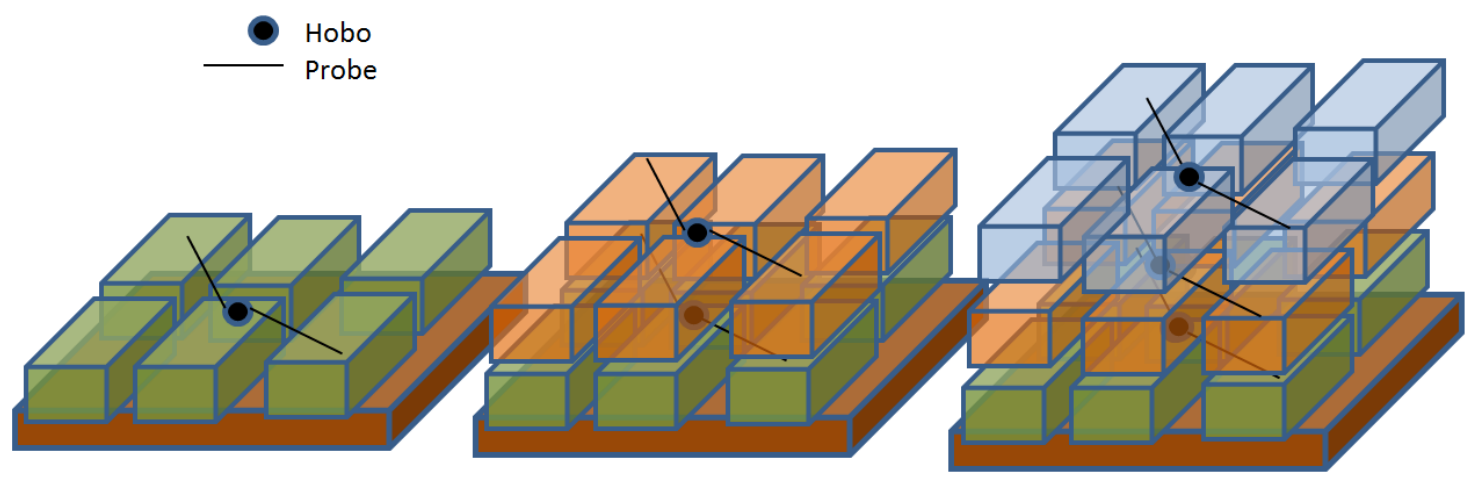

Figure 7.41. Sensors distribution in the pallet

Then the second layer is built, a data logger and probes are located in the same distribution than the bottom layer. Finally the top layer is finished in the same disposition as the bottom layer, with the sensors in the same corners. The sensors were set to log temperature and humidity every 5 minutes. After building the pallet the corresponding cover was installed. The position of the sensors is covering the three highs of the pallet and one diagonal, which represents the maximum, minimum and average temperatures among the pallet, as observed in previous studies (Badia-Melis et al., 2013; Badia-Melis et al., 2016; do Nascimento Nunes et al., 2014).

At this moment the product was at room temperature and the cold room was set to cool down to a temperature of $4{ }^{\circ} \mathrm{C}$. After 24 hours, the refrigerating unit was switched off and the temperature increased until reach the ambient temperature $\left(23^{\circ} \mathrm{C}\right)$.

The temperature ramp from $4{ }^{\circ} \mathrm{C}$ to $10{ }^{\circ} \mathrm{C}$ was selected for one part of the data analysis; it represents an important gap that could affect the quality of the vegetables. This leap is common when there is a break in the cold chain, such as refrigeration failure or the freight is exposed to ambient temperatures, the product temperature might not reach the ambient temperature, but it increases. In addition the authors wanted to have identical temperature ranges in all the scenarios, it makes the experiments replicable.

Thus, the temperature ramp was replicated in twelve occasions, with three different real fresh vegetables - it is important to remark that real produce is 
a good difficult to find in research experiments, due to their perishable characteristics - and with each vegetable type it was repeated using three different covers and no cover.

When the process was finished, the data was analysed with ad hoc software developed in Matlab.

\subsubsection{Results}

The presented results are separated by product. Independent figures and tables are shown for each kind of product.

\section{Chard}

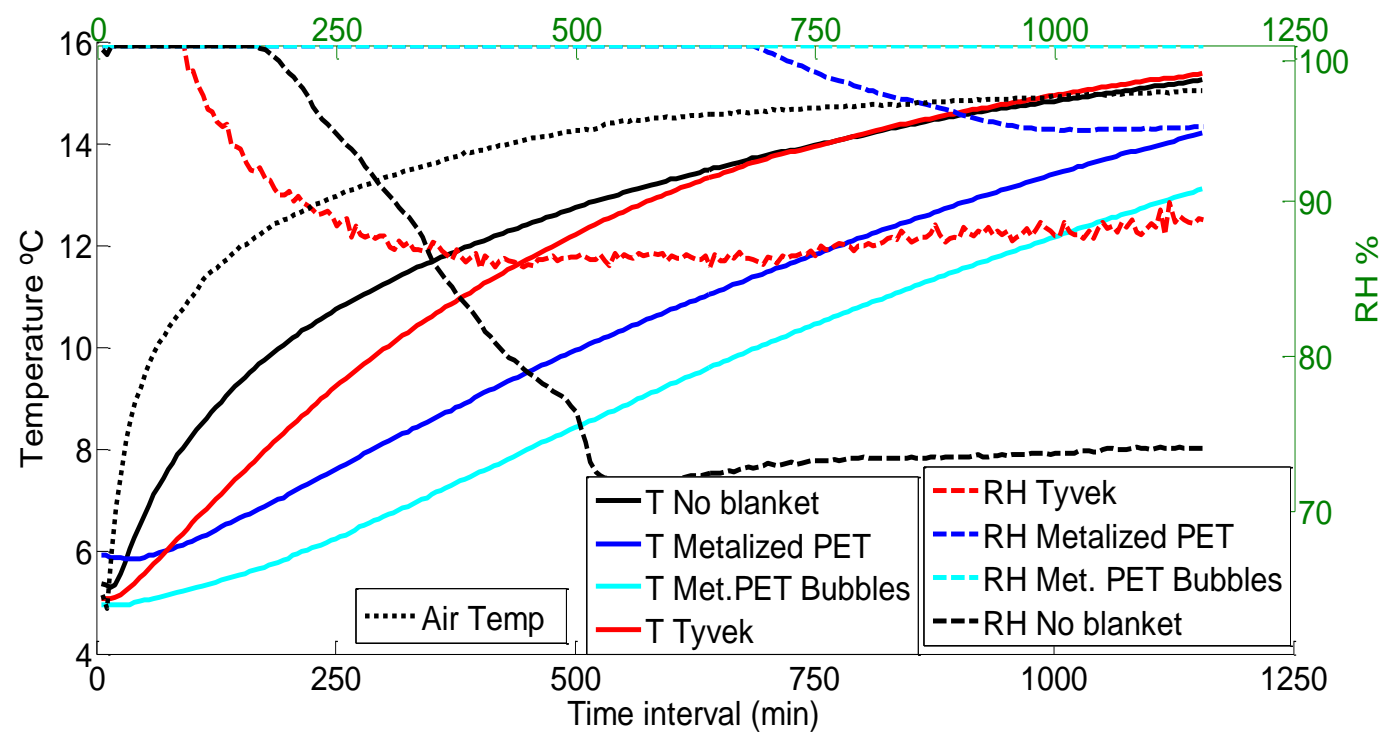

Figure 7.42. Comparison of different cover temperatures and RH for chard

Figure 7.42 shows the temperature lines following a rising trend for a pallet of chard; the dotted line represents the temperature changes in the air of the cold room, and solid lines represent an average (from the 9 temperature sensors) of the air temperatures inside the pallet.

The Metalized PET bubbles cover provided the slowest temperature increase followed by the Metalized PET cover; the two are closer than they appear in 
the graph because the start point of the Metalized PET cover was approximately $1^{\circ} \mathrm{C}$ above the Metalized PET bubbles cover.

On the other hand, the Tyvek $₫$ cover presents a more inclined line than the other two covers. At the beginning, this line stays below the no cover temperature but after 750 minutes ( 12.5 hours), the two lines merge until the end of the graph. Both lines merge with the air temperature after 1000 minutes.

The dashed lines in Figure 7.42 represent the relative humidity measurements during the chard experiment; these are plotted versus the temperature lines in order to compare the influence of both parameters simultaneously. In the case of no cover, the fall of $\mathrm{RH}$ is almost instant. It is important to notice that, because the water content in chard leaves is very high, the humidity loss is high as well, therefore the sensors encapsulated in the plastic covers were easily saturated with water and the fall of the RH lines may possibly present some delay with regards to the actual humidity. With Tyvek ${ }^{\circledR}$ cover, the RH fell after 200 minutes and remained stable around $90 \%$ for the rest of the time. For the no cover scenario, the RH line presents a downward trend from the time interval from 200 to 500 minutes, but in this case, the $\mathrm{RH}$ reached 75\%. The Metalized PET bubbles cover did not present any drop throughout the duration of the experiment and for the Metalized PET cover, RH only fell after 700 minutes and then it never fell below $95 \%$.

Table 7.14. Time to increase from $4{ }^{\circ} \mathrm{C}$ to $10{ }^{\circ} \mathrm{C}(\mathrm{min})$. Chard

\begin{tabular}{lcccc}
\hline $\begin{array}{c}\text { Chard } \\
\text { Initial point 4 }{ }^{\circ} \mathbf{C}\end{array}$ & No cover & Tyvek® & $\begin{array}{c}\text { Metalized } \\
\text { PET }\end{array}$ & $\begin{array}{c}\text { Metalized } \\
\text { PET Bubbles }\end{array}$ \\
\hline $\begin{array}{l}\text { Mean time } \\
\text { (min) }\end{array}$ & 211 & 214 & 506 & 493 \\
Max. time (min) & 355 & 560 & 745 & 675 \\
Min. time (min) & 30 & 40 & 75 & 70 \\
\hline
\end{tabular}

Among all the times measured by the sensors installed in the pallet, the maximums, minimums and means are represented in Table 7.14. The time for the temperature to increase from 4 to $10^{\circ} \mathrm{C}$ presents an upward trend starting with no cover, then Tyvek $\AA$, Metalized PET and finally Metalized PET bubbles 
in Table 7.14 for the maximum. The Metalized PET and Metalized PET bubbles switch positions for the average and minimum times for the temperature increase.

The overall maximum is found with the Metalized PET cover and the minimum during the no cover experiment. The average times are very close in the Tyvek $\AA$ and no cover scenarios, which present concordance with Figure 7.42, where the two curves coming closer together at the end of the curve can be observed.

\section{Cucumbers}

In the case of the cucumbers, the temperature increase shortened over time, reaching 350 minutes while the chard and carrots surpassed 1000 minutes.

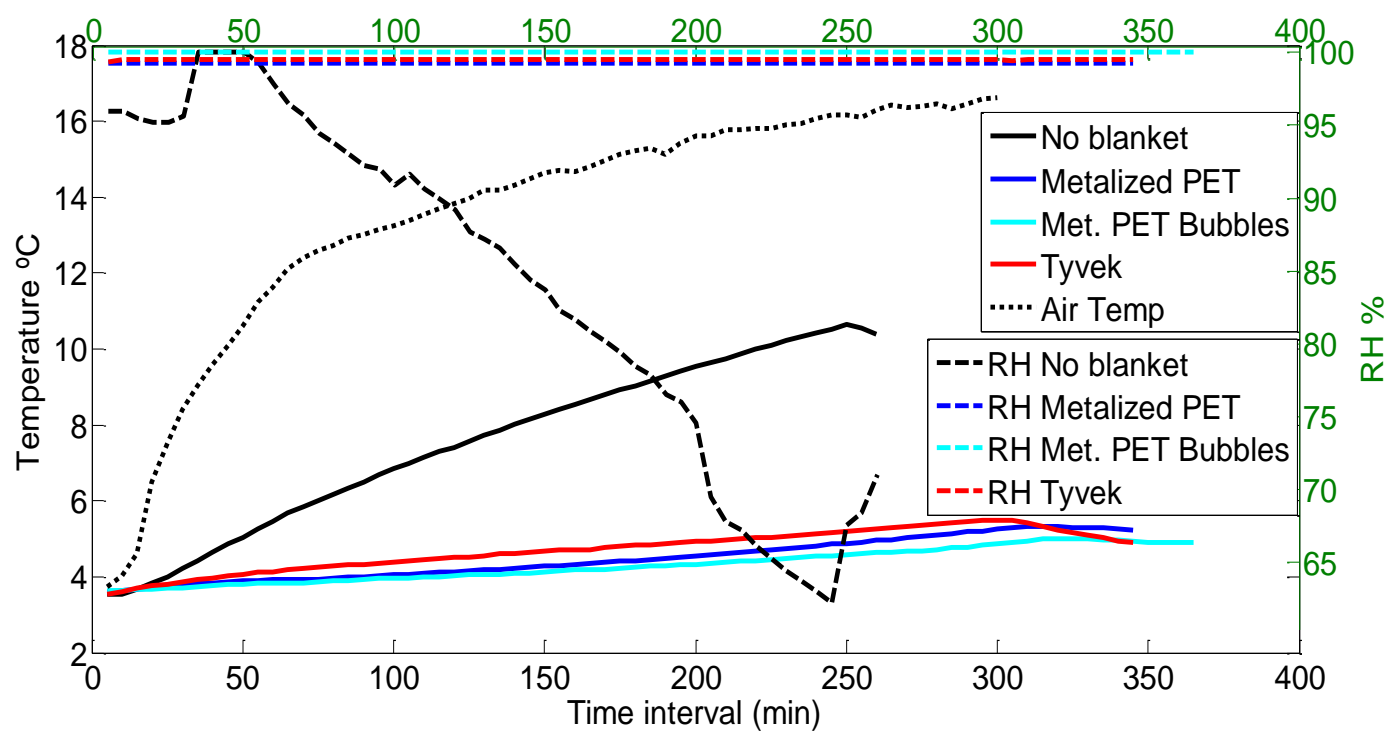

Figure 7.43. Comparison of different cover temperatures and RH for cucumbers

Figure 7.43 shows how the air temperature increased faster than the other temperatures and reached a certain stabilization point around 75 minutes. The following temperature on the increase is that obtained during the no cover experiment. All the covers presented a very small increase during 350 minutes, barely reaching $5^{\circ} \mathrm{C}$, with the Tyvek $\AA$ being the fastest to increase, followed by the Metalized PET and finally the Metalized PET bubbles cover. 
The relative humidity in this case did not fall at any moment, and remained at $100 \%$ for the three different covers, with the only exception of the graph being the no cover $\mathrm{RH}$ line, which decreases rapidly when the temperature rises. This happened drastically after 75 minutes after the temperature increase began (see Figure 7.43).

Table 7.15. Time to increase from $4^{\circ} \mathrm{C}$ to $10^{\circ} \mathrm{C}(\mathrm{min})$. Cucumber

\begin{tabular}{lcccc}
\hline $\begin{array}{c}\text { Cucumber } \\
\text { Initial point 4 }{ }^{\circ} \mathbf{C}\end{array}$ & No cover & Tyvek ${ }^{\circ}$ & $\begin{array}{c}\text { Metalized } \\
\text { PET }\end{array}$ & $\begin{array}{c}\text { Metalized } \\
\text { PET Bubbles }\end{array}$ \\
\hline Mean time & 176 & 267 & -- & -- \\
$(\mathbf{m i n})$ & & & & -- \\
Max. time (min) & 290 & 480 & -- & -- \\
Min. time (min) & 45 & 30 & -- & - \\
\hline
\end{tabular}

It was not possible to achieve a temperature increase from $4^{\circ} \mathrm{C}$ to $10^{\circ} \mathrm{C}$ for all of the covers due to some technical problems, and therefore some spaces remain blank in Table 7.15. Between the Tyvek ${ }^{\circledR}$ and the no cover situations, Tyvek $\AA$ gives longer times in the means and in the maximum, but for the minimum the situation is reversed and no cover was 15 minutes slower than the Tyvek ${ }^{\circledR}$ cover.

\section{Carrots}

Figure 7.44 shows how the temperature increased in the carrots pallet with the different covers. All the measurements start from around 4 and $5{ }^{\circ} \mathrm{C}$, and present an upward trend according to the temperature increase in the room. The air temperature, as expected, was the fastest temperature to rise and the no cover temperature was second fastest. In this case, the 3 covers gave more similar results than for the chard pallet, which will be reflected as well in Table 7.15. The fastest line to rise from the covers is, as in the other two examples, the Tyvek $\AA$, followed by the Metalized PET bubbles and the Metalized PET coming in last. 


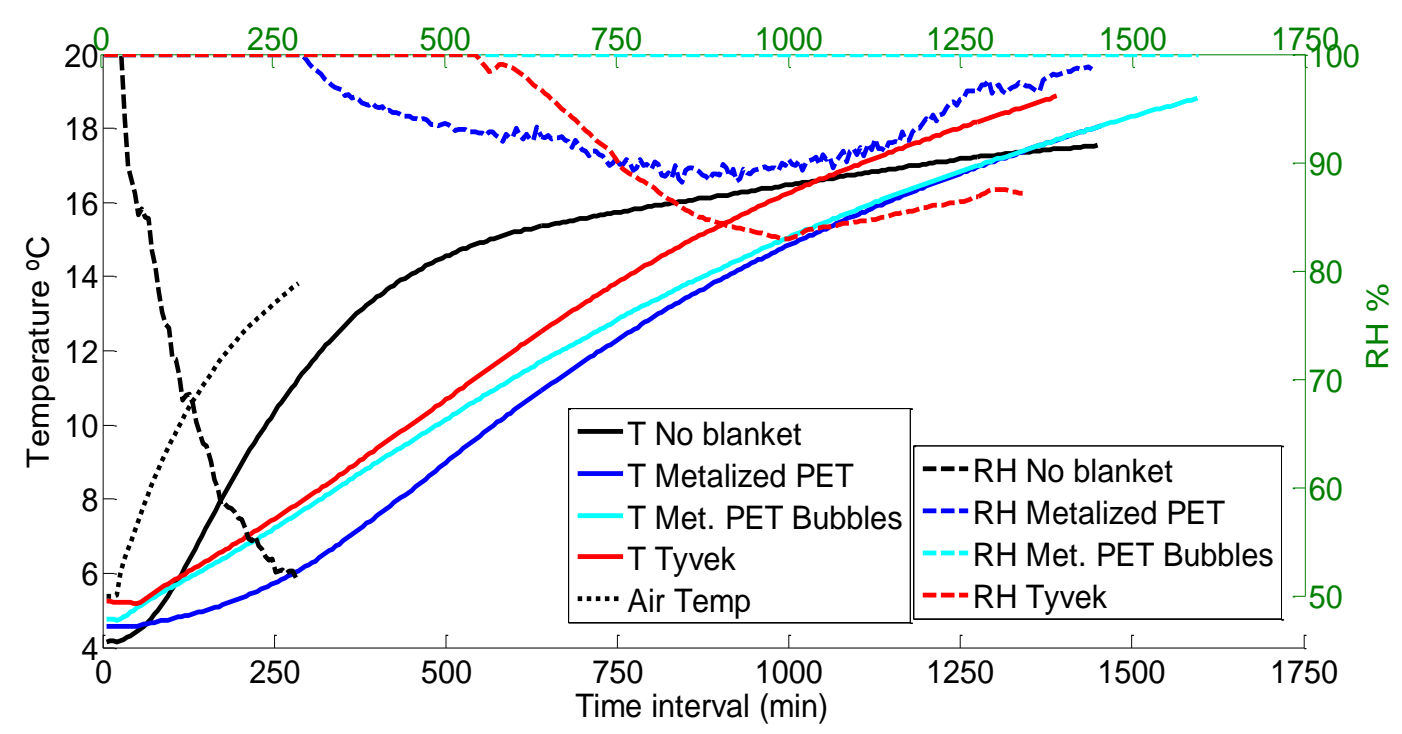

Figure 7.44. Comparison of different cover temperatures and RH for carrots

The temperature increase produced an RH decrease (see Figure 7.44); the no cover scenario was the fastest scenario to lose humidity, reaching almost $50 \% \mathrm{RH}$ in barely 250 minutes. Then the Metalized PET cover presented a decrease in humidity to $90 \%$, but in more than 875 minutes, very similar to

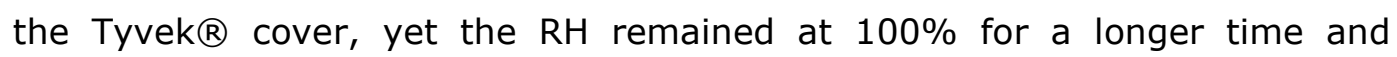
descended to $85 \%$ at the end of the curve. The Metalized PET bubbles cover, on the other hand, did not decrease the humidity at any moment, creating condensation inside the pallet.

Table 7.16. Time to rise from $4^{\circ} \mathrm{C}$ to $10^{\circ} \mathrm{C}(\mathrm{min})$. Carrots

\begin{tabular}{lcccc}
\hline $\begin{array}{l}\text { Carrot Initial } \\
\text { point 4 }{ }^{\circ} \mathbf{C}\end{array}$ & No cover & Tyvek ${ }^{\circledR}$ & Metalized PET & $\begin{array}{c}\text { Metalized } \\
\text { PET Bubbles }\end{array}$ \\
\hline $\begin{array}{l}\text { Mean time } \\
(\mathbf{m i n})\end{array}$ & 162 & 450 & 408 & 436 \\
$\begin{array}{l}\text { Max. time } \\
\text { (min) }\end{array}$ & 250 & 620 & 670 & 565 \\
$\begin{array}{l}\text { Min. time } \\
\text { (min) }\end{array}$ & 30 & 150 & 80 & 135 \\
\hline
\end{tabular}

In this case, the time to reach $10^{\circ} \mathrm{C}$ from $4^{\circ} \mathrm{C}$ for all the covers was very similar between the three (see Table 7.16); the mean time rose from 408 to 450 minutes, while the time to reach $10^{\circ} \mathrm{C}$ with no cover was shorter (162 minutes). In the maximum, the biggest difference is found between the 
Metalized PET bubbles and the Metalized PET (105 minutes). Finally, the minimum times were again more homogeneous, with the Tyvek $\AA$ and the Metalized PET bubbles covers being closer than the Metalized PET.

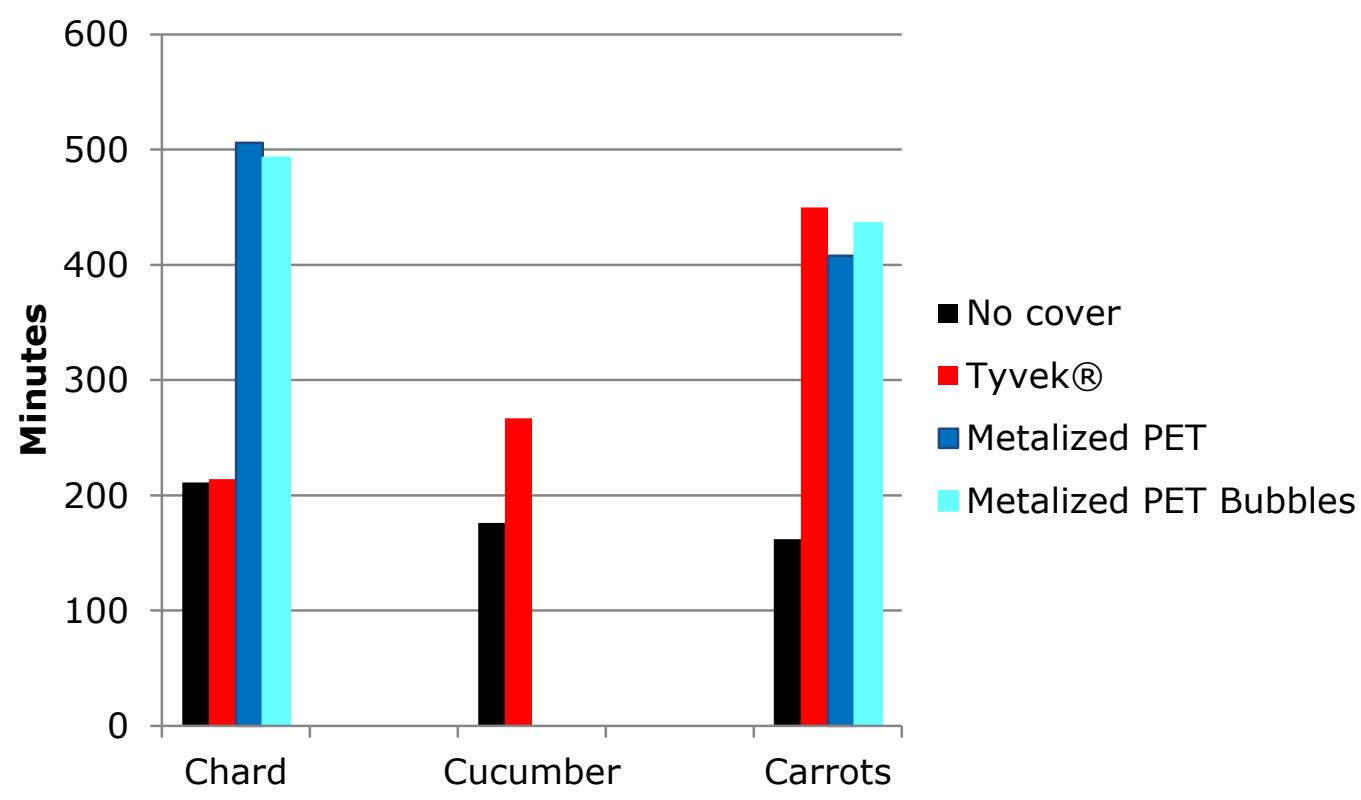

Figure 7.45. Time to rise from $4^{\circ} \mathrm{C}$ to $10^{\circ} \mathrm{C}$ (Average)

Finally in Figure 7.45 , the times to rise from 4 to $10{ }^{\circ} \mathrm{C}$ are displayed in a columns figure, it gathers the average times from the Table 7.14, Table 7.15 and Table 7.16. The times for no cover in the three products are similar, from 211 (chard) to 162 (carrots) minutes, the times for Tyvek $®$ present the greatest changes among different products, from 214 (chard) to 450 (carrots). And the two metalized PET covers do not present a variability as big as Tyvek ${ }^{\circledR}$ between chard and carrots, as it is said before, it was not possible to achieve the temperature rising times from metalized PET covers due to technical problems.

\subsubsection{Discussion}

In terms of humidity, in the case of chard, the humidity lines fell faster in the beginning for the no cover situation, but at the end, $\mathrm{RH}$ was the lowest with no cover, reaching $75 \%$ while Tyvek ${ }^{\circledR}$ never fell below $90 \%$. In the other two 
products, no cover RH always fell faster, though in reality, for the cucumbers, none of the lines for the covers fell at all, however this is attributed to the short experiment time. According to Table 7.13, the most suitable cover for all the products (with regards to $\mathrm{RH}$ ) would be the Metalized PET cover, because despite the Metalized PET bubbles cover never presenting any fall in $\mathrm{RH}$, it caused significant condensation inside the pallet. This condensation could ultimately cause mold or fungus problems.

The minimum increase times were the most important, since this was when some parts of the pallet started to increase in temperature to critical points. All the cases had a better performance or slower temperature rising times in the transition from 4 to $10{ }^{\circ} \mathrm{C}$ when comparing cover versus no cover, with the only exception of the cucumbers, for which the Tyvek ${ }^{\circ}$ and no cover values were very close ( 30 and 45 minutes, respectively).

Tyvek ${ }^{\circledR}$ cover demonstrated to attenuate the effect in the thermal increment and presents the lower condensation rates in front of the other two covers. Peck et al. (2015) showed that single skin fabric covers can provide resistance to certain temperature changes when a hot or cold air streams happens; if these fabric covers are permeable, they provide breathability and therefore can avoid or lower condensation. Also the studied cover made of Metalized PET presents an acceptable attenuation for thermal increment but the breathability is lover that in the case of Tyvek $®$. However, as explained by Peck et al. (2015) the reflective material of this cover is expected to be effective versus the radiation, especially direct sunlight. With the Metalized PET bubbles cover it is expected a slower rate of thermal change due to thicker insulating character of the material, and so it was as showed in the results, the slower temperature changes occur using the Metalized PET bubble cover.

Finally there were found differences between products with the same covers in terms of temperature and $\mathrm{RH}$. Regard to temperature increment times it was found a wide range between chard and carrots in Tyvek $\AA$. And regard to $\mathrm{RH}$, it was found a complete different behavior for the Metalized PET cover among the three scenarios (chard, cucumber and carrots), it could be caused 
by their different physiological characteristics, it should be studied in future researches.

\subsubsection{Conclusions}

The Different types of covers evaluated in the present study show temperature preservation regard to no cover. The temperature changes occur slower than with no cover.

When comparing between covers, Metalized PET bubbles cover shows better protection than the other two covers. Tyvek ${ }^{\circledR}$ cover shows the lowest isolation rates. The temperature increments follow an expected order especially in cucumbers and carrots.

In the other hand, with no cover the $\mathrm{RH}$ always falls until 55 to $70 \%$ depending on the product, and also there are differences observed between different products for the covers. With Tyvek ${ }^{\circledR}$ the $\mathrm{RH}$ falls in chard and carrots until around $90 \%$, Metalized PET also falls with both products but with carrots falls faster than with chard and at the end presents a rising trend. The influence of the different products in the different blankets is a fact that was revealed in the results of this section, but it is not subject of study in this document, it should be studied in deep in future experiments, and why they cause different $\mathrm{RH}$ and temperature trends. 


\section{Chapter 8}

\section{Discussion}

In this chapter it is presented a discussion of the results with regard to the international state of the art about the implementation of different technologies, techniques and methods for the food cold chain traceability, and for its monitoring.

\subsection{Implementation of new technologies in cold chain}

As it was highlighted by Ruiz-Garcia and Lunadei (2011), there are certain challenges and limitations that hinder a perfect data flow when using RFID in cold chain. That limitation is addressed in this thesis, since it is showed the good complementarity between RFID and WSN, especially the data loss by RFID can be eliminated with the RFID tags, and the lack of variety of sensors in RFID can be complemented by the wide sensing range from the WSN nodes.

In section 7.1, the refrigerated chamber with most extreme temperatures had a set point of $7{ }^{\circ} \mathrm{C}$, however the temperatures that sensors revealed, ranged 
from $3.5{ }^{\circ} \mathrm{C}$ to $10.5{ }^{\circ} \mathrm{C}$, other authors such as Ruiz-Garcia et al. (2010a) also found this variability in a refrigerated transport trailer, their set point was 0 ${ }^{\circ} \mathrm{C}$ and their temperatures ranged from a maximum of $8.52{ }^{\circ} \mathrm{C}$ and a minimum of $-3.0{ }^{\circ} \mathrm{C}$ with an average of $5.33^{\circ} \mathrm{C}$.

In the commercial warehouses studied (in section 7.1) it is showed that the $\mathrm{RH}$ ranged from $35 \%$ to $80 \%$ or from $65 \%$ until $95 \%$, these results show concordance with the work from Ruiz-Garcia et al. (2010a) since both studies show wide range of $\mathrm{RH}$ when working with fresh fruits and vegetables. In their study the $\mathrm{RH}$ ranged from 55 to $95 \%$. And in their case the humidity was always higher at the middle of the trailer (average RH 74\%) near the top than at the rear (average RH 62.1\%). In the tests performed in this thesis only the $\mathrm{RH}$ near to the door, inside and outside the refrigerated chamber was studied.

Pallet covers have proven to be very effective for protecting the goods when there are extreme temperature oscillations. As explained by Peck et al. (2015), single skin fabric covers can provide resistance to hot or cold air streams or sudden changes, and provide breathability which can avoid or lower condensation; Tyvek ${ }^{\circledR}$ cover (used in 7.4 and 7.5) demonstrated to attenuate the effect in the thermal increment and presets the lower condensation rates in front of the other two covers. On the other hand, Metalized PET cover (used in 7.4 and 7.5) also presents an acceptable attenuation for thermal increment but the breathability is lover that in the case of Tyvek $\AA$. However, as explained by Peck et al. (2015) the reflective material of this cover is expected to be effective versus the radiation, especially direct sunlight. Finally, with the Metalized PET bubble cover (used in 7.4 and 7.5) it is expected a slower rate of thermal change compared to the other two covers due to thicker insulating character of the material, and so it was as showed in the results (sections 7.4 and 7.5), the slowest temperature changes occur using the bubble cover.

Thermal imaging have proven to be useful when it is used for measuring directly the surface temperature of the product, as showed in section 7.3; It was showed the utility before by other authors such as Jha et al. (2011) for evaluating the cooked level inside the chicken, Q. Chen et al. (2013) used thermal image for food safety, and Castro-Giráldez et al. (2014) implemented 
the thermal imaging as a temperature control for meat freezing process. But when there are covers protecting the product, it is necessary to evaluate certain parameters, such as the emissivity from the surface of the covers. As it is gathered in the existing literature (Estrada-Flores \& Eddy, 2006, 2007), the emissivity of the surfaces may cause difficulties during the interpretation of the thermograms; a reflected image appears when there is a radiation source that directly impacts the surface of the covered pallet and can create a "false positive". In the studied scenarios (section 7.4) it was found some heterogeneity of results, from errors from 0.1 to $21.8^{\circ} \mathrm{C}$, it is explained due to the emissivity stated by Estrada-Flores and Eddy (2006, 2007). It has been demonstrated that changing the emissivity does not affect to the measured temperature when the object emissivity is very low, however it affects to the temperature range captured by the camera.

When the pallet has been cooled down, covers always cool faster than the pallet, same thing happens when warming up the pallet, temperature changes occur faster on the surface than under the cover. During long transit transportation, rapid temperatures changes do not occur often therefore the cover and the load usually have the same temperature and the thermal camera can detect real temperature by recording the surface. In some occasions direct air flow on top of the pallets due to the cooling unit may create a noticeable temperature differential between the cover and the load. It is important to measure the cover temperature immediately at arrival since it can warm up faster than the inside of the pallet. Similar observations have been reported by Ruiz-Garcia et al. (2010a) and Badia-Melis et al. (2016).

The industry is currently using thermal image evaluation for product temperature (Dupont, 2016), with pallet covers, during load and unload of the produce, which can lead to some errors since we know that the surface temperature may not be the inside temperature. 


\subsection{Implementation of new techniques in cold chain}

This section compares the results obtained in the thesis with international publications, when using new techniques in cold chain, especially temperature estimation methods.

Good temperature distribution can be represented with adequate data, and it becomes more accurate the higher the volume of data, but when there is a good understanding of the environment, certain spots of the cold room can be monitored with temperature estimation methods and bypass the actual sensors, as was successfully shown by Badia-Melis et al. (2013); Jedermann and Lang (2009); Uysal et al. (2011), and therefore this was put into practice in the sections 7.2 and 7.3, where it was improved and ratified that the temperature estimation is a powerful tool.

The existing literature is mainly focused on the neural network modeling, its structure, and the deep learning techniques, above all for research purposes (N. Liu et al., 2014; M. Qi \& Zhang, 2008; Romeu et al., 2013), the value of the work here is that the results are based on the profit obtained by using these tools in a real industrial scenario.

In the present work, the lowest error obtained in temperature prediction using physical sensors for reference in the estimation was $0.11{ }^{\circ} \mathrm{C}$ (section 7.2.3), when in the existing literature (Badia-Melis et al., 2013; do Nascimento Nunes et al., 2014) the error obtained with artificial neural network (ANN) was 0.16 ${ }^{\circ} \mathrm{C}$, being this error the $2.85 \%$ of the total error from the regular measurements.

These errors from regular measurements are obtained when using only the cold room temperature as a reference. In this thesis, in section 7.2.3, the error was $3.85{ }^{\circ} \mathrm{C}$; on the other hand, do Nascimento Nunes et al. (2014) obtained an error of $3.38{ }^{\circ} \mathrm{C}$ RMSE with regards to real temperature. Also in this thesis, when using thermal image as a source (section 7.3.3), the error was $3.56{ }^{\circ} \mathrm{C}$ of RMSE compared with the real temperature inside the product. 
Yousefi et al. (2013) achieved $0.007{ }^{\circ} \mathrm{C}$ as RMSE in temperature estimation when studying papaya moisture prediction, they had a correlation coefficient between estimated and real temperature of $R^{2}=0.9994$, whilst in the present document the correlations are between $\mathrm{R}^{2}=0.9995$ and $\mathrm{R}^{2}=0.9828$ as showed in section 7.3.3.

When it is applied the ANN temperature prediction using thermal image as source, it was achieved an error of $0.08{ }^{\circ} \mathrm{C}$ RMSE across all the errors (section 7.3.3), meantime do Nascimento Nunes et al. (2014) obtained 0.16 ${ }^{\circ} \mathrm{C}$ as an average error, with a temperature sensor as the input for the ANN.

Also using ANN with thermal image as source, Ibarra et al. (2000) obtained an error of $1.07{ }^{\circ} \mathrm{C}$, the difference with the present document is that their experiments were performed in the cocking industry at product level. 



\section{Chapter 9}

\section{Conclusions}

This chapter summarizes the main conclusions of this thesis and draws out their implications in the field of cold chain monitoring and food tracking. It thereby aims to enrich our knowledge about software, hardware and accessories that can be used towards improving the cold chain traceability while demonstrating the practical usability in real scenarios.

\subsection{On the improvement of the implementation for wireless sensing devices in cold chain}

The combination of the WSN and the RFID technologies have been proven of high utility, since in some of the fields where RFID fails, the WSN success and vice versa. WSN nodes lack robustness, these devices are always weak and the electronics are very exposed to any possible damage. WSN systems are always more expensive than RFID tags. On the other hand RFID presents shorter reading range than WSN and so far it is not able to perform a communication Point to Point. The RFID also lacks in the sensing range, and it is usually limited by one kind of sensor, such as temperature sensor. 
The data handling in these two systems was at some point difficult to address, large amounts of data was produced, that needs time for analysis and computer processing capacity, and during the process of recording the data some data packets are lost, which can interfere in further actions.

The last conclusion from this experiment is that chamber design and storage protocols should be revised for improving energy consumption and helping to extend the freshness of the cargo.

\subsection{On the temperature estimation for perishable products}

Temperature estimation is proven to be feasible due to the good results obtained when comparing with the ambient temperature, usually used as a reference. However it is needed to achieve certain estimation parameters that suppose complicated sensor deploy for the first time the scenario is being evaluated, but once the estimation parameters are obtained it is possible to estimate the temperature at different levels, container, pallet or even box level.

Among the three ambient estimation methods used, the ANN is proven to be the most accurate since it presented the lowest RMSE. The information achieved using these methods is very useful when any problem arises during the cold supply chain, it could reduce reaction times to fix such problems or to make more informed decisions regarding product stability and reduce the food waste. The predicted data can be used for more accurate shelf life calculations and enhancing the logistical operations of all stakeholders of the largest industrial food sector. Therefore the temperature mapping and prediction in transportation or storage is a potent tool in developing cold chain strategies with better monitoring to significantly reduce product losses. 


\subsection{On the thermal image and ANN complementarity for improvement in the cold chain monitoring}

IR image performed adequately for temperature estimation. It was possible to estimate the temperature across a pallet of real product with thermal image as the source. Any error achieved between the estimated temperature and the real temperature, that is below the error between the source temperature and the real temperature is an improvement; in this work all the scenarios studied presented lower errors with the estimated temperature compared the source temperature.

It was not appreciated any big difference in terms of temperature estimation between cardboard and plastic boxes, the emissivity from the two kind of boxes was very similar, but the emissivity was not object of study in section 7.3.

It is recommended implementation of thermal imaging in certain places during the cold chain transportation or storage. The information provided by the thermal camera can always give a real idea of what is happening in any moment with the product surface temperature which is usually the most sensitive one.

\subsection{On the surface temperature evaluation through the thermal image}

Results from this study showed that using thermal camera to read the temperature of a pallet of fresh produce by using the cover surface temperature is not a reliable method to assess temperature distribution. Many factors are involved such as water condensation, evaporation, type of product and load density, actual surface temperature, the heat transfer through the cover, and emissivity, the most important in the use of thermal image. Camera manufacturer recommends adjusting the camera emissivity according to the material emissivity, but the results do not show that these adjustments are effective. The temperature readings are difficult to assess with metalized 
materials, the temperature really depends of the small spot selected where the camera focuses, and this spot can have in the same square centimeter a temperature difference of $4{ }^{\circ} \mathrm{C}$. The same temperature measurement inconsistency was observed for chard and cucumber. This methodology must be revised and improved before taken as valid.

\subsection{On the evaluation of pallet covers for produce protection in cold chain logistics}

It was tested different pallet covers in different scenarios with different products; all the covers presented an improvement of temperature and $\mathrm{RH}$ preservation. In terms of humidity, the Metalized PET and Tyvek ${ }^{\circledR}$ covers present a $\mathrm{RH}$ closer to the produce requirements compared to the Metalized PET bubbles cover. The humidity lines fell faster in the beginning for the no cover situation, at the end, RH was the lowest with Tyvek ${ }^{\circledR}$, but still within the range accepted for the studied vegetables. In terms of temperature on the other hand, all the scenarios with cover had a better performance or slower temperature rising times in the transition from 4 to $10{ }^{\circ} \mathrm{C}$ when compared with no cover. The fastest changes always occur in the top layers of the pallet, a fact that can indicate the covers could be enhanced in the top part, for example, adding an extra layer of material just at the top. The average and slowest changes were always slower when using any kind of cover than when using no cover, again an indicator of the positive benefits of using pallet covers.

The utility of using the different covers has to be deeply studied, also the correlation with the type of temperature requirements of the product as well as the process for which it is wanted to apply the cover, such as high or low temperature protection. The reason of different behaviors between products with the same covers should be studied as well. 


\section{Chapter 10}

\section{Suggestions for future research}

It is believed that the following key areas require further investigation in the view of the results and conclusions from this thesis:

1. Design a more robust system using the complementarity between WSN and RFID, the principal requisites are: low price, small size, better communications with the gateway and highly improved software, it has to be smart enough to make an initial decision towards a cold chain improvement.

2. Implement ambient parameters estimation methods in the software of monitoring systems for food industry, especially ANN method for temperature. It has to be applied to local scenarios such as refrigerated trucks or containers as well as cold warehouses.

3. Evaluation of thermal imagesupervision in different scenarios than the studied in this thesis (section 7.3), such as distribution centers, cold rooms and especially focusing in any transition point e.g. loading and unloading docks.

4. Parametrization of the available commercial covers and the study of new type of covers with special dedication comparing results with 
different products. The usage and benefits of the pallet covers is barely studied and the characterization of these covers has to be complete.

5. Deeper study is suggested in the transpiration and evaporation of fresh fruits and vegetables using Tyvek $\AA$ cover, and the possible cooling effect in the surface.

6. Study the influence of the different variables involved in surface temperature evaluation when using thermal image, such as emissivity, surface temperature, type of product, density of the load, condensation and evaporation.

7. Develop a smart packaging, it should include sensors able to detect ambient parameters, it also needs to be compatible with the showed advances in this work, such as temperature estimation and thermal image monitoring. 


\section{Chapter 11}

\section{References}

Abad, E., Palacio, F., Nuin, M., De Zarate, A., Juarros, A., Gómez, J., \& Marco, S. (2009). RFID smart tag for traceability and cold chain monitoring of foods: Demonstration in an intercontinental fresh fish logistic chain. Journal of food engineering, 93(4), 394-399.

Amador, C., \& Emond, J.-P. (2010). Development of RFID temperature tracking systems for combat feeding logistics. Paper presented at the XVIIthWorld Congress of the International Commission of Agricultural and Biosystems Engineering (CIGR), CSBE/SCGAB. Quebec City, Canada.

Amador, C., Emond, J.-P., \& Nunes, M. C. d. N. (2009). Application of RFID technologies in the temperature mapping of the pineapple supply chain. Sensing and Instrumentation for Food Quality and Safety, 3(1), 26-33. doi: 10.1007/s11694-009-9072-6

Amaral, L. A., Hessel, F. P., Bezerra, E. A., Corrêa, J. C., Longhi, O. B., \& Dias, T. F. (2011). eCloudRFID-A mobile software framework architecture for pervasive RFID-based applications. Journal of Network and Computer Applications, 34(3), 972-979.

Angeles, R. (2005). RFID technologies: supply-chain applications and implementation issues. Information systems management, 22(1), 5165. 
Anon. (2011). Getting technical over food traceability, from http://www.china.org.cn/business/2011-07/11/content 22965087.htm

Arcuri, E. F., El Sheikha, A. F., Rychlik, T., Piro-Métayer, I., \& Montet, D. (2013). Determination of cheese origin by using 16S rDNA fingerprinting of bacteria communities by PCR-DGGE: Preliminary application to traditional Minas cheese. Food Control, 30(1), 1-6.

ASABE. (2005). Psychrometric Data ASAE D271.2 APR1979, R2005.

Atlas, R. M. (2002). Bioterrorism: the ASM response. ASM News-American Society for Microbiology, 68(3), 117-121.

Attaran, M. (2007). RFID: an enabler of supply chain operations. Supply Chain Management: An International Journal, 12(4), 249-257.

Atzori, L., Iera, A., \& Morabito, G. (2010). The internet of things: A survey. Computer networks, 54(15), 2787-2805.

Aung, M. M., \& Chang, Y. S. (2014). Traceability in a food supply chain: Safety and quality perspectives. Food control, 39, 172-184.

Badia-Melis, R., Brecht, E., Lowe, A., \& Uysal, I. (2013). Pallet wide temperature estimation and mapping for perishable food. Paper presented at the Proceedings of the Poster on Annual Conference ASABE.

Badia-Melis, R., Garcia-Hierro, J., Ruiz-Garcia, L., Jiménez-Ariza, T., Villalba, J. I. R., \& Barreiro, P. (2014). Assessing the dynamic behavior of WSN motes and RFID semi-passive tags for temperature monitoring. Computers and Electronics in Agriculture, 103, 11-16.

Badia-Melis, R., Qian, J., Fan, B., Hoyos-Echevarria, P., Ruiz-García, L., \& Yang, X. (2016). Artificial Neural Networks and Thermal Image for Temperature Prediction in Apples. Food and Bioprocess Technology, 111.

Badia-Melis, R., Ruiz-Garcia, L., Garcia-Hierro, J., \& Villalba, J. I. R. (2015). Refrigerated fruit storage monitoring combining two different wireless sensing technologies: RFID and WSN. Sensors, 15(3), 4781-4795.

Barge, P., Gay, P., Merlino, V., \& Tortia, C. (2014). Item-level RadioFrequency IDentification for the traceability of food products: Application on a dairy product. Journal of Food Engineering, 125, 119130.

Becker, S., Hanner, R., \& Steinke, D. (2011). Five years of FISH-BOL: brief status report. Mitochondrial DNA, 22(sup1), 3-9. 
Bertacchini, L., Cocchi, M., Vigni, M. L., Marchetti, A., Salvatore, E., Sighinolfi, S., Silvestri, M., \& Durante, C. (2013). The impact of chemometrics on food traceability. Chemometrics in Food Chemistry, Elsevier, Oxford, UK, 371-410.

Bevilacqua, M., Bucci, R., Magrì, A. D., Magrì, A. L., \& Marini, F. (2012). Tracing the origin of extra virgin olive oils by infrared spectroscopy and chemometrics: a case study. Analytica chimica acta, 717, 39-51.

Bhatt, T., Buckley, G., \& McEntire, J. C. (2013a). Proceedings of the August 2011 traceability research summit. Journal of food science, 78(s2), B9B14.

Bhatt, T., Buckley, G., McEntire, J. C., Lothian, P., Sterling, B., \& Hickey, C. (2013b). Making traceability work across the entire food supply chain. Journal of food science, 78(s2), B21-B27.

Bhatt, T., Hickey, C., \& McEntire, J. C. (2013c). Pilot projects for improving product tracing along the food supply system. Journal of food science, 78(s2), B34-B39.

Bhatt, T., \& Zhang, J. J. (2013). Food product tracing technology capabilities and interoperability. Journal of food science, 78(s2), B28-B33.

Bosona, T., \& Gebresenbet, G. (2013). Food traceability as an integral part of logistics management in food and agricultural supply chain. Food Control, 33(1), 32-48.

Bujji, M. (2012). Tracing the Footsteps, from http://www.fnbnews.com/article/detnews.asp?articleid=26342\&section $\underline{i d=32}$

Bulanon, D., Burks, T., \& Alchanatis, V. (2008). Study on temporal variation in citrus canopy using thermal imaging for citrus fruit detection. Biosystems Engineering, 101(2), 161-171.

Burg, S. (2014). Hypobaric Storage in Food Industry: Advances in Application and Theory: Elsevier.

Cai, Y., Zhang, L., Shen, F., Zhang, W., Hou, R., Yue, B., Li, J., \& Zhang, Z. (2011). DNA barcoding of 18 species of Bovidae. Chinese Science Bulletin, 56(2), 164-168.

Camin, F., Larcher, R., Nicolini, G., Bontempo, L., Bertoldi, D., Perini, M., Schlicht, C., Schellenberg, A., Thomas, F., \& Heinrich, K. (2009). Isotopic and elemental data for tracing the origin of European olive oils. Journal of agricultural and food chemistry, 58(1), 570-577.

Cantwell, M., \& Suslow, T. (2002). Lettuce, Crisphead. Recommendations for Maintaining Postharvest Quality. . Department of Plant Sciences, 
University of California, Davis., from http://postharvest.ucdavis.edu/pfvegetable/LettuceCrisphead/

Castro-Giráldez, M., Balaguer, N., Hinarejos, E., \& Fito, P. (2014). Thermodynamic approach of meat freezing process. Innovative Food Science \& Emerging Technologies, 23, 138-145.

Catarinucci, L., Cuiñas, I., Expósito, I., Colella, R., Fernández, J. A. G., \& Tarricone, L. (2011). RFID and WSNs for traceability of agricultural goods from Farm to Fork: electromagnetic and deployment aspects on wine test-cases. Paper presented at the software, telecommunications and computer networks (SoftCOM), 2011 19th international conference on.

Consonni, R., \& Cagliani, L. (2010). Nuclear magnetic resonance and chemometrics to assess geographical origin and quality of traditional food products. Advances in food and nutrition research, 59, 87-165.

Consumers, E. C. H. a. (2010). Guidance on the Implementation of Articles $11,12,16,17,18,19$ and 20 of Regulation (EC) N 0 178/2002. Retrieved February, 2, 2006.

Costa, C., Antonucci, F., Pallottino, F., Aguzzi, J., Sarriá, D., \& Menesatti, P. (2013). A review on agri-food supply chain traceability by means of RFID technology. Food and Bioprocess Technology, 6(2), 353-366.

Cozzolino, D. (2014). An overview of the use of infrared spectroscopy and chemometrics in authenticity and traceability of cereals. Food Research International, 60, 262-265.

Chen, Q., Zhang, C., Zhao, J., \& Ouyang, Q. (2013). Recent advances in emerging imaging techniques for non-destructive detection of food quality and safety. TrAC Trends in Analytical Chemistry, 52, 261-274.

Chen, Y.-Y., Wang, Y.-J., \& Jan, J.-K. (2014). A novel deployment of smart cold chain system using 2G-RFID-Sys. Journal of Food Engineering, $141,113-121$.

Chifu, V. R., \& Salomie, I. (2007). Ontology-enhanced description of traceability services. Paper presented at the Intelligent Computer Communication and Processing, 2007 IEEE International Conference on.

Dabbene, F., Gay, P., \& Tortia, C. (2014). Traceability issues in food supply chain management: A review. Biosystems Engineering, 120, 65-80.

De Mattia, F., Bruni, I., Galimberti, A., Cattaneo, F., Casiraghi, M., \& Labra, M. (2011). A comparative study of different DNA barcoding markers for 
the identification of some members of Lamiacaea. Food Research International, 44(3), 693-702.

Defraeye, T., Cronje, P., Berry, T., Opara, U. L., East, A., Hertog, M., Verboven, P., \& Nicolai, B. (2015a). Towards integrated performance evaluation of future packaging for fresh produce in the cold chain. Trends in Food Science \& Technology, 44(2), 201-225.

Defraeye, T., Cronje, P., Verboven, P., Opara, U. L., \& Nicolai, B. (2015b). Exploring ambient loading of citrus fruit into reefer containers for cooling during marine transport using computational fluid dynamics. Postharvest Biology and Technology, 108, 91-101.

Defraeye, T., Lambrecht, R., Tsige, A. A., Delele, M. A., Opara, U. L., Cronjé, P., Verboven, P., \& Nicolai, B. (2013). Forced-convective cooling of citrus fruit: package design. Journal of Food Engineering, 118(1), 818.

do Nascimento Nunes, M. C., Nicometo, M., Emond, J. P., Melis, R. B., \& Uysal, I. (2014). Improvement in fresh fruit and vegetable logistics quality: berry logistics field studies. Philosophical Transactions of the Royal Society of London A: Mathematical, Physical and Engineering Sciences, 372(2017), 20130307.

Drummond, N., Horridge, M., Stevens, R., Wroe, C., \& Sampaio, S. (2007). Pizza ontology. The University of Manchester, 2.

Dupont. (2010). Evaluation report, Tyvek Homewrap, Air Barrier Material, from http://www.dupont.com/content/dam/assets/products-andservices/construction-materials/assets/SPEC-29\%20$\%$ 20Evaluation\%20Report\%20Tyvek\%20HomeWrap\%20CCMC\%2012857-R.pdf

Dupont. (2016). Tyvek ${ }^{\circledR}$ Cargo Covers: The Science Behind the Covers., from http://www.dupont.com/products-and-services/fabrics-fibersnonwovens/covers/articles/air-cargo-covers-science-behind.html

Dutra, S., Adami, L., Marcon, A., Carnieli, G., Roani, C., Spinelli, F., Leonardelli, S., Ducatti, C., Moreira, M., \& Vanderlinde, R. (2011). Determination of the geographical origin of Brazilian wines by isotope and mineral analysis. Analytical and bioanalytical chemistry, 401(5), 1571-1576.

Easwaran, S., \& Thottupuram, R. (2011). Farm-agro ontology formation: a black pepper model. International Journal of Research and Reviews in Information Technology, 1.

Emond, J., \& Nicometo, M. (2006). Shelf-life prediction and FEFO inventory management with RFID. Paper presented at the Cool Chain Association Workshop. 
Estrada-Flores, S., \& Eddy, A. (2006). The use of thermography to aid design of refrigerated road vehicles. Paper presented at the IIRIRHACE Conference University of Auckland.

Estrada-Flores, S., \& Eddy, A. (2007). Thermographic survey of refrigerated facilities. Proc. 22nd Int Cong Ref. ICR 2007. International Institute of Refrigeration. Beijing, China.

FAO. (2012). Final 2012 Data and Preliminary 2013 Data for 5 major commodity aggregates, from http://faostat.fao.org/site/339/default.aspx

FAO. (2013). Food wastage footprint-Impacts on natural resources: summary report (Vol. AC11057878,): Food and Agriculture Organization of the United Nations.

Feng, J., Fu, Z., Wang, Z., Xu, M., \& Zhang, X. (2013). Development and evaluation on a RFID-based traceability system for cattle/beef quality safety in China. Food control, 31(2), 314-325.

Fiddes, L. K., \& Yan, N. (2013). RFID tags for wireless electrochemical detection of volatile chemicals. Sensors and Actuators B: Chemical, $186,817-823$.

FLIR. (2013). User's manual FLIR Ex series

FLIR. (2015). Use low-cost materials to increase target emissivity, from http://www.flir.com/science/blog/details/?ID=71556

Fritz, M., \& Schiefer, G. (2009). Tracking, tracing, and business process interests in food commodities: A multi-level decision complexity. International Journal of Production Economics, 117(2), 317-329.

FSMA, U. (2011). Food Safety Modernization Act, from http://thomas.loc.gov/cgi-bin/bdquery/z?d111:H.R.2751

Galimberti, A., De Mattia, F., Losa, A., Bruni, I., Federici, S., Casiraghi, M., Martellos, S., \& Labra, M. (2013). DNA barcoding as a new tool for food traceability. Food Research International, 50(1), 55-63.

Giusto, D., Iera, A., Morabito, G., \& Atzori, L. (2010). The internet of things: 20th Tyrrhenian workshop on digital communications: Springer Science \& Business Media.

Glykas, K. B. (2010). Fuzzy cognitive maps: advances in theory, methodologies, tools and applications (studies in fuzziness and soft computing): Springer, Heidelberg 
Golan, E., Krissoff, B., Kuchler, F. . (2004). Food traceability: one ingredient in a safe and efficient food supply, economic research service. Amber Waves 2, 14-21.

González-Martín, M. I., Moncada, G. W., González-Pérez, C., San Martín, N. Z., López-González, F., Ortega, I. L., \& Hernández-Hierro, J.-M. (2014). Chilean flour and wheat grain: tracing their origin using near infrared spectroscopy and chemometrics. Food chemistry, 145, 802806.

Gowen, A., Tiwari, B., Cullen, P., McDonnell, K., \& O'Donnell, C. (2010). Applications of thermal imaging in food quality and safety assessment. Trends in food science \& technology, 21(4), 190-200.

Graça, M., Cressa, C., Gessner, T., Feio, M., Callies, K., \& Barrios, C. (2005). Food quality, feeding preferences, survival and growth of shredders from temperate and tropical streams. Freshwater Biology, 46(7), 947957.

GSI, A. (2010). Australia serving up safety and traceability, from http://www.ferret.com.au/c/GS1-Australia

Gunders, D. (2012). Wasted: How America is losing up to 40 percent of its food from farm to fork to landfill. Natural Resources Defense Council.

Gustavsson, J., Cederberg, C., Sonesson, U., Van Otterdijk, R., \& Meybeck, A. (2011). Global food losses and food waste. Food and Agriculture Organization of the United Nations, Rom.

Gwanpua, S. G., Verboven, P., Leducq, D., Brown, T., Verlinden, B., Bekele, E., Aregawi, W., Evans, J., Foster, A., \& Duret, S. (2015). The FRISBEE tool, a software for optimising the trade-off between food quality, energy use, and global warming impact of cold chains. Journal of Food Engineering, 148, 2-12.

Hendrik Haan, G., Hillegersberg, J. V., De Jong, E., \& Sikkel, K. (2013). Adoption of wireless sensors in supply chains: a process view analysis of a pharmaceutical cold chain. Journal of theoretical and applied electronic commerce research, 8(2), 138-154.

Hong, I.-H., Dang, J.-F., Tsai, Y.-H., Liu, C.-S., Lee, W.-T., Wang, M.-L., \& Chen, P.-C. (2011). An RFID application in the food supply chain: A case study of convenience stores in Taiwan. Journal of food engineering, 106(2), 119-126.

Horacek, M., \& Min, J.-S. (2010). Discrimination of Korean beef from beef of other origin by stable isotope measurements. Food Chemistry, 121(2), 517-520. 
Ibarra, J. G., Tao, Y., \& Xin, H. (2000). Combined IR imaging-neural network method for the estimation of internal temperature in cooked chicken meat. Optical engineering, 39(11), 3032-3038.

Iglesias, I., Echeverría, G., \& Lopez, M. (2012). Fruit color development, anthocyanin content, standard quality, volatile compound emissions and consumer acceptability of several 'Fuji'apple strains. Scientia Horticulturae, 137, 138-147.

James, S., James, C., \& Evans, J. (2006). Modelling of food transportation systems-a review. International Journal of Refrigeration, 29(6), 947957.

Jedermann, R., Becker, M., Gorg, C., \& Lang, W. (2011a). Testing network protocols and signal attenuation in packed food transports. International Journal of Sensor Networks, 9(3-4), 170-181.

Jedermann, R., \& Lang, W. (2009). The Minimum Number of SensorsInterpolation of Spatial Temperature Profiles in Chilled Transports. Paper presented at the EWSN.

Jedermann, R., Nicometo, M., Uysal, I., \& Lang, W. (2014a). Reducing food losses by intelligent food logistics. Philosophical Transactions of the Royal Society of London A: Mathematical, Physical and Engineering Sciences, 372(2017), 20130302.

Jedermann, R., Nicometo, M., Uysal, I., Opara, L., Janssen, S., \& Lang, W. (2015). Intelligent food logistics. The Royal Society: London, UK.

Jedermann, R., Palafox-Albarrán, J., Robla, J. I., Barreiro, P., Ruiz-García, L., \& Lang, W. (2011b). Interpolation of spatial temperature profiles by sensor networks. Paper presented at the Sensors, 2011 IEEE.

Jedermann, R., Pötsch, T., \& Lloyd, C. (2014b). Communication techniques and challenges for wireless food quality monitoring. Philosophical Transactions of the Royal Society of London A: Mathematical, Physical and Engineering Sciences, 372(2017), 20130304.

Jedermann, R., Ruiz-Garcia, L., \& Lang, W. (2009). Spatial temperature profiling by semi-passive RFID loggers for perishable food transportation. Computers and Electronics in Agriculture, 65(2), 145154.

Jha, S. N., Narsaiah, K., Basediya, A., Sharma, R., Jaiswal, P., Kumar, R., \& Bhardwaj, R. (2011). Measurement techniques and application of electrical properties for nondestructive quality evaluation of foods-a review. Journal of food science and technology, 48(4), 387-411.

Jones, P., Clarke-Hill, C., Shears, P., Comfort, D., \& Hillier, D. (2004). Radio frequency identification in the UK: opportunities and challenges. 
International Journal of Retail \& Distribution Management, 32(3), 164171.

Karlsen, K. M., Dreyer, B., Olsen, P., \& Elvevoll, E. O. (2013). Literature review: Does a common theoretical framework to implement food traceability exist? Food Control, 32(2), 409-417.

Kelepouris, T., Pramatari, K., \& Doukidis, G. (2007). RFID-enabled traceability in the food supply chain. Industrial Management \& Data Systems, 107(2), 183-200.

Kim, H. M., Fox, M. S., \& Gruninger, M. (1995). An ontology of quality for enterprise modelling. Paper presented at the Enabling Technologies: Infrastructure for Collaborative Enterprises, 1995., Proceedings of the Fourth Workshop on.

Kim, W. R., Aung, M. M., Chang, Y. S., \& Makatsoris, C. (2015). Freshness Gauge based cold storage management: A method for adjusting temperature and humidity levels for food quality. Food Control, 47, 510-519.

Kiritsis, D. (2011). Closed-loop PLM for intelligent products in the era of the Internet of things. Computer-Aided Design, 43(5), 479-501.

Kosko, B. (1986). Fuzzy cognitive maps. International Journal of manmachine studies, 24(1), 65-75.

Koutsoumanis, K., Taoukis, P., \& Nychas, G. (2005). Development of a safety monitoring and assurance system for chilled food products. International journal of food microbiology, 100(1), 253-260.

Kumar, R., Kumar, A., \& Murthy, U. N. (2008). Heat transfer during forced air precooling of perishable food products. Biosystems engineering, 99(2), 228-233.

Laniel, M., Uysal, I., \& Emond, J.-P. (2011). Radio frequency interactions with air cargo container materials for real-time cold chain monitoring. Applied Engineering in Agriculture, 27(4), 647-652.

Lee, W., Alchanatis, V., Yang, C., Hirafuji, M., Moshou, D., \& Li, C. (2010). Sensing technologies for precision specialty crop production. Computers and electronics in agriculture, 74(1), 2-33.

Lian, F., Zhao, W., Yang, R.-j., Tang, Y., \& Katiyo, W. (2015). Survival of Salmonella enteric in skim milk powder with different water activity and water mobility. Food Control, 47, 1-6.

Likar, K., \& Jevšnik, M. (2006). Cold chain maintaining in food trade. Food Control, 17(2), 108-113. 
Liu, N., Babushkin, V., \& Afshari, A. (2014). Short-Term Forecasting of Temperature Driven Electricity Load Using Time Series and Neural Network Model. Journal of Clean Energy technologies, 2(4), 327-331.

Liu, Y., Gao, M., Wu, W., Tanveer, S. K., Wen, X., \& Liao, Y. (2013). The effects of conservation tillage practices on the soil water-holding capacity of a non-irrigated apple orchard in the Loess Plateau, China. Soil and Tillage Research, 130, 7-12.

Lopuch, K., Syrett, L., Conrad, J., \& Steenhuis, H.-J. (2011). Technology, quality and trade in the apple industry. Paper presented at the Industrial Engineering and Engineering Management (IEEM), 2011 IEEE International Conference on.

Lutjen, M., Dittmer, P., \& Veigt, M. (2012). Towards Quality Driven Distribution of Intelligent Containers in Cold Chain Logistics Networks.

Lütjen, M., Dittmer, P., \& Veigt, M. (2013). Quality driven distribution of intelligent containers in cold chain logistics networks. Production Engineering, 7(2-3), 291-297.

Mack, M., Dittmer, P., Veigt, M., Kus, M., Nehmiz, U., \& Kreyenschmidt, J. (2014). Quality tracing in meat supply chains. Philosophical Transactions of the Royal Society of London A: Mathematical, Physical and Engineering Sciences, 372(2017), 20130308.

Macnish, A. J., Padda, M. S., Pupin, F., Tsouvaltzis, P. I., Deltsidis, A. I., Sims, C. A., Brecht, J. K., \& Mitcham, E. J. (2012). Comparison of pallet cover systems to maintain strawberry fruit quality during transport. HortTechnology, 22(4), 493-501.

Mahajan, P. V., Caleb, O., Singh, Z., Watkins, C., \& Geyer, M. (2014). Postharvest treatments of fresh produce. Philosophical Transactions of the Royal Society of London A: Mathematical, Physical and Engineering Sciences, 372(2017), 20130309.

Mainetti, L., Mele, F., Patrono, L., Simone, F., Stefanizzi, M. L., \& Vergallo, R. (2013a). An RFID-based tracing and tracking system for the fresh vegetables supply chain. International Journal of Antennas and Propagation, 2013.

Mainetti, L., Patrono, L., Stefanizzi, M. L., \& Vergallo, R. (2013b). An innovative and low-cost gapless traceability system of fresh vegetable products using RF technologies and EPCglobal standard. Computers and electronics in agriculture, 98, 146-157.

Mainetti, L., Patrono, L., \& Vergallo, R. (2012). IDA-Pay: a secure and efficient micro-payment system based on Peer-to-Peer NFC technology for Android mobile devices. Journal of Communications Software \& Systems, 8(4). 
Mc Carthy, U. M., Ayalew, G., Mc Donnell, K., Butler, F., \& Ward, S. (2011). The Case for UHF RFID application in the meat supply chain in the Irish context: a review perspective. Agricultural Engineering International: CIGR Journal, 13(3).

Mc Inerney, B., Corkery, G., Ayalew, G., Ward, S., \& Mc Donnell, K. (2010). A preliminary in vivo study on the potential application of e-tracking in poultry using ink printed 2D barcodes. Computers and electronics in agriculture, 73(2), 112-117.

McEntire, J. C., Arens, S., Bernstein, M., Bugusu, B., Busta, F. F., Cole, M., Davis, A., Fisher, W., Geisert, S., \& Jensen, H. (2010). Traceability (product tracing) in food systems: an IFT report submitted to the FDA, volume 1: technical aspects and recommendations. Comprehensive Reviews in Food Science and Food Safety, 9(1), 92-158.

Miller, B. D., Welt, B.A. . (2014). Critical Tracking Events Approach to Food Traceability. Encyclopedia of Agriculture and Food Systems, 387-398.

Molkentin, J., \& Giesemann, A. (2007). Differentiation of organically and conventionally produced milk by stable isotope and fatty acid analysis. Analytical and Bioanalytical Chemistry, 388(1), 297-305.

Montanari, R. (2008). Cold chain tracking: a managerial perspective. Trends in Food Science \& Technology, 19(8), 425-431.

NAFTS. (2013). Canadian Traceability, from http://www.atssea.agr.gc.ca/trac/sys-eng.htm

Newsome, R. L., Bhatt, T., \& McEntire, J. C. (2013). Proceedings of the July 2011 Traceability Research Summit. Journal of food science, 78(s2), B1-B8.

NFC-Forum. (2014). NFC Forum What is NFC, from http://nfcforum.org/what-is-nfc/about-the-technology/

Ngai, E. W., Cheng, T. E., Au, S., \& Lai, K.-h. (2007). Mobile commerce integrated with RFID technology in a container depot. Decision Support Systems, 43(1), 62-76.

Ngcobo, M. E., Delele, M. A., Opara, U. L., \& Meyer, C. J. (2013). Performance of multi-packaging for table grapes based on airflow, cooling rates and fruit quality. Journal of Food Engineering, 116(2), 613-621.

Norton, T., Tiwari, B., \& Sun, D.-W. (2013). Computational fluid dynamics in the design and analysis of thermal processes: A review of recent advances. Critical reviews in food science and nutrition, 53(3), 251275. 
Noy, N. F., \& McGuinness, D. L. (2001). Ontology development 101: A guide to creating your first ontology: Stanford knowledge systems laboratory technical report KSL-01-05 and Stanford medical informatics technical report SMI-2001-0880, Stanford, CA

Olsen, P., \& Borit, M. (2013). How to define traceability. Trends in food science \& technology, 29(2), 142-150.

Opara, L. U. (2003). Traceability in agriculture and food supply chain: a review of basic concepts, technological implications, and future prospects. Journal of Food Agriculture and Environment, 1, 101-106.

Pang, Z., Chen, Q., \& Zheng, L. (2012). Scenario-based design of wireless sensor system for food chain visibility and safety Advances in Computer, Communication, Control and Automation (pp. 541-548): Springer.

Peck, R., Peter, M., Karl, K., Royce, H., Peter, L., Travis, H., Désirée, V., \& Andrew, G. (2015). Technical Report No. 72, Passive Thermal Protection Systems for Global Distribution: Qualification and Operational Guidance. In P. D. Association (Ed.).

Pelletier, W., Brecht, J. K., do Nascimento Nunes, M. C., \& Émond, J.-P. (2011). Quality of strawberries shipped by truck from California to Florida as influenced by postharvest temperature management practices. HortTechnology, 21(4), 482-493.

Perini, M., Camin, F., Bontempo, L., Rossmann, A., \& Piasentier, E. (2009). Multielement $(\mathrm{H}, \mathrm{C}, \mathrm{N}, \mathrm{O}, \mathrm{S})$ stable isotope characteristics of lamb meat from different Italian regions. Rapid communications in mass spectrometry, 23(16), 2573-2585.

Pizzuti, T., Mirabelli, G., Sanz-Bobi, M. A., \& Goméz-Gonzaléz, F. (2014). Food Track \&amp; Trace ontology for helping the food traceability control. Journal of Food Engineering, 120, 17-30. doi: http://dx.doi.org/10.1016/j.jfoodeng.2013.07.017

Qi, L., Xu, M., Fu, Z., Mira, T., \& Zhang, X. (2014). C 2 SLDS: a WSN-based perishable food shelf-life prediction and LSFO strategy decision support system in cold chain logistics. Food Control, 38, 19-29.

Qi, L., Zhang, J., Xu, M., Fu, Z., Chen, W., \& Zhang, X. (2011). Developing WSN-based traceability system for recirculation aquaculture. Mathematical and Computer Modelling, 53(11), 2162-2172.

Qi, M., \& Zhang, G. (2008). Trend time-series modeling and forecasting with neural networks. Neural Networks, IEEE Transactions on, 19(5), 808816. 
Qian, J.-P., Yang, X.-T., Wu, X.-M., Zhao, L., Fan, B.-L., \& Xing, B. (2012). A traceability system incorporating 2D barcode and RFID technology for wheat flour mills. Computers and electronics in agriculture, 89, 76-85.

Regattieri, A., Gamberi, M., \& Manzini, R. (2007). Traceability of food products: General framework and experimental evidence. Journal of food engineering, 81(2), 347-356.

Ren, G., Wang, S., Ning, J., Xu, R., Wang, Y., Xing, Z., Wan, X., \& Zhang, Z. (2013). Quantitative analysis and geographical traceability of black tea using Fourier transform near-infrared spectroscopy (FT-NIRS). Food research international, 53(2), 822-826.

Romeu, P., Zamora-Martínez, F., Botella-Rocamora, P., \& Pardo, J. (2013). Time-series forecasting of indoor temperature using pre-trained deep neural networks Artificial Neural Networks and Machine LearningICANN 2013 (pp. 451-458): Springer.

Ruiz-García, L. (2008). Development of monitoring applications for refrigerated perishable goods transportation. Agronomos.

Ruiz-Garcia, L., Barreiro, P., \& Robla, J. (2008). Performance of ZigBee-based wireless sensor nodes for real-time monitoring of fruit logistics. Journal of Food Engineering, 87(3), 405-415.

Ruiz-Garcia, L., Barreiro, P., Robla, J. I., \& Lunadei, L. (2010a). Testing ZigBee motes for monitoring refrigerated vegetable transportation under real conditions. Sensors, 10(5), 4968-4982.

Ruiz-Garcia, L., \& Lunadei, L. (2011). The role of RFID in agriculture: Applications, limitations and challenges. Computers and Electronics in Agriculture, 79(1), 42-50. doi: http://dx.doi.org/10.1016/j.compag.2011.08.010

Ruiz-Garcia, L., Steinberger, G., \& Rothmund, M. (2010b). A model and prototype implementation for tracking and tracing agricultural batch products along the food chain. Food Control, 21(2), 112-121.

Sakai, Y., Ishihata, K., Nakano, S., Yamada, T., Yano, T., Uchida, K., Nakao, Y., Urisu, A., Adachi, R., \& Teshima, R. (2010). Specific detection of banana residue in processed foods using polymerase chain reaction. Journal of agricultural and food chemistry, 58(14), 8145-8151.

Sánchez-López, T., \& Kim, D. (2008). Wireless sensor networks and RFID integration for context aware services. In White Paper Series 2008; AUTOIDLABS-WP-SWNET-026, Daejeon, Korea, 2008.

Scheer, F. (2006). Optimising supply chains using traceability systems. Improving traceability in food processing and distribution, 52-64. 
Schwanghart, W. (2010). Ordinary Kriging. http://www.mathworks.com/

Shanahan, C., Kernan, B., Ayalew, G., McDonnell, K., Butler, F., \& Ward, S. (2009). A framework for beef traceability from farm to slaughter using global standards: An Irish perspective. Computers and electronics in agriculture, 66(1), 62-69.

Storøy, J., Thakur, M., \& Olsen, P. (2013). The TraceFood FrameworkPrinciples and guidelines for implementing traceability in food value chains. Journal of food engineering, 115(1), 41-48.

Sugahara, K. (2008). Traceability system for agricultural productsbased on RFID and mobile technology Computer and Computing Technologies in Agriculture II, Volume 3 (pp. 2293-2301): Springer.

Suzuki, Y., Chikaraishi, Y., Ogawa, N. O., Ohkouchi, N., \& Korenaga, T. (2008). Geographical origin of polished rice based on multiple element and stable isotope analyses. Food Chemistry, 109(2), 470-475.

Thakur, M., Sørensen, C.-F., Bjørnson, F. O., Forås, E., \& Hurburgh, C. R. (2011). Managing food traceability information using EPCIS framework. Journal of Food Engineering, 103(4), 417-433.

Theodorou, S. (2006). A classification approach for RFID-based sensor integration. A thesis for the degree of Master.

Trafton, A. (2014). Detecting gases wirelessly and cheaply. MIT News Office

Twist, D. C. (2005). The impact of radio frequency identification on supply chain facilities. Journal of Facilities Management, 3(3), 226-239.

UNEP. (2013). Food waste facts, from http://www.unep.org/wed/2013/quickfacts/

Uysal, I., Emond, J.-P., \& Bennett, G. (2011). Tag testing methodology for RFID enabled temperature tracking and shelf life estimation. Paper presented at the RFID-Technologies and Applications (RFID-TA), 2011 IEEE International Conference on.

Van der Vorst, J., Van Kooten, O., Marcelis, W., Luning, P., \& Beulens, A. J. (2007). Quality controlled logistics in food supply chain networks: integrated decision-making on quality and logistics to meet advanced customer demands. Paper presented at the Proceedings of the Euroma 2007 conference, Ankara, Turkey.

Vandeginste, B., \& Brereton, P. (2013). Chemometrics in studies of food origin. New analytical approaches for verifying the origin of food, 117145. 
Varela, P., Salvador, A., \& Fiszman, S. (2008). Shelf-life estimation of 'Fuji'apples: II. The behavior of recently harvested fruit during storage at ambient conditions. Postharvest biology and technology, 50(1), 6469.

Versari, A., Laurie, V. F., Ricci, A., Laghi, L., \& Parpinello, G. P. (2014). Progress in authentication, typification and traceability of grapes and wines by chemometric approaches. Food Research International, 60, 218.

Wang, Y., Yang, Y., \& Gu, Y. (2012). Research on Quality and Safety Traceability System of Fruit and Vegetable Products Based on Ontology. Journal of Convergence Information Technology, 7(1).

Welt, B., Blanchfield, J.R. . (2012). UFoST Scientific Information Bulletin (SIB) from http://www.iufost.org/iufostftp/IUF.SIB.Food\%20Traceability.pdf

Yang, Z. F., Cong, P. H., Nie, J. Y., Li, J., \& Li, H. F. (2006). Current status, problems and suggestions of apple industry in China. Northern Fruits, $5,34-35$.

Yousefi, A., Asadi, V., Nassiri, S. M., Niakousari, M., \& Aghdam, S. K. (2013). Comparison of mathematical and neural network models in the estimation of papaya fruit moisture content. The Philippine Agricultural Scientist, 95(3).

Yue, J., Wen, H., Zhang, X., \& Fu, Z. (2005). Ontology based vegetable supply chain knowledge expressing. Paper presented at the Semantics, Knowledge and Grid, 2005. SKG'05. First International Conference on.

Zhang, G., \& Qi, M. (2005). Neural network forecasting for seasonal and trend time series. European journal of operational research, 160(2), 501514.

Zhang, M., \& Li, P. (2012). RFID application strategy in agri-food supply chain based on safety and benefit analysis. Physics Procedia, 25, 636-642.

Zhao, Y., Zhang, B., Chen, G., Chen, A., Yang, S., \& Ye, Z. (2014). Recent developments in application of stable isotope analysis on agro-product authenticity and traceability. Food chemistry, 145, 300-305.

Zou, Z., Chen, Q., Uysal, I., \& Zheng, L. (2014). Radio frequency identification enabled wireless sensing for intelligent food logistics. Philosophical Transactions of the Royal Society of London A: Mathematical, Physical and Engineering Sciences, 372(2017), 20130313. 



\section{Appendices}

\section{A.1. Food traceability: new trends and recent advances. A review}

This section has been published as an article in the journal of Food Control. Badia-Melis, R., Mishra, P., \& Ruiz-García, L. (2015). Food traceability: New trends and recent advances. A review. Food Control, 57, 393-401.

\section{Abstract}

Current traceability systems are characterized by the inability to link food chains records, inaccuracy and errors in records and delays in obtaining essential data, which are fundamental in case of food outbreak disease; these systems should address the recall and withdraw of non-consumable products. The present paper provides a review of the various latest technological advancements such as innovative implementations of RFID that can make to increase the sales of wheat flour, or allowing the consumer to know the full record of the IV range products through the smartphone; knowing the food authenticity with an isotope analysis or by analysing the DNA sequences. There are also presented some conceptual advancements in the field of food 
traceability such as the development of a common framework towards unifying the present technical regulations, the interconnectivity between agents, environment loggers and products, all of them in the form of Internet of things system as well as the development of intelligent traceability, where it is possible to retrieve the temperature of a product or its remaining shelflife.

These new techniques and concepts provide new opportunities for enhancing the efficiency and compatibility of the present traceability systems.

\section{Keywords: Food traceability, food control, traceability systems, Internet of Things}

\section{Introduction}

After a detailed investigation of the true definition of traceability Olsen and Borit (2013), came with a compendium of all the definitions saying that traceability is "The ability to access any or all information relating to that which is under consideration, throughout its entire life cycle, by means of recorded identifications".

Food traceability pretends to be of high potential for consumer's protection by targeting precisely the recall, eliminate the non-consumable food products and promoting the investigation of the causes of food safety issues; all of that by being an integral part of food safety, food quality, food defence and intrinsic requirement of the food supply-chain. The worldwide acceptance of the food traceability such as Patagonia traces in Argentina (Welt, 2012), merging of GS1 Australia with Efficient Consumer Response Australasia (ECRA), supported by the Australian Food and Grocery Council (AFGC) and other key government agencies and department to establish a portal for all products recall and withdraw (GSI, 2010), National Agriculture and Food Traceability System (NAFTS, 2013) in Canada, the embracement of "Internet of Things" and establishment of a future cloud computing centre in Shanghai's Jinshan district to ensure food traceability in China (Anon, 2011), regulation 
no. 178/2002 and EU Rapid Alert System for Food and Feed (RASFF) in European Union, use of tracking and tracing software Grapenet for export of table grapes from India to EU (Bujji, 2012), introduction of full beef traceability system in Korea (ICT in 2011), the US Bioterrorism Act (Atlas, 2002) and the Food Modernization and Safety Act (FSMA, 2011) in USA, further strengthen the faith of global community in Food Traceability. Therefore since traceability is a well-known concern for the majority of the food industry, a study like the presented here aims to bring some perspective about the new trends and recent advances, presenting the newer technological and conceptual techniques and showing their novelty.

Pizzuti et al. (2014) write about the inability to link food chains records that characterizes the current traceability systems, also describes the inaccuracy and errors in records and delays in obtaining essential data. The access to this information is key in case of a food outbreak disease and it's necessary for the job of food safety agents.

Also traceability has driven many issues related to Food crisis management, traceability of bulk products, Quality and identity-preservation concerns and Fraud prevention and anti-counterfeiting concerns in the past years (Dabbene et al., 2014). USDA Economic Research Service states that besides ensuring a safe food supply, use of traceability system results in lower cost distribution systems, reduced recall expenses, and expanded sales of products with attributes that are difficult to discern (Golan, 2004). Even many food producers have good electronic traceability system internally, but exchange of information between the links in the supply chain is very time consuming or difficult due to the diversity and proprietary nature of the respective internal systems (Storøy et al., 2013) hence, they do not realize the true value of using an electronic traceability system as the cost of installing technology and operating the system exceeds the benefits.

So there is a need of a change, where all the agents in the supply chain stand to gain, there are new trends in the Food Traceability sector focused on improving the processes such as Food Track and Trace Ontology (FTTO) and Critical Tracking Events (CTE) combined within the TraceFood Framework, can provide new advances for improving the efficiency and compatibility of the 
present traceability system. On one hand the Critical Tracking Event provides fast and effective food traceability system (McEntire et al., 2010) with security in terms of data ownership, data access and proprietary information protection, and Food Track and Trace Ontology provides integration among heterogeneous databases enabling inter-operability among different systems (Pizzuti et al., 2014), which is not a common fact in Food Traceability, in the other hand TraceFood Framework provide principles and guidelines for implementing traceability in food value chains. The growing diffusion of new technologies coupled together with the availability of new computational and simulation models seems to be significantly improving the present value of Food Traceability and would solve the problems of no communication between agents and provide a solid and homogeneous line to work, instead having a whole variety of rules completely heterogeneous.

Tracking and tracing can only be effective; if it is implemented as a sector encompassing systems approach (Fritz \& Schiefer, 2009). In order to do an efficient product monitoring, the industries have always required an easily applicable and low cost traceability technique, the most recent advances can offer efficiency with the latest technologies such as chemometrics modelling, isotope analysis or DNA barcoding despite of not being the cheapest techniques. And in the other hand wireless monitoring devices are still being improved and implemented in many innovative research studies (Badia-Melis et al., 2013; Badia-Melis et al., 2014; Badia-Melis et al., 2015; L. Qi et al., 2014; Zou et al., 2014), with the purpose of bringing an affordable and easy way of traceability

Supply chain visibility is being pushed to a new stage by government regulations and consumer requirements; it means that food traceability is becoming a reality, reality that will go from "farm to fork" (Aung \& Chang, 2014).

\section{Technological Advancements}

In the recent years as the world has become more global, food traceability has gained importance, traditional methods are not enough for certain 
products and the necessity for obtaining food records has increased, the recent advances in terms of technology are summarized in the Table A.1.

\subsection{RFID, still a promising tool for traceability control}

The current advancements in RFID technology and the incorporation of integral parts such as data logger capabilities and integrated sensors, has provided a new dimension to the application of RFID technology in the food traceability systems, as it is gathered in the article of Ruiz-Garcia and Lunadei (2011), the applications of RFID to the food traceability are many and varied. During the last decade RFID has emerged as a lead actor in the development of traceability systems in the food supply chain and their implementations are increasing at a fast rate (Costa et al., 2013). With the implementation of RFID technology, food traceability systems can become more reliable and efficient since RFID enables a higher reading rate than traditional barcodes (Hong et al., 2011). With identification of the products without any physical contact, the RFID technology provides effective information sharing with efficient customization and handling (M. Zhang \& Li, 2012). Kelepouris et al. (2007) proposed an infrastructure using RFID, where it was compared with the traditional lot numbering and internal information systems, it has the advantages of automatic identification, uniform EPC for all partners, small investment in equipment and easily drawn information.

Table A.1. Technological advancements

\begin{tabular}{lll} 
Technology & Concept & Author \\
\hline RFID & $\begin{array}{l}\text { Higher reading rate than } \\
\text { traditional barcodes. } \\
\text { RFID proved better than lot } \\
\text { numbering. }\end{array}$ & Hong et al. (2011) \\
$\begin{array}{l}\text { Cold traceability for combat } \\
\text { feeding logistics. } \\
\text { Cold traceability for temperature } \\
\text { sensitive products. }\end{array}$ & Amador and Emond (2010) \\
$\begin{array}{l}\text { Wheat Flour Milling Traceability } \\
\text { System. }\end{array}$ & Qian et al. (2012) \\
$\begin{array}{l}\text { Integration of RFID and Barcode } \\
\text { printer for cattle/beef supply } \\
\text { chain. } \\
\text { Cheese wheels tracking. } \\
\text { Enhance the traceability of the } \\
\text { white wine. }\end{array}$ & Feng et al. (2013) \\
& Barge et al. (2014)
\end{tabular}


Intelligent food logistics.

Zou et al. (2014)

End consumer knows the history Mainetti et al. (2013b)

of the product.

IV gama products traceability Mainetti et al. (2013a)

information.

Safely purchase the food. $\quad$ Y.-Y. Chen et al. (2014)

Gas detector in NFC tag. $\quad$ Trafton (2014)

Unique Quality tracing model for vacuum- Mack et al. (2014)

identification packed lamb.

and quality RFID, biometrics and identifiers for Shanahan et al. (2009)

of livestock verification of cattle identity.

Farm-to-fork traceability using Mc Carthy et al. (2011)

GS1-128 barcode.

DataMatrix barcodes onto the Mc Inerney et al. (2010)

beaks of chickens.

Isotope Approach for agro-product Zhao et al. (2014)

analysis authenticity and traceability using isotope analysis.

Identification of isotopes of beef Horacek and Min (2010);

and lamb.

Classification of milk, rice, wine

Perini et al. (2009)

Molkentin and Giesemann and olive oil.

(2007); Suzuki et al. (2008);

Dutra et al. (2011); Camin et al. (2009)

\begin{tabular}{ll}
\hline Chemometric & Traceability of cereals, olive oil, \\
s and NIRS & tea and wheat grain using NIR and \\
& MIR.
\end{tabular}

Near Magnetic Resonance for Bevilacqua et al. (2012);

Cozzolino (2014); GonzálezMartín et al. (2014); Ren et al. (2013). geographical origin and quality of Consonni and Cagliani (2010) traditional food products. Chemometrics analysis for wine identification.

\begin{tabular}{lll}
\hline DNA & DNA analysis applied for & Arcuri et al. (2013); S. Becker \\
barcoding & $\begin{array}{l}\text { traceability of seafood, meat, milk, } \\
\text { edible plants and processed food } \\
\text { and fruit residues. }\end{array}$ & $\begin{array}{l}\text { (2011); De Mattia et al. } \\
\text { (2011); Versari et al. (2014) }\end{array}$ \\
\hline
\end{tabular}

Agro-food logistics and supply chain management processes for food traceability using RFID are discussed since some years ago by several authors, i.e. Angeles (2005); Attaran (2007); Jones et al. (2004); Ngai et al. (2007); Shanahan et al. (2009); Twist (2005). Also quality oriented tracking and tracing systems FEFO implementing Radio Frequency Identification tags, is a topic argued in the literature (Emond \& Nicometo, 2006; Koutsoumanis et al., 2005; Scheer, 2006). Amador and Emond (2010) developed a system of RFID temperature tracking for combat feeding logistics. The capability of hosting sensors of the tags allows the called "cold traceability", concept that has been introduced to trace groups of temperature- sensitive products are transported in different atmosphere requirements (Ruiz-Garcia et al., 2010a). 
A Wheat Flour Milling Traceability System was developed by Qian et al. (2012) (WFMTS), incorporating 2D barcode and RFID technology, to validate the system in wheat flour mill in China. Labels with a QR Code were used to identify small wheat flour packages, and RFID tags were used to identify wheat flour bins and record logistics information automatically. They obtained that the total cost of the system increased by $17.2 \%$ however, with the new system the sales income increased by $32.5 \%$ and proved the high potential of good application of WFMTS in medium and large wheat mill enterprises.

Feng et al. (2013) developed and evaluated a cattle/beef traceability system, which integrated RFID technology with PDA and barcode printer. They obtained real-time and accurate data acquisition and transmission, and the high efficiency of information tracking and tracing across the cattle/beef supply chain.

Barge et al. (2014) automatically recorded cheese wheels movements during the production, handling in the maturing room and warehouse, delivery, packing and selling phases in a dairy factory with the help different techniques by fixing RFID tags to the cheese. They considered factors such as tag type and shape, required power, antennas polarization and orientation, fixing method and ripening duration to verify their effect on reading performance and system reliability.

Catarinucci et al. (2011) used a combination between WSN and RFID, in order to enhance the traceability of the white wine from vineyard to consumer glass. WSN is a wireless technology like RFID also tried in many other authors to improve the traceability in food quality (L. Qi et al., 2014) and aquaculture (L. Qi et al., 2011).

An IoT platform with a two-layer network architecture is the innovative way for implementing RFID for traceability in what is called "intelligent food logistics" (which is discussed further in this document), it consist on an asymmetric tag-reader link (RFID layer) and an ad-hoc link between readers (WSN layer), which are further connected to the Internet via cellular or Wi-Fi (Zou et al., 2014). 


\section{RFID barriers}

Some of the Ultra High Frequency tags (bands 860 MHz Europe 915 MHz USA) potentially useful and currently used for cold chain monitoring and traceability control present the disadvantages of more interferences than other frequencies. These different bands are only available in USA and Europe. Japan and China do not allow these transmissions (Ruiz-Garcia \& Lunadei, 2011).

The main barriers for implementing the RFID system in cattle/beef traceability system are the inapplicable method of inputting information, the inefficient sequence of data input and communication mechanism associated with RFID reader, and the high implementation cost (Feng et al., 2013). With many advantages of RFID technology it is still not a preferable choice of most of the companies as it leads additional cost to the company. However, the balance between the benefit and safety requirement of the company is the major driving force for the adoption of technologies like RFID (M. Zhang \& Li, 2012).

\subsection{Near Field Communication}

NFC or Near Field Communication is actually an extension or a subcategory of RFID. NFC technology enables simple and safe two-way interactions between electronic devices; it complements many popular wireless technologies at consumer level (in the existing standards for contactless card technologies ISO/IEC 14443 A\&B and JIS-X 6319-4). NFC enables devices to share information in less than $4 \mathrm{~cm}$ (NFC-Forum, 2014). It operates at $13.56 \mathrm{MHz}$ and currently supports data rates of $106,212,424$ or $848 \mathrm{Kbit} / \mathrm{s}$ (Mainetti et al., 2013a). These tags are made very small so that they can fit inside products for various reasons such as security, anti-theft and individual identification. NFC is the newer version of RFID that is typically for use in a very short distance for making payments (Mainetti et al., 2012) and information retrieval. Like RFID, the main advantage of NFC technology above barcode and QR codes is that it does not require a laser beam to have a solid path so that it can travel between two devices. 
Recently, Mainetti et al. (2013b) describe the potentialities from the combination of RFID and NFC; it allows the end consumer to know the complete history of the purchased product. They implemented the usage of NFC in a IV range products supply chain. NFC is proved to work together with a mobile app to allow the linking of plants and traceability information (Mainetti et al., 2013a).

Y.-Y. Chen et al. (2014) propose a scenario in the near future, where the consumer can use the smart phone to read passive information and essential parameters, and finally safely purchase the food.

MIT chemists have developed a NFC tag based in chemiresistors that is able to detect certain gases. They disrupted the electronic circuit by making a hole in it, and after reconnect the circuit with a linker made of carbon nanotubes. When the targeted gas is present the conductivity of the nanotubes change and they are able to read the tag with a smartphone and detect the presence of the gas (Trafton, 2014).

\subsection{New advances in unique identification and quality of livestock}

In order to reduce the food waste and improve the resources efficiency of food production, Mack et al. (2014) developed a quality tracing model for vacuum-packed lamb that is applicable in different meat supply chains. It is a system able to register the most relevant sensory parameters, then processing the data with Arrhenius model, a linear primary model and finishing with a decision support tool, in combination with the temperature monitoring equipment for the improvement of quality and storage management within the meat logistics network.

Shanahan et al. (2009) proposed a system of traceability that can be used to identify all aspects of beef traceability from farm to slaughter, as they point, an integrated traceability system involving all of the stakeholders along the supply chain, can serve to increase consumer confidence in beef products by making traceability data accessible to the consumer. In their publication they propose the usage of RFID, biometrics and identifiers for verification of cattle identity. The final idea is to convert the animal ID data to the EPC, in order to 
facilitate the use of EPC global Network for the exchange of traceability data. Also Mc Carthy et al. (2011) wrote about the traditional ear tag in calves and its challenges above all the human interaction and the consequent error possibility and manipulation, that is why they included in their paper the concept farm-to-fork traceability with the use of GS1-128 barcode. Since the animal is slaughtered and divided in quarters a barcode is printed and attached to each quarter with information such as carcass number, ear tag number, origin, factory of slaughter and some other relevant points, then as the meat is being processed to smaller parts the information of the process is recorded, including even the time under cold storage. There are certain problems according to Mc Carthy et al. (2011) like the limited data in the barcode and the weak integrity of the label in harsh environments. Due to these limitations they presented an alternative using RFID tags.

Mc Inerney et al. (2010) performed a preliminary in vivo study on application of e-tracking in poultry using different inks printed $10 \times 10$ DataMatrix barcodes onto the beaks of broiler chickens in a live commercial setting but the results demonstrated very poor percentage of readability. However they project future work possibilities, like using different kinds of inks, such as delayed effect ink, apply pre- or post-printing treatments to the beak or laser printing. These alternative are worthy of investigation in the future because the development of an individual identification system for the poultry chain would greatly enhance the security of the chain.

\subsection{Traceability for food products and processed food using isotope analysis and DNA barcoding}

The term stable isotope is preferably used when speaking of nuclides of a specific elements, it usually refers to isotopes of the same element. The relative abundance of such stable isotopes can be measured experimentally (isotope analysis), yielding an isotope ratio that can be used as a research tool. Stable isotope ratio analysis combined with other chemical methods like isotope ratio mass spectroscopy (IRMS), inductively coupled plasma mass (ICP-MS), chromatography, near infrared spectroscopy provides a promising approach for agro-product authenticity and traceability (Zhao et al., 2014). 
Stable isotope analysis has emerged as a powerful tool for tracing the geographical origin of the agro food products. Varying degrees of success has been obtained in identifying and differentiating the different agro food products such as meat, milk, cereal crops, wine and oil. Horacek and Min (2010) examined for carbon, nitrogen and hydrogen isotopes ratio in the defatted dry mass of beef samples from Korea, USA, Mexico, Australia and New Zealand and obtained a clear trend of carbon isotope for each group of sample and identifying their origin. Perini et al. (2009) with the help of multielement stable isotope classified the lambs from seven Italian regions according to their feeding and obtained a high classification of $97.7 \%$. Molkentin and Giesemann (2007) with the analysis of carbon isotope differentiated the conventional and organic milk successfully. Suzuki et al. (2008) clearly differentiated the rice samples from different areas of Australia, Japan and USA based on elemental and isotopic composition. Dutra et al. (2011) differentiated wines from three different wine making regions in south Brazil with the isotopic ratios of oxygen of wine water and carbon of ethanol. Camin et al. (2009) classified $95 \%$ of the olive oil samples from 8 European sites according to their production areas based on $\mathrm{H}, \mathrm{C}$ and $\mathrm{O}$ stable isotope ratios and 14 other elements.

The validation of food authenticity relies mostly on the analysis of proteins and/or DNA sequences. Protein-based methods include immunological assays, electrophoretical and chromatographic techniques such as HPLC and TLC (Galimberti et al., 2013).

DNA barcoding has been proven to be particularly effective in the traceability of seafood (Becker et al., 2011), this can be considered a reliable method for traceability of mammalian meat (Cai et al., 2011) or raw milk (Arcuri et al., 2013), as well as tracing system for edible plants (De Mattia et al., 2011). Other uses are encountered also for processed food, fruit residues (e.g. banana) in juices, purees, chocolates, cookies, etc. (Sakai et al., 2010).

\subsection{Chemometrics and NIRS for food traceability}

Chemometrics is the mathematical and statistical modeling applied to analytical data acquired in wide ranges of platforms in order to obtain relevant 
chemical information. The benefits of chemometric models over normal statistical models are that they are easy to maintain with good updatability, simple, robust for defective data and also can be easily converted into a set of specifications which can help in developing decision rules on the authenticity of the origin of food, which is an important consideration for traceability studies (Vandeginste \& Brereton, 2013). Synergistic use of instrumental analytical techniques and chemometrics modeling represents a promising way for the development of authenticity and traceability models, as traceability of food is an essential element in ensuring safety and high quality of food (Bertacchini et al., 2013).

Cozzolino (2014) performed a review regarding the use of near infrared (NIR) spectroscopy and mid infrared (MIR) spectroscopy combined with multivariate data analysis such as such as principal component analysis (PCA), partial least squares discriminant analysis (PLS-DA), linear discriminant analysis (LDA) to aid on the authentication and traceability of cereals. He stated and concluded that the development of new spectroscopy technologies such as hyper spectral imaging, micro spectroscopy combine with new algorithms will enhance the use of spectroscopy as one of the most useful tools for traceability and authentication of cereals.

Bevilacqua et al. (2012) used mid- and near-infrared spectroscopic techniques and chemometric methods for the traceability of extra virgin olive oil samples. Their results concluded that infrared spectroscopy with chemometrics being a fast, relatively cheap and non-invasive/non-destructive analysis is a powerful tool for the traceability of olive oil.

Versari et al. (2014) reviewed typification and authentication of wine and found that analytical chemistry tools, used in combination with chemometric analyses are well successful on the discrimination and classification of wines. Thus improved classification power can be helpful in traceability of wine.

Consonni and Cagliani (2010) successfully used Near Magnetic Resonance (NMR) with chemometrics to access geographical origin and quality of traditional food products. 
Ren et al. (2013) used Near-infrared spectroscopy (NIRS) combined with chemometrics as a rapid analysis method to assess quality and to differentiate geographical origins of black tea. Their study demonstrated that determine regarding the main chemical compositions and geographical origins of black tea can be made successfully and rapidly with NIR spectroscopy.

It has been proven that near-infrared spectroscopy (NIRS) combined with chemometric methods are able to predict the geographic origin of wheat grain. $76 \%$ of the wheat grain samples were classified correctly and in the case of the flour between 90\% to 96\% (González-Martín et al., 2014).

\section{Conceptual advancements}

\subsection{The concept of Critical Tracking Events and Key Data Elements}

The Critical Tracking Event (CTE) concept is flexible, scalable, adaptive, efficient and interconnected and that is the reason why it can simplify the food logistics supply chain by identifying the smallest and the most useful units in the supply chain (Welt, 2012). CTE provides traceability by combining latest tools and technologies for targeting the main sources of actual interest of the investigation to provide an easily understandable, fast and accurate recall. CTE changes its approach from being specific to food products for collecting data than to more focus on the events that manipulate the products in the supply chain. The events are viewed and corresponding data related to specific locations, dates and times are stored for future recall (Miller, 2014).

Miller (2014), provided the classification of CTEs by dividing the supply chain into four main categories i.e. Terminal CTEs, Aggregation/Disaggregation CTEs, Transfer CTEs and Commingling CTEs. Terminal CTEs are the events existing at the terminals of supply chain such as cooling, washing and sorting. Aggregation/Disaggregation CTEs are events followed by terminal CTEs such as packaging. Transfer CTEs are associated with any movement of the products in the supply chain for example shipping, receiving, and loading on truck. Commingling CTEs are the events which arise when a new product is formed by using different products from different sources. 
CTEs have certain advantages over the other concepts of food traceability. In CTEs, while maintaining ownership and control of the CTE data, operators are free to choose the methods and technologies according to their requirements and availability. Also, an immediate universal participation is not a requirement of the CTEs to benefit from it (Welt, 2012). An example of CTEs is use of shopper-cased data and the event data together. This data can be queried by investigators by consciously designed Critical Tracking Events at critical points in the supply chain to better facilitate product tracing.

\subsection{Food Track and Trace Ontology (FTTO) model}

Ontology is an explicit formal specification of terms in the domain and relations among them (H. M. Kim et al., 1995), supports the management of a unique body of knowledge through the integration of different concepts and terms coming from heterogeneous sources of information and users involved in the supply chain (Pizzuti et al., 2014). Many authors have focussed their work on the definition of ontologies but remained specified on a specific product or on a particular class of products, such as fruits and vegetables (Wang et al., 2012; Yue et al., 2005), meat (Chifu \& Salomie, 2007), pepper (Easwaran \& Thottupuram, 2011), wine (Graça et al., 2005; Noy \& McGuinness, 2001), pizza (Drummond et al., 2007). However, their work can be reused and correctly implemented for the definition of the Global Food Track and Trace Ontology (FTTO) for traceability purpose (Pizzuti et al., 2014).

The FTTO ontology consists of the following main classes:

- Agent: An agent is an entity or actor involved in the process of food manipulation.

- Food Product: This class includes ingredients such as salt, spices, sugar, oil and vinegar and food products in the form of raw material or manipulated products.

- $\quad$ Service Product: These are the product used during the manipulation of raw material (or unprocessed food) or during the transformation phase, 
such as phytosanitary products, colouring, and flavouring and food additives. It includes also material for packaging and container of products.

- $\quad$ Process: Business processes and agro-food processes are included in this class.

\subsection{The TraceFood Framework}

Several different definitions and principles of traceability are currently being applied, which make the concept of traceability confusing. There is no common theoretical framework with respect to implementation of food traceability (Karlsen et al., 2013). However, there is a joint collaboration of many EU-funded projects TraceFood Framework, dealing with traceability of food products. The TraceFood Framework has been designed to provide an international, non-proprietary standard for electronic exchange of data related to Food Traceability. With recommendations for "Good Traceability Practice", common principles for unique identification of food items, a common generic standard for electronic exchange of traceability information (TraceCore $\mathrm{XML}$ ) and sector-specific ontologies it describes how a message can be constructed, sent and received and also how the data elements in the messages should be identified, measured and interpreted (Storøy et al., 2013).

The framework consists of the following components (Storøy et al., 2013).

- $\quad$ Principle of unique identifications

- Documentation of transformations of products

- Generic language for electronic exchange of information

- $\quad$ Sector-specific language

- $\quad$ Generic guidelines for implementation of traceability

- $\quad$ Sector-specific guidelines 
Both FTTO like the Trace Food Framework are focused on the information management but each in a different way, as it is showed in Table A.2.

Table A.2. FTTO and trace food framework

\begin{tabular}{lll}
\hline \multicolumn{1}{c}{ FTTO } & The Trace Food Framework \\
\hline Base & Unique body of knowledge & International standard \\
Focus & $\begin{array}{l}\text { Focusing on the sources of } \\
\text { information }\end{array}$ & $\begin{array}{l}\text { Focusing on electronic } \\
\text { information for data exchange }\end{array}$ \\
Parts & $\begin{array}{l}\text { Agents involved in any process } \\
\text { Food product, raw or manipulated }\end{array}$ & $\begin{array}{l}\text { Unique ID } \\
\text { Documentation of product } \\
\text { transformation }\end{array}$ \\
& $\begin{array}{l}\text { Service product, which has any } \\
\text { intervention in the food life }\end{array}$ & $\begin{array}{l}\text { Generic and specific language for } \\
\text { e-exchange information }\end{array}$ \\
& $\begin{array}{l}\text { Process that the food has } \\
\text { suffered }\end{array}$ & $\begin{array}{l}\text { Generic and specific guidelines } \\
\text { for traceability implementation }\end{array}$ \\
\hline
\end{tabular}

\subsection{Internet of Things}

The Internet of Things (IOT) is a network that combines everyday objects with the ability to identify and interact with each other to reach cooperation goals (Giusto et al., 2010). Its purpose is that all the items can be perceived and controlled remotely, and combined with the internet to form a more wisdom production and living systems. IOT describes a world where humans are surrounded by machines that communicate with each other and can allow people to interact with the digital world. The concept of IoT break the traditional ideas and start a new technology field, it will bring a new revolution of world information industry after the computer, internet and mobile communication network.

Internet of things is an infrastructure to facilitate the information exchange of products (Amaral et al., 2011; Atzori et al., 2010). The system itself is composed of three dimensions which contain information items, independent networks and intelligent applications. Information items are those that can identify and perceive their own message; independent networks have the capabilities of self-configuration, self-healing, self-optimizing, self-protection; intelligent applications mean the application with the capabilities of intelligent control and processing. 
RFID can enhance the efficiency of Food chain by storing the meaningful information such as producing area, the planting methods, the producing process and other special information that consumer will consider about them when they purchase products ( $M$. Zhang \& Li, 2012). The conceptual sensor data integration has been exploited the classification approach by using the EPC in RFID (Theodorou, 2006). Kiritsis (2011) introduced the "intelligent products", which are meant to be used in the IoT.

Atzori et al. (2010) describe in their article how EPC is a mean to support the spread use of RFID in world-wide modern trading networks, and to create the industry-driven global standards for the EPCglobal Network ${ }^{\mathrm{TM}}$. These standards are mainly designed to improve object visibility (i.e. the traceability of an object and the awareness of its status, current location, etc.).

\subsection{Intelligent traceability inside intelligent food logistics}

After an extensive review of many studies, Bosona and Gebresenbet (2013) concluded that food traceability should be considered as an important and integral part of logistics management, so the information is stored on the go and it can be retrieved at any moment.

The term intelligent food logistics is becoming and important topic about food chain, meantime, as described by Jedermann et al. (2014a), intelligent food logistics are called to reduce the perishable waste along the food supply chain by means of reduction of the deviation from the optimal cold chain, to do that it is necessary to quantify these deviations, making shelf life variation know and remote monitoring.

In the other hand, traceability as is described in the introduction of this document, is an integral part of food safety, food quality and food defence which make it part of the food supply-chain, pretends to be of high potential for the protection of consumers.

Both intelligent logistics like traceability are happening during the supply chain. 
As Scheer (2006) described in his article, the data obtained in the traditional tracking and tracing (T\&T) systems are usually used only to recall management, nonetheless the proposed quality oriented tracking and tracing system (QTT) uses the information retrieved with what we could call intelligent logistic tools, such as wireless sensors (temperature and humidity for instance).

The QTT concept represents a perfect alliance between logistics and traceability, improving the supply chain. Jedermann et al. (2014b) published how the integration of QTT and FEFO (first expire first out) using shelf life models, can enhance the demand and supply chain. Van der Vorst et al. (2007) also emphasizes in the implementation of quality controlled logistics in the food supply chain networks, if the product quality can be predicted in advance it can lead to a better goods flow and better chain design.

Ruiz-Garcia et al. (2010b) proposed a web-based system for data processing, storage and transfer. It integrates all information along the food and feed chain, oriented for the needs of the consumer.

\section{Fuzzy Cognitive Maps (FCM)}

This system can also help improving intelligent traceability. First introduced by Kosko (1986). A FCM consists of nodes and weighted arcs. Nodes represent concepts or states. A FCM is composed of concept node of a problem, signed directed arrows, and causality value among the other nodes. Glykas (2010) gathers some of the most important applications of FCM in the food supply chain.

Thakur et al. (2011) present that state and transitions (nodes and arcs) can be used for modelling food traceability information.

\subsection{Traceability normative and legal advances worldwide}

As it is gathered in the European Commission Health and Consumers (2010) (2010, p. 15, Article 3 Point 15) tracing and tracking became mandatory by legislation in 2005 by EU as "the ability to trace and follow a food, feed, food- 
producing animal or substance through all stages of production and distribution".

The requirements gathered in this regulation are low and restrict themselves to a documentation of supplier and customer relationships, failing to require the monitoring of batches inside enterprises or any further specifics on a system's quality as, e.g. speed of analysis etc. (Regattieri et al., 2007).

In September 2011, the U.S. Food and Drug Administration (FDA) asked the Institute of Food Technologists (IFT) to execute product tracing pilot projects (Bhatt et al., 2013c) and to address how to meet the growing requirement for agriculture and food traceability (Bhatt et al., 2013a).

Although any forthcoming actions from the US FDA are unknown, industry fully expects that improvements in product tracing will be necessary. While the ability to rapidly link products across the supply chain serves as an ideal goal, there are still substantial concerns to be addressed, particularly regarding confidentiality of data (Newsome et al., 2013).

IFT's Traceability Improvement Initiative aims to advance work in the area of food product tracing through several means, pilots or implementation studies in seafood, dairy, and other industries (Bhatt et al., 2013b).

The objectives of the pilot projects were 1) to identify and gather information on methods to improve product tracing of foods in the supply chain and 2) to explore and evaluate methods to rapidly and effectively identify the recipient of food to prevent or mitigate a foodborne illness outbreak and to address credible threats of serious adverse health consequences or death to humans or animals (Bhatt et al., 2013c).

IFT found inconsistencies in terminology, numbering systems, formatting while the participants appeared to have the tools and processes required for the tracking process. IFT developed some recommendations to allow rapid effective investigations during foodborne illness outbreaks which lead to enhance protection of public health (Bhatt et al., 2013c). 
Better information management can provide a return of investment if the data is well managed. Standards in data and interoperability of technology were approached by the report of Bhatt et al. (2013b). The first approach "one up/one down" by requiring electronic records has the benefits low cost of implementation, resulting in a higher probability of adoption. The major disadvantage to this process is the longer response time required during a trace (back or forward).

The second approach is similar to a "pedigree", historical information about the food. A major advantage of this approach is the quickest response time during a trace. Some of the disadvantage is a big volume of data.

The third approach requires individual nodes to maintain electronic records for its own data and make them available for querying during a traceback for outbreak investigation. The major advantage of this approach is the protection of confidential information and quick access during a trace. However, the primary disadvantage of this approach is the need for greater computational power.

Bhatt and Zhang (2013) conducted a study analysing product tracing information to identify the contaminated ingredient and likely source, as well as distribution of the product. It also determined if these systems can work together to better secure the food supply (their interoperability). IFT provided supply-chain data for one complex product to 9 products tracing technology providers, and then compared and contrasted their effectiveness at analysing product tracing information to identify the contaminated ingredient and likely source. Only 6 were able to provide the data required and only 4 of them were able to provide the evidence of the contamination. Nonetheless they also demonstrated this interoperability capability mandatory by the US FDA.

As these systems get deployed by clients in the food industry, interoperability will no longer be an afterthought but will be built into their traceability systems (Bhatt \& Zhang, 2013)

\section{Conclusions}


The most recent advances in food traceability in terms of technology are able to provide certain increment in efficiency and effectiveness. Nowadays it is possible to achieve essential information by using RFID during the food supply chain and NFC when the product arrives to the end consumer, this wireless monitoring devices have been improved for the past few years, they offer control in situ or in the moment while the goods are on the go; nonetheless none are capable to fulfil all the requirements of the nowadays heterogeneous food supply chains. The very new advancements (DNA barcoding, chemometrics...) can cover some of the gaps, like the disease spreading or historical control, but these technologies are in testing phases or require a big deployment of resources not affordable for all the agents of the food chain, therefore it is assumed that they will not become an alternative in the short term.

New trends are about how to aboard the traceability, this means a whole new point of view of traceability, focusing in the parts implicated in the food supply chain such as agents involved, processes, elements added to the food and the product itself which was the only objet of study before these new trends. In the same line, the CTE are focusing in the events that manipulate the products in the supply chain. Also the way of acquiring the data and transmitting it is becoming more standardized, thank to concepts like the Trace Food Framework.

Food traceability is having new uses since these new traceability concepts are pointing to register not only the origin of the products but new parameters integrated in the intelligent logistics, so it is possible to know the quality of the product and therefore enhance the chain design and the goods flow. The connection between identifiers or, environment/event loggers, allows a dynamic traceability of quality, and finally it is possible to achieve a homogeneous traceability system.

In the future it would be expected the possibility of having the traceability information absolutely centralized across the supply chain, being able to access at any moment in order to act in case it would be necessary. This possibility seems to be still a bit far in time, since it is showed in this 
document that the research performed by the FDA in US proved that the continuous traceability during the supply chain is very difficult to achieve.

Another great challenge is to engage the technology and the conceptual advancements together, future research can be directed on implementing these two topics, for the moment intelligent food logistics is advancing in that direction. 